MARÍA VERÓNICA CARRANZA OROPEZA

AVALIAÇÃO DO MÉTODO WAVELET-GALERKIN MULTI-MALHA PARA CARACTERIZAÇÃO DAS PROPRIEDADES DE PETRÓLEO E SUBPRODUTOS 


\section{AVALIAÇÃO DO MÉTODO WAVELET-GALERKIN MULTI-MALHA PARA CARACTERIZAÇÃO DAS PROPRIEDADES DE PETRÓLEO E SUBPRODUTOS}

Dissertação apresentada à Escola

Politécnica da Universidade de

São Paulo para obtenção do

Título de Mestre em Engenharia

Área de Concentração:

Engenharia Química

Orientador:

Prof. Dr. Galo Antonio Carrillo Le Roux 
Este exemplar foi revisado e alterado em relação à versão original, sob responsabilidade única do autor e com a anuência de seu orientador.

São Paulo, 19 de março de 2007.

Assinatura do autor

Assinatura do orientador

FICHA CATALOGRÁFICA

Carranza Oropeza, María Verónica

Avaliação do método wavelet Galerkin com multi-malha para caracterização das propriedades de petróleo e subprodutos I

M.V. Carranza Oropeza. -- São Paulo, 2006.

$173 \mathrm{p}$.

Dissertação (Mestrado) - Escola Politécnica da Universidade de São Paulo. Departamento de Engenharia Química.

1.Metodologia de programação (Avaliação) 2.Computação aplicada 3.Modelagem matemática 4.Simulação 5.Petróleo (Propriedades) I.Universidade de São Paulo. Escola Politécnica. Departamento de Engenharia Química II.t. 
A Deus pela Abenção da vida, aos meus pais e meus irmãos pelo amor e apoio de sempre, e aos meus amigos incondicionais, sem os quais não poderia ter alcançado este objetivo 


\section{AGRADECIMENTOS}

A Deus, pois sem a vontade Dele nada seria possível.

Ao Prof. Dr. Galo Antonio Carrillo Le Roux, pela acolhida, oportunidade e confiança dadas para desenvolver este trabalho, além das diretrizes e discussões que possibilitaram conclui-lo com êxito.

Ao Prof. Dr. Song Won Park, pelo acompanhamento na conclusão final deste trabalho.

Ao Prof. Dr. Pedro Alcántara Pessoa, pelo acompanhamento na conclusão final deste trabalho.

Aos colegas do LSCP, pela amizade e apoio incondicionais.

A todos que, direta ou indiretamente, colaboraram na execução deste trabalho. 
Bom mesmo é ir a luta com determinação, abraçar a vida é viver com paixão, perder com classe é vencer com ousadia, porque o mundo pertence a quem se atreve $e$ a VIDA É MUITO para ser insignificante charles Chaplin 


\section{RESUMO}

Atualmente, restrições ambientais impostas à industria de refino de petróleo estão fazendo com que se procure otimizar os seus processos. Uma das maneiras de se alcançar este objetivo é através da melhoria dos métodos analíticos de caracterização e dos métodos de representação, cuja finalidade é permitir maior precisão na simulação. O método mais comum de representação através de pseudocomponentes, apresenta algumas desvantagens, as quais não permitem precisão adequada em determinadas situações. Uma nova metodologia apresentada neste trabalho, que permite superar essas desvantagens foi aplicada em um exemplo de flash de petróleo. Esta metodologia envolve varias etapas: a implementação dos algoritmos necessários à representação das composições da mistura por funções de distribuição contínua e sua aproximação por funções wavelets, e a simplificação do modelo flash com a discretização "Wavelet-Galerkin" e sua resolução através de um enfoque multi-malha adaptativo.

Neste contexo, na primeira etapa da tese foram apresentados diferentes aspectos relacionados ao processo complexo de caracterização de petróleos, que consideram sua importância tanto econômica quanto tecnológica. Mostraram-se também, o uso de ferramentas matemáticas e suas vantagens para resolver os problemas complexos em diversas áreas científicas.

Na segunda etapa foi desenvolvida a metodologia proposta. Para tanto, os algoritmos foram construídos na linguagem de programação de Matlab. Em seguida, duas simulações do modelo flash permitiram avaliar sua precisão e sua eficiência. A primeira foi realizada sem a implementação de seleção de malhas adaptativamente, enquanto que a segunda foi realizada utilizando dita implementação, a qual permitiu construir quatro casos e analisar os resultados dos mesmos. Finalmente, com o objetivo de avaliar seu potencial de utilização em um ambiente de simulação, estes resultados foram comparados com uma terceira simulação, utilizando o simulador HYSYS, o qual se baseia na representação de pseudocomponentes.

Palavras-chave: Caracterização de Petróleo. Wavelet-Galerkin. Pseudo-componentes 


\begin{abstract}
Current environmental constraints to the refining industry make process optimization a necessary task. It can be achieved by improving the analysis methods applied to oil characterization and the representation methods, in order to improve simulation accuracy. The most common method of representation based on pseudocomponents presents some disadvantages, which do not enable a detailed accuracy in some situations. In this work a new methodology is proposed to surpass these disadvantages, and applied to oil flash as an example. The proposed methodology involves the representation of the mixture compositions by continuous distribution functions, which are approximated by wavelet functions, and the simplification of the flash model by the "Wavelet-Galerkin" discretization which are solved by multigrid adaptive approach.
\end{abstract}

In this contex, in the first part of this work different aspects related to the complex process of petroleum characterization are discussed, considering their economical and technological importance. Besides, the utility of mathematical tools, and their advantages to solve complex problems in different scientific fields, are presented.

In the second part, the proposed methodology is developed. All algorithms are built with MatLab programming languages. Two simulations of the model of flash process enabled to evaluate the precision and the efficiency of the methodology. The first simulation was developed without the implementation of an adaptability selection grid. The second was carried out with this implementation, which enabled to build four cases and analyze their results. Finally, with the objective of evaluating its potential of utilization in a simulation environment, the results were compared with a third simulation, using the simulator HYSYS, which itself is based on the representation of pseudo-components.

Keywords: Petroleum characterization. Wavelet - Galerkin. Pseudo-components 


\section{Lista de Figuras}

Figura 2.1. Definição de um pseudocomponente e seu ponto de ebulição na mistura substituta desde a curva TBP.

Figura 2.2. $\quad$ Procedimento de seleção de mistura substituta para caracterização de petróleos

Figura 3.1. Representação dos componentes e pseudocomponentes discretos em relação à função de distribuição contínua.

Figura 4.1. Representação esquemática do procedimento do método multimalha adaptativo wavelet-Galerkin

Figura 4.2. Representação das funções escala e wavelet correspondentes aos espaços $V_{2}, W_{2}, W_{3}$.

Figura 4.3. Representação esquemática de uma decomposição em resolução multipla

Figura 4.4. Representação esquemática de uma decomposição em resolução multipla da função $X$ na escala $j=3 . \quad X=A_{3}+D_{3}+$

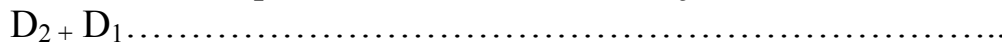

Figura 4.5. Representação esquemática do procedimento de correção de malhas.

Figura 4.6. Representação esquemática do processo de interpolação de pontos de discretização de malha fina para a malha grossa.........

Figura 4.7. Representação esquemática do processo de interpolação conhecido como ciclo multi-malha completo

Figura 5.1. Esquema de um separador flash

Figura 5.2. Curva TBP do petróleo cru (temperatura de ebulição verdadeira vs. porcentagem de volumen destilado)

Figura 5.3. Propriedades físicas da corrente de alimentação do petróleo cru vs. variável de caracterização $\xi$.

Figura 5.4. Funções de distribuição contínuas da fração molar da corrente de alimentação (FDCfmCA)

Figura 5.5. FDCfmCA* aproximadas através da análise wavelet 105

Figura 5.6. Aproximação reduzida da função de distribuição da alimentação para uma escala $j=3$ com referência a uma escala t. : 
máxima $j=6$

Figura 5.7. Esquema do separador flash representando a composição das correntes com funções de distribuição contínua 109

Figura 5.8. Esquema do algoritmo multi-malha adaptativo 118

Figura 5.9. Aproximação das funções de distribuição nas escalas $\hat{j}_{s}=3$ e $6 . v s$. $\xi$, para $\alpha=0.5$

Figura 5.10. Simulação do modelo flash com escalas fixas. (a) Tempos de simulação vs. $\operatorname{Mmax}_{\mathrm{F}}$ (b) Erros ponderados de aproximação das equações do modelo vs. Mmax $_{\mathrm{F}}$.

Figura 5.11. Simulação do modelo flash. Método wavelet-Galerkin malha fixa. (a) Temperatura do processo, Tint (K) vs. $\alpha$ (b) Tempos de simulação (seg) vs. $\alpha$

Figura 5.12. Simulação do modelo flash utilizando malhas adaptativas para $\alpha=$ 0.5.(a) FPixRRi vs. Etol (b) Tint. (K) vs. Etol

Figura 5.13. Simulação do modelo flash em estado estacionário usando malhas adaptativas. Resultado para os casos 1 e 2 para $\alpha=0.5$ (a) Iterações vs. Etol (b) Tempo vs. Etol (c) Msel vs. Etol .....

Figura 5.14. Simulação do modelo flash utilizando malhas adaptativas para $\alpha=0.05$.(a) FPixRRi vs. Etol (b) Tint. (K) vs. Etol

Figura 5.15. Simulação do modelo flash em estado estacionário usando malhas adaptativas. Resultado para os casos 1 e 2 para $\alpha=0.05$ (a) Iterações vs. Etol (b) Tempo vs. Etol (c) Msel vs. Etol .....

Figura 5.16. Simulação do modelo flash utilizando malhas adaptativas para $\alpha=$ 0.1.(a) FPixRRi vs. Etol (b) Tint. (K) vs. Etol

Figura 5.17. Simulação do modelo flash em estado estacionário usando malhas adaptativas. Resultado para os casos 1 e 2 para $\alpha=0.1$ (a) Iterações vs. Etol (b) Tempo vs. Etol (c) Msel vs. Etol .....

Figura 5.18. Simulação do modelo flash utilizando malhas adaptativas para $\alpha=0.9$. (a) FPixRRi vs. Etol (b) Tint. (K) vs. Etol 130

Figura 5.19. Simulação do modelo flash em estado estacionário usando malhas adaptativas. Resultado para os casos 1 e 2 para $\alpha=0.9$

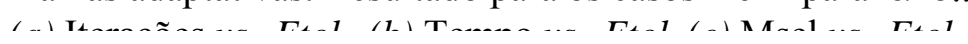


(a) Iterações vs. Etol (b) Tempo vs. Etol (c) Msel vs. Etol .....

Figura 5.20. Simulação do modelo flash utilizando malhas adaptativas para $\alpha=$ 0.95.(a) FPixRRi vs. Etol (b) Tint. (K) vs. Etol

Figura 5.21. Simulação do modelo flash em estado estacionário usando malhas adaptativas. Resultado para os casos 1 e 2 para $\alpha=0.95$ (a) Iterações vs. Etol (b) Tempo vs. Etol (c) Msel vs. Etol .....

Figura 5.22. Temperatura de ebulição normalizada $E[0,1]$ vs. fração molar acumulativa $[0,1]$. Fases líquido e vapor para $\alpha=0.5$. M. Wavelet-Galerkin com malhas adaptativas e método de pseudocomponentes (HYSYS 2.1)....

Figura 5.23. Temperatura de ebulição normalizada $E[0,1]$ vs. fração molar acumulativa [0,1]. Fases líquido e vapor para $\alpha=0.05$. M. Wavelet-Galerkin com malhas adaptativas e método de pseudocomponentes (HYSYS 2.1).

Figura 5.24. Temperatura de ebulição normalizada $E[0,1]$ vs. fração molar acumulativa [0,1]. Fases líquido e vapor para $\alpha=0.1$. M. Wavelet-Galerkin com malhas adaptativas e método de pseudocomponentes (HYSYS 2.1).

Figura 5.25. Temperatura de ebulição normalizada $E[0,1]$ vs. fração molar acumulativa [0,1]. Fases líquido e vapor para $\alpha=0.9$. M. Wavelet-Galerkin com malhas adaptativas e método de pseudocomponentes (HYSYS 2.1).

Figura 5.26. Temperatura de ebulição normalizada $\mathrm{E}[0,1]$ vs. fração molar acumulativa $[0,1]$. Fases líquido e vapor para $\alpha=0.95$. M. Wavelet-Galerkin com malhas adaptativas e método de pseudocomponentes (HYSYS 2.1).

Figura 5.27. Comparação de métodos wavelet-Galerkin com malha fixa e com malha adaptada. (a) Tempo de simulação vs. $\alpha$. (b) Número de funções base vs. $\alpha$. (c) FPi $\times R R i v$ s. $\alpha$.

Figura 5.28. Comparação de métodos wavelet-Galerkin com malha fixa e com malha adaptada, e com o método de pseudocomponentes. Temperatura de processo, Tint (kelvin) vs. $\alpha$. 


\section{Lista de Tabelas}

Tabela 2.1 Frações de petróleo...................................................................... 27

Tabela 2.2. Destilações em testes de laboratório para caracterização de petróleo

Tabela 5.1 Dados Função de distribuição da fração molar da corrente de alimentação. Dados da TBP e da densidade

Tabela 5.2 Propriedades físicas da corrente de alimentação do petróleo cru normalizadas em relação à variável de caracterização $\xi . . .$.

Tabela 5.3 Função de distribuição da fração molar da corrente de alimentação.

Tabela 5.4 Primeira aproximação da FDCfmCA*, para escalas fixas $\hat{j}_{s}$

Tabela 5.5 Resultados da análise de coeficientes da aproximação reduzida da função de distribuição, FDCfmCA*. Tratamento dos dados com toolbox wavelet de Matlab 6.5.

Tabela 5.6 Valores da aproximação reduzida para a função de distribuição, FDCfmCA*, considerando uma escala $\hat{j}_{s}=3 \ldots$. .

Tabela 5.7 Parâmetros considerados nas simulações

Tabela 5.8 Tempos da simulação e erros ponderados de aproximação das equações do modelo obtidos para cada escala fixa

$\hat{j}_{s}=2,3,4$ e 5 em relação a escala de referência $\hat{j}_{s}=6$

para $\alpha=0.5$.

Tabela 5.9 Resultados da simulação do modelo flash em estado estacionario. M. wavelet-Galerkin malha fixa. Temperatura do processo, Tint, e tempo de simulação para cada $\alpha=\{0.05$, $0.1,0.9,0.95\}$ à escala $\hat{j}_{s}=6$

Tabela 5.10 Simulação do modelo flash em estado estacionário usando malhas adaptativas. Resultados dos casos 1 e 2 com parâmetro $\alpha=0.5$.

Tabela 5.11 Simulação do modelo flash em estado estacionário usando malhas adaptativas. Resultados dos casos 1 e 2 com parâmetro $\alpha=0.05$. 
Tabela 5.12 Simulação do modelo flash em estado estacionário usando malhas adaptativas. Resultados dos casos 1 e 2 com

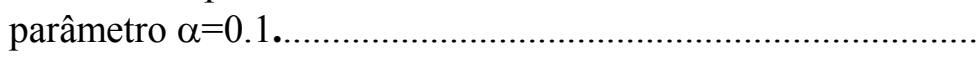

Tabela 5.13 Simulação do modelo flash em estado estacionário usando malhas adaptativas. Resultados dos casos 1 e 2 com parâmetro $\alpha=0.9$.

Tabela 5.14 Simulação do modelo flash em estado estacionário usando malhas adaptativas. Resultados dos casos 1 e 2 com parâmetro $\alpha=0.95$

Tabela 5.15 Simulação do modelo flash em estado estacionário, malhas adaptativas, resultados do caso 2 com Etol $=0.01$ para $\alpha=$ \{0.5; 0.05; 0.1; 0.9; 0.95\}, (o número de iterações Iter, o tempo da simulação, os erros ponderados das equações do modelo RRixFPi, e as funções base selecionadas Msel )........

Tabela 5.16 Simulação do modelo flash em estado estacionário. Comparação de métodos wavelet-Galerkin malhas fixas (tabela 5.9), malhas adaptativas (tabela 5.15), e método pseudocomponentes. Avaliação para $\alpha=.\{0.5 ; 0.05 ; 0.1 ; 0.9$; $0.95\}$ 


\section{Lista de Siglas}

\begin{tabular}{|c|c|}
\hline AMG & Algebraic Multigrid \\
\hline API & American Petroleum Institute \\
\hline ASTM & American Society for Testing and Materials \\
\hline AWGM & Adaptive Wavelet-Galerkin Method \\
\hline AWCM & Adaptive Wavelet Collocation Method \\
\hline CABP & Cubic average boiling point \\
\hline DSC & Diferencial Scan Calorimetry \\
\hline DIPPR & Design Institute for Physical Properties \\
\hline EFV & Equilibrium flash vapor \\
\hline FAC & Fast Adaptive Composite \\
\hline FDCfmCA & $\begin{array}{l}\text { Função de Distribuição Contínua de fração molar da Corrente de } \\
\text { Alimentação }\end{array}$ \\
\hline FWT & Fast Wavelet Transform \\
\hline IFWT & Inverse Fast Wavelet Transform \\
\hline MABP & Molal average boiling point \\
\hline MeABP & Mean average boiling point \\
\hline NIPER & National Institute for Petroleum and Energy Research \\
\hline PVT & Pressão, Volume, Temperatura \\
\hline SIMDIST & Simulation distillation \\
\hline TBP & True Boiling Point, Ponto de Ebulição Verdadeiro \\
\hline
\end{tabular}


TG

VABP

WABP
Termo-gravimetria

Volumetric average boiling point

Weight average boiling point 


\section{Lista de Símbolos}

$A_{j} \quad$ aproximação da função escalonada, adimensional,equação (4.14)

$A^{h} \quad$ Matriz da discretização (tridiagonal, simétrica e positiva definida), adimensional.

$a, b \quad$ Contrações, translações, para formar as familias wavelets, adimensional, equação (4.1)

$a_{i} \quad$ Coeficiente da discretização, adimensional, equação (4.22)

$c_{j 0, k} \quad$ Coeficientes da função escala, adimensional, equação (4.4)

$D_{j} \quad$ detalhes da função wavelet, adimensional, equação (4.15)

$d_{j, k} \quad$ Coeficiente multi-escala wavelet, adimensional, equação (4.4)

$d_{i}{ }^{E L V} \quad$ Coeficiente wavelet para o equilíbrio líquido-vapor

$\xi$, E Variável de caracterização (temperatura do ponto de ebulição normal), adimensional, equação (3.1)

Etol Tolerancia para o criterio do erro, adimensional, tabela 5.7

Fdliq Coeficientes multi-escala wavelet para a distribuição do líquido

Fdvap Coeficientes multi-escala wavelet para a distribuição do vapor

fdc. Função de distribuição contínua

$F(\xi) \quad$ Função de distribuição intensiva, equação (3.2)

$F(\xi)$ Função de aproximação à função de distribuição, adimensional, equação (4.3) e (5.5)

$F(\xi) \quad$ Função de distribuição, adimensional, equação (5.5)

$f(\xi) \quad$ Função de distribuição extensiva, equação (3.1)

$f_{\text {aprox }}$ Solução aproximada de alguma função $f$, adimensional, equação (4.22)

$f_{0} \quad$ Aproximação grosseira de alguma função $f$, adimensional, equação (4.22)

Fdfeed Função de distribuição da corrente de alimentação, adimensional, tabela 5.7 
fliq Aproximação da fdc. para fase líquida, adimensional, tabela 5.7

fvap Aproximação da fdc. para fase vapor, adimensional, tabela 5.7

$F^{r}(\xi) \quad$ Aproximação da fdc. reduzida, adimensional, equação (5.7)

$F_{Z}(\xi)$ Aproximação intermediaria da fdc., adimensional, equação (5.16)

$F_{V}(\xi)$ fdc. da fraçaõ volumétrica de destilado, equação (5.1) e (5.2)

$\widetilde{f}, \widetilde{g}$ Operadores não lineares, adimensional, equação (5.16)

FPi Fator de ponderação para as equações do modelo, adimensional

$g \quad$ Operador que estabelece condições iniciais nos contornos, adimensional, equação (5.16)

Ge Gravidade específica, adimensional

h Tamanho de malha

Iter Número de iterações do algoritmo, adimensional, tabela 5.7

j $\quad$ Nível de escala, adimensional, equação (4.3)

$j_{0} \quad$ Valor de escala inteira não negativa, adimensional, equação (4.3)

J Nível de escala mais fina, adimensional, equação (4.6)

$j \quad$ Escala maior para representação multi escala, adimensional

K Graus Kelvin

$\overline{K w} \quad$ Fator de Watson, adimensional, equação (2.1c)

$k \quad$ Parâmetro de deslocamento para gerar uma quantidade de funções base por escala (representação multi-escala), adimensional, equação (4.3)

l $\quad$ Número de funções bases geradas segundo a escala (representação a escala simples), adimensional, equação (5.5)

L Operador não linear, adimensional, equação (4.23)

L Fluxo de líquido, $\mathrm{kmol} / \mathrm{h}$ equação (5.8)

$L^{2}(R) \quad$ Espaço de Euler, adimensional, equação (4.10) 
$M \quad$ Uma quantidade extensiva arbitraria, equação (3.4 e 3.5)

Mi Peso molecular do componente i na mistura, $(\mathrm{g} / \mathrm{mol})$, equação (5.1) e (5.2)

$\bar{M} \quad$ Peso molecular da mistura, $(g / m o l)$, equação (5.1) e (5.2)

$m \quad$ Número de funções base, adimensional.

$M_{\max } \quad$ Número máximo de funções base para seleção no processo de adaptação, adimensional. Tabele 5.7 .

$\operatorname{Mmax}_{\mathrm{F}}$ Número de funções base fixo para cada escala $j$. Tabela 5.7.

Msel Número de funções bases selecionadas, pelo algoritmo, para representação do modelo adaptativo, adimensional, tabela 5.7

N Número natural, equação (4.23)

$n_{i} \quad$ Quantidade da substancia, equação (3.2)

$O\left[F_{i}(\xi)\right]$ Operador que retorna valores escalares, adimensional, equação (5.16)

$P_{\text {feed }} \quad$ Fluxo de alimentação de processo, $\mathrm{kmol} / \mathrm{h}$ equação (5.8)

p Parâmetros do processo, equação (5.16)

P, p1 Pressão do sistema e pressão de alimentação (bar)

$R \quad$ Números reais

$R(\xi) \quad$ Residual da equação em função a $\xi$, adimensional, equação (4.23)

RR1 Erro residual das equações de balanço de material, item p.4.1

RR2 Erro residual das equações de equilíbrio líquido - vapor, item p.4.1

T, T0 Temperatura do sistema e temperatura de alimentação, tabela 5.7

Tempo tempo de simulação do algoritmo (seg), tabela 5.7

$T b_{i}$ Temperatura de ebulição normal de um pseudocomponente i, equação $(2.1 a)$

$u^{h} \quad$ Solução exata para a função $f^{h}$ na malha de tamanho $h$, adimensional.

$v^{h} \quad$ Aproximação à solução exata da função $f^{h}$ na malha de tamanho $h$, adimensional. 
V Fluxo de vapor, $\mathrm{kmol} / \mathrm{h}$ equação (5.8)

$V_{j}, W_{j} \quad$ Espaços de aproximação, adimensional, equação (4.8)

$w_{k} \quad$ Função teste da discretizaçaõ, adimensional, equação (4.24)

$X, X_{Z}$ Variáveis de estado do processo e variáveis de estado intermediarias, equação (5.16)

Xi Fração molar do componente i na mistura, adimensional, equação (5.1) e (5.2)

Xvi Fração volumétrica de destilado, adimensional, equação (5.1) e (5.2)

Z Números inteiros

$\mathrm{Zi} \quad$ Fdfeed

$\alpha \quad$ Fator de vaporização, adimensional, equação (5.10)

$\xi_{0}, \xi_{m} \quad$ Limites da ocorrência dos valores da variável $\xi$.

$e_{j} \quad$ Erro de aproximação, adimensional, equação (4.16)

$\bar{\varepsilon}_{i} \quad$ Erro das funções discretizadas estimado em cada escala

$\varepsilon_{\text {tol }} \quad$ Valor de tolerancia para o erro $\bar{\varepsilon}_{i}$ e $\varepsilon$, adimensional

$\varepsilon \quad$ Limite de tolerancia para o modulo do coeficiente wavelet, adimensional, equação (5.7)

$\delta d_{\left(j^{*}, k^{*}\right)}$ Componentes do vetor de resíduos, adimensional.

$\Delta F_{Z}^{r}(\xi)$ Termo de correção da função aproximada reduzida intermediária

$\vartheta_{i} \quad$ Função tentativa da discretização, adimensional, equação (4.22)

$\phi_{j 0, k}(\xi) \quad$ Função escala, scaling, adimensional, equação (4.3)

$\widetilde{\psi} \quad$ wavelet básica" ou "wavelet mãe", adimensional

w $\quad$ wavelet ou função wavelet, adimensional, equação (4.1)

$\psi_{j, k}(\xi) \quad$ Função wavelet, adimensional, equação (4.3) 
$\Psi \quad$ Função base wavelet, adimensional, equação (5.16)

$\Lambda \quad$ Pares de índices das funções bases para malha completa (representação a multi-escala), adimensional, equação (5.6)

$\Lambda^{r} \quad$ Pares de índices das funções bases da malha reduzida, adimensional, equação (5.7)

$\Lambda^{r, a d} \quad$ Pares de índices das funções bases da malha reduzida adaptada, adimensional, equação (5.7)

$\Lambda^{h}, \Lambda^{2 h}$ Representação dos pontos para malha de tamanho $h e$ $2 h$, adimensional.

$\Gamma \quad$ Pares de índices das funções bases para representação a escala simples, adimensional, equação (5.5)

$\rho, \rho_{i}$ Densidade da mistura e densidade do componente i na mistura, $\left(\mathrm{kg} / \mathrm{m}^{3}\right)$, equação (5.1) e (5.2) 


\title{
SUMÁRIO
}

\section{Lista de Figuras}

\author{
Lista de Tabelas
}

\section{Lista de Siglas}

\section{Lista de Símbolos}

1. Introdução........................................................................................................... 22

1.1. Mistura Multicomponente de Petróleo ................................................... 22

1.2. Objetivos do trabalho ...................................................................... 24

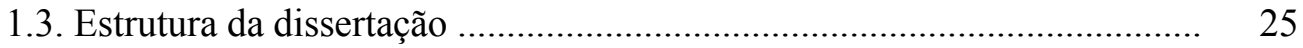

2. Petróleo e Caracterização das Frações de Petróleo .......................................... 27

2.1. Petróleo e Frações de Petróleo ................................................................ 27

2.2. Caracterização ................................................................................. $\quad 30$

2.2.1. Métodos em laboratório para Caracterização das Frações de Petróleo... 32

2.2.2. Estimativas em Simulação da Caracterização das Frações de Petróleo.. 34

3. Revisão Bibliográfica da Termodinâmica do Contínuo aplicada à 48 Caracterização de Petróleo

3.1. Fundamento do método da termodinâmica do contínuo........................... 52

3.2. Aplicações ...................................................................................... 56

\section{Método Multi-Malha Adaptativo wavelet-Galerkin para}

Caracterização de Petróleo

4.1. Método multi-malha adaptativo wavelet-Galerkin

4.2. Wavelets

4.2.1. Análise de Wavelets

4.2.2. Análise de Resolução Múltipla ................................................................. 69

4.2.3. Aplicações de Wavelet ......................................................................... 76

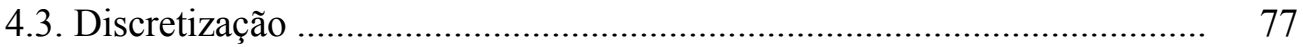

4.3.1. Aplicações da discretização Wavelet-Galerkin ................................... 80

4.4. Algoritmo Multi-Malha Adaptativo .................................................... 81

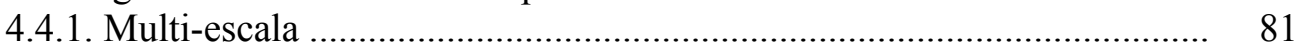




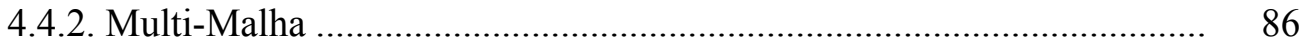

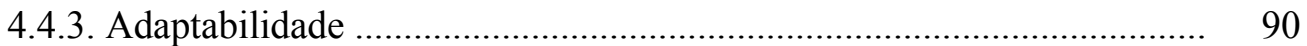

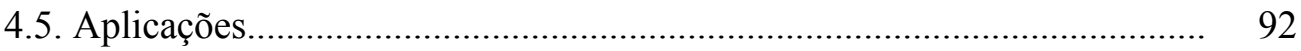

\section{Aplicação do Método Wavelet-Galerkin em Processo Flash de Mistura de 96 Multi-Componentes de Petróleo

5.1 Modelagem de um separador flash.

5.1.1. Tratamento e análise dos dados de alimentação

5.1.2. Formulação contínua das equações do modelo do separador flash ...... 109

5.1.3. Discretização das equações do modelo do separador flash .................. 110

5.2 Desenvolvimento do Algoritmo Proposto ............................................... 112

5.2.1. Passos do algoritmo para a simulação do processo .............................. 114

5.3 Simulação do modelo do separador Flash ............................................... 119

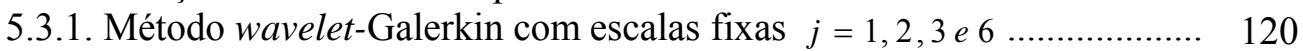

5.3.2. Método wavelet-Galerkin com adaptação de malhas, escalas $\hat{j}_{s}=[2-6]$

5.3.3. Método pseudocomponentes, simulador HYSYS v. 2.1..................... 136

5.3.4. Comparação entre os resultados das simulações................................... 139

5.4 Conclusões da Simulação do modelo do separador flash ........................ 142

6. Comentários Finais, perspectivas e sugestões.................................................... 145

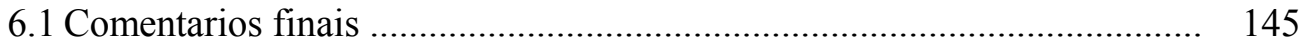

6.2 Perspectivas e sugestões .................................................................... 146

7. Referências bibliográficas ....................................................................... 148

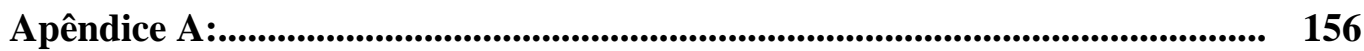

Tratamento da representação da constante de equilibrio de fases

Apêndice B:

Programa utilizado para a simulação do algoritmo 


\section{INTRODUÇÃO}

Atualmente, as indústrias estão obrigadas a fabricar produtos com elevada qualidade a baixos custos. Além disto, a legislação ambiental exige que os produtos sigam especificações cada vez mais rigorosas. Por estes motivos, as refinarias de petróleo, também, em um futuro próximo, terão, não somente, que produzir combustíveis "limpos", mas deverão também produzir quantidades crescentes de produtos petroquímicos (lubrificantes, xilenos, etileno, pentano, etc.) com propriedades particulares ou composições moleculares especiais.

Para atingir estas metas, métodos de modelagem de processos mais precisos devem ser desenvolvidos com o objetivo de melhorar a operação, visando a otimização dos processos de refino. Moro (2003) cita que a otimização em tempo real ainda não tem uma aceitação comercial universal porque, além das incertezas nos dados econômicos, várias dificuldades práticas contrapõem-se aos benefícios potenciais como, por exemplo, caracterização insuficiente das correntes de alimentação, modelos imprecisos ou com poucos detalhes, e a inexistência de estados estacionários legítimos em plantas razoavelmente perturbadas.

Sequeira et al. (2002) é um dos vários trabalhos ilustrativos de otimização em tempo real para processos contínuos, onde pode-se rever os exemplos de diversas metodologías integradas ao controle avançado.

\subsection{Mistura Multi-componente de Petróleo}

O petróleo pode conter em torno de $10^{6}$ componentes (Briesen e Marquardt 2003), impossibilitando a análise da concentração individual de cada espécie química e a simulação com balanços independentes para cada uma destas espécies. Tradicionalmente, consideram-se, nos simuladores comerciais, algumas dezenas de componentes para representar a mistura multicomponente complexa. O método de caracterização físico-químico considerado mais confiável para a previsão do processo de refino através de simuladores de processo é a curva de destilação denominada Ponto de Ebulição Verdadeiro, TBP (True Boiling Point). No entanto, a 
análise através deste método é demorada (dois a três días aproximadamente), o equipamento para a sua realização tem custo elevado, além de envolver mão de obra especializada durante todo o ensaio. Existem diversos estudos para se traduzir as análises de destilação em termos de pseudo-componentes.

Briesen e Marquardt (2003) citam que devido às melhorias nas técnicas analíticas de caracterização de frações de petróleo, o nível de detalhe com respeito à composição tem aumentado sensivelmente, e aumentará certamente no futuro. Além disso, a inclusão desta caracterização detalhada em nível molecular parece ser a única maneira de melhorar fundamentalmente a capacidade de predição de processos de petróleo.

Alguns abordagens mais recentes propostas para a representação de misturas complexas são: a discretização wavelet-Galerkin com enfoque multi-malha adaptativo (Briesen e Marquardt, 2003), a representação de misturas substitutas utilizando componentes reais (Eckert e Vaneck, 2005a, 2005b), a representação molecular (Hu et. al. 2002).

A abordagen proposta por Briesen e Marquardt (2003) será desenvolvida no presente trabalho. Nesta abordagem os autores propuseram um algoritmo que não resolve $o$ modelo em termos de balanços por componentes separados, e sim, o modelo formulado utilizando-se uma distribuição contínua para representar a composição. 


\subsection{Objetivos do trabalho}

O trabalho tem como objetivo a implementação de uma metodologia para a representação de misturas complexas em casos envolvendo petróleo e frações de petróleo, de modo a avaliar seu potencial de utilização em um ambiente de simulação.

Esta metodologia baseia-se na representação das propriedades físico-químicas dos hidrocarbonetos através de distribuições contínuas, utilizando o método WaveletGalerkin multi-malha.

O resultado do presente trabalho contribuirá para melhorar a eficácia da implementação da otimização em tempo real em refinarias. 


\subsection{Estrutura da dissertação}

A dissertação está apresentada de acordo com a estrutura indicada a seguir:

Capítulo 2: Apresenta uma revisão da bibliografia que aborda de maneira geral a importância tecnológica e econômica da indústria do refino de petróleo, além da sua caracterização utilizando diversos métodos. Apresenta, também, os métodos convencionais utilizados para esta caracterização no laboratório e sua aplicação como ferramenta para estimativas na simulação dos processos de refino. Além do mais, introduz novos enfoques alternativos aos métodos convencionais de caracterização.

Capítulo 3: Descreve a Termodinâmica Contínua como um método de caracterização, baseado na representação da composição das misturas multicomponentes complexas de forma contínua, utilizando, portanto, as funções de distribuição contínua.

Capítulo 4: Descreve o novo enfoque multi-malha adaptativo wavelet-Galerkin, apresentado por Briesen e Marquardt (2003), como método de caracterização de misturas multicomponentes complexas, aplicado na simulação de processos de separação térmica de petróleo e frações de petróleo. Além disso, descreve as ferramentas matemáticas utilizadas neste enfoque abrangendo a importância de cada uma delas através das várias aplicações em diversas áreas científicas.

Capítulo 5: Apresenta a metodologia utilizada para o desenvolvimento do método proposto por Briesen e Marquardt (2003), aplicado na simulação de um separador flash. Além disso, é desenvolvida a simulação através do método convencional usando um simulador comercial (HYSYS). Os resultados e as conclusões das simulações realizadas são apresentadas de forma comparativa.

Capítulo 6: Apresenta os comentários finais com respeito ao desenvolvimento do enfoque proposto, a eficiência no uso das ferramentas matemáticas, e as vantagens deste novo enfoque em relação ao convencional, além de apresentar sugestões para 
continuação do trabalho desenvolvido com perspectivas de avaliação de outras metodologias.

Capítulo 7: Reune as referências bibliográficas.

Apêndices. Mostram alguns tratamentos matemáticos do equacionamento do método avaliado e o programa utilizado para a simulação do processo flash com o algoritmo proposto. 


\section{PETRÓLEO E CARACTERIZAÇÃO DAS FRAÇÕES DE PETRÓLEO}

\subsection{Petróleo e Frações de Petróleo}

A definição de petróleo é muito variada. Segundo Speight (1991), o petróleo é essencialmente uma mistura de componentes químicos do tipo gasoso, líquido e sólido que se acham em depósitos de rochas sedimentares em todo o mundo. No estado cru tem valor mineral, mas quando ele é refinado fornece combustíveis líquidos, solventes, lubrificantes e muitos outros produtos de alto valor. De modo geral, o petróleo cru é definido como uma mistura de compostos que entram em ebulição em diferentes temperaturas, e que por isso, eles podem ser separados, em uma variedade de frações genéricas, através de um processo de destilação.

A tabela 2.1 mostra um exemplo de classificação destas frações segundo o ponto de ebulição e número de carbonos.

Tabela 2.1. Frações genéricas de pontos de ebulição em que pode ser separado o petróleo cru. Fonte: Speight, J., (1991).

\begin{tabular}{|l|c|}
\hline \multicolumn{1}{|c|}{ Frações } & Pontos de ebulição ${ }^{\circ} \mathrm{C}$ \\
\hline Nafta leve & $-1-150$ \\
\hline Gasolina & $-1-180$ \\
\hline Nafta pesada & $150-205$ \\
\hline Querosenes & $205-260$ \\
\hline $\begin{array}{l}\text { Petróleos para } \\
\text { forno }\end{array}$ & $205-290$ \\
\hline $\begin{array}{l}\text { Gases leves de } \\
\text { petróleo }\end{array}$ & $260-315$ \\
\hline $\begin{array}{l}\text { Gases pesados de } \\
\text { petróleo }\end{array}$ & $315-425$ \\
\hline Lubrificante & $>400$ \\
\hline $\begin{array}{l}\text { Gases de petróleo } \\
\text { isolado }\end{array}$ & $425-600$ \\
\hline Residuos & $>600$ \\
\hline
\end{tabular}


O petróleo e as frações de petróleo, como fontes de energia não renováveis, são utilizados principalmente na geração de calor e eletricidade na indústria e no setor urbano e como combustível no setor de transporte. Por este motivo, a indústria do refino de petróleo é uma das mais importantes no mundo. Briesen e Marquardt (2004a) citam que, somente para o ano 2000, foram processadas 4066 milhões de toneladas. Os problemas atuais que o setor de petróleo enfrenta, como por exemplo, queda nos rendimentos dos produtos, aumento do preço de óleo, competição de mercado e as rigorosas regulamentações ambientais, estão forçando o desenvolvimento de extensivas modificações em suas operações para melhorar seus resultados econômicos e operacionais. Para atender a tais necessidades, uma ideia fundamental é a utilização de uma modelagem detalhada do processo, através de técnicas e métodos mais eficientes, que permitam a obtenção de resultados cada vez mais proximos do processo real, e a sua consequente aplicação para a otimização dos processos. Moro (2003) analisa a tecnologia de processo e a otimização em tempo real na indústria do refino de petróleo sob o ponto de vista de controle de processos, otimização, planejamento e sequenciamento da produção.

Um dos grandes desafios na indústria do refino é a obtenção de um modelo detalhado com uma melhor representação da composição das correntes, pois o petróleo contém um grande número de espécies químicas na sua composição, definidas como misturas multicomponentes complexas (Briesen e Marquardt, 2004a).

Os métodos convencionais de tratamento destas correntes são:

- Divisão e agrupamento em pseudo-componentes (frações de intervalos de ebulição) que permitem estimar, através de ábacos, as frações molares e os valores de $\mathrm{k}$ (constante de equilíbrio) para cada um destes componentes.

- As curvas ASTM (American Society for Testing and Materials) ou TBP “True Boiling Point” de misturas que permitem usar correlações empíricas para construir a curva de vapor de equilíbrio flash, EFV (equilibrium flash vapor) à pressão atmosférica, eventualmente corrigidas para a pressão de operação. 
Seader et al. (1997), “Os princípios da destilação multicomponente aplicado a petróleo, síntese de petróleo cru e outras misturas complexas, justificam uma especial consideração pelas seguintes razões:

1. Tais reservas são de composição excessivamente complexa, consistindo, no caso do petróleo, de muitos tipos diferentes de hidrocarbonetos e talvez de compostos inorgânicos e orgânicos.

2. Os produtos da destilação das misturas complexas são em si mesmas, misturas complexas. A qualidade e os rendimentos destes produtos variam significativamente dependendo, sobretudo da fonte destas reservas. Até petróleos crus da mesmo origem podem exibir marcadas variações.

3. A escala das operações de destilação de petróleo é geralmente ampla e comum em muitos processos de refinação de petróleos, incluindo destilação atmosférica de petróleo cru, destilação a vácuo dos resíduos do fundo obtidos desde a destilação atmosférica, fracionamento principal de efluentes gasosos de cracking catalítico e de coking térmico. Estas operações de destilação ocorrem em grandes equipamentos com alto consumo energético. Além disto, a otimização do projeto e operação é importante e com freqüência levam a uma configuração relativamente complexa dos equipamentos".

Portanto, a simulação atual dos processos de refino requerem, necessariamente, modelos mais rigorosos, devido à necessidade cada vez mais detalhada dos componentes. O desenvolvimento historico mostra que, na maior parte dos casos, modelos mais rigorosos resultavam em modelos de grande tamanho e enorme esforço computacional.

Esta necessidade de modelar o processo químico e o desafio de tornar a simulação factível para processos industriais, são discutidos de modo amplo e abrangente por Backx et al. (2006). 
Modelos confiáveis de precisão conhecida são indispensáveis para a aplicação de técnicas baseadas em modelos. No caso de misturas multicomponentes, tais como óleo cru ou frações de hidrocarbonetos, técnicas adequadas de redução podem ser aplicados para obter modelos de complexidade conveniente. A aplicação de uma abordagem para a modelagem reduzida de misturas multicomponentes foi apresentada por von Watzdorf e Marquardt (1997), originado da combinação da termodinâmica contínua com a discretização de wavelet-Galerkin.

\subsection{Caracterização}

Os tipos de caracterização para misturas de petróleo e frações de petróleo são muito variados. Segundo API/PETRO (1992), os hidrocarbonetos podem ser caracterizados, por exemplo, pelas seguintes propriedades físicas: ponto de ebulição, ponto crítico e densidade do líquido. Assim, os sistemas que contêm misturas de hidrocarbonetos com composição conhecida são muito bem caracterizados por estas propriedades. Em misturas complexas, como as frações de petróleo, nem sempre é possível definir a concentração de todos os componentes, por isso elas são, usualmente, caracterizadas por parâmetros derivados da análise das destilações de laboratório, por exemplo, do tipo ASTM e da gravidade específica da mistura. Aliás muitos parâmetros de caracterização a partir desta análise são conhecidos, mas os mais utilizados geralmente são cinco diferentes pontos de ebulição (VABP, volumetric average boiling point, ponto de ebulição volumétrica promédio; MABP, molal average boiling point, ponto de ebulição molal promédio; WABP, weight average boiling point, ponto de ebulição de peso promédio; CABP, cubic average boiling point; ponto de ebulição cúbica promédio; MeABP, mean average boiling point, ponto de ebulição média promédio) e o fator de caracterização de Watson $\bar{K}_{W}$.

Um problema inerente à caracterização das misturas do petróleo e frações de petróleo decorre da falta de precisão na identificação de todas as espécies químicas presentes nestas misturas, sendo desta maneira impossível obter a expressão das composições destas espécies em termos e quantidades convencionais (frações mássicas ou molares); além disso uma caracterização mínima deve ser feita usando uma curva de 
destilação TBP e a magnitude da gravidade específica. Para resolver este problema é preciso obter informação suficiente sobre a composição de tais misturas, para assim alcançar alto nível de detalhe na caracterização. Segundo Briesen e Marquardt (2004b), a informação mais detalhada das composições das misturas permitem considerar que tais composições expressem os componentes químicos reais.

\section{Formas de representação da composição da mistura}

É possível obter um alto nível de detalhe com uma melhor representação da composição das misturas. Para isso, duas formas de representação são conhecidas, a discreta e a contínua.

Atualmente nos processos de refino, o método mais empregado para representar a composição das misturas é a introdução de uma série de componentes fíctícios chamados pseudo-componentes. Esta representação é do tipo discreta e permite ponderar aproximadamente as características termofísicas da mistura. As vantagens desta representação são a simplicidade e o alto grau de descrição da mistura, porém as grandes desvantagens mostram-se na simulação dos modelos do processo que são atribuídos à falta de adaptabilidade e a ausência de controle do erro na aproximação. Estes dois problemas, geralmente, são evitados pela seleção de um grande número de pseudocomponentes ou eles simplesmente são ignorados.

No enfoque de representação contínua, funções de distribuição podem ser empregadas para representar a composição das misturas de infinitos componentes, como é o caso das espécies químicas presentes no petróleo (Riazi, 2004). Além disso, esta forma de representação não está limitada para nenhum tipo de caracterização especial de mistura. Por exemplo, os resultados discretos de uma análise detalhada de uma mistura multicomponente, obtidos por cromatografia gasosa, podem ser interpretados como uma função de distribuição contínua que usa valores constantes por patamares. Desde a década de 80 , as pesquisas em relação ao uso dessas funções têm progredido amplamente (Cotterman e Prausnit, 1985; Ratzsch e Kehlen, 1983), e são mais conhecidas dentro do conceito de Termodinâmica contínua. 
Segundo Watzdorf et al. (1996) a vantagem de representar as composições de forma contínua é a possibilidade de tratar o problema como um caso de discretização, o que facilita a solução numérica. Este fato está diretamente relacionado ao tamanho do problema gerado pela modelagem do processo, que ao serem tão grandes precisaram ser reduzidos para minimizar os cálculos para resolvê-los.

\subsubsection{Métodos em laboratório para Caracterização de Frações de Petróleo}

O procedimento de caracterização de cru ou frações de petróleo feitas no laboratório tem sua importância nos resultados que ela oferece na apresentação de dados de propriedades termofísicas, que podem ser usadas para a predição dos processos de refino em plantas industriais.

A situação real dos bancos de dados destas propriedades são considerados ainda incompletos, inconsistentes e com sérios vazios na sua informação, segundo reportaram alguns estudos feitos pela API (American Petroleum Institute, Instituto Americano de Petróleo) em 2000. Estes motivos permitem manter, ainda, a constante procura de dados confiáveis para a caracterização dessas propriedades.

Nesse caminho, por exemplo, a NIPER (National Institute for petroleum and energy research, Instituto Nacional para pesquisa em petróleo e energia) em união com outras várias instituições como II $T$ research Institute and BDM Ocklahoma, desenvolveram esse tipo de trabalho em 2000. A parte experimental que esteve a cargo da NIPER consistiu-se basicamente na produção de ensaios detalhados e dados de propriedades termofísicas, que envolveram a discussão dos testes de caracterização, sua precisão e uma compilação condensada de dados de três correntes de alimentação de petróleo cru. Os resultados obtidos foram considerados altamente confiáveis.

Em resumo, o trabalho que eles realizaram nos três crus selecionados consistiu na destilação de estreitas frações de ponto de ebulição. A caracterização detalhada foi desenvolvida em todo o cru, em estreitas frações de ebulição, em combinações apropriadas e em resíduos, após uma avaliação das várias correlações. 
O laboratório analítico da NIPER é um dos mais confiáveis pela API, pela sua ampla reputação, pela alta eficiência e precisão nos dados obtidos nos seus ensaios.

Como referência pode-se resumir o procedimento experimental que eles desenvolvem em três passos principais:

(1).Preparativos para a destilação: $O$ cru fornecido para caracterização é submetido à análise, segundo o tipo de destilação selecionada, como a ASTM, com suas respectivas especificações de operação (temperatura, tipo de coluna, refluxo, vácuo, etc., o equipamento e os parâmetros), e segundo a precisão da destilação em relação aos outros tipos de destilação ASTM.

(2).Destilação analítica do cru: foi empregado o tipo ASTM D 2892, embora os resultados deste método não sejam aceitos como material de referência adequado para determinação de tendências.

(3).Destilação de frações: Os cortes, ou compósitos da etapa preparatória da destilação, são destilados por vários métodos, isto deve-se ao fato de que esta destilação é feita com aparatos automatizados que não foram desenhados para destilação de cortes de faixa estreitas, provocando assim, dificuldades no controle da destilação. Os métodos utilizados para isso são a ASTM D 86 e a ASTM D 1160 .

Na tabela 2.2 mostra-se diferentes tipos de destilações em testes de laboratório para caracterização de petróleos. 
Tabela 2.2. Destilações em testes de laboratório para caracterização de petróleo Fonte: Seader (1997) (Nelson', Petroleum refinery Engeneering, th ed. , McGraw-Hill, New York, 1958, pp. 95-99, Nelson*, Ibid., pp. 104-105)

\begin{tabular}{|c|c|c|}
\hline Nome do teste & Referencia & Aplicação principal \\
\hline ASTM (atmosférico) & ASTM D86 & $\begin{array}{l}\text { Frações de petróleo ou produtos, incluindo gasolinas, } \\
\text { combustível para turbo, nafta, gás de petróleo, } \\
\text { combustíveis destilados do petróleo, e solventes que não } \\
\text { se decompõem quando são vaporizados a } 760 \mathrm{mmHg}\end{array}$ \\
\hline $\begin{array}{l}\text { ASTM [vácuo, com freqüência } \\
\text { a } 10 \text { torr }(1.3 \mathrm{kPa}) \text { ] }\end{array}$ & ASTM D1160 & $\begin{array}{l}\text { Frações de petróleo pesados ou produtos que tendem a } \\
\text { se descompor no teste ASTM D86 mas podem ser } \\
\text { parcialmente ou totalmente vaporizados a uma máxima } \\
\text { temperatura do líquido de } 750^{\circ} \mathrm{F}\left(400{ }^{\circ} \mathrm{C}\right) \text { para pressões } \\
\text { baixas a } 1 \text { torr }(0.13 \mathrm{kPa}) \text {. }\end{array}$ \\
\hline $\begin{array}{l}\text { TBP [atmosférico ou a } 10 \text { torr } \\
(1.3 \mathrm{kPa})]\end{array}$ & $\begin{array}{l}\text { ASTM D2892 } \\
\text { (Nelson') }\end{array}$ & Petróleo cru e frações de petróleo \\
\hline $\begin{array}{l}\text { TBP simulada (cromatografia } \\
\text { gasosa) }\end{array}$ & ASTM D2887 & Petróleo cru e frações de petróleo \\
\hline $\begin{array}{l}\text { EFV (atmosférica, } \\
\text { atmosferica ou } \\
\text { atmosferica) }\end{array}$ & Nelson * & Petróleo cru e frações de petróleo \\
\hline
\end{tabular}

\subsubsection{Estimativas em Simulação da Caracterização de Frações de Petróleo}

Modernos programas de simulação são empregados para simular processos que envolvem frações de petróleo, por exemplo, HYSYS, PRO II, Chem CAD. Neles é possível a caracterização de misturas multi-componentes do petróleo, na base do conhecimento, de algumas curvas de destilação, como: TBP, ASTM D86, EFV (equilibrium flash vapor), etc. através de uma mistura substituta que consiste de um determinado número de pseudocomponentes.

É preciso mencionar que os métodos de caracterização, convencionais e modernos, buscam atingir, sempre, um mesmo objetivo: usar a informação proporcionada pelos dados obtidos através das análises das correntes, nas refinarias, e assim caracterizar melhor as suas propriedades.

Por isso, a tendência moderna é continuar usando a informação destas análises de modo cada vez mais eficiente, aproveitando os detalhes que ela proporciona. Para isso, técnicas e métodos mais sofisticados e fáceis de utilizar são procurados. 
Dada a complexidade da composição do petróleo e de seus produtos, além das limitações nos procedimentos de medidas para sua caracterização, novas metodologias para esta caracterização são apresentadas no transcurso do tempo. Neste sentido, busca-se à melhora dos procedimentos de medida, através de, por exemplo, métodos térmicos, que são também abordagens que permitem melhorar a análise destas substâncias. O trabalho de Kopsch (1997) apresenta a termogravimetria (TG) e a calorimetria diferencial de varredura (DSC, Diferencial Sweep Calorimetry) para sua aplicação na destilação simulada e em medidas de atmosferas inertes ou, oxidativas, obtendo-se com eles uma rápida informação inicial das amostras da substância. Além disso, também foi considerada a aplicação sistêmica deste método termo-analítico, para betume e betume de polímero modificado, residuais pesados, óleo de xisto, lubrificantes e óleos de silicone. O potencial desta análise térmica na caracterização de sistemas multicomponentes, da mesma maneira que suas restrições metodológicas, são descritas pelo autor considerando seus próprios resultados.

Por outro lado, o método convencional que predomina nas refinarias é o agrupamento em pseudocomponentes, mas novos enfoques de agrupamento são apresentandos, além da termodinâmica contínua e os mais recentes como a discretização wavelet-Galerkin, e mistura substituta de componentes reais. Este método de agrupamento é apresentado com mais detalhes, no seguinte item, através de sua importância na comparação dos resultados da proposta desenvolvida neste trabalho.

\section{Métodos de Agrupamento em Pseudocomponentes}

Entre os vários métodos de agrupamento que se conhece na literatura, o método mais comum, é aquele onde as misturas complexas são caracterizadas pela informação composicional disponível, agrupadas dentro de uma determinada série de pseudocomponentes. Porém, algumas desvantagens estão relacionadas a este procedimento: a qualidade da informação dos produtos é somente obtida em termos de pseudocomponentes, e não na concentração de uma espécie química definida; a estabilidade na seleção de pseudocomponentes em um fluxo de alimentação é difícil 
de ser obtida e as propriedades físicas dos pseudocomponentes são estimados através de métodos empíricos falíveis.

Os modernos programas de simulação usam uma mistura substituta baseada no agrupamento de pseudocomponentes. O mecanismo da simulação consiste em definir no programa somente a composição dos chamados leves finais, obtidos a partir de algumas curvas de destilação, e em seguida determinar o número de cortes de pseudocomponentes ao longo dos intervalos de temperatura em que eles são definidos. Os programas calculam a composição da mistura substituta de pseudocomponentes e armazenam a informação termodinâmica dentro da base de dados do usuário. Essa informação será necessária para os cálculos do comportamento do equilíbrio líquido-vapor ou de entalpias da mistura. Uma desvantagem é a introdução dos erros inerentes a este procedimento, pelo fato de estimar os parâmetros termodinâmicos de simples pseudocomponentes através de correlações empíricas, as quais somente têm uma faixa limitada de validade e não são igualmente adequadas para toda a mistura.

\section{Fundamento do método}

O fundamento do método de agrupamento de pseudocomponentes pode ser visto em Edmister (1955); e Katz e Brown (1933). Pode ser definido através de dois passos:

a. Obter experimentalmente uma curva de caracterização padrão, de preferência uma curva TBP. Porém, a curva TBP pode ser substituída por seu equivalente mais exato SIMDIST cromatográfica ou pela transformação de curvas resultantes de outros procedimentos de caracterização (ASTM D86, EFV-Equilibrium Flash Vapor) que usam correlações empíricas (API, 1992). Entretanto, a transformação destas curvas alternativas para a curva TBP não são tão confiáveis e podem originar desvios consideráveis em comparação à curva experimental.

b. Dividir a faixa dos pontos de ebulição da curva TBP, a fim de se obter intervalos de temperatura entre $\left(T_{i}, T_{i+1}\right)$, com $i=1, \ldots . I$, cobrindo continuamente a faixa inteira de temperatura. Na literatura existe várias possibilidades de seleção do 
tamanho dos intervalos, algumas sugestões são dadas por Whitson e Brulé (2000) apud Eckert e Vanek (2005b). Usualmente, considera-se suficiente usar 15K para pontos de ebulição normal até $700 \mathrm{~K}, 30 \mathrm{~K}$ para intervalos entre $700 \mathrm{~K}$ até $900 \mathrm{~K}$, e 50K para maiores pontos de ebulição da mistura (como é feito no programa de simulação HYSYS, quando se usa a opção de divisão automática). Cada intervalo de temperatura representa um pseudocomponente com seu ponto de ebulição normal e descreve-se pelas seguintes relações: aritmética eq. (2.1a) e a integral média de temperatura eq. $(2.1 b)$ que compreende todo o intervalo da fração destilada. A figura (2.1) mostra esta descrição.

$T b_{i}=\frac{T b\left(\xi_{i}^{R}\right)+T b\left(\xi_{i}^{L}\right)}{2} ; i=1, \ldots . I$

ou

$$
T b_{i}=\frac{1}{\xi_{i}^{R}-\xi_{i}^{L}} \int_{\xi_{i}^{R}}^{\xi_{i}^{L}} T b(\xi) d \xi ; \quad i=1, \ldots . I
$$

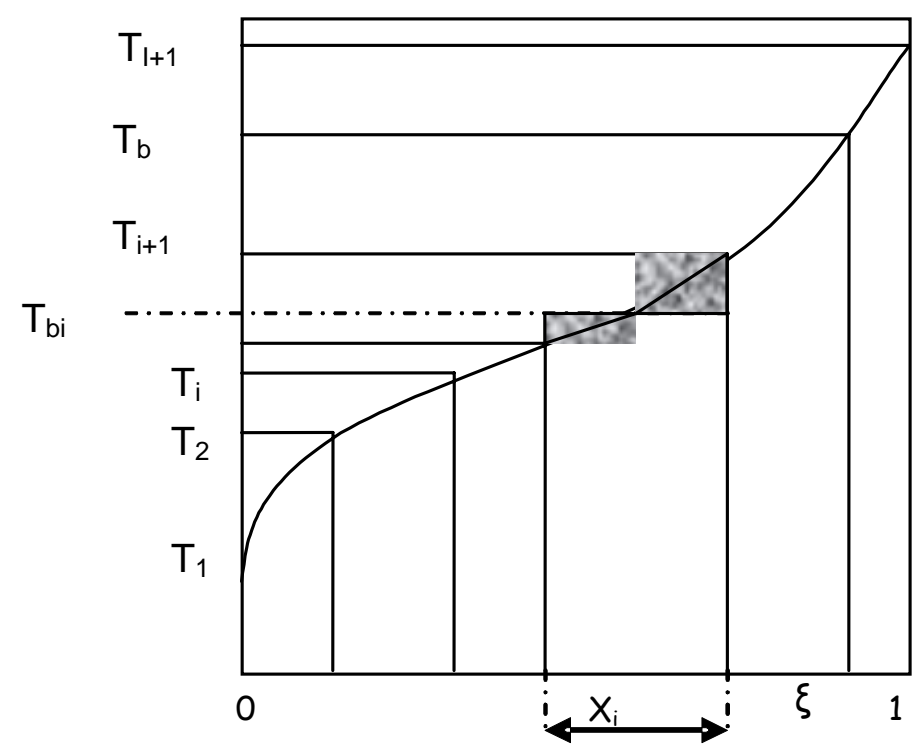

Figura 2.1. Definição de um pseudocomponente e seu ponto de ebulição na mistura substituta desde a curva TBP. Fonte: Miquel e Castell (1998)

Cada intervalo da fração destilada $\mathrm{Xi}=\left(\xi_{i}^{R}-\xi_{i}^{L}\right)$, em que $i=1, \ldots . I$, determina a relativa contribuição de cada pseudocomponente para a mistura, que também é usado 
para definir sua composição. Por outro lado, para usar a mistura, substituta de pseudocomponentes, é necessário fornecer a mesma estrutura de propriedades físicas que são usadas para os componentes reais. Usualmente, medir estas propriedades não apresenta dificuldades porque além da informação da curva TBP, a informação da curva de densidade e da viscosidade de frações individuais são obtidas na coluna do laboratório durante a destilação teste. Deste modo pode-se estimar para cada fração o peso molecular médio, além de duas a quatro propriedades para cada pseudocomponente. Um exemplo é o ponto de ebulição normal médio. Todas essas propriedades podem ser usadas para originar uma série de procedimentos de estimação empírica obtendo outras propriedades importantes como: propriedades críticas, fator acêntrico, etc., lembrando que este procedimentos não apresentam muita confiabilidade.

Medir os parâmetros globais, para as misturas complexas, é relativamente simples, por exemplo, propriedades bulk, como a densidade, o peso molecular, o índice de refração ou a viscosidade, isto é, com freqüência, resgatado com outras medidas. O uso direto deles para a derivação de uma mistura, modelo ou substituta é somente conhecida para a densidade, que se obtém cumprindo algumas condições específicas, permitindo obter uma aproximação da curva de caracterização desde o fator de Watson, $\bar{K}_{W}$, (Wauquier, 1995 apud Eckert e Vanek (2005b)).

Quando a densidade global de uma mistura é conhecida, o fator de Watson, $\bar{K}_{W}=\frac{\left(1.8 \overline{T_{b}}\right)^{1 / 3}}{\bar{S}}$

pode ser assumido a ser constante. Assim, é possível conseguir uma aproximação da curva de caracterização da densidade (Wauquier, 1995 apud Eckert e Vanek $(2005 b)$ ). Isto pode ser uma alternativa para a medida dos dados de densidade para cada fração durante o experimento de caracterização (Eckert e Vanek, 2005b).

A principal vantagem deste método, na simulação, é que o procedimento de caracterização não é iterativo, este fato ainda é amplamente aceito como um método 
conveniente na simulação dos equipamentos de separação. Porém, os problemas que origina são:

- Não se pode definir nenhum carácter químico para os pseudocomponentes por exemplo, quando é necessário definir o carácter químico dos componentes que formam uma mistura, por terem um papel importante nas reações químicas que acontecem nos processos estudados.

- Um pseudocomponente é definido, primariamente, por seu (pseudo) ponto de ebulição e por alguns parâmetros adicionais, principalmente pela gravidade específica, peso molecular ou viscosidade. Todas as outras propriedades físicas, por exemplo, necessárias para cálculos da simulação, devem ser estimadas. Infelizmente, a confiabilidade dos métodos de estimação comums (mencionados, por exemplo, por Whitson e Brulé, 2000 apud Eckert e Vanek (2005b)) para propriedades críticas, do fator acêntrico, etc. é um tanto deficiente com relação aos resultados de alguns testes publicados, como no caso de Lindqvist et al. (1994) apud Eckert e Vanek (2005b), Riazi (2005) apud Eckert e Vanek (2005b), e Twu (1984).

- Para pseudocomponentes não se pode usar métodos de contribuição de grupos (por exemplo, UNIFAC), pois, requerem informação da estrutura molecular dos componentes para estimar alguns parâmetros (como parâmetros de interação binária para equilíbrio líquido-vapor).

- É ineficiente a informação do tipo de mistura, de componentes que prevalecem, os parafínicos ou os aromáticos, ou em relação ao tipo de alguns de seus componentes importantes, como a polaridade, os que não poderiam ser facilmente utilizados.

- Combinações arbitrárias de pseudocomponentes e componentes identificados na mistura original não são suportados nos programas de simulação comercial. Isto mostra que não é possível achar um componente real dentro da faixa de 
temperaturas usadas para a definição de pseudocomponentes sem conhecer seu conteúdo.

Entretanto, o uso de pseudocomponentes tem uma importante vantagem quando é definido e previsto por uma série de (pseudo) propriedades físicas, pois eles podem ser tratados dentro dos programas de simulação como algum outro componente real (exceto em processos com reação química).

Isso leva a concluir que, além dos esforços em apresentar melhorias nas técnicas de caracterização dos petróleos, utilizando o critério de pseudocomponentes, ainda torna-se necessária a informação cada vez mais detalhada da composição destes petróleos, a fim de atingir ótimos resultados na modelagem dos processos e de se obter descrição mais precisa das propriedades destes.

Alguns trabalhos em relação a estes esforçõs são apresentados nos seguintes parágrafos.

A caracterização de petróleos pesados, a descrição destes através de pseudocomponentes torna-se difícil por duas razões: o fluído é representado por componentes que são definidos de maneira não muito precisa; e, as misturas de petróleo contêm um número limitado de componentes leves, cuja fração molar não pode ser determinada. Esses petróleos, contêm uma númerosa quantidade de componentes pesados, cujas propriedades físicas não são usualmente conhecidas e não conseguem ser quantificadas e nem identificadas com precisão. Embora a quantidade de componentes, mais pesados que o n-decano, representa uma porcentagem bem menor em relação aos totais pesados, sua modelagem é crucial para obter uma boa idéia das propriedades PVT das misturas de petróleo.

Neau e Jaubert (1993) utilizaram um número restrito, de quatro a nove pseudocomponentes para predizer as propriedades PVT de petróleos pesados, aplicado na simulação de reservatórios. Os resultados obtidos foram considerados interessantes, dado o uso de 4 pseudocomponentes na simulação real realizada nas fábricas de petróleo. 
Montel e Gouel (1984) apresentaram um novo algoritmo para agrupar componentes do fluído em componentes hipotéticos. O esquema de agrupamento foi baseado na similaridade de algumas propriedades de todos os componentes identificados pela análise cromatográfica. O objetivo deste algoritmo foi aproveitar a crescente quantidade de dados analíticos que provêem de modernos equipamentos de laboratório na aplicação sob a simplicidade na descrição composicional do fluído na projeção dos modelos. O interessante deste método é que pode ser adaptado para qualquer equação de estado, para qualquer número de componentes ou propriedades. Além de possuir uma definição de cálculo vantajoso de propriedades críticas, este método sugere um critério de seleção entre os cálculos de propriedades críticas verdadeiras e a regra de mistura clássica. E após a simulação numérica do comportamento PVT de petróleo líquido e gás condensado, definida para 150 componentes, o algoritmo proposto simplificou o agrupamento do fluído em 7 e 5 componentes, mostrando que os resultados nos cálculos das propriedades críticas foram melhores se comparados com o tratamento da regra de mistura clássica.

Edmister (1956) propôs um método integral nos cálculos da destilação de petróleo. O princípio do método é simples e, em algumas aplicações prévias, os resultados foram ineficientes ou aproximados. Porém, o conceito introduzido, de continuidade e a integral, para se representar a quantidade de um número indefinido de componentes da mistura permite notar os esforços para se obter melhores resultados em relação à descrição composicional, das misturas complexas, visando a otimização dos cálculos nos procedimentos de destilação do petróleo.

Miquel e Castell (1992) apresentaram um novo procedimento para caracterização de petróleo e frações de petróleo, baseado no agrupamento de pseudocomponentes pelo método integral, mais usual do que aquele obtido pelo método mais comum, da constante $\bar{K}_{W}$, sugerido por Lion e Edmister (1975). Os autores utilizaram somente dados experimentais de uma curva TBP atmosférica e a curva inteira das frações de densidade, e conseguiram fechar o balanço de material e minimizar o erro do balanço molar. O erro obtido é significativamente menor do que o erro obtido pelo método da constante $\bar{K}_{W}$. 
A temperatura de ebulição normal e a gravidade específica são dois dados importantes na predição de propriedades do petróleo. Baseando-se nestes dados é que pode-se desenvolver diferentes métodos para atingir a predição. Twu (1984) utilizou estes dados para desenvolver um método, segundo as conclusões apresentadas após os testes necessários, simples mas confiável e preciso, na predição de propriedades críticas e peso molecular de petróleo e líquidos de alcatrão de hulha. As correlações obtidas por este método em comparação com muitos outros publicados até essa data representaram uma melhor predição das propriedades da mistura.

Fica clara a importância de se ter, cada vez mais, informação detalhada das propriedades de qualquer substância, pois, este fato permite descrever melhor os processos visando obter mais controle dos mesmos. Neste sentido, Design Institute for Physical Properties (DIPPR), o Instituto de Projetos para Propriedades Físicas, continua trabalhando na procura e compilação de base de dados, que são importantes industrialmente, e assim, atingir às necessidades dos processos da engenharia química.

\section{Novos enfoques}

A representação apropriada da composição das misturas é muito importante para uma boa caracterização. Para uma grande quantidade de componentes, em uma mistura complexa de petróleo, é necessário definir uma mistura substituta que simplifique o problema gerado nos cálculos da simulação dos modelos. Esta mistura substituta deve representar um número mínimo de componentes, ou usar uma representação alternativa que a descreva, o mais verdadeiramente possível.

Para atingir uma mistura substituta, ou uma representação alternativa, tem-se utilizado, tradicionalmente, o agrupamento em pseudocomponentes (visto no item anterior) e o método da termodinâmica contínua, respectivamente. Novas propostas têm sido apresentadas, nas duas últimas décadas, com a finalidade de melhorar a descrição das misturas complexas. Uma delas é o chamado método de discretização adaptativa wavelet-Galerkin (Briesen e Marquardt, 2003, 2004a, 2004b), que utiliza o critério de representação da mistura proposta pela termodinâmica contínua, porém, 
com algumas variações, (o método está apresentado nos capítulos 4 e 5). Outros são: a representação da mistura baseada na seleção de componentes reais (Eckert e Vanek, 1998, 2003, 2005a, 2005b, 2005c), e a caracterização através de métodos moleculares como novo enfoque de agrupamento (HU et. al, 2002).

Estas novas propostas estão sendo muito estudadas nos últimos anos, pois a termodinâmica contínua, dada como alternativa para superar algumas desvantagens do método tradicional de pseudocomponentes, recebeu pouca atenção na prática industrial. Mas, dada sua importância na abordagem desenvolvida neste trabalho, é tratada com mais detalhe no capítulo 3.

O fundamento do enfoque wavelet-Galerkin adaptativo, está baseado na formulação do modelo de processo utilizando funções de distribuição contínua, do tipo constantes por patamares (wavelet). Para representar a composição da mistura e para a resolução do modelo tem-se utilizado a combinação da discretização waveletGalerkin adaptativa com um enfoque multi-malha (Briesen e Marquardt, 2003).

A principal vantagem desta primeira proposta é a possibilidade de ajustar a representação da mistura através do controle de erro de maneira adaptativa, que é o problema fundamental do método de caracterização tradicional. Ele representa uma alternativa promissora, embora utiliza experiência matemática não muito simples, reformula os modelos em função a incorporar a representação contínua de algumas variáveis do modelo, e converte também as propriedades físicas em funções de distribuição. Neste trabalho, precisamente, procura-se avaliar o potencial deste método em um ambiente de simulação aplicado a processos de separação térmica de petróleo, tal como é apresentado na proposta de Briesen e Marquardt (2003).

Por outro lado, o enfoque de mistura substituta na base de componentes reais está baseada na representação da mistura original por um sistema de componentes reais (Eckert, 1999; Eckert e Vanek, 2005a; Ba et al., 2003), assim, a mistura substituta é definida tanto em relação a seu carater químico, quanto às suas propriedades físicas e podem ser obtidas a partir de uma base de dados, Eckert e Vanek (2005a). 
As vantagens deste método mostra-se, não somente nos processos de separação térmica de petróleo (Belohlav et al. 2005; Eckert e Vanek, 2005a), mas também na aplicação de modelagem e simulação de outros tipos de equipamentos (Eckert e Vanek, 2003). Por exemplo, reatores químicos, e outras operações onde ocorrem reações químicas. E nela é possível a omissão de correlações empíricas usadas na estimativa de propriedades termodinâmicas, as quais, com freqüência, são pouco confiáveis e errôneas. Ele permite, também, incorporar alguns componentes reais que são obrigatórios na mistura substituta, porque dados reais de suas quantidades presentes na própria mistura são conhecidos. Estes dados reais podem combinar-se com os pseudocomponentes, quando os componentes representativos para maiores pontos de ebulição normal estão ausentes na base de dados.

Em relação as correlações empíricas usadas para estimar parâmetros termodinâmicos, nos diversos métodos de caracterização, pode-se dizer que as desvantagens que apresentam são devido às limitadas faixas de validade e à não adequação para todas as misturas. E como já foi dito, eles podem ser omitidos no procedimento de caracterização que utiliza componentes reais, mas para o enfoque de pseudocomponentes e a termodinâmica contínua, esta omissão não é possível. Este fato é considerado como uma possível razão de porque a termodinâmica contínua não tem progredido na caracterização de misturas de petróleo (Ratzsch, 1989).

Em 1999, Eckert desenvolveu um método de caracterização baseado neste conceito de representação em termos de componentes reais. $\mathrm{O}$ autor explica que, a partir de resultados de análises laboratoriais e a partir de algumas curvas de destilação, são selecionados alguns componentes presentes nas misturas para serem utilizados de base para esta representação. O autor considera a curva EFV mais adequada para este enfoque. Ele explica, também, que o modelo matemático pode encontrar a composição da mistura substituta, que representa uns poucos componentes reais da mistura, mostrando comportamento muito similar do equilíbrio líquido-vapor da mistura original, isto faz com que seja possível simplificar os cálculos. Além disso, é possível, também, omitir o uso de correlações empíricas para estimar os parâmetros termodinâmicos em todos os seguintes cálculos (pois eles são conhecidos para os 
componentes reais), pois estes usualmente são os que introduzem erros consideráveis na modelagem, fato que acontece quando se tem usado o método de pseudocomponentes. O objetivo do autor é mostrar um caminho simples de usar, tanto a informação contida nos grupos simples de hidrocarbonetos, quanto a informação resultante de algumas curvas de destilação para caracterizar misturas multicomponentes de petróleo, tornando este método uma alternativa ao método de pseudocomponentes.

Ba et. al. (2003) apresentaram algoritmos para o procedimento de seleção dos componentes reais, para a formação da mistura substituta e para a determinação da composição da mistura, a serem usados na caracterização das misturas complexas de petróleo visando alcançar uma caracterização mais confiável. O procedimento para estabelecer a mistura substituta tem duas etapas: a primeira é a seleção de uma série de componentes puros para serem incluídos na mistura. E segundo, uma técnica de otimização adequada é usada para ajustar a composição da mistura substituta em relação à curva de caracterização TBP ou para o modelo matemático de algum outro procedimento de caracterização. Os resultados que eles obtiveram na aplicação deste enfoque, em relação aos dados de uma mistura de gasolinas, são, segundo o ponto de vista dos critérios considerados, uma alternativa promissora ao enfoque de pseudocomponentes.

A figura 2.2 mostra comparativamente um esquema do procedimento de seleção da mistura substituta entre o enfoque tradicional (pseudocomponentes) e a nova proposta de componentes reais. 


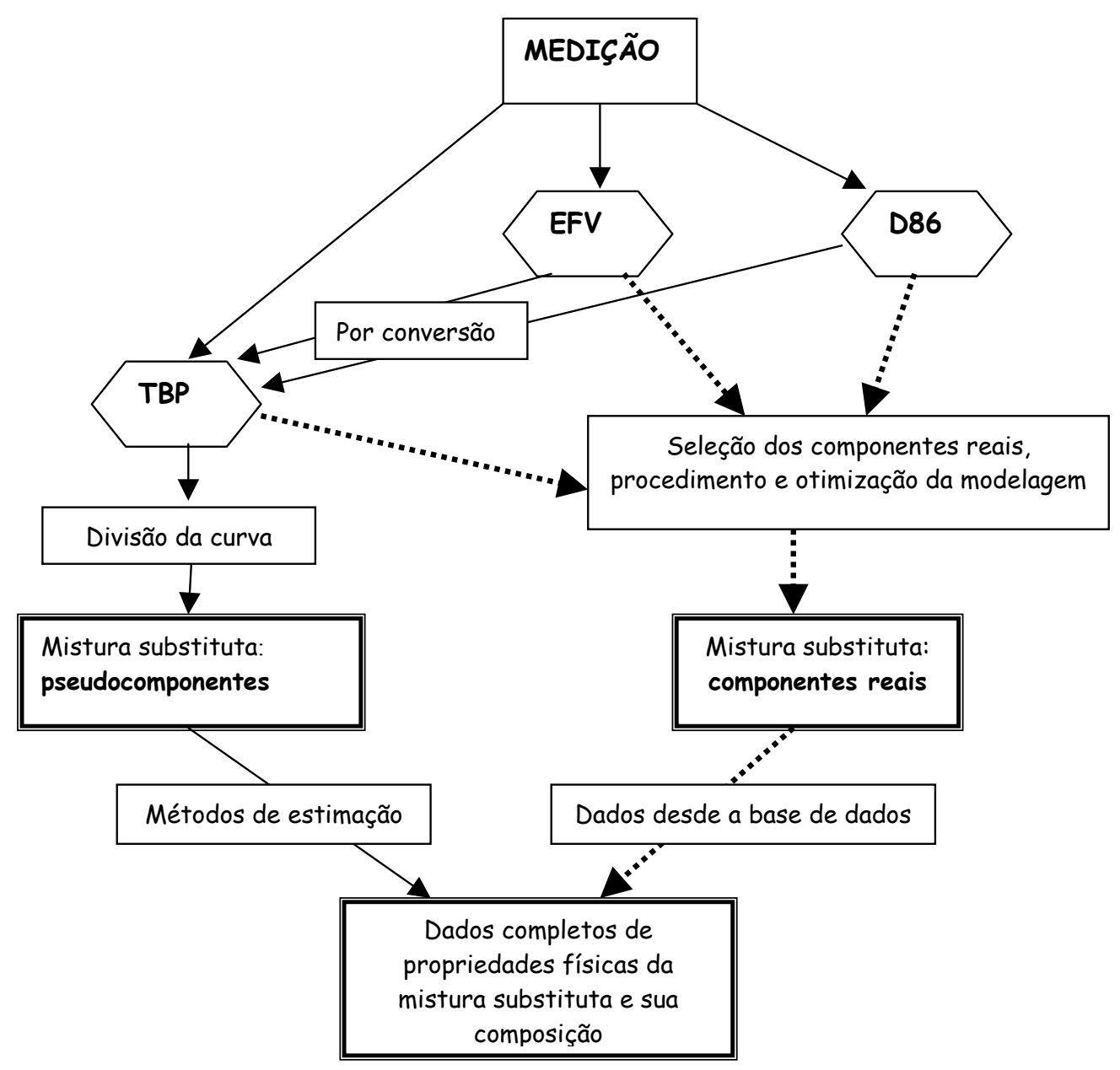

Figura 2.2. Procedimento de seleção de mistura substituta para caracterização de petróleos: $(\rightarrow)$ Pseudocomponentes,$(\cdots \rightarrow)$ componentes reais. Fonte: Eckert; Vanek (2005a).

O outro enfoque é uma moderna estratégia de agrupamento conhecida como a caracterização molecular. Briesen e Marquardt (2004) referem-se a esta estratégia como aquela que usa, mais diretamente, a informação detalhada obtida das análises experimentais para realizar a representação apropriada das misturas.

Essa estratégia é também considerada, atualmente, como uma das mais promissoras para as simulações dos processos de separação e reação. Hu et. al (2002) empregaram este tipo de agrupamento na modelagem do processo de refino desenvolvendo uma metodologia que combina a modelagem com a otimização, permitindo acrescentar as operações de refinaria. Na modelagem utilizaram uma matriz molecular (representação proposta por Peng e Towler, 1999 apud Hu et. al 
(2002)) baseada em uma série homóloga de compostos de hidrocarbonetos, caracterizando as correntes do processo de refino. Neste trabalho o método de transformação é desenvolvido para obter a composição molecular desde as principais propriedades da corrente. Com esta metodologia conseguiram adaptar novos critérios nas operações da refinaria relacionados diretamente a seu processo de otimização. 


\section{REVISÃO BIBLIOGRÁFICA DA TERMODINÂMICA DO CONTINUO APLICADO À CARACTERIZAÇÃO DE PETRÓLEO}

Segundo Chen e Mathias (2002), as indústrias de processos fazem fortes investimentos cada ano com o objetivo de desenvolver com sucesso os processos nos quais estão envolvidos. Uma ferramente chave para o sucesso é a modelagem do processo. Este conceito abrange desde o desenvolvimento e desenho da tecnologia do processo, passando pelo dimensionamento de equipamentos até chegar à otimização do mesmo.

Chen e Mathias (2002) referem, também, que o sucesso que pode-se alcanzar com esta modelagem depende, criticamente, da precisão na descrição tanto das propriedade temodinâmicas quanto do comportamento de fases dos sistemas químicos envolvidos em um processo. Assim, os autores apresentam, uma perspectiva ampla do conceito da termodinâmica aplicada abrangendo seu desenvolvimento progressivo, suas aplicações nos diferentes processo industriais e suas vantangens ao serem aplicados nos mesmos.

Os autores citam que, além dos avanços, e as novas técnicas desenvolvidas na modelagem termodinâmica dos processos, na prática, os engenheiros, ainda, preferem usar os modelos termodinâmicos simples e intuitivos, que possam ser aplicados fácilmente. Pois, aqueles modelos sofisticados apresentam algumas desvantagens que limitam sua aplicação industrial (por exemplo, excessivo gasto computacional para resolver os modelos, os modelos podem requerir excesiva parametrização, precisa-se de usuarios especializados, etc.).

Chen e Mathias (2002) mencionam que, entre muitos dos problemas na indústria ainda não resolvidos; na caracterização de crú pesado, basicamente estão relacionados aos dados experimentais e aos parâmetros de modelos, este último claramente necessarios para melhorar os modelos.

Neste contexto, além do grande sucesso da termodinâmica aplicada em processos que não implicam misturas multicomponentes, ainda procura-se alternativas 
adequadas para esses casos. Por tal, dentro dos conceitos que implicam a termodinâmica aplicada, desenvolveu-se uma estrutura chamada termodinâmica contínua, tanto para resolver os problemas de sistemas com multi-componentes, quanto para tentar resolver as deficiências do método de agrupamento de pseudocomponentes. Este último método é mais comumente utilizado na representação da componentes de misturas multicomponentes complexas.

Esta estrutura tem recebido muita atenção desde a metade da decada de 1980, graças as facilidades computacionais emergentes, as quais posibilitaram a diminuição do tempo consumido por uma CPU nos cálculos das composições de misturas, além de se obter para estes maior precisão. Pois, estas composições sendo tratadas comummente como discretas passam a ser representadas por funções de distribuição contínua, Silva (1992).

A termodinâmica contínua tem aplicação, principalmente, no equilíbrio de fases de toda mistura que contém um grande número de espécies químicas similares, por exemplo, o equilíbrio Líquido-Vapor na destilação de misturas multi-componentes complexas especialmente de petróleo e outros similares (Ratzsch e Kehlen, 1983).

A descrição da composição molar através de frações molares, quando se tem uma mistura com poucos componentes, não representa um problema. Mas, se a quantidade de componentes é muito grande e, além disso, se as espécies químicas são muito similares, como acontece em muitas misturas industriais (por exemplo, o petróleo, frações de petróleo, líquidos derivados de hulha, polímeros, ou óleos vegetais) isto sim representa um grande problema. Por exemplo as nomeadas de misturas multi-componentes complexas ou misturas poli-dispersas, nestes casos é difícil e, até, praticamente impossível isolar e identificar cada uns dos componentes por análises químicas ordinárias. Assim, deveria considerar-se idealmente conhecidas as frações de centenas ou até milhares destes componentes mas, este fato representa um problema ainda complicado para manipular e resolver o sistema de equações que gera essa quantidade de componentes, Margit e Ratzsch (1989). 
Silva (1992) refere-se a muitos autores, tais como: Katz e Brown (1933), Bowman (1949), Aris e Gavalas (1966), Taylor e Edmister (1971), Robinson e Peng (1978), Pedersen et al. (1984, 1985), que preocuparam-se em buscar soluções, tanto práticas como teóricas, para resolver o problema envolvido na caracterização de misturas multicomponentes complexas, com tendencia a estudo de casos aplicados à indústria petroquímica. A solução comumente utilizadas por eles foi baseada no conceito de pseudocomponentes, neste, quanto maior o número de intervalos, melhor a aproximação com a composição real da mistura, porém, este fato é uma dificuldade representada por o acrescimo do tempo de procesamento computacional.

A termodinâmica contínua corrige essa dificuldade através do uso de funções de distribuição contínua para descrever a composição das espécies químicas em vez de frações molares ou mássicas dos componentes individuais. Basicamente ele assume um número infinito de componentes presentes nas misturas para representar sua composição com funções de distribuição contínua de alguma variável independente $\xi \in R$ (que pode ser peso molecular, temperatura de ebulição normal ou simples número de carbono).

Ratzsch (1989) menciona que, não obstante, o uso destas funções introduz uma inconsistência na termodinâmica usual que se baseia em frações molares dos componentes individuais. Para superá-la duas possibilidades são conhecidas, o enfoque pseudocomponente e o componente chave. A primeira consiste na aproximação da distribuição contínua por uma distribuição descontínua (barras), onde cada barra representa um pseudocomponente. Com este procedimento a mistura complexa pode ser tratada como uma mistura multi-componente clássica destes pseudocomponentes. No segundo caso do componente chave, estas são espécies químicas presentes na mistura. Em que a quantidade delas são ajustadas em função a que a mistura multi-componente formada por elas apresentam propriedades termodinâmicas similares aos da mistura complexa. Porém, estes dois enfoques são incipientes, pois o número e a maneira de seleção dos pseudocomponentes ou componentes chaves são arbitrários. 
Ratzsch (1989) refere-se ao conteúdo da termodinâmica contínua como uma maneira oposta de resolver esta inconsistencia, pois, nela se faz a conversão da termodinâmica química em forma adaptada às funções de distribuição contínua. Para mostrar esta adaptação o autor apresenta algumas analogias entre a termodinâmica contínua e a tradicional, esta são:

- Na termodinâmica contínua as especies químicas são identificadas por uma variável contínua $\xi$ em vez de uma discreta de indice $\mathrm{i}$.

- A composição é descrita por uma função de distribuição contínua $f(\xi)$ em vez de quantidade de substancia $n_{i}$.

- As quantidades termodinâmicas são funcionais da função de distribuição $f(\xi)$ em vez de funções das quantidades de substancias $n_{i}$.

No seguinte item é desenvolvido com mais detalhes os fundamentos em que baseiase a termodinâmica contínua. A figura 3.1 baseada em Watzdorf e Marquardt (1995), representa-se as frações molares dos componentes discretos, os pseudocomponentes e a função de distribuição.

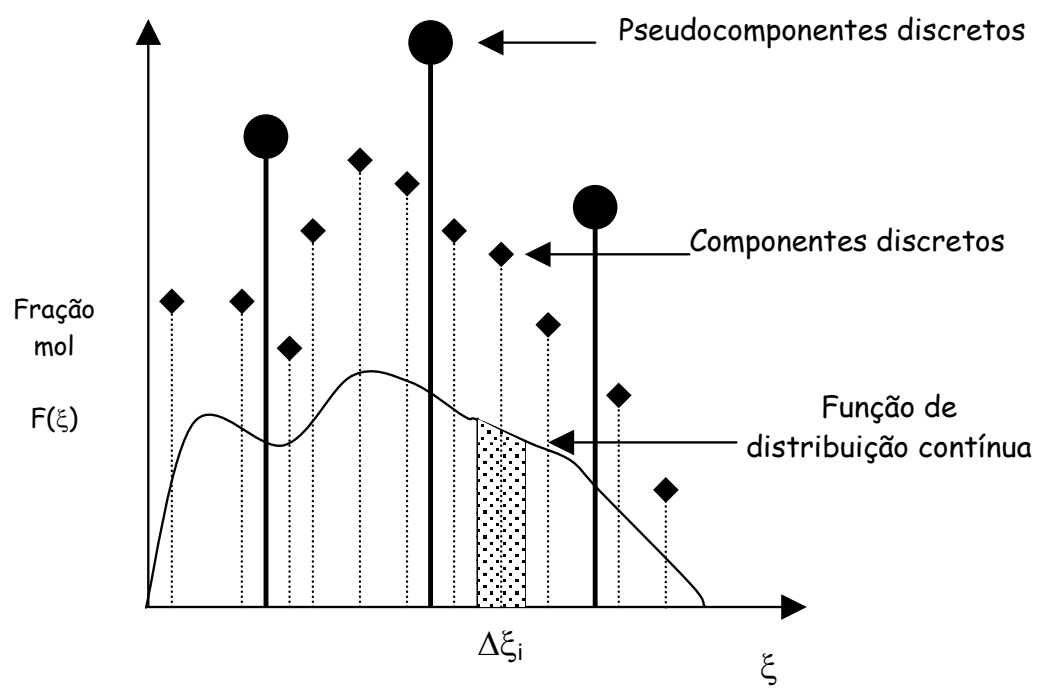

Figura 3.1. Representação dos componentes discretos e pseudocomponentes discretos e relação da função de distribuição contínua. 


\subsection{Fundamento do método da termodinâmica do contínuo}

Os fundamentos da termodinâmica contínua podem ser vistas em Kehlen e Ratzsch (1980), Salacuse e Stell (1982), Gualtieri et al. (1982), Briano e Glandt (1983) apud Ratzsch et. al. (1989), e podem-se resumir nos seguintes pontos:

(a) A termodinâmica contínua considera um conjunto grande de espécies químicas similares. Estas são assumidas como suficientemente identificáveis por uma variável $\xi$, no sentido em que duas espécies químicas são diferenciadas por uma pequena diferença de $\xi$, e que também as mesmas diferenciem-se em quantidades pequenas em relação as suas propriedades termodinâmicas.

(b) A variável $\xi$ selecionada pode ser a temperatura do ponto de ebulição (normal) da espécie pura, mas outras quantidades também podem-se selecionar, como: a massa molar ou número de segmentos, número de carbonos.

(c) A função de distribuição extensiva $f(\xi)$ para o conjunto considerado é definida pela equação integral $\int_{\xi_{0}}^{\xi_{f}} f(\xi) d \xi$, a qual engloba a quantidade de todas as espécies entre $\xi_{0}$ e $\xi_{\text {f. }}$ Logo a quantidade da substancia $n_{i}$ é dada por:

$$
n_{i}=\int_{\Delta \xi_{i}} f(\xi) d \xi
$$

(d) Quando a integração é desenvolvida para o domínio total de $\xi$, entre os limites da ocorrência dos valores de $\xi, \xi_{0}$ e $\xi_{m}\left(\Delta \xi=\xi_{m}-\xi_{0}\right)$, a divisão de $f(\xi)$ por $n_{i}$, chamada função de distribuição intensiva $F(\xi)$, que é correspondente à fração molar $X i$ na termodinâmica usual, é obtida assim:

$$
F(\xi)=\frac{f(\xi)}{n_{i}}
$$


introduzindo a condição de normalização se tem:

$$
\int_{\Delta \xi} F(\xi) d \xi=1
$$

Com este fundamento, as frações de petróleos e misturas similares complexas podem ser caracterizadas por suas curvas de ponto de ebulição verdadeiro (TBP); que são determinadas experimentalmente por destilação, usando uma coluna com um grande número de pratos teóricos, e com uma razão de refluxo alta. Por conseguinte, a temperatura no topo da coluna é identificada com a temperatura de ponto de ebulição $\xi$ das correspondentes espécies puras. Logo a função de distribuição $F(\xi)$ é obtida por diferenciação em relação a $\xi$.

Ratzsch (1989) explica que na termodinâmica usual uma quantidade extensiva arbitraria $M$ ( por exemplo, volume, entalpia, energia livre de Gibbs) de uma fase pode ser considerada como uma função de temperatura $\mathrm{T}$, pressão $\mathrm{P}$ e das quantidades de substancias $n_{1}, \ldots, n_{c}$ :

$M=M_{\text {dis }}\left(T, P, n_{1}, \ldots, n_{c}\right)$

e no caso contínuo a função de distribuição extensiva $f(\xi)$ ocorre em vez de $n_{1}, \ldots, n_{c}:$

$M=M(T, P ; f)$

portanto, define-se que na termodinâmica contínua, $M$, além de ser, uma função em relação a T e P, necessita de uma representação em função a $f$, que é chamada de funcional em relação a $f$. Uma funcional é uma função real, estimado em um espaço de vetores $V$, normalmente de funções, que asigna um número a cada função de uma classe dada de funções . A razão de utilizar o termo "funcional" deve-se a que $V$ pode ser um espaço de funções, que é representada como segue: 
$V=\{f:[0,1] \rightarrow R: f$ é contínua $\}$

Por otro lado, uma questão importante na termodinâmica contínua é a seleção da função de distribuição $f$, isto é determinada principalmente por sua habilidade de representar a composição da mistura com suficiente grau de aproximação, mas uma outra consideração para esta seleção é a conveniência matemática, pois algumas funções são mais adequadas que outras para representar misturas complexas em certas condições do processo.

Assim, por exemplo, Vakili-Nezhaad et. al. (2001) indicam que as funções de distribuição mais conhecidas aplicadas para o petróleo, no contexto da termodinâmica contínua, são as funções de distribuição gamma e gaussiana. E Whitson (1983) apud Ratzsch (1989) mostrou como a distribuição gamma pode ser utilizada para caracterizar as porções de alto peso molecular de petróleos crús.

Cotterman (1985) menciona que uma das vantagens de utilizar a termodinâmica contínua é a economia no requerimento computacional, pois para desenvolver o procedimento de cálculos nesta estrutura contínua são utilizados programas de computadores eficientes e rápidos, isto gera aproximadamente a metade do gasto ocasionado se for utilizado o método de pseudocomponentes, um exemplo disto são os resultados apresentados no trabalho de Ratzsch et. al. (1989).

No entanto, Silva (1992) menciona que, a possibilidade de representar melhor o comportamento fisico das misturas complexas, em termos de distribuições de componentes, é usando as funções de distribuição analíticas em vez de funções probabilisticas. O autor indica que até 1992 foram encontrados trés trabalhos que desenvolveram, primariamente, esta nova abordagem, sendo estes: Ying et al. (1989) que sugerira o uso da função spline cúbica como função de distribuição de uma das correntes que permita reproduzir os dados experimentais de sua caracterização, enquanto que Rochocz e Rajagopal $(1989,1990)$ usaram a interpolação de dados experimentais, para aprimorar os cáculos, e as funções arbitradas para a representação da mistura. 
Embora, estes trabalhos tentem melhorar os modelos, Silva (1992) considera que estes trabalhos levantam algumas desvantagens dos modelos decorrentes de funções de distribuição probabilísticas, os quais são:

- Uma única função de distribuição não poderia representar varias correntes de um mesmo processo, por exemplo, no modelo de um "flash" a mesma função de distribuição não poderia representar as correntes de alimentação, de vapor e de líquido.

- O método de resolução numérico utilizado para resolver o modelo, a quadratura de Gauss, não deixa de ser, conceitualmente, o mesmo apresentado pelo método de pseudocomponentes; sendo a única diferença a escolha automática dos pontos da quadratura que substituem aos componentes.

Em relação a estes fatos, Watszordf e Marquardt (1996) comentaram que a termodinâmica contínua é um método que não tem alcançado relevância nas práticas industriais, já que sua aplicação está rigorosamente relacionada com a seleção de técnicas de aproximação para as funções de distribuição e, o fato de utilizarem, geralmente, funções de distribuição estatísticas restringiu a flexibilidade do método evitando assim seu uso na indústria.

Atualmente, Lage (2006) menciona que o desenvolvimento das pesquisas em relação à melhoria dos modelos probabilísticos passou primariamente pelo procedimento de discretização das funções de distribuição contínua da fração molar do componente $F(\xi)$, usando intervalos arbitrarios de massa molar que poderiam ser uniformes ou determinados por uma função arbitraria de $\xi$, tal como fora descrito por Huang e Radosz (1991).

Esse tipo de procedimento foi mais desenvolvido a partir da metade da decada de 1990. Assim, em 1997, o trabalho de Liu e Wong demostrou o tratamento rigoroso do método de discretização da quadratura gaussiana, estendendo como as funções de interés às bases de polinomiais ortonormais. Mas, eles não definiram quais poderiam 
ser as melhores bases funcionais nem sua regra de quadratura associada para os casos em que estas sejam aplicadas.

Lage (2006) afirma que a caracterização das misturas é estática e depende somente da definição do intervalo da variável de caracterização $\xi$, a seleção das bases polinomiais e do número de pontos na regra de quadratura.

Em relação a esta afirmação, segundo Lage (2006), atualmente o método mais aceito para a discretização da função de distribuição contínua passa pelo uso da quadratura Gauss-Laguerre generalizada. Mas, isso não exclue outros métodos desenvolvidos nesse mesmo contexto, como é o caso de von Watzdorf e Marquardt (1997), que usa o esquema de discretização wavelet-Galerkin para tentar resolver modelos de misturas complexas nos problemas de termodinâmica contínua. O mérito deste enfoque e sua possibilidade de adaptação, pois o nível da representação da mistura pode ser variada pela seleção de uma serie de funções bases wavelet, consideradas como as mais importantes para a representação da função de distribuição da fração molar, alem de usar estimadores de erro.

No seguinte item serão discutidos mais amplamente diferentes pesquisas em relação aos progressos da Termodinâmica contínua.

\subsection{Aplicações}

Muitos trabalhos em relação ao método da termodinâmica contínua foram desenvolvidas visando melhorar os procedimentos de caracterização de misturas multicomponentes complexas, com o objetivo de otimizar os processos onde estas misturas estão presentes.

Segundo Tamin e Hallet (1995) a diferença mais relevante, apresentada na literatura, entre os tratamentos e aplicações da termodinâmica contínua derivam, principalmente, na seleção da função de distribuição (distribuições gamma ou Gaussiana como os mais utilizados), a seleção da variável de distribuição (peso molecular do componente, ponto de ebulição ou número de carbonos, mais 
comumente usados) e os modelos para o equilibio líquido-vapor (usualmente a lei de Raoult com a equação de Clausius- Clapeyron, ou também diferentes equações de estado).

Para verificar esta diferença no caso da seleção de funções de distribuição, por exemplo, Vakili-Nezhaad et. al. (2001) utilizaram o método da termodinâmica contínua para obter a pressão de vapor de uma composição de mistura indefinida. $\mathrm{O}$ objetivo deste trabalho foi verificar a eficiência do método utilizando diferentes tipos de funções de distribuição para propriedades termodinâmicas sob misturas ideais e comparar os resultados obtidos tanto pela modelagem quanto pela informação experimental.

As aplicações da termodinâmica contínua, no equilíbrio líquido-vapor de misturas complexas, foram discutidas por Ratzsch e Kehlen $(1983,1985)$ apud Ratzsch et. al. (1989) e por Prausnitz et al. (Cotterman et al. (1985)). Ratzsch (1989) descreve com mais detalhe o procedimento da termodinâmica contínua, aplicado ao equilíbrio líquido-vapor em um processo flash de petróleo, definido com as mesmas especificações utilizadas neste trabalho. Além disso, o autor apresenta também a aplicação no equilíbrio líquido-líquido de polímeros.

Cotterman et al. (1985), ilustraram o conceito de termodinâmica contínua através de sua aplicação no cálculo de ponto de orvalho para misturas de gás natural, perda de solventes em um absorvedor de alta pressão e no equilíbrio de fase líquido-líquido de um processo de fracionamento de polímero. Os resultados que eles alcançaram em relação ao método de pseudocomponentes teve menor gasto computacional.

Casos mais específicos desta aplicação contínua, são desenvolvidos na predição do equilíbrio líquido-vapor para faixas amplas de temperaturas e pressões. Baer et al. (1997) desenvolveram, com este objetivo, a versão contínua da regra de mistura de Wong-Sandler incluindo o modelo de contribuição de grupos. Também, estão os casos em que tenta-se descrever o comportamento do equilibrio líquido-vapor no processo de evaporação de droplets de misturas multi-componentes complexas, (Tamir e Hallet, 1995; Zhu e Reitz, 2002; Abdel-Qader e Hallet, 2005). Como 
contribuição a esta aplicação Manafi et al. (1999) apresentaram um método computacional para o cálculo de propriedades e a predição de equilibrio de fases desenvolvido em fluídos de petróleo.

No caso da caracterização de frações de petróleo, o enfoque contínuo representa uma alternativa promisoria, tal como é mostrado por: Sportisse et al. (1997), Manafi et al. (1999), Fang e Lei (2003). Mas, também, na caracterização de soluções de polímeros este enfoque tem progredido para obter cada vez melhores resultados, $\mathrm{Hu}$ et al. (1994, 1995).

Outras aplicações da termodinâmica contínua é observado no cálculo das propriedades críticas de mistura de fluídos multi-componentes. Nos trabalhos de Cai et al. (2004, 2005) nota-se o esforço para obter melhores resultados para estas propriedades. Por exemplo, os autores não somente utilizam o enfoque contínuo se não que, tambén, fazem uso de procedimentos baseados na teoria de renormalização de grupos. Com este método conseguiram reduzir o costo computacional nos cálculos em relação ao método tradicional (método de Gibbs).

Também, a generalização da destilação de misturas multi-componentes complexas com muitos estágios foi dada por Kehlen e Ratzsch (1987) apud Ratzsch et. al. (1989). Assim, uma boa referência para comparação da simulação da destilação de misturas multicomponentes complexas de hidrocarbonetos é o trabalho desenvolvido por Ratzsch et al. (1989). Os autores apresentam a descrição da destilação através das equações básicas da termodinâmica contínua para compará-la com o tratamento do tradicional método de pseudocomponentes. Nessa comparação os autores discutiram várias questões, com base nas simulações por computador, essas questões resultaram nos efeitos das propriedades de alimentação, construção da coluna e condições de operação.

Alguns enfoques diferenciados para os casos de separação de misturas multicomponentes complexas foram apresentados por Von Watszdorf e Marquardt (1997), este enfoque foi melhorado com a introdução de estrategias multi-malha por 
Briesen e Marquardt (2004a) e estendidos a processos de destilação mais complexos, Briesen e Marquardt (2004b).

Em 2006, Lage propôs um novo método para a solução da termodinâmica contínua de operações flash e de mistura. Este baseia-se na conservação dos momentos das distribuições, e pode-se chamar como método de quadratura de momentos para a termodinâmica contínua.

Finalmente, visto os progressos e desenvolvimentos da Termodinâmica contínua, através de suas aplicações em diferentes sistemas multicomponentes, pode-se concluir que ela ainda representa uma alternativa promissora nos processos da engenharia química que envolvem misturas multi-componentes complexas. 


\section{MÉTODO MULTI-MALHA ADAPTATIVO WAVELET- GALERKIN PARA CARACTERIZAÇÃO DE PETRÓLEO}

Uma das principais vantagens da representação da composição contínua, comparada à representação discreta de pseudocomponentes, recae no fato em que, a redução do modelo do problema pode ser observado como uma discretização do problema, pela qual um grande número de técnicas adaptativas estão sendo desenvolvidas no campo das matemáticas numéricas.

Briesen e Marquardt (2003b) "Em trabalhos prévios temos estabelecido uma estratégia de solução multi-malha adaptativa para modelos de processo de refino em estado estacionario. Em principio, cada modelo dado em uma formulação discreta (ou pseudocomponente) pode-se reescrever fazendo uso de funções de distribuição contínua. Esta formulação contínua ainda não reduce o tamanho do modelo, mas, comprime o modelo detalhado completo. Em um algoritmo iterativo a solução do modelo do processo é obtido em alto detalhe. Em cada laço de iteração a atual iteração é corregida por um termo de correção, que é determinado em detalhe reduzido na representação da composição. De acordo a uma estrutura multi-malha a solução intermediaria obtida é prolongada para o alto detalhe da composição fazendo uso da linearização das equações do modelo".

A técnica apresentado por Briessen e Marquardt (2003a), através de um algoritmo multi-malha adaptativo, utiliza ferramentas da termodinâmica contínua (para a representação da composição de misturas) e ferramentas da matemática aplicada (método de discretização Galerkin, multi-malha, wavelets) e tem como objetivo principal desenvolver um método geralmente aplicável, completamente adaptativo e com erro controlado para a simulação e otimização de processos que envolven misturas multicomponentes complexas. Além disso, que permita superar as desvantagens do tradicional método de agrupamento por pseudocomponentes.

Nesse contexto, Briesen e Marquardt (1999, 2000, 2003, 2004), von Watzdorf (1996, 1997), desenvolveram esta técnica e aplicaram a processos de separação térmica de hidrocarbonetos, desde os mais simples como flasheamento até destilação múltipla, 
tanto em estado estacionário quanto dinâmico. Entre os resultados que alcançaram-se pode-se mencionar a flexibilidade na redução dos modelos desses processos, a minimização dos cálculos dos sistemas de equações gerados por estes com a especificação da precisão desejada.

A principal vantagem deste novo enfoque em relação à representação discreta de pseudocomponentes é a introdução da adaptabilidade e o controle do erro na representação das misturas. A modelagem discreta com pseudocomponentes é uma discretização fixa onde não é obtida a informação da aproximação do erro. No entanto, no enfoque proposto por Briesen e Marquardt (2003), um estimador do erro é avaliado para mostrar essa informação. Isto se consegue através do desenvolvimento de uma estratégia de adaptação sob a base das propriedades das wavelets para prover um controle do erro na discretização global.

Com o objetivo de conhecer mais detalhes deste novo enfoque, quanto a sua aplicabilidade e vantagens, os itens seguintes apresentam suscintamente a fundamentação matemática e a descrição de cada uma das técnicas empregadas nele.

\subsection{Método multi-malha adaptativo Wavelet-Galerkin}

Como dito no enfoque da termodinâmica contínua, uma mistura com número finito de componentes pode ser representada, geralmente, por funções de distribuição contínua. Neste enfoque, a representação da mistura é feita através destas funções de distribuição, mas que não são estritamente as empregadas no conceito da termodinâmica contínua (é dizer, funções de tipo estatístico, gama, gauss, etc). No desenvolvimento deste método, por exemplo, são utilizadas funções constantes por patamares, onde cada valor da função corresponde a um valor discreto (neste enfoque este valor corresponde à fração molar do componente). Aliás, a relação entre a composição dos componentes e a função de distribuição foi apresentada nas eqs. 3.1 e 3.2 .

Na figura 4.1 mostra-se, esquemáticamente, o procedimento deste método. 


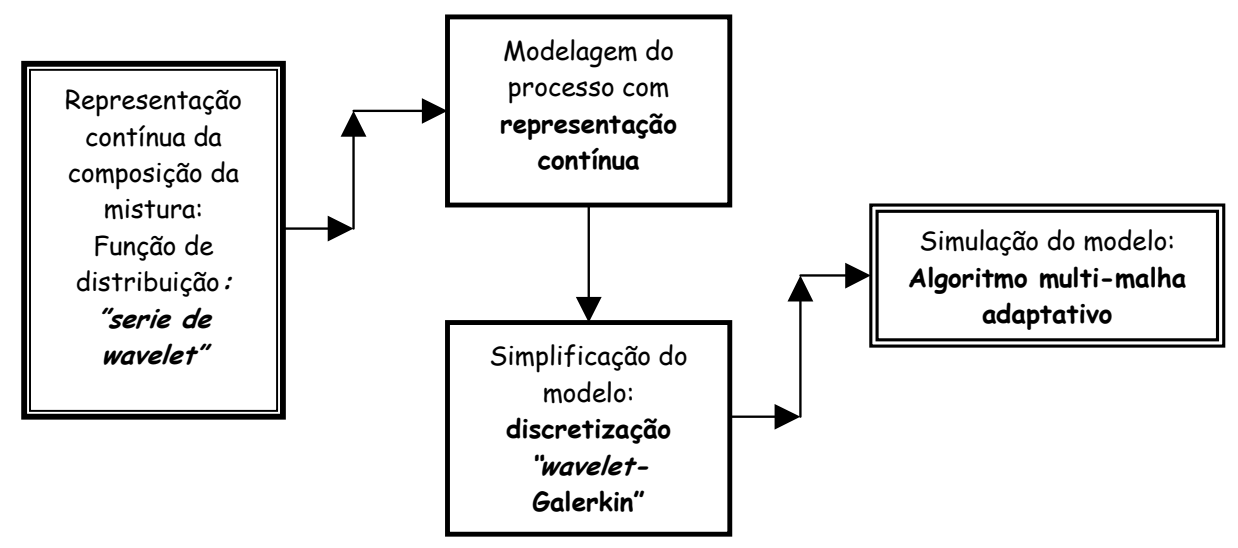

Figura 4.1. Representação esquemática do procedimento do método multi-malha adaptativo wavelet-Galerkin.

\subsection{Wavelets}

Cruz et. al. (2002) referenciam as wavelets como um conceito matemático relativamente novo e introduzido ao final da década dos anos oitenta (ver Daubechies 1992; Mallat, 1989). Geralmente o termo wavelet é usado para descrever uma função que tem características de suporte compacto. Isto significa que a função é localizada no espaço, somente sendo diferente de zero em um intervalo finito.

Muitos autores definem as wavelets como funções que satisfazem certas propriedades matemáticas especiais, que são abordadas mais adiante. Algumas características delas são mencionadas a seguir:

- São usadas na representação de dados ou de outras funções.

- Utilizam a idéia de aproximação usando a superposição de funções.

- Podem ser suaves ou não, simétricas ou não, e podem ter expressões matemáticas simples, ou não.

- Tem encontrado usos em muitas áreas não matemáticas, por exemplo, processamento de sinais (compressão, transmissão e reconstrução), estatística 
(regressão não paramétrica, estimação de funções de densidades de probabilidade, estimação do espectro dependente do tempo de processos nãoestacionários).

Segundo Morettin (1999), o livro de Y. Meyer (1993), aborda o tema das wavelet desde Fourier (1806) até as contribuições recentes de A. Grossmann, J. Morlet, S. Mallat e outros.

Morettin (1999) referencia as wavelets como competidoras, ou talvez alternativas, a outros sistemas de funções usados como base para representação de funções pertencentes a certos espaços, como os senos e cosenos, polinômios ortogonais, etc.

As vantagens deste tipo de função em comparação às funções convencionais usadas, por exemplo, na representação de dados são:

- Diferentes tipos de resolução podem ser usadas para descrever distintas regiões da função, e podem ser descritas por escalas segundo sua localização.

- Permitem uma representação detalhada dos dados em um formato multi-escala, em que os coeficientes envolvidos representam detalhamentos com incremento da resolução.

- Suportam pre-condicionamentos.

- As propriedades de ortogonalidade, o suporte compacto $^{1}$ e a representação exata de polinomiais de um grau fixo permitem fazer cálculos eficiêntes e estavéis em regiões com fortes gradientes ou oscilações.

\footnotetext{
${ }^{1}$ Uma função com suporte compacto é aquela que está definida em um dominio limitado e finito.
} 


\subsubsection{Análise de Wavelet}

Recentemente o tema da análise wavelet tem recebido muita atenção de pesquisadores das áreas de matemática e engenharias. Isto se deve, em parte, ao fato de que as wavelets constituem ferramentas versáteis e com grande potencial para múltiplas aplicações. Entre as mais conhecidas estão o processamento de sinais e a análise numérica.

Segundo Chui (1992), a análise wavelet é análoga à análise de Fourier porque também conta com duas entidades matemáticas que são: a "transformada integral wavelet" e a "série wavelet". A primeira definida como a convolução em relação à

dilatação da ponderação de alguma função $\widetilde{\psi}$ que é nomeada "wavelet básica" ou "wavelet mãe", enquanto que a série wavelet expressando-se em termos de uma simples função $\psi$ é nomeada simplesmente, wavelet ou função wavelet. Ela é obtida por duas operações simples: dilatação binária $a=2^{j}$ e translação diádica $b=k 2^{-j}$ da função básica.

Assim, os membros da família wavelet são formados por translações “ $b=k 2^{-j}$ ” $\mathrm{e}$ contrações " $a=2^{j}$ " definidas por :

$\psi^{a, b}(\xi)=|a|^{-1 / 2} \psi\left(\frac{\xi-b}{a}\right)$

e sua transformada definida por:

$W_{\psi}(f)(a, b)=\frac{1}{\sqrt{a}} \int_{-\infty}^{\infty} f(\xi) \psi\left(\frac{\xi-b}{a}\right) d \xi$

Logo, com $a=2^{j}$ e $b=k 2^{-j}$ as funções $\psi_{j, k}(\xi)$ são definidas como bases ortonormais no espaço $L^{2}(R)$ segue:

$\psi_{j, k}(\xi)=2^{j / 2} \psi\left(2^{j} \xi-k\right), \quad j, k \in Z$ 
e este espaço $L^{2}(R)$ forma um espaço de Hilbert $V$, em geral um espaço de Hilbert esta formado por bases de Hilbert $h_{i}$, e se elas são bases ortonormais, como as bases wavelets, então todo elemento $v \in V$ pode ser escrito como: $v=\sum_{i=1}^{\infty} \alpha_{i} h_{i}$ para algum $\alpha_{i} \operatorname{com} \sum\left|\alpha_{i}\right|^{2}<\infty$

No entanto, $\left\{\psi_{j, k}(\xi), j, k \in Z\right\}$ formam uma base que não precisa ser necessariamente ortogonal. Uma vantagem de trabalhar com este tipo de bases ortogonais é a possibilidade de fazer ajustes de cada parâmetro independente de outros parâmetros. Daí o interesse em considerar bases ortogonais. Uma outra vantagem de se utilizar estas bases é conseguir a reconstruição de forma perfeita de uma sinal original a partir dos coeficientes da transformada, mas esta vantagem não é exclusiva deste tipo de bases.

Define-se a ortogonalidade das funções wavelets $\psi_{j, k}(\xi)$ e $\psi(\xi)$ em $[0,1]$ como segue:

$$
\begin{array}{lll}
\int_{0}^{1} \psi(\xi) \psi_{j, k}(\xi) d \xi=0 & \text { para } & (j, k) \neq(0,0) \\
\int_{0}^{1} \psi_{j, k}(\xi) \psi_{l, m}(\xi) d \xi=0 & \text { para } & (j, k) \neq(l, m)
\end{array}
$$

Uma propriedade importante da análise wavelet consiste na sua caracteristica e praticidade de analisar diferentes partes de uma função em diferentes escalas de maneira dinâmica.

\section{Transformada de Wavelets}

A transformada wavelet pode ser vista como um mecanismo para decompor ou quebrar sinais nas suas partes constituintes, permitindo analisar os dados em 
diferentes domínios de escala com a resolução dada e, cada componente amarrada a sua escala (Lima, 2003).

Quando uma série de dados vão diretamente a uma transformada wavelet, este é decomposto em dois tipos de coeficientes: um deles, representa as características gerais (coeficientes da função escala $C_{j 0, k}$ ) e o outro descreve as características localizadas (coeficientes wavelet $d_{j, k}$ ). Para desenvolver o tratamento de compressão de dados, alguns dos coeficientes wavelet, correspondentes a regiões no espaço de menos importância (e dizer regiões pouco irregulares), são rejeitados. Logo após a reconstrução da função, a alta resolução é mantida somente em regiões relevantes.

\section{Séries de Wavelets}

Segundo Nielsen (1998), muitas funções matemáticas podem ser representadas, também, pela soma de funções, simples ou fundamentais, denominadas "funções base". Esta forma de representação é chamada de expansões ou séries de uma função. Por exemplo, a mais conhecida é a série de Fourier, válida razoávelmente para um

conjunto de funções $f$ bem comportadas em uma faixa de $[0,1]$, apresentando boa aproximação, por exemplo, em regiões contínuas.

Por outro lado, a expansão, ou série wavelet, também pode ser usada como função base para a expansão de uma função $f$, porque capturam a informação tanto, posicional quanto, de escala de $f$. E além disso, podem ser usadas para aproximar as descontinuidades da função $f$ de forma mais precisa que a série de Fourier.

A expansão, ou série wavelet para a aproximação $(F(\xi))$ de uma função $f$ tem a seguinte forma: Nielsen (1998).

$$
F(\xi)=\sum_{k=0}^{2^{j 0}-1} c_{j 0, k} \phi_{j o, k}(\xi)+\sum_{j=j 0}^{\infty} \sum_{k=0}^{2^{j}-1} d_{j, k} \psi_{j, k}(\xi), \quad \text { com } \quad \xi \in R
$$


onde:

$c_{j 0, k}=$ coeficient es da função escala

$\phi_{j 0, k}(\xi)=$ função escala

$d_{j, k} \quad=$ coeficient es da função wavelet

$\psi_{j, k}(\xi)=$ função wavelet

$j=1,2,3 \ldots \ldots . . . N($ parâmetro ou nível de escala $)$

$j_{0}=$ int eiro no negativo

$k=0,1,2 \ldots . .2^{j}-1$ (parâmetro de deslocamen to que gera as funções bases)

e os coeficientes são dados por:

$c_{j 0, k}=\int_{0}^{1} f(\xi) \phi_{j o, k}(\xi) d \xi$
$d_{j, k}=\int_{0}^{1} f(\xi) \psi_{j, k}(\xi) d \xi$

a partir do ponto de vista comparativo, uma diferença entre a série wavelet e a série de Fourier, esta no fato desta primeira ter dois tipos de funções base, $\phi_{j o, k} \mathrm{e}^{\psi_{j, k}}$, e dois índices inteiros $(j 0, k)$ e $(j, k)$, e ambas as bases, terem suporte compacto:

$$
\phi_{j o, k}(\xi)=\psi_{j, k}(\xi)=0 \quad \text { para } \quad \xi \notin\left\lfloor\frac{k}{2^{j}}, \frac{k+3}{2^{j}}\right\rfloor
$$

A base $\phi(\xi)$ é chamada função de escalamento e é uma função real contínua que não satisfaz a propriedade da condição admissível ${ }^{2}$. Ela é deslocada para valores discretos para se construir uma base em cada nível de resolução, isto quando a análise é desenvolvida em forma multipla (isto significa que ela é a base a partir da qual são calculadas as bases wavelet para cada escala). E também por fatores de escala $2^{-\mathrm{j}}$ obtendo-se assim a base de escalonamento em uma análise de resolução múltipla:

$\phi_{j, k}(\xi)=2^{-j / 2} \phi\left(2^{-j} \xi-k\right)$.

\footnotetext{
${ }^{2}$ Condição admisível: $\int \phi(\xi) d \xi=0$
} 
mas, tanto, a série wavelet quanto, a série de Fourier devem ser truncadas para uma escala mais fina, denotada por ${ }^{J-1}$ :

A representação truncada da série wavelet é:

$\sum_{k=0}^{2^{j 0}-1} c_{j 0, k} \phi_{j o, k}(\xi)+\sum_{j=j 0}^{J-1} \sum_{k=0}^{2^{j}-1} d_{j, k} \psi_{j, k}(\xi)$

e os coeficientes wavelet são ordenados como:

$$
\left\{\left\{c_{j 0, k}\right\}_{k=0}^{2^{j 0}-1}, \quad\left\{\left\{d_{j, k}\right\}_{k=0}^{2^{j}-1}\right\}_{j=j o}^{J-1}\right\}
$$

na eq. (4.3) o primeiro elemento da soma é uma representação pouco precisa de $f$, onde $f$ é substituída por uma combinação linear de $2^{j_{0}}$ translações da função escala $\phi_{j o, 0}$. No segundo termo, define-se para cada $j$ uma camada representada por $2^{j}$ translações da Wavelet $\psi_{j, 0}$, as quais se aderem para obter, mais satisfatoriamente, os detalhes na aproximação da função $f$.

Os espaços de aproximação (espaço de Hilbert) são definidos como segue:

$$
\begin{aligned}
& V_{j}=\operatorname{span}\left\{\phi_{j o, k}\right\}_{k=0}^{2^{j}-1} \\
& W_{j}=\operatorname{span}\left\{\psi_{j, k}\right\}_{k=0}^{2^{j}-1}
\end{aligned}
$$

estes espaços relacionam-se da seguinte forma:

$$
V_{j}=V_{j 0} \oplus W_{j 0} \oplus \ldots \oplus W_{J-1}
$$


a aproximação grosseira de $f$ toma seu lugar no espaço $V_{j 0}$ e os refinamentos sucessivos estão no espaço $W_{j}$, para $j=j 0, j 0+1, \ldots . . J-1$. Em conjunto, todas estas contribuições constituem uma aproximação refinada de $f$.

Para ilustrar melhor este conceito na figura 4.2 mostra-se a representação da função escala e algumas das funções wavelet correspondentes a $V_{1}, W_{1}, W_{2}$. Onde, $\phi(\mathrm{t}) \mathrm{e}$ $\psi_{0,0}(\mathrm{t}) \in V_{1}, \psi_{1,1}(\mathrm{t}) \in W_{1}, \psi_{2,0}(\mathrm{t}) \in W_{2}$.
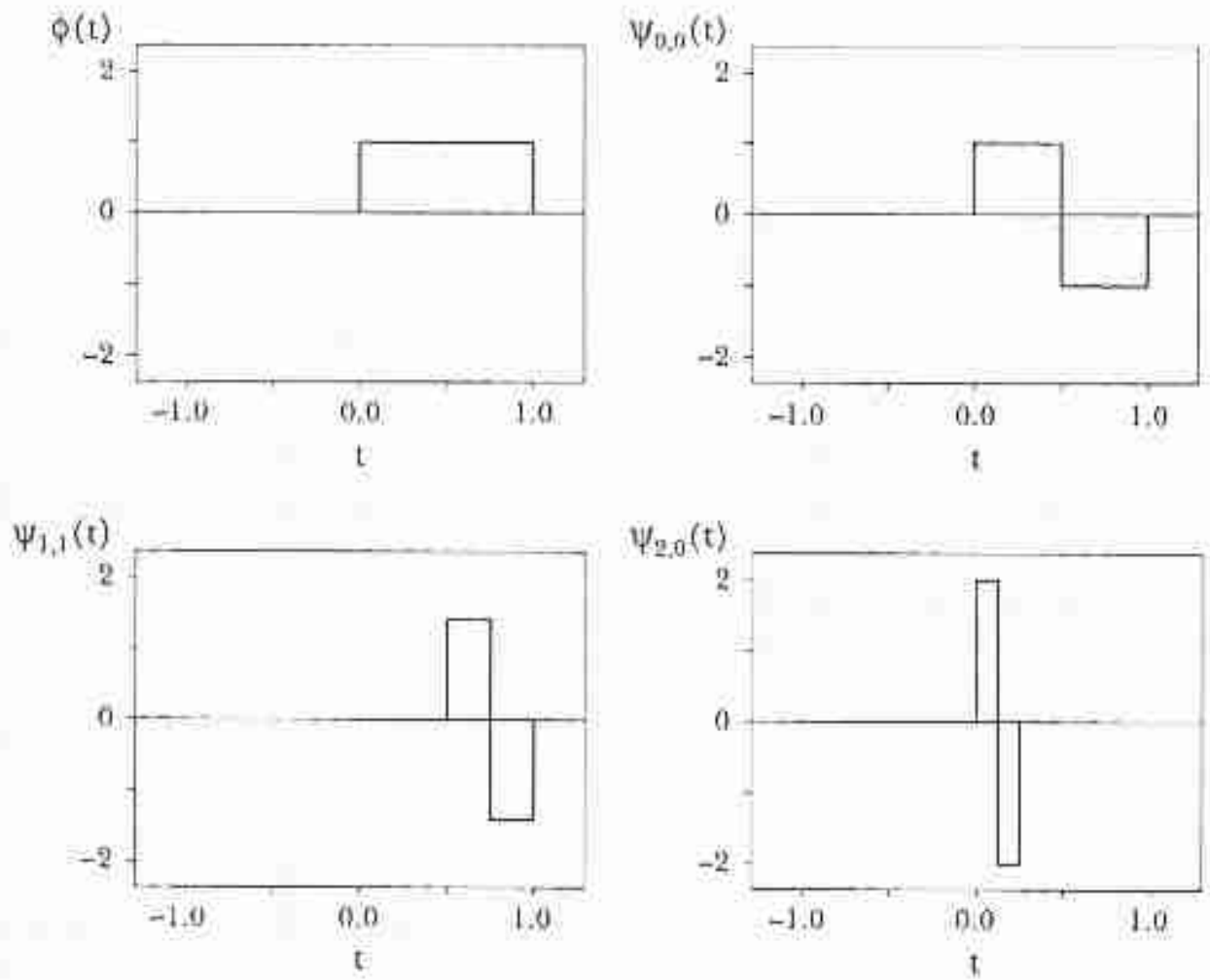

Figura 4.2. Representação das funções escala e wavelet correspondentes aos espaços $V_{1}, W_{1}, W_{2}$.Fonte: Moretin (1999). $(\mathrm{t}=\xi[0,1])$

\subsubsection{Análise de Resolução Múltipla}

Segundo Daubechis (1992), a formulação para a análise de resolução múltipla, desenvolvida por Mallat e Meyer (1986) é considerada um exemplo de motivação para o desenvolvimento teórico das aplicações das bases wavelets. Tal análise 
proporciona uma formulação direta para entender as bases wavelets. Isto leva a ver as bases de tipo ortonormal wavelet como uma ferramenta para descrever, matematicamente, o incremento na informação necessária para ir desde uma aproximação, pouco precisa, até uma aproximação, com melhor resolução, ou, representar-se o incremento de informações entre duas escalas ou, resoluções sucessivas (Lima, 2003).

O objetivo da análise de resolução múltipla é aproximar uma função arbitrária $f \in L^{2}(R)$ e representá-la em multi-escala, (quer dizer, em sucessivos níveis de detalhamento ou, resoluções $j$ ). Esta análise é caracterizada pelos seguintes axiomas, (Meyer (1993), Nielsen (1998), Lima (2003)) com $V_{j}$ : subespaço fechado:

$$
\begin{aligned}
& \{0\} \subset \ldots . . V_{-2} \subset V_{-1} \subset V_{0} \subset V_{1} \subset V_{2} \subset \ldots . . L^{2}(R) \\
& \bigcup_{j \in Z} V=L_{j}^{2}(R), \text { ou é denso em } L^{2}(R) \\
& \bigcap_{j \in Z} V_{j}=\{0\} \\
& \{\phi(\xi-k)\}_{k \in Z} \text { é uma base ortonormal para } V_{0} \\
& f(\cdot) \in V_{j} \Leftrightarrow f(2 \cdot) \in V_{j+1}
\end{aligned}
$$

Além desses axiomas, uma característica desta análise é a decomposição dos subespaços que for descrito na eq. (4.9).

o axioma representado pela eq. 4.10 em que $V_{j} \subset V_{j+1}$ significa que ao passar do nível de resolução $j$ (ou escala $2^{-j}$ ) para o nível de resolução $j+1$, ganha-se informação (ou são adicionados "detalhes"). E a medida que a resolução aumenta $(j \rightarrow \infty)$, a função aproximada converge para a função original e se obtem $\bigcup_{j \in Z} V=L^{2}(R)$, no caso em que $(j \rightarrow-\infty)$ a aproximação converge para a função 
nula e temos $\bigcap_{j \in Z} V_{j}=\{0\}$. A idea e o fato de se obter aproximações de $f$ em varios níveis de resolução $j$, então, cada subespaço $V_{j}$ será constituido por funções aproximantes, sendo que a melhor aproximação é obtida considerando-se a projeção ortogonal de $f, P_{j} f$, sobre cada $V_{j}$.

Para ilustrar melhor o conceito da análise de resolução multipla o seguinte esquema é apresentado:

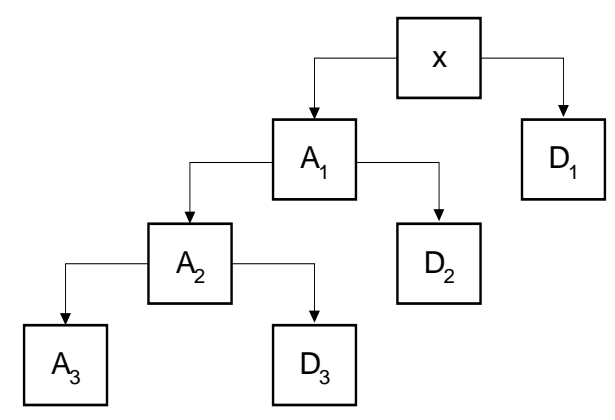

Figura 4.3. Representação esquemática de uma decomposição em resolução multipla.

$A_{j}$ : são as aproximações da sinal en cada nível $j$, e são obtidas a partir do primeiro termo da eq. 4.3 , considerando $j_{0}=j$

$A_{j}=\sum_{k=0}^{2^{j 0}-1} c_{j 0, k} \phi_{j o, k}(\xi)$

$D_{j}$ : são os detalhes da sinal em cada nível $j$, obtidos do segundo termo da eq. 4.3

$D_{j}=\sum_{j=j 0}^{\infty} \sum_{k=0}^{2^{j}-1} d_{j, k} \psi_{j, k}(\xi)$

Para ilustrar melhor este conceito de análise de resolução multipla um exemplo e apresentado a seguir, neste é mostrada a decomposição de um sinal com ruído em 3 níveis usando a wavelet de Haar: 
Assim a decomposição em aproximações A, e detalhes D, é:

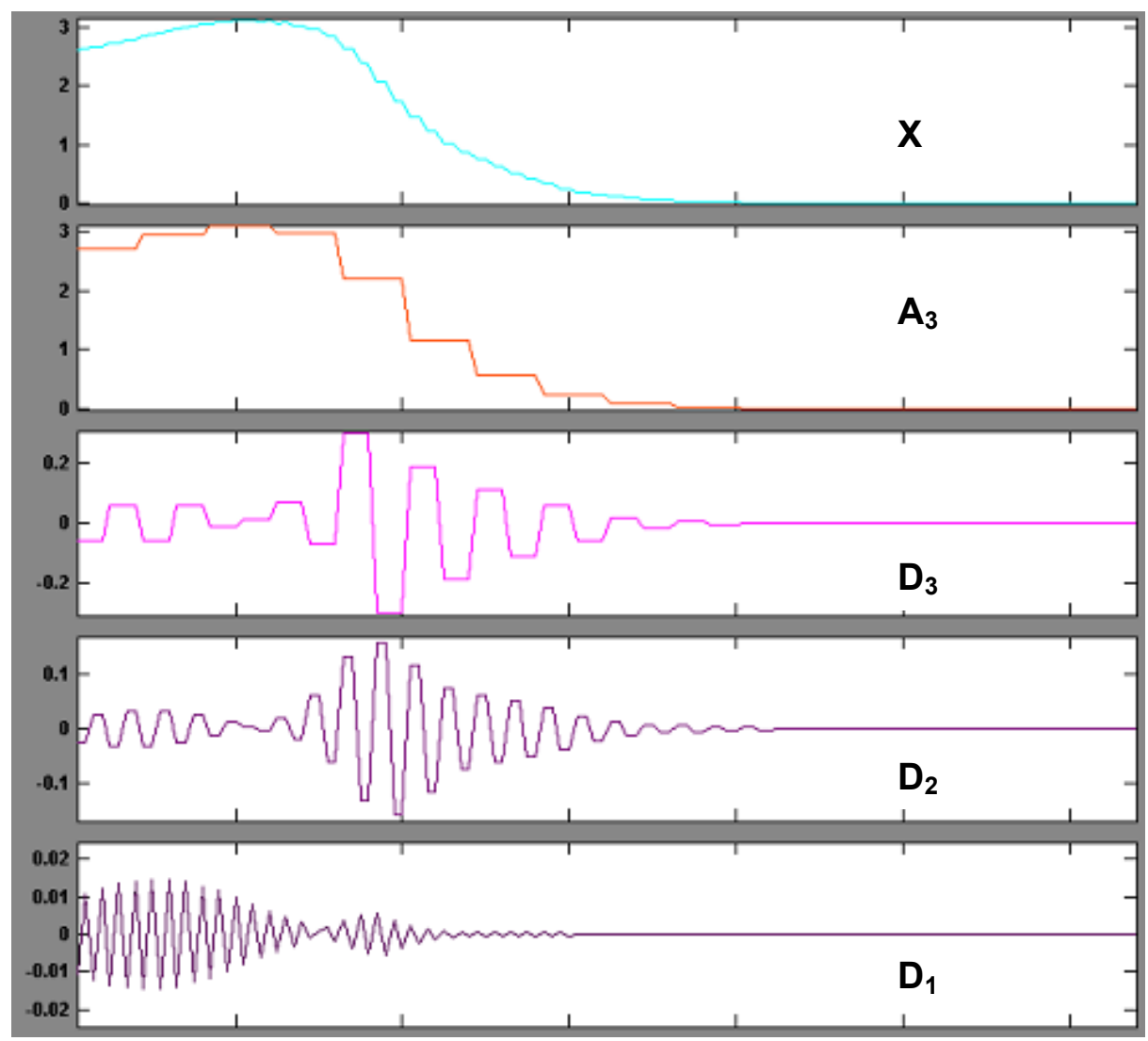

Figura 4.4. Representação esquemática de uma decomposição em resolução multipla da função $X$ na escala $j=3 . \quad X=A_{3}+D_{3}+D_{2}+D_{1}$

\section{Propriedades de aproximação}

Quando trata-se de aproximações, inerentemente, está envolvida o tema de compressão de dados. Na compressão, via wavelet, existem dois esquemas de aproximação: um com perda e o outro sem perda. Lima (2003) explica que, no primeiro caso a reconstrução dos dados tem que ser exata, sem qualquer perda de informação, enquanto que no segundo caso é permitido um erro, desde que a qualidade, depois da descompressão, seja aceitável. Este último esquema tem a vantagem de atingir fatores de compressão muito maiores do que o caso anterior, no entanto, ele só pode ser usado quando for possível substituir os dados originais por uma aproximação que seja fácil de se comprimir. 
A idéia, por trás de qualquer esquema de compressão, é a remoção da correlação (correlação espacial, espectral ou, temporal) presente nos dados. Isto significa que dados correlacionados são caracterizados pelo fato de que, a partir de uma das partes, pode-se preencher a parte que esteja faltando. A finalidade de se representar os dados usando uma base matemática diferente, como as bases wavelet, é a possibilidade de verificar a existencia ou não de correlação entre os dados. Como nesta nova base a maioria dos coeficientes são muito pequenos, a compressão é alcançada calculandose a transformada associada a esta base, dando valor zero aos coeficientes menores do que um certo valor limiar e, portanto, a informação será caracterizada por um pequeno número de coeficientes. Este procedimento é conhecido, também na literatura, como "aproximações reduzidas".

$\mathrm{Na}$ prática procura-se uma série ou transformada que tenha as seguintes propriedades:

- seja independente dos dados

- exista um algoritmo rápido para calculá-la e,

- seja capaz de remover a correlação para um conjunto grande e geral de dados (ou seja, ajustar a correlação dos dados de maneira a obter a solução mais proxima à solução real).

Um bom candidato é uma transformada de Fourier, mas ele só cumpre com as duas primeiras propriedades. Portanto, é necessária uma base adaptada que seja local no tempo e freqüência. Duas maneiras de se construir tais bases são:

口 dividindo-se o domínio espacial em intervalos e usando uma série de Fourier em cada intervalo, separadamente, assim obtém-se uma base trigonométrica local.

a ou usar uma base de wavelet, objetivo deste trabalho.

Assim, uma função $f$ pode ser aproximada utilizando somente uma sub-série de funções base wavelet, obtidas a partir de uma série de sub-índices selecionados 
segundo o critério de significância limite dos coeficientes wavelet $d_{j, k}$, expressado por: $\left|d_{j, k}\right|>$ tolerancia .

Frequentemente, este fato esta baseado na idéia chave de economizar recurso computacional por descarte de muitos dos coeficientes wavelet com valores pequenos.

Por outro lado, quando se aproxima uma função, introduz-se um erro em relação à função aproximada, definido por:

$e_{j}(\xi)=f(\xi)-P f(\xi) \quad \xi \in(R)$

$e_{j}(\xi)=\sum_{j}^{\infty} \sum_{k=-\infty}^{\infty} d_{j, k} \psi_{j, k}(\xi) \quad \xi \in(R)$

onde:

$e_{j}(\xi)=$ erro

$f(\xi)=$ função

$P f(\xi)=$ projeção ortogonal da função perpendicular ao espaço de aproximação

Em relação à aproximação com as wavelets existem três fatos importantes:

1. Uma boa aproximação da descontinuidade de uma função $f$ é conseqüência de ter grandes coeficientes nas mais finas escalas (ou maiores resoluções $j$ ). O conteúdo da alta freqüência local para a descontinuidade é capturada muito melhor que com a série de Fourier.

2. O fato do que o erro é restrito a uma pequena vizinhança da descontinuidade é o resultado da "localidade" da wavelet. O comportamento de $f$ para uma posição afeta somente aos coeficientes wavelet localizados nesta posição. 
3. Quase toda a parte linear de $f$ é representada exatamente. Esta observação é a manifestação de uma propriedade chamada vanishing moment, que significa que as funções escalas $(\phi)$ podem representar localmente polinomiais de baixo ordem exatamente. Esta propriedade é crucial para o sucesso das aproximações wavelet. (Nielsen, 1998)

\section{Base de HAAR}

O termo wavelet denota uma família de funções dada pela eq. (4.1), a partir da qual são gerados os diferentes tipos de bases wavelet.

A base de HAAR é o exemplo mais simples de uma base wavelet, composta por funções constantes formando patamares. Os patamares, ou intervalos, em que as funções são constantes, são de tamanho, arbitrariamente pequeno, e as bases são completas para $L^{2}(R)$. Ela se define como segue:

$\psi(\xi)=\left\{\begin{array}{l}1 \text { se } \quad \xi \in[0,1 / 2) \\ -1 \quad \text { se } \xi \in(1 / 2,1] \\ 0 \quad \text { caso contrário }\end{array}\right.$

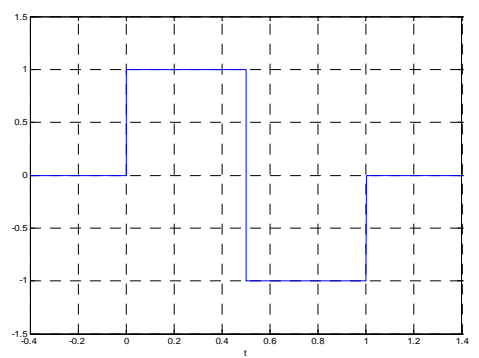

Assim, esta base wavelet de HAAR permite gerar a seguinte wavelet de suporte compacto:

$\psi_{j, k}(\xi)=2^{-j / 2} \psi\left(2^{-j} \xi-k\right)$

as que são utilizadas dentro do contexto da análise de resolução múltipla. E associada a esta wavelet conta-se com sua respectiva função de escala definida por:

$\phi_{j, k}(\xi)=2^{-j / 2} \phi\left(2^{-j} \xi-k\right)$ 
obtida a partir de sua função base seguinte, que é definida como a função característica no intervalo $[0,1)$, em que $\phi: R \rightarrow R$ :

$\phi(\xi)= \begin{cases}1 & \text { se } \quad 0<\xi<1 \\ 0 & \text { caso contrário }\end{cases}$

\subsubsection{Aplicações de wavelet}

A análise wavelet como uma ferramenta de ampla aplicação continuará mostrando inúmeras pesquisas em diferentes áreas científicas e com grande sucesso, por exemplo, na identificação de sistemas (Engin e Musa, 2005) e na resolução de equações não lineares integrais (Mahmoudi, 2005).

Justen et. al. (2003) apresentaram um trabalho que, envolve a análise de dados discretos de perfis de vento com o objetivo de mostrar uma visão geral da filtragem wavelet sob sinais discretos contaminados de radares de perfis de vento e explicar como as wavelets podem ser utilizadas para remoção de ruídos. Além de introduzir uma nova técnica envolvendo a decomposição dos pacotes wavelet e uma divisão progressiva e regressiva dos componentes do sinal. Os resultados da pesquisa quanto à precisão sob detecção de ruídos menores, ao ar livre, foram promissores deixando assim aberta a possibilidade de explorar seu grande potencial na filtragem de grandes ruídos.

Oleg e Kevlahan (2005) apresentam um método de colocação wavelet multi-nível adaptativo para problemas de equações diferenciais parciais. Neste trabalho, os autores utilizam a decomposição wavelet para a adaptação e interpolação da malha, enquanto que um esquema de diferença finita hierárquica aproveita as vantagens da decomposição, multi-nível wavelet, usada para cálculos derivativos, como parte da estrutura multi-nível de aproximação wavelet que permite obter a solução mais próxima a uma malha ótima.

Oleg e Kevlahan (2005) mencionam também, o crescente interesse em desenvolver algoritmos numéricos baseados em wavelet para problemas elípticos e problemas de 
evolução. Existe, hoje, uma classificação rigorosa destes algoritmos: o método adaptativo wavelet-Galerkin (AWGM) e o método adaptativo de colocação wavelet (AWCM), a maior diferença entre estes enfoques, segundo os autores, é que o primeiro algoritmo (AWGM) resolve problemas no espaço de coeficientes wavelet e, em geral, pode ser considerado como um método de poucas malhas. Por outro lado, o algoritmo (AWCM) resolve problemas no espaço físico sob uma malha computacional adaptativa.

Duas dificuldades associadas com AWGM são a não linearidade e as condições de contornos gerais. Para estes problemas Beylkin (1992) propôs alguns procedimentos alternativos, no entanto, no AWCM estes problemas são resolvidos de forma simples. Aliás, a principal vantagen do AWGM é gerar uma representação de operador disperso (Beylkin, 1992), sendo esta representação uma razão do contínuo desenvolvimento de algoritmos AWGM.

\subsection{Discretização}

Discretizar algo depende do contexto em que a palavra é utilizada, por exemplo, seja: $f: R \rightarrow R$, discretizar $f$, significa escolher um $\Delta \xi$ de tal modo que $f$ tome apenas valores quando $\xi=i \times \Delta \xi$ com $i$ pertencente a $Z$. Por exemplo, em processamento de sinais, um sinal discreto é um sinal com amostragem periódica em intervalos de tempo constantes. As amostras do sinal são as representações digitais correspondentes às amostras dos valores analógicos do sinal naqueles instantes.

A discretização aqui é um processo de transferência de modelos e equações contínuas à forma discreta. Este processo é feito geralmente como um primeiro passo do tratamento destes para fazê-los mais convenientes para a avaliação e a implementação numérica nos computadores digitais. Isto em função de ser processados em um computador digital.

Nesse contexto, um esquema de discretização no campo da análise numérica é uma ferramenta poderosa na resolução de problemas de grande complexidade. Este 
esquema resolve equações por aproximações contínuas de quantidades, como se fosse uma série de quantidades em pontos discretos, regularmente distribuídos em malhas.

Geralmente, quando um sistema de equações não lineares é obtido a partir da modelagem de um processo, a solução deste sistema é feita através da técnica de aproximação numérica. Dentre os vários métodos desta técnica, um método que tem recebido especial atenção é o chamado método de resíduos ponderados, aplicados na resolução de diversos problemas da engenharia química. Watzdorf e Marquardt (1996) mencionam este método como a escolha mais usual devido a sua simplicidade conceitual, além de seu rigor matemático.

Segundo Rice e Do (1994), o método dos resíduos ponderados é utilizado principalmente na resolução de problemas de valores de contorno como, por exemplo, fluxo de fluídos, transferência de massa e calor. Os autores citam, ainda, que o método permite ao usuário interagir com os problemas, possibilitando estimar uma primeira aproximação, da solução do problema, que satisfaça as equações do modelo com as condições de contorno impostas. Portanto, a chave para obter uma solução ótima está na escolha adequada da solução aproximada.

Esta solução aproximada $f_{\text {aprox }}(\xi)$ é representada por:

$f_{\text {aprox }}(\xi)=f_{0}(\xi)+\sum_{i=1}^{N} a_{i} \vartheta_{i}(\xi)$

onde :

$f_{0}(\xi)$ : escolhida adequadame nte para satisfazer as condições de contorno $\vartheta_{i}(\xi)$ : função tentativa escolhida para satisfazer as condições de contorno $a_{i}$ : var iável a ser det er min ada

por outro lado, a estimativa inicial não satisfaz com precisão o sistema de equações ou condições de contorno, estando por isso sempre associada a um "erro", 
denominado resíduo. Assim, a solução do sistema de equações requer a utilização de mais dois tipos de funções previamente conhecidas:

(i) Função tentativa ("trial”): utilizada para obtenção da solução tentativa que deve satisfazer as condições de contorno, além de ser selecionada pelo usuário.

(ii) Função peso: usada como base para minimizar o resíduo para que o erro da solução aproximada seja mínimo.

A seguinte relação define o resíduo sobre a função aproximada $f_{a p r o x}(\xi)$ :

$R(\xi)=L\left[f_{0}(\xi)+\sum_{i=1}^{N} a_{i} \vartheta_{i}(\xi)\right]$

onde:

$R(\xi)$ : residual da equação em função de $\xi$

$L$ : operador não linear

A minimização do resíduo é obtida quando o produto interno deste resíduo e da função peso é igual a zero, permitindo obter a solução do sistema para as variáveis desconhecidas $a_{i}$.

A relação para a minimização é dada por:

$\int_{V} R(\xi) w_{k}(\xi) d \xi=0$

onde:

$V$ : domínio de int eresse

$w_{k}(\xi)$ : função peso

$k: 1,2, \ldots \ldots ., N$

$N=$ número natural

O método dos resíduos ponderados apresenta cinco diferentes enfoques dependendo da escolha da função teste. Dentre estes métodos uma que tem chamado a atenção 
pela boa precisão e fácil aplicação (dependendo do tipo de problema) é o método de Galerkin (chamada também, discretização de Galerkin).

Uma vantagem de utilizar o método de Galerkin é a possibilidade de selecionar as funções tentativa e de peso da mesma família de funções base e que são linearmente independentes. Além disso, esta seleção está baseada no conhecimento da solução exata do problema, permitindo assim, grande eficiência no resultado.

O enfoque denominado discretização wavelet-Galerkin esta fundamentado na utilização de funções wavelet como funções tentativa e teste.

Segundo Watzdorf e Marquardt (1997) uma propriedade natural do método waveletGalerkin é a construção da função aproximada através da interação de diferentes escalas, utilizando a função tentativa tanto global quanto local.

\subsubsection{Aplicações da discretização wavelet-Galerkin}

Mahmoudi (2005), utiliza o método wavelet Galerkin para resolver equações não lineares integrais. $\mathrm{O}$ autor mostra neste trabalho que o método pode ser estendido e aplicado não somente para este tipo de equações, mas também para equações integrodiferenciais lineares e não lineares com algumas modificações.

Comincioli et al. (2000), apresentaram o método wavelet-Galerkin para a solução numérica de problemas de elasticidade. A finalidade do trabalho é mostrar a capacidade da wavelet para localizar regiões onde a plasticidade esta em crescimento sem a necessidade de al

gum outro indicador, como acontece com outros enfoques tradicionais utilizados na resolução deste tipo de problemas.

Ko et al. (1993) apresentaram uma estratégia para obter aproximações dimensionais finitas de operadores de Riccati originados em problemas de controle. Os autores 
derivam uma formulação wavelet-Galerkin para uma classe específica de problemas de controle computacional.

Linhares e Prado (2003) aplicaram o método wavelet-Galerkin a equações diferenciais parciais com coeficientes variáveis. A finalidade deste trabalho foi provar a estabilidade do método aplicado em problemas mal definidos, nos que distúrbios pequenos nas condições de contorno podem produzir grandes variações sobre sua solução.

\subsection{Algoritmo Multi-Malha Adaptativo}

Atualmente o enfoque do algoritmo multi-malha adaptativo é uma das ferramentas mais poderosas conhecida na matemática numérica com extensa faixa de aplicação (Briggs et al., 2000).

Segundo Briesen e Marquardt (1999), o enfoque multi-malha adaptativo é um método que estabelece uma estrutura matemática similar para uma variedade de diferentes métodos numéricos. Dois de seus principais componentes são:

- o estimador de erro, que se estabelece para monitorar o erro introduzido pela discretização.

- uma estratégia adequada de adaptação (Liu 1996 apud Briesen e Marquardt (1999)), estabelecido para selecionar as malhas adaptativamente.

Este enfoque envolve três conceitos importantes da análise numérica: multi-escala, multi-malha, propriamente dito, e adaptabilidade, apresentados com mais detalhe nos seguintes itens.

\subsubsection{Multi-escala}

Além da técnica dos resíduos ponderados que introduz o procedimento de discretização, outra técnica que tem recebido grande atenção, no campo da engenharia, é a técnica multi-escala. Essa é uma ferramenta fundamental na solução 
dos problemas multi-escala. Este tipo de problemas e as ferramentas matemáticas utilizadas para resolvê-los são discutidos atualmente ${ }^{3}$.

Duas grandes limitações dos métodos clássicos são:

(i). impossibilidade de reunir a evidência experimental suficiente do comportamento de processos físicos complexos, nas mais finas escalas.

(ii).potencial limitado das ferramentas matemáticas que apesar da disponibilidade de informação em escalas refinadas, não é possível uma descrição matemática completa do sistema, ou seja não existe uma alternativa para um tratamento matemático, apropriado, do comportamento para esta região.

Como conseqüência disso, os matemáticos e pesquisadores, de diferentes áreas, continuam introduzindo condições de fechamento nos modelos matemáticos que melhoram o comportamento empírico, originando, no entanto dúvidas ao respeito da eficiência de tais modelos.

Atualmente, existe a necessidade crescente de encaminhar os resultados do comportamento multi-escala em sistemas físicos complexos. Diz-se que, as complicações físicas e matemáticas, originam-se em um sistema multi-escala e é um dos maiores obstáculos no progresso de muitos campos da ciência e da engenharia. Por isso, a crescente pressão sobre a comunidade da matemática aplicada está levando ao desenvolvimento de novos métodos multi-escala. A consequencia disso é que cientistas e engenheiros estão sempre procurando simular, analisar e controlar uniformemente sistemas mais complexos, por exemplo: modelagem de reatores de fusão usando magneto-hidrodinâmica extendida, simulação da operação de células de combustível, simulação de transporte de poluentes no subsolo, modelagem do processo de desdobramento da proteína, estudo de materiais maleáveis, incremento da confiança nas predições, a longo prazo, de modelos climáticos e atmosféricos, a modelagem complexa de grandes escalas de gráficos e redes que podem ser usados

\footnotetext{
${ }^{3}$ ESTEP. D. Multiscale problems: past and present. In: WORKSHOP ON MULTISCALE PROBLEMS, 2., 2004, Broomsfield. (Final Report)
} 
para representar sistemas biológicos, modelagem de informação complexa e redes de comunicação.

Além disso, o incremento da instrumentação nas ciências, experimentais e computacionais, faz pressão sobre a matemática aplicada, trazendo como conseqüência o desenvolvimento de novas formas de medidas e ferramentas de caracterização em muitos campos. Assim, é possível explorar fenômenos físicos e temporais sobre faixas de escalas não exploradas anteriormente. Em sistemas onde a informação pode ser avaliada, constróem-se blocos para criar modelos matemáticos, realístas de comportamento, sobre um número individual de escalas, mas este fato aumenta a pressão para entender como combinar modelos realistas, em diferentes escalas para obter um sistema musti-escala.

A simulação de sistemas multi-escala complexos são, em geral, um componente problemático. Assim, por exemplo, os métodos de continuação ou homotipos para resolver soluções de estado estacionário, estudos paramétricos de soluções de estado, otimização, problemas de controle ótimo e resolução de controle de retro alimentação em tempo real, requerem muitas soluções multi-escala.

As técnicas matemáticas modernas como a teoria de homogeneização, técnicas de renormalização de grupo, métodos numéricos híbridos, operador de intensidade, análise multi-escala variacional, discretização adaptativa e modelagem, tem produzido avanços significativos em termos de entendimento de problemas multiescala, dando assim, suporte à continuação do ambicioso estudo de problemas multiescala mais complexos.

Certamente, nem todos estes métodos foram pesquisados a partir de técnicas clássicas. Particularmente, muitos deles assumem uma grande separação entre escalas e são, comumente, aplicados com o objetivo de descrever o comportamento sobre uma escala. Estas técnicas significam uma evolução, desde a metodologia clássica, por outro lado, elas devem ser desenvolvidas e utilizadas em muitas áreas científicas, específicas e de aplicação, além de que as pesquisas multi-escala permanecem grandemente separadas das diversas disciplinas físicas. Por estes 
motivos os pesquisadores estão receptivos a se familiarizar com mais de um método, criando o desafio para desenvolver uma estrutura completa.

O encaminhamento futuro da discussão matemática, originada nos modernos problemas multi-escala, parte da identificação e caracterização de problemas comuns que permitirão desenvolver estruturas matemáticas para a análise multi-escala, guiando o desenvolvimento de técnicas avançadas. Alguns desses problemas são mencionados a seguir:

- Determinação de escalas para serem incluídas sob vários intervalos do domínio, espaço e tempo, determinação da forma e força de união entre estas escalas. Em ambos os casos observando informação desejada a ser obtida a partir do modelo.

- Seleção do modelo apropriado para cada escala que capture o comportamento físico relevante.

- Entendimento da ligação da informação obtida dos modelos às várias escalas para conhecer seus efeitos e assim conseguir um melhor controle deste processo de ligação.

- Assegurar que os erros associados com a transferência das soluções e as aproximações, ou representações, usadas para os componentes do modelo sejam adequadamente controlados.

- Caracterização das propriedades essenciais que a conclusão do modelo apresenta para prover fisicamente comportamento realista no contexto de uma aplicação multi-escala específica.

- Determinação dos valores dos parâmetros do modelo, necessários para executálos, em várias escalas. Quantificar o efeito das incertezas nos valores dos parâmetros. Observar sua propagação através dos componentes do modelo para cada escala e pelos operadores de transferência inter-escala, para as quantidades de interesse. 
- Estimação e controle da discretização espacial e temporal e a integração de erros (esta referência clássica ganhou nova importância no contexto da resolução de problemas multi-escala complexos, onde os erros, desde cada componente e a transferência da informação, entre escalas, pode comprimir o resultado, das outras escalas de maneira óbvia e sutil).

- Desenvolvimento de ferramentas de análise matemática e produção de resultados para a consistência, estabilidade e precisão de métodos multi-escala complexos, aplicado ao protótipo de problemas multi-escala e aplicações desafiantes.

Todas as questões mencionadas anteriormente podem ser resumidas de forma geral como a descrição de: representação de escalas, separação de escalas, comunicação entre escalas e a habilidade de aplicar a análise matemática a métodos de solução multi-escala.

Finalmente, pode-se concluir que, a combinação do sistema de equações dos modelos com as técnicas multi-escala, é capaz de proporcionar soluções para diferentes níveis de precisão, para a mesma formulação do problema físico. Isto permite o desenvolvimento de um algoritmo adaptativo não sendo necessária a reformulação contínua do sistema de equações, como ocorre no enfoque pseudo-componente, por exemplo de misturas de petróleo.

As vantagens da técnica multi-escala são:

(i) A solução pode ser obtida pelo refinamento gradual das soluções intermediárias, mesmo que a estimativa inicial seja pouco precisa.

(ii) A solução pode ser obtida instantaneamente a partir das funções tentativas em diferentes escalas. Além disso, caso a seleção destas funções seja feita para determinadas posições, ela contribuirá significativamente para a solução, abrindo o caminho para a adaptabilidade. 


\subsubsection{Multi-Malha}

Briggs et al. (2000) descrevem os métodos multi-malha desde sua aplicação original sobre simples problemas de valores de contornos, originados em muitas aplicações físicas sobre domínios espaciais, até suas mais atuais idéias de aplicação em que muitas vezes não se tem associado algum tipo de malha física. Este fato motiva a geração de níveis mais gerais de organização a partir do conceito original multimalha, dando origem a novas e poderosas técnicas com amplo faixa de aplicabilidade estendendo o termo multi-malha a multi-nível.

Por exemplo, algumas aplicações são: problemas dependentes do tempo, problemas no processamento de imagem, teoria de controle, otimização combinatória, mecanismo estatístico e eletrodinâmica. Esta lista de problemas favoráveis para os métodos multi-nível é amplo e crescente.

Kwon (2002) refere que a parte chave do método multi-malha é usar correção de malhas grossas em função a reduzir erros de baixa freqüência na análise. $O$ procedimento clássico desta correção consiste em restringir o erro na malha fina para a resolução do erro grosseiro por um operador, e logo a solução da malha fina é atualizada por meio de um operador de interpolação, estes operadores tem características multi-escala, todos os elementos do vetor e a matriz são ordenados por suas escalas. Isto sugere o enquadramento do método multi-malha dentro do ambiente multi-escala, como é mostrado em Kwon (2002).

Por exemplo, a modelagem teórica de processo dinâmicos da engenharia química frequentemente implica na solução numérica de uma o mais equações diferenciais parciais. Além disso a complexidade dos problemas gerados por tais equações é incrementado quando as soluções deles exibem movimentos rápidos de fronteira. Por isso a necessidade de estabelecer novos métodos numéricos baseados na interpolação wavelet, que dinamicamente adapta a colocação de malhas, para que a maior resolução seja automaticamente atribuída ao domínio de regiões onde as características acentuadas estão presentes. 
Existem algumas variações nos passos de correção das malhas grosseiras, Kwon (2002) por exemplo propôs, no âmbito multi-escala, a solução de baixa resolução contem a parte de freqüência relativamente baixa de uma solução aproximada. Desta maneira para cada estado de relaxação, o presente esquema não requer procedimento para baixar à mais fina escala dado que a solução de baixa resolução pode ser usada como uma aproximação inicial para o seguinte estado de maior resolução.

Em um contexto geral, pode-se dizer do método multi-malha o seguinte:

- Independente do tipo de problema em que este é aplicado, ele é um método iterativo, em que testes de convergência fazem parte de seu desenvolvimento.

- Os elementos inerentes a ele são esquemas de relaxação e engrossamentos de malha através de processos de interpolação entre malhas, chamado também, no ambito unidimensional como prolongação.

- A implementação do método através de diferentes algoritmos, variam em sua complexidade, dependendo do problema a tratar.

- Três tipos de algoritmos são conhecidos para sua implementação, estes são: multi-malha algébrico, multi-nível adaptativo, e algoritmos que relaciona-se ao conceito de elementos finitos.

Como for dito por Kwon (2002), o processo de correção de malhas, definido como engrossamento de malhas, é parte chave do enfoque multi-malha, este precesso é descrito de forma concreta pelas seguites definições:

- Relaxar o sistema $A^{h} u^{h}=f^{h}$ em malha $\Lambda^{h}$ para conseguir uma aproximação inicial $v^{h}$.

- Calcular o resíduo: $r^{h}=f^{h}-A^{h} v^{h}$

- Relaxar: $A e=r$ em malha $\Lambda^{2 h}$ para obter uma aproximação do erro $e^{2 h}$ 
- corregir a aproximação $v^{h} \leftarrow v^{h}+e^{h} \operatorname{com} e^{h}=I_{2 h}^{h} e^{2 h}$

onde:

$h: \quad$ espaciamento de malha fina

$2 h$ : espaciamento de malha grosseira

$v$ : aproximação da função $u$

$u$ : funções a serem aproximadas

e: erro

$I_{2 h}^{h}$ : indicador de interpolação de malha grossa para malha fina

A maneira de ilustrar o procedimento anterior apresenta-se o seguinte esquema:

Processo de correção de malhas

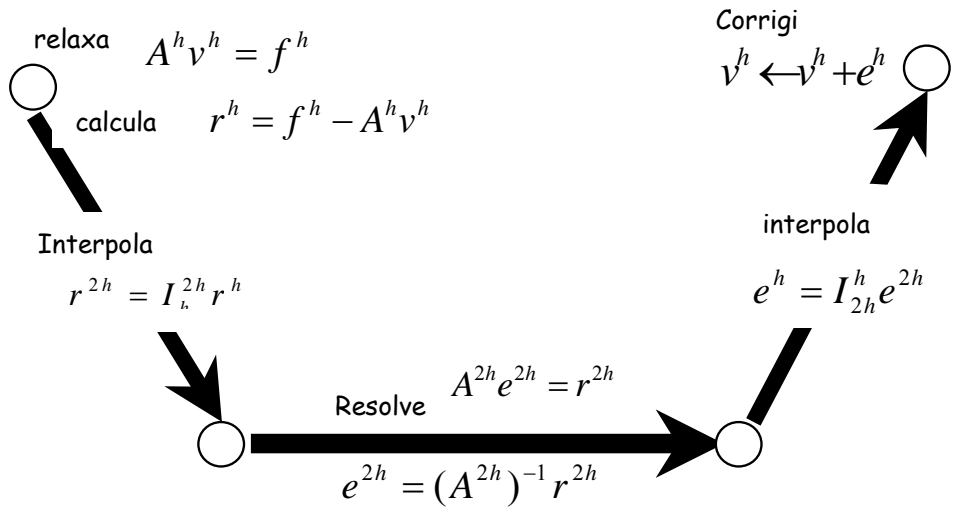

Figura 4.5. Representação esquemática do procedimento de correção de malhas.

As figuras 4.6 e 4.7 mostram esquemáticamente o processo de interpolação de pontos de discretização desde a malha fina para a malha grosseira. Especificamente a figura 4.6 mostra como podem-se representar grupos de pontos de uma malha fina $\left(\Lambda^{h}\right)$ por somente alguns deles em uma outra malha chamada grosseira $\left(\Lambda^{2 h}\right)$. Este procedimento é feito considerando alguns critérios de seleção, isto chama-se também processo de adaptabilidade ou estratêgia de adaptação. 

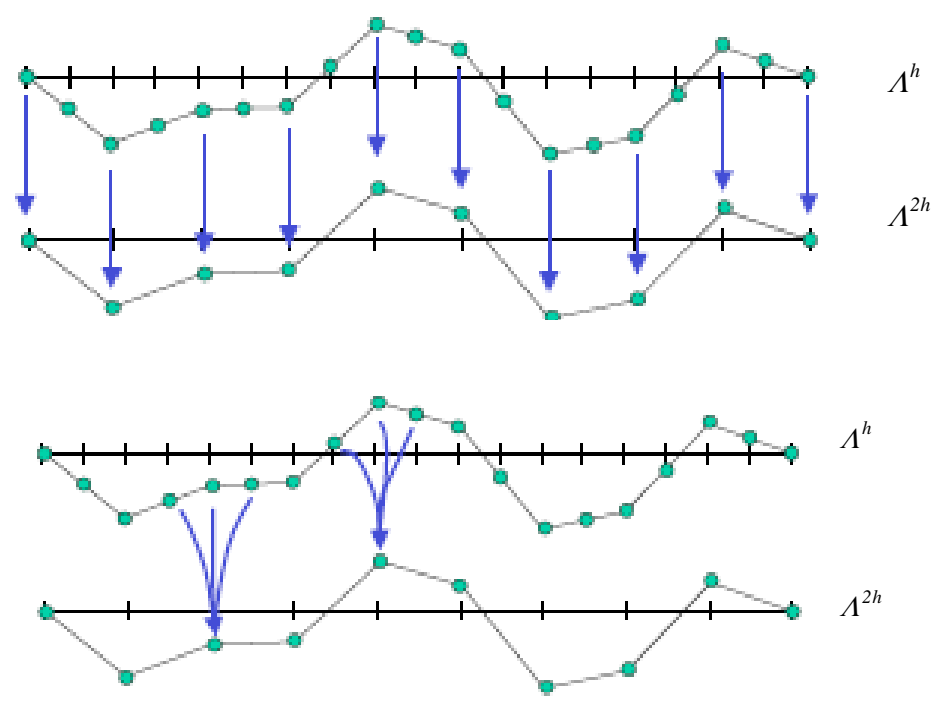

Figura 4.6. Representação esquemática do processo de interpolação de pontos de discretização de malha fina para a malha grossa.

Por outro lado a figura 4.7 explica esquematicamente o chamado ciclo de interpolação multi-malha completo. Ele desenvolve-se através de um proceso consecutivo de refinamento e engrosamento de malhas para conseguir passar de um nível de menos detalhes até outro com mais detalhes. As restrições que são introduzidas neste processo de interpolação determinam a qualidade da aproximação em cada nível, consiguindo-se com isto melhorar a aproximação nos resultados.

\section{Ciclo multi-malha completo}

FMG

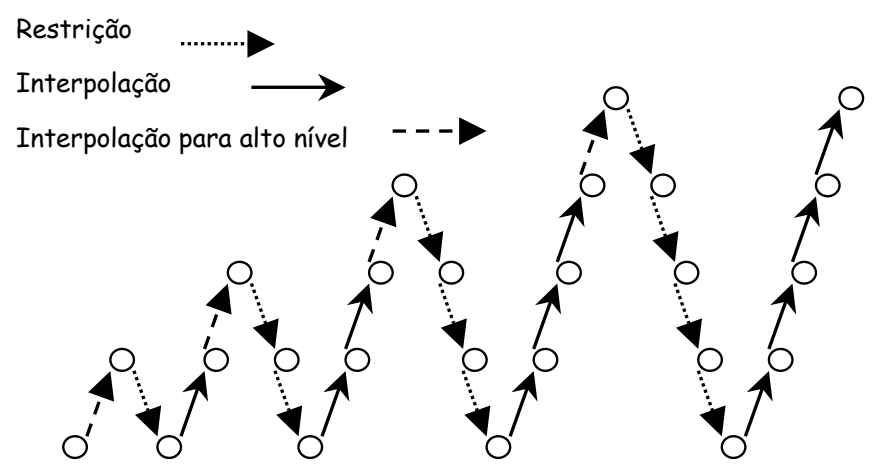

Figura 4.7. Representação esquemática do processo de interpolação conhecido como ciclo multi-malha completo. 
A apresentação básica do multi-malha neste item, deve-se a que esta metodologia abrange muitos conceitos, que poderiam ser tratados com mais detalhes em trabalhos em que o método em se mesmo deva ser avaliado. No presente trabalho o enfoque multi-malha passa pela utilização da parte básica que for descrita, também, pelas figuras 4.5-4.7.

Embora, a seguir são destacados alguns aspectos importantes desta metodologia, segundo resultados de pesquisas em relação a seu desenvolvimento:

- Além de ter alcançado sucesso na aplicação de problemas que envolvem equações diferencias parciais, tem também encontrado aplicação em problemas que envolvem PDEs parabólicas e hiperbólicas, equações integrais, problemas de evolução, geodésicos, etc.

- Os métodos mult-malha são otimos, para reduzir a complexidade dos problemas.

- Eles podem ser robustos.

- E são de grande interesse porque construem algoritmos escalonados que podem ser processados em paralelo de forma eficiente.

\subsubsection{Adaptabilidade}

A adaptabilidade é também uma técnica recente que permite poupar esforços desnecessários devido ao refinamento redundante das malhas para cada laço de iteração nos algoritmos, os quais resolvem problemas de discretização, permitindo modificar a malha a cada passo durante as iterações (Briesen e Marquardt, 2003). Assim, esta substituição é estendida, pois, a homogeneidade da malha pode detalhála em domínios na qual a aproximação atual seja totalmente adequada, enquanto que para outros domínios com aproximações menos precisas, podem ocorrer resultados insatisfatórios. O potencial da adaptabilidade deriva do fato de que ela pode ser 
aproveitada para escolher diferentes séries de funções base correspondentes a diferentes medidas dos balanços em um modelo (Briggs et al. 2000).

No DOE (2004) menciona-se que os métodos adaptativos tem por objetivo o controle dos erros associados com a simulação. Por exemplo, no caso de simulações multiescala a fonte dos erros incluem:

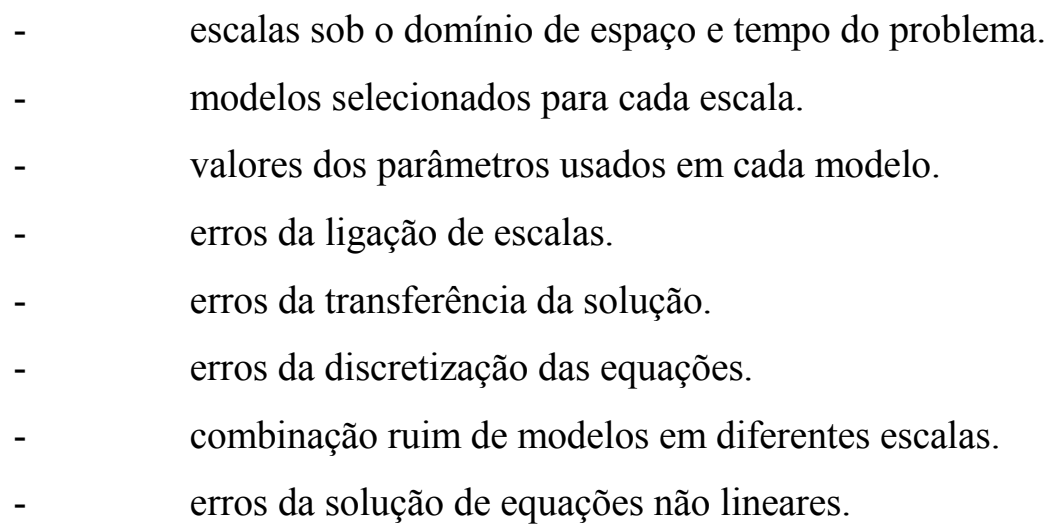

O enfoque desejado para executar uma simulação multi-escala adaptativa pode-se iniciar com o modelo em uma escala grosseira e, adaptativamente, ser enriquecida para incluir as escalas, modelos e discretizações necessárias para predizer as quantidades de interesse para o nível desejado de precisão. Isto requer recursos efetivos para estimar as mudanças na solução dos modelos em uma escala mais fina sem a aplicação destes modelos sob todo o domínio. Esforços significativos são requeridos para direcionar a questão associada com o desenvolvimento de um estimador de erro e de indicadores de correção para vários componentes da estrutura matemática que vem dando inicio à forma para modelagem e análise multi-escala.

Nesse sentido, os problemas numéricos apresentam, com freqüência, algumas características especiais em regiões locais pequenas que requerem resolução e precisão mais do que o necessário para o resto do domínio. Assim por exemplo, na modelagem numérica temporal, fenômenos isolados, tais como, tornados ou frentes temporais podem atingir substancial precisão. A simulação numérica dos vôos de uma aeronave podem requerer, especialmente, aproximações precisas ao redor da fuselagem ou asa. Neste, e em muitos outros casos não é possível prever a precisão 
local necessária para a solução do processo via discretização global. É nestas situações, por exemplo, que um processo de adaptação se faz necessario. Em Briggs et al. (2000) pode-se verificar com mais detalhes a matemática relacionada aos processo de adaptação, por exemplo, o nomeado método de malha FAC (fast adaptive composite), cujas principais características são a possibilidade da utilização de malhas e sub-malhas uniformes.

\subsection{Aplicações}

Nos anais do DOE (2004) faz-se referência ao fato de que a técnica de discretização adaptativa tem conseguido avanços importantes nas ciências físicas e biológicas, no desenvolvimento de novas formas de medida e ferramentas de caracterização que tem possibilitado entender os fenômenos espaciais e temporais sob escalas atômicas, molecular, microscópica, e macroscópica.

A técnica de discretização permitiu, ainda, avanços na microeletrônica para o desenvolvimento de circuitos integrados, assim como avanços recentes em nanotecnologia e biotecnologia, ampliando o pacote de conhecimentos desta técnica como, por exemplo, a possibilidade de desenhar e construir blocos em escala nanométrica.

Além disso, este documento deixa claro que, a continuidade dos avanços desta técnica dependem fortemente da capacidade de lidar com simulações multi-escala e da aplicação efetiva destas simulações para o desenvolvimento de métodos adaptativos com o objetivo de obter modelos e discretizações apropriados sobre as escalas de espaço e tempo dos problemas.

No entanto, um dos maiores obstáculos no desenvolvimento de um eficiente método numérico baseado em wavelet é a dificuldade no tratamento de domínios gerais de contorno para segunda ou terceira dimensão. Uma variedade de trabalhos foram publicados com a finalidade de contornar este obstáculo. 
Assim, por exemplo, Jang et. al (2004) desenvolveram um método numérico multiescala adaptativo baseado em wavelet capaz de lidar com condições de contorno gerais. O objetivo dos autores foi demostrar através de estudos de caso a validade do método proposto e a efetividade do esquema adaptativo multi-escala.

Segundo Vlachos (2005), a simulação multi-escala é um campo científico emergente, que engloba diversas disciplinas, como, por exemplo, a física, a química, a matemática, a estatística, a engenharia química, a engenharia mecânica e ciência dos materiais. $\mathrm{O}$ autor menciona que a simulação híbrida e o granulamento grosso ou modelagem mesoscópica são identificados a partir de dois enfoques: um enfoque geral e um enfoque complementar da modelagem multi-escala. O primeiro é classificado, ainda, dentro de um âmbito competente e dependente da simulação tipo multi-malha sob comprimentos de escalas e na presença ou não de gradientes.

Vasilyev e Kevlahan (2005) indicam que apesar da similaridade com os métodos multi-malha, o algoritmo iterativo multi-nível wavelet é diferente em alguns pontos importantes. As maiores diferenças estão na estrutura das malhas incluídas, o uso de interpolação wavelet para ambos operadores de prolongação e restrição e o uso de métodos numéricos mais exatos.

Binder et. al. (2001) estudaram o potencial dos esquemas de refinamento multiescala para a solução numérica de problemas de otimização dinâmica, de problemas relacionados ao monitoramento de sistemas de processos químicos, apresentando para isso algoritmos iterativos.

Outros exemplos de aplicação destas ferramentas são descritos a seguir:

Fish e Belski (1995) desenvolveram um método multi-malha para meios heterogêneos periódicos em dimensões múltiplas e que, baseia-se na teoría de homogeneização especial de operadores de transferência inter-malha, desenvolvidos para simular respostas de baixa frequência em problemas de valores de contornos com coeficientes oscilatórios. Uma estratégia adaptativa é desenvolvida para formar um modelo computacional a dupla escala quase ótima, consistindo de malhas de 
elementos finitos, construidas inteiramente por micro-escala em regiões identificadas pela idealização dos indicadores de erro, no entanto, no mesmo nível, a modelagem é suficiente somente para capturar a resposta do meio homogeneizado. Alguns experimentos numéricos são apresentados para mostrar a utilidade do procedimento multi-nível adaptativo proposto na predição da resposta detalhada de composições dos espécimes. Esta proposta é dada como uma alternativa ao método clássico de homogeneização que inclui a hipótese clássica de uniformidade dos campos macroscópicos dentro do domínio da unidade celular.

Cruz et. al. (2002) enfocaram em seu trabalho uma discussão sobre a apresentação de um método adaptativo de malha baseado em wavelet para a resolução de equações diferenciais parciais, não lineares. Os autores implementaram um algoritmo simples, modular, flexível e independente do problema, sem a demanda de um conhecimento prévio da sua solução. Sendo necessário apenas a avaliação da sub-rotina de adaptação da malha (aqui ela mesma pode ser incorporada dentro de algum pacote de solução genérica para equações diferenciais parciais, EDP) em conjunto com algum operador diferencial apropriado.

Vasileva et. al. (2005) apresentaram um algoritmo multi-nível, com refinamento de malhas em forma adaptativa, para resolver, localmente, fortes variações de comportamento nas camadas de contorno e interiores, em problemas de convecção e difusão. O método está baseado na discretização discontínua de Galerkin (BaumannOden DG). A adaptação recursiva da malha esta ligada com o solver multi-malha (baseado nos ciclos $\mathrm{V}$ multi-malha com relaxação damped de blocos Jacobi como um linearizador). Os autores propuseram um indicador de erro baseado na comparação da soluçaõ discreta e a solução na mais fina escala, e sua restrição para a próxima malha mais grosseira. Com isto, conseguiram refinar regiões onde esta diferença é grande. Alguns resultados numérico-experimentais apresentados ilustram a eficiência do algoritmo.

Bittencourt et. al. (2002) apresentaram alguns métodos multi-malha non-nested adaptativos lineares, aplicados a problemas lineares elásticos, discretizados com elementos finitos triangular e tetraédrico, usando geradores de malha não estruturada. 
Domínguez, M. C.; Ferragut, L. (2001) apresentaram um método para a formulação mista de problemas de elasticidade plana. O método está baseado em uma formulação híbrida mista que utiliza duas aproximações numéricas diferentes, e um estimador de erro a posteriori. Os autores elaboraram um algoritmo multi-malha, não-padrão, para resolver este tipo de modelo, e para verificar sua eficiência e seu bom desenvolvimento apresentam uma aplicação numérica.

Wille (1996) desenvolveu um solver multi-malha adaptativo iterativo de equações para resolver, simultaneamente, equações implícitas de Navier-Stokes, com a geração de malhas tri-árvore. Neste solver, uma estrutura hierárquica das malhas permite que as soluções aproximadas das equações de Navier-Stokes, obtidas em cada nível, sejam projetadas para cada seguinte malha mais fina, onde é usada como vetor inicial da equação iterativa. E quando a malha mais fina é alcançada, o solver itera até abter a solução tolerada. As equações não lineares de Navier-Stokes são linearizadas com o método Newton e o processo de adaptação de malhas. 


\section{APLICAÇÃO DO MÉTODO WAVELET-GALERKIN EM PROCESSO FLASH DE MISTURA DE MULTI- COMPONENTES DE PETRÓLEO}

A representação de misturas multi-componentes complexas pelo método mais comum de pseudocomponentes apresenta algumas desvantagens, que foram vistos no capitulo 2. Algumas alternativas na tentativa de resolver estas desvantagens mais recentes, são apresentadas nos trabalhos de Briesen e Marquardt (1996-2004) e, Eckert e Vanek (1998-2005).

A base fundamental da metodologia estudada por Briesen e Marquardt é apresentada nos trabalhos publicados em 1999, 2000 e 2003, neles é descrita a metodologia como uma proposta flexível para a "Simulação estacionária e dinâmica de processos de separação térmica”, usando a representação contínua da composição da mistura e um esquema completo de discretização wavelet-Galerkin adaptativo. $\mathrm{O}$ algoritmo também é descrito e aplicado a um flash de petróleo para verificar sua eficiência.

Por outro lado, a metodologia estudada por Eckert e Vanek (1998, 2003, 2005a, 2005b, 2005c) fundamenta-se na representação da mistura baseada na seleção de componentes reais. Os algoritmos para o procedimento de seleção dos componentes reais, para formação da mistura substituta e a determinação da suas composições, foram apresentados por Ba et. al. (2003).

\subsection{Modelagem de um separador Flash}

Existem muitos fatores que influenciam nos procedimentos de destilação, determinando assim a complexidade do processo. Estes fatores são, por exemplo, a natureza dos líquidos e seus vapores, o grau de fracionamento desejado, o número de produtos requeridos, o tipo de processo de destilação empregado, o equipamento empregado, as condições de operação e a economia do processo. Com o objetivo de verificar a eficiência do método proposto, ele é aplicado aos princípios básicos de um separador flash, um dos processos mais simples de separação térmica na indústria do petróleo. 
O princípio da destilação flash implica na separação dos componentes através da diferença de temperaturas, aqui o vapor está em íntimo contato com o líquido, de tal forma que supõe-se que o líquido residual e o vapor formado estão em constate equilíbrio. $\mathrm{O}$ procedimento envolve o aquecimento de uma corrente de alimentação seguida de uma expansão dentro do equipamento de destilação, mantido a baixa pressão. A figura 5.1 mostra um típico separador flash.

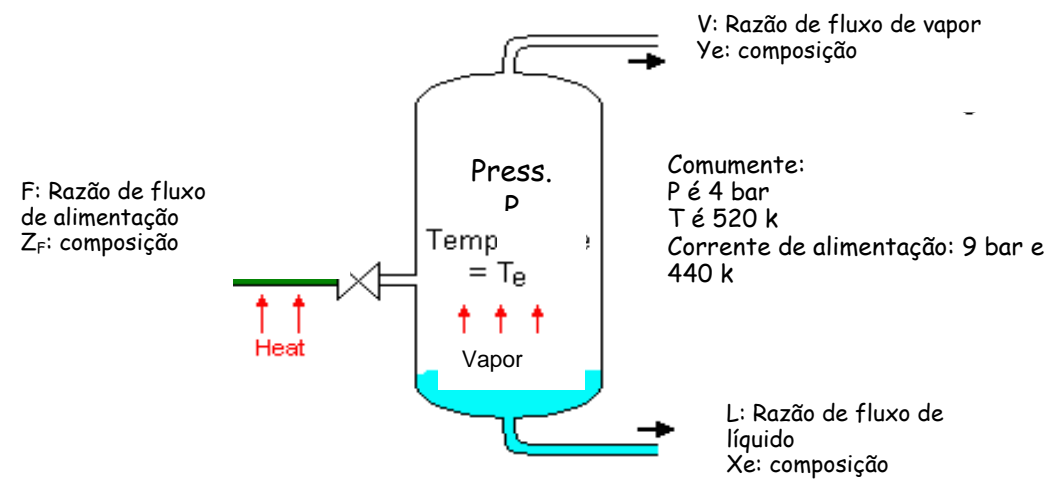

Figura 5.1. Esquema de um separador flash.

A simulação foi desenvolvida em um separador "flash de petróleo", restrito ao estado estacionário.

As variáveis conhecidas ou de entrada são:

- Fluxo de alimentação

: $\quad P_{\text {feed }}$

- Composição de alimentação : curva TBP

- Pressão do sistema : $\quad$ :

- Fator de vaporização $\quad: \quad \alpha$

As variáveis desconhecidas ou de saída são:

- Temperatura do sistema : $\quad$ T ou Tint

- Fdc. da fração de vapor : : fvap

- Fdc. da fração de líquido : : fliq 
O tratamento dos parâmetros, considerados na simulação, são descritos e apresentados com mais detalhes nos itens seguintes.

\subsubsection{Tratamento e análise dos dados de alimentação}

A alimentação do processo flash é uma mistura multicomponente complexa de hidrocarbonetos. Para descrever estes dados as curvas TBP são as mais confiáveis, e para interpretar estas curvas um dos enfoques mais utilizado é o agrupamento em pseudocomponentes descrito, por exemplo, por Edmister (1955).

A aplicação do algoritmo é feita sobre os dados fornecidos pela literatura. Como são as curvas TBP ou dados detalhados de composição fornecidos pelas análises cromatográficas de gás. Neste trabalho é considerado dados a partir das curvas TBP e de densidade de um petróleo cru, apresentados por Miquel e Castell (1992). A tabela 5.1 e a figura 5.2 mostram estes dados:

Tabela 5.1. Dados experimentais da corrente de alimentação de um petróleo cru, para gerar as curvas TBP e densidade. Fonte: Miquel e Castell (1992)

\begin{tabular}{|c|c|c|}
\hline $\begin{array}{c}\text { Volume destilado } \\
(\% \text { vol) }\end{array}$ & $\begin{array}{c}\text { Tbp } \\
\text { Temperatura de ebulição verdadeira }(\mathrm{K})\end{array}$ & $\begin{array}{c}\rho \\
\text { densidade }\left(\mathrm{kg} / \mathrm{m}^{3}\right)\end{array}$ \\
\hline 0.0 & $284.3^{*}$ & $649.8^{*}$ \\
10.0 & 363.2 & 714.3 \\
20.0 & 416.1 & 763.4 \\
30.0 & 460.5 & 791.2 \\
40.0 & 509.0 & 817.7 \\
50.0 & 558.3 & 844.4 \\
60.0 & 612.3 & 871.6 \\
70.0 & 668.8 & 902.1 \\
80.0 & 731.0 & 930.1 \\
90.0 & $804.2^{\star}$ & $955.5^{\star}$ \\
100.0 & $893.7^{*}$ & $977.95^{\star}$ \\
\hline \multicolumn{2}{|c}{${ }^{*}$ valores extrapolados }
\end{tabular}




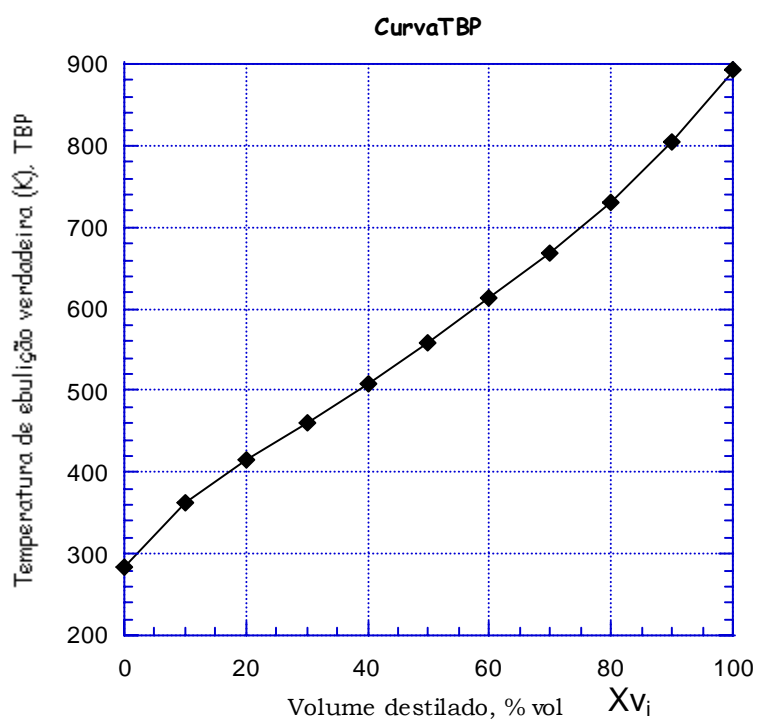

Figura 5.2 Curva TBP de um petróleo cru. Fonte: Miquel e Castell (1992).

Para a análise dos dados, segundo o enfoque proposto, são consideradas técnicas de aproximação numérica, pelas que pode-se representar as misturas de alimentação através de funções de distribuição contínua, do tipo constantes por patamares (piecewise constant). Estes patamares são regiões pequenas ligadas por uma seqüência de intervalos. Neste trabalho "as wavelets" serão utilizadas para este fim, e como dito no capítulo quatro, existem vários tipos de bases wavelet, sua seleção depende da função a ser representada. Wartzdorf (1998) menciona que a base Hat wavelet é superior à base Haar wavelet somente no caso em que as funções a serem representadas por elas sejam regulares, em sentido matemático. Não obstante, para representar as misturas complexas de petróleo, a informação mais detalhada está diretamente relacionada à alta variabilidade dessas funções, então, por simplicidade, a base Haar wavelet seria a mais adequada para a representação proposta, além do que, a discretização, tendo como base a Haar, é mais simples de ser implementada.

\section{Representação da composição da mistura}

Os dados da tabela 5.1 são tratados através das seguintes correlações termodinâmicas, os que são representados com funções de distribuição contínua como segue: 
- fração molar do componente $X_{i}$,

$$
X_{i}=X v_{i} \times \frac{\rho_{i}}{M_{i}} \times \frac{\bar{M}}{\rho}
$$

onde:

$$
\begin{array}{ll}
X v_{i}=\int_{\Delta \xi} F_{v}(\xi) d \xi & \text { fração volumétrica expressada como fdc } \\
\frac{\rho}{\bar{M}}=\sum_{i=1}^{n} X v_{i} \times \frac{\rho_{i}}{M_{i}} & \text { densidade acumulada }
\end{array}
$$

desta forma define-se a fração molar como fdc:

$$
X_{i}=\int_{\Delta \xi} F(\xi) d \xi=\int_{\Delta \xi} F_{V}(\xi) d \xi \times \frac{M_{i}}{\rho_{i}} \times \frac{1}{\sum_{i=1}^{n} X v_{i}}
$$

onde:

$X_{i}$ : fração molar de componente i na mistura

$X v_{i}:$ fração volumétrica de destilado

$\rho, \rho_{i}$ : densidade da mistura e densidade do componente i na mistura $\left(\mathrm{kg} / \mathrm{m}^{3}\right)$

$M_{i}, \bar{M}$ : peso molecular da mistura e peso molecular do componente i na mistura $(\mathrm{g} / \mathrm{mol})$

$F(\xi), F_{V}(\xi)$ : fdc da fração molar do componente e fdc da fração volumétrica de destilado

- peso molecular do componente $M_{i}$, a correlação utilizada foi tomada de Riazi e Daubert (1980). (Ge: gravidade específica)

$$
\begin{aligned}
& M_{i}=4.5673 \times 10^{-5} \times \mathrm{Tb}_{i}^{2.1962} \times G e_{i}^{-1.0164} \\
& G e=\rho / 999.24 \quad(\text { a } 288.04 \mathrm{~K})
\end{aligned}
$$

a tabela 5.2, apresenta dados para as variáveis da eq. 5.1, obtidos em função da variável de caracterização (temperatura de ebulição normalizada, $\xi$ ) para construir a representação contínua de cada uma delas como mostra-se nas figuras 5.3 (a, b, c, d). 
Tabela 5.2. Propriedades físicas da corrente de alimentação do petróleo cru normalizadas em relação à variável de caracterização $\xi$.

\begin{tabular}{|l|c|c|c|c|}
\hline$\xi$ & $F_{V}(\xi)$ & $\rho_{i}$ & $M_{i}$ & $F(\xi)$ \\
\hline 0 & 0.5660 & 649.79 & 62.96 & 3.50 \\
0.1474 & 0.8564 & 691.04 & 87.59 & 4.05 \\
0.2315 & 1.1844 & 745.52 & 112.76 & 4.70 \\
0.3020 & 1.3794 & 785.63 & 142.69 & 4.55 \\
0.3790 & 1.2329 & 815.99 & 177.12 & 3.41 \\
0.4573 & 1.1818 & 845.94 & 214.52 & 2.80 \\
0.5431 & 1.0962 & 873.95 & 255.25 & 2.25 \\
0.6329 & 1.0366 & 903.81 & 297.98 & 1.89 \\
0.7317 & 0.9201 & 928.73 & 344.92 & 1.49 \\
0.8564 & 0.7996 & 948.84 & 396.52 & 1.15 \\
1.0000 & 0.6967 & 965.08 & 452.88 & 0.89 \\
\hline
\end{tabular}

* ver tabela 5.3
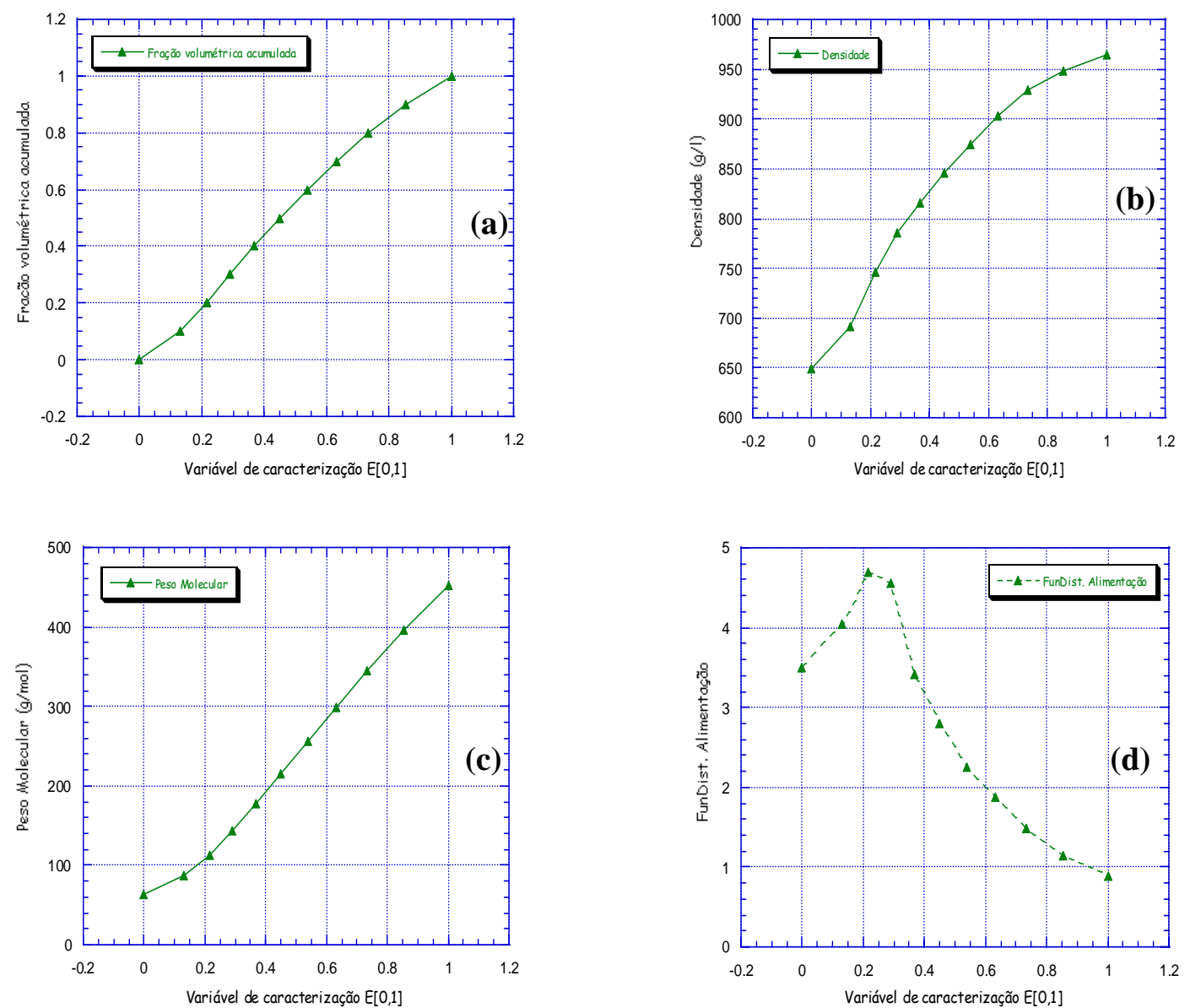

Figura 5.3. Propriedades físicas da corrente de alimentação do petróleo cru vs. variável de caracterização $\xi$. (a) fração volumétrica acumulada (b) densidade (c) peso molecular (d) fdc. da fração molar do componente. 
A condição, "soma das frações molares igual a um", no caso das funções de distribuição contínua, é equivalente à integral embaixo da curva dentro da faixa da variável de caracterização $\xi[0,1]$ com valor também igual a 1 .

Este fato permite avaliar, de modo simples, se realmente a condição foi atingida para os dados tratados, caso contrário, tem-se que normalizar o resultado. Nesta análise, por exemplo, foi introduzida a normalização, obtendo-se assim os dados apresentados na tabela 5.3, e a figura 5.4 mostra comparativamente a variação entre os resultados das distribuições obtidas.

Tabela 5.3. Função de distribuição da fração molar da corrente de alimentação. $\left(^{+}\right.$ obtidos pelas correlações termodinâmicas, ${ }^{++}$obtidos após a normalização para atingir a condição*)

\begin{tabular}{|c|c|c|}
\hline$\xi$ & $X i=f(\xi)^{+}$ & Xil $=$Ffeed $(\xi)^{++}$ \\
\hline 0 & 3.50 & 1.315 \\
0.1474 & 4.05 & 1.521 \\
0.2315 & 4.70 & 1.763 \\
0.3020 & 4.55 & 1.709 \\
0.3790 & 3.41 & 1.278 \\
0.4573 & 2.80 & 1.049 \\
0.5431 & 2.25 & 0.845 \\
0.6329 & 1.89 & 0.708 \\
0.7317 & 1.49 & 0.558 \\
0.8564 & 1.15 & 0.431 \\
1.0000 & 0.89 & 0.334 \\
\hline & $\int_{0}^{1} f(\xi) \neq 1$ & $* \int_{0}^{1}$ Ffeed $(\xi)=1$ \\
\hline
\end{tabular}

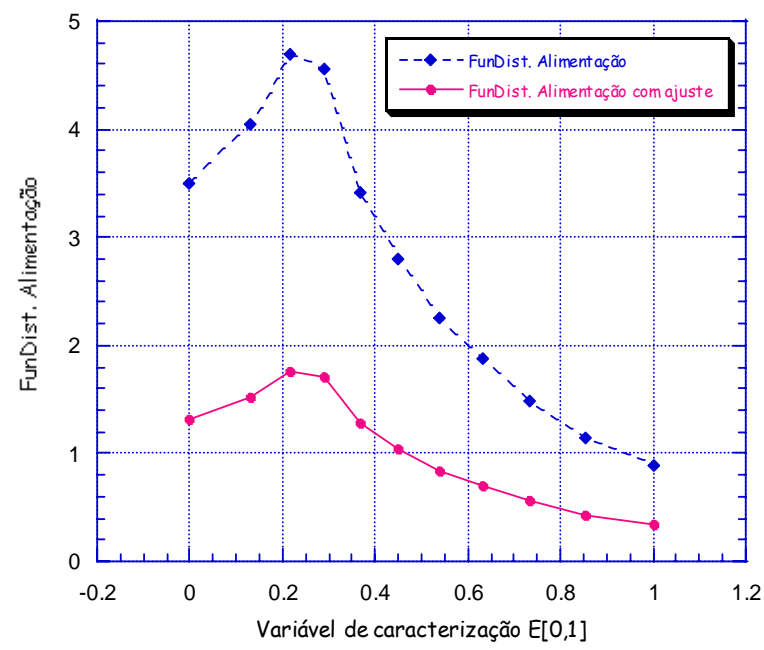

Figura 5.4. Funções de distribuição contínuas da fração molar da corrente de alimentação (FDCfmCA) 
A seguir, os dados que geram a curva normalizada FDCfmCA* representam as condições de alimentação a serem processadas na modelagem do separador flash. A curva é obtida através do ajuste spline cúbica (Matlab 6.5). Foram considerados 128 pontos para a extensão da spline.

\section{Aproximação inicial da representação da mistura}

A função de distribuição para a alimentação (dados da tabela 5.3, Ffeed $(\xi)$, figura 5.4, FDCfmCA) é aproximada através da série de wavelet, eq. (4.3).

Dependendo da escala a utilizar, define-se como $F(\xi)$ a aproximação para a função de distribuição Ffeed $(\xi)=\hat{F}(\xi)$, sendo representada pelas seguintes expansões:

(a) Para um nível arbitrário de detalhe, em escala simples:

$$
\hat{F}(\xi) \approx F(\xi)=\sum_{(j, l) \in \Gamma} c_{j, l} \phi_{j, l}(\xi)
$$

Com os índices:

$$
\Gamma:=\left\{(j, l): j=\hat{j}_{s} ; l=0,1, \ldots . .\left(2^{\hat{j}_{s}}-1\right)\right\} \quad \text { para } \xi=[0,1]
$$

(b) Para um nível arbitrário de detalhe, em multi-escala:

$$
\hat{F}(\xi) \approx F(\xi)=\sum_{(j, k) \in \Lambda} d_{j, k} \psi_{j, k}(\xi)
$$

com os índices:

$$
\Lambda:=\{(-1,0)\} \bigcup\left\{(j, k): j=0,1 \ldots, \hat{j}, k=0,1, \ldots . .,\left(2^{j}-1\right)\right\} \quad \text { para: } \quad \xi=[0,1]
$$


onde:

$\xi$ : var iável de caracteriz ação (temperatur a do ponto de ebulição normal)

$\hat{F}(\xi)$ : função de distribuiç ão

$F(\xi)$ : aproximaçã o para a função de distribuição

$j$ : nível de escala

$\hat{j}_{s}$ : escala maior para representa ção na escala simples

$\hat{j}$ : escala maior para representa ção multi - escala,

$\hat{j}_{s}=\hat{j}+1$

$c_{j, l}$ : coeficentes de escala simples

$d_{j, k}$ : coeficentes multi - escala

$\phi_{j, l}(\xi)$ : equação de refinament o para gerar as funções bases para escala simples

$\psi_{j, k}(\xi)$ : equação de refinament o para gerar as funções bases multi - escala

$l$ : número de funções bases geradas segundo a escala (representa ção a simples escalas)

$k$ : número de funções bases geradas segundo a escala (representa ção multi - escala)

$\Lambda$ : pares de índices das funções bases para representa ção a escala simples

$\Gamma$ : pares de índices das funções bases para representa ção multi - escala

Segundo sugerido por Briesen e Marquardt (2003), escolhe-se um valor elevdo para $\hat{j}$ ou $\hat{j}_{s}, \hat{F}(\xi)$ que é tido como a melhor representação possível podendo ser considerada a aproximação de referência para as aproximações reduzidas obtidas com diferentes níveis de detalhe (ver eq. 5.7).

\section{Resultados dos primeiros testes da aproximação a nível multi-escala}

Trabalhando em um ambiente de simulação do Matlab 6.5 os resultados quantitativos e qualitativos da aproximação para $\mathrm{FDCfmCA}^{*}$ são apresentados na tabela 5.4 e na

figura 5.5. respectivamente. As máximas escalas utilizadas foram: $\hat{j}_{s}=1,2,3,6$ 
Tabela 5.4. Primeira aproximação da FDCfmCA*, para escalas fixas $\hat{j}_{s}(*$ Valores da tabela 5.3)

\begin{tabular}{|c|c|c|c|c|c|c|}
\hline \multirow{2}{*}{$\begin{array}{l}\hat{F}(\xi){ }^{*} \\
\text { função de distribuição } \\
\text { para } 20 \text { pontos }\end{array}$} & \multicolumn{6}{|c|}{$\begin{array}{l}F(\xi) \text { função aproximada } \\
\text { para } 20 \text { pontos da curva }\end{array}$} \\
\hline & $\begin{array}{l}F(\xi) \\
\text { com } \\
\hat{j}_{s}=1\end{array}$ & $\begin{array}{c}\text { erro } \\
\left|\hat{F}(\xi)^{*}-F(\xi)\right|\end{array}$ & $\begin{array}{l}F(\xi) \\
\text { com } \\
\hat{j}_{s}=2\end{array}$ & $\begin{array}{c}\text { erro } \\
\left|\hat{F}(\xi)^{*} F(\xi)\right|\end{array}$ & $\begin{array}{l}F(\xi) \\
\text { com } \\
\hat{j}_{s}=6\end{array}$ & $\begin{array}{c}\text { erro } \\
\left|\hat{F}(\xi)^{*}-F(\xi)\right|\end{array}$ \\
\hline 1.3148 & 1.4647 & 0.1499 & 1.3806 & 0.0658 & 1.3148 & 0 \\
\hline 1.4463 & 1.4647 & 0.0184 & 1.3806 & 0.0657 & 1.4463 & 0 \\
\hline 1.6146 & 1.4647 & 0.1499 & 1.6952 & 0.0806 & 1.6146 & 0 \\
\hline 1.7759 & 1.4647 & 0.3112 & 1.6952 & 0.0807 & 1.7759 & 0 \\
\hline 1.8116 & 1.5372 & 0.2744 & 1.6312 & 0.1804 & 1.8116 & 0 \\
\hline 1.4507 & 1.5372 & 0.0865 & 1.6312 & 0.1805 & 1.4507 & 0 \\
\hline 1.2628 & 1.5372 & 0.2744 & 1.1860 & 0.0768 & 1.2628 & 0 \\
\hline 1.1092 & 1.5372 & 0.428 & 1.1860 & 0.0768 & 1.1092 & 0 \\
\hline 0.9194 & 0.8233 & 0.0961 & 0.8709 & 0.0485 & 0.9194 & 0 \\
\hline 0.8225 & 0.8233 & 0.0008 & 0.8709 & 0.0484 & 0.8225 & 0 \\
\hline 0.7272 & 0.8233 & 0.0961 & 0.6744 & 0.0528 & 0.7272 & 0 \\
\hline 0.6217 & 0.8233 & 0.2016 & 0.6744 & 0.0527 & 0.6217 & 0 \\
\hline 0.5227 & 0.4449 & 0.0778 & 0.4802 & 0.0425 & 0.5227 & 0 \\
\hline 0.4377 & 0.4449 & 0.0072 & 0.4802 & 0.0425 & 0.4377 & 0 \\
\hline 0.3672 & 0.4449 & 0.0777 & 0.3382 & 0.029 & 0.3672 & 0 \\
\hline 0.3092 & 0.4449 & 0.1357 & 0.3382 & 0.029 & 0.3092 & 0 \\
\hline
\end{tabular}

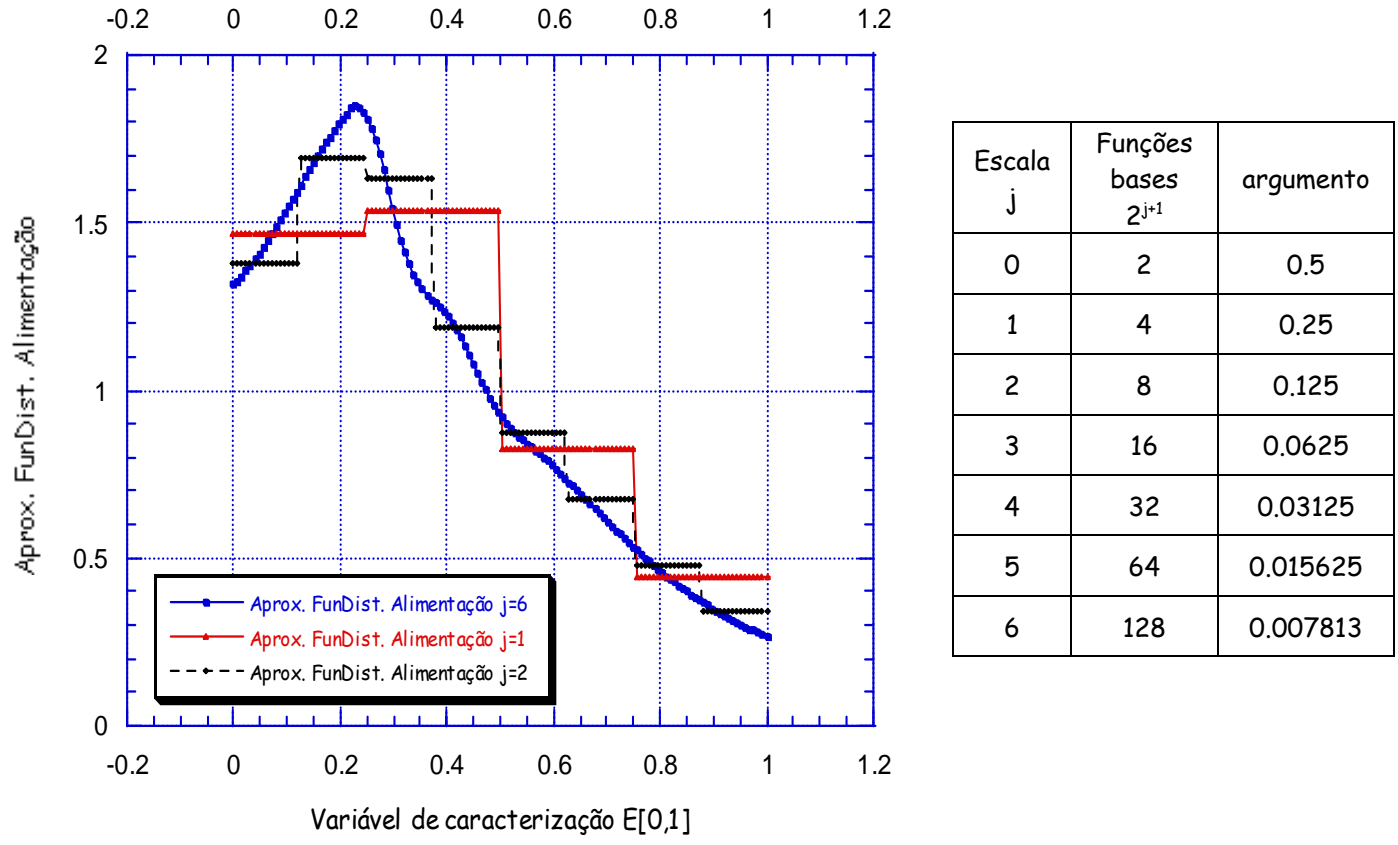

Figura 5.5. FDCfmCA* aproximada através da análise Wavelet (escala $\hat{j}_{s}=1,2,6$ ) 


\section{Resultados da aproximação reduzida}

A representação do tamanho dos modelos depende do nível de detalhe que se deseja conseguir na sua simulação, seu efeito está diretamente relacionado à quantidade dos componentes que são representados. Portanto, se as equações do modelo são muito extensas, elas precisam ser reduzidas para minimizar o esforço computacional para resolvê-las, mas isto tem que ser conseguido sem muita perda de informação.

Outro teste feito com os dados de alimentação (tabela 5.3) baseou-se no conceito de aproximação reduzida. A formulação deste procedimento é apresentada a seguir e os resultados desta simulação mostram-se nas tabelas 5.5, 5.6 e a figura 5.6. em que

consideram-se as escalas máximas $\hat{j}_{s}=1,2,3$, e como referência de solução a maior nível de detalhes tem-se a escala $\hat{j}_{s}=6$.

(a) Para um nível arbitrário de detalhe em representação multi-escala a aproximação reduzida é obtida como segue:

$F(\xi) \approx F^{r}(\xi)=\sum_{(j, k) \in \Lambda^{r}} d_{j, k} \psi_{j, k}(\xi) \quad \xi=[0,1]$

Com os índices: $\quad \Lambda^{r}:=\{(-1,0)\} \bigcup\left\{(j, k): j=0,1 \ldots, \hat{j}, k: 0 \leq k \leq\left(2^{j}-1\right) \wedge\left|d_{j, k}\right|>\varepsilon\right\}$

Onde:

$F^{r}(\xi)$ : função de aproximaçã o reduzida

$\Lambda^{r}$ : pares de indices das funções bases dos coeficient es de det alhe com valor significat ivo, malha reduzida $d_{j, k}$ : coeficient es multi - escala wavelet

$\varepsilon: \lim$ ite de tolerância

Os resultados que são apresentados na tabela 5.5 foram obtidos da análise de resolução multipla para aproximação reduzida, isto, sobre os dados da corrente de alimentação. Esta análise foi desenvolvida para ilustrar a definição de aproximação reduzida (eq. 5.7). A simulação realizada sobre estes dados utilizou as ferramentas de toolbox wavelet de Matlab, para a simulação foram introduzidas algumas condições, 
como: tamanho da malha de discretização, 10000 pontos, níveis de escala a serem analisadas $\hat{j}_{s}=1,2,3$, o valor de Etol foi atribuido por default do toolbox. Assim, através do processamento interno do toolbox foram obtidos os valores de Msel mostrados na tabela 5.5.

Tabela 5.5: Resultados da análise de coeficientes da aproximação reduzida da função de distribuição, FDCfmCA*. Tratamento dos dados com toolbox wavelet de Matlab 6.5.

\begin{tabular}{|c|c|c|c|}
\hline$\hat{j}_{s}$ & $\begin{array}{c}\text { MmaxF } \\
(\text { quantidade de coeficientes de } \\
\left.\text { detalhe totais } d_{j, k}\right)\end{array}$ & $\begin{array}{c}\text { Msel } \\
\text { quantidade de coeficientes } \\
\text { maiores de detalhe } \\
\text { selecionados }\left(\left|d_{j, k}\right|>\varepsilon\right)\end{array}$ & $\begin{array}{c}\varepsilon \\
\text { (limite para escolha dos } \\
\text { coef. de detalhe maiores) }\end{array}$ \\
\hline 1 & 5000 & 1768 & 0.00016134 \\
\hline 2 & 2500 & 481 & 0.0002469 \\
\hline 3 & 5000 & 884 & 0.0004566 \\
\hline & 1250 & 156 & 0.0004 \\
& 5000 & 241 & 0.0007 \\
\hline
\end{tabular}

Pode-se observar que os valores de Msel obtidos para cada escala analisada, em relação à quantidade total $\mathrm{MmaxF}$, representam um valor reduzido. Assim, considerando os resultados da tabela 5.5 foi construida a tabela 5.6 com o objetivo de comparar o grau de aproximação do conceito reduzido. Aqui apresentam-se os erros ou diferença de aproximação entre 16 coeficientes de escala simples obtidos da malha reduzida (Msel), e 16 coeficientes de escala simples mas, obtidos da malha completa (10000 pontos).

A figura 5.6 mostra também, comparativamente, estes resultados. 
Tabela 5.6. Valores da aproximação reduzida para a função de distribuição, FDCfmCA*, considerando uma escala $\hat{j}_{s}=3$. (mostran-se 16 pontos da curva)

\begin{tabular}{|c|c|c|}
\hline $\begin{array}{c}\hat{F}(\xi)^{*} \\
\text { função de distribuição }\end{array}$ & $\begin{array}{c}F^{r}(\xi) \\
\text { função aproximada reduzida }\end{array}$ & $\begin{array}{c}d(\xi)=\hat{F}(\xi)^{*}-F^{r}(\xi) \\
\text { (diferença da aproximação reduzida) }\end{array}$ \\
\hline 1.3148 & 1.3352 & -0.0204 \\
1.4463 & 1.4730 & -0.0267 \\
1.6146 & 1.6420 & -0.0274 \\
1.7759 & 1.8014 & -0.0255 \\
1.8116 & 1.7814 & 0.0302 \\
1.4507 & 1.4205 & 0.0302 \\
1.2628 & 1.2421 & 0.0207 \\
1.1092 & 1.0790 & 0.0302 \\
0.9194 & 0.8963 & 0.0231 \\
0.8225 & 0.8060 & 0.0165 \\
0.7272 & 0.7071 & 0.0201 \\
0.6217 & 0.6026 & 0.0191 \\
0.5227 & 0.5057 & 0.0170 \\
0.4377 & 0.4235 & 0.0142 \\
0.3672 & 0.3556 & 0.0116 \\
0.3092 & 0.2996 & 0.0096 \\
\hline
\end{tabular}

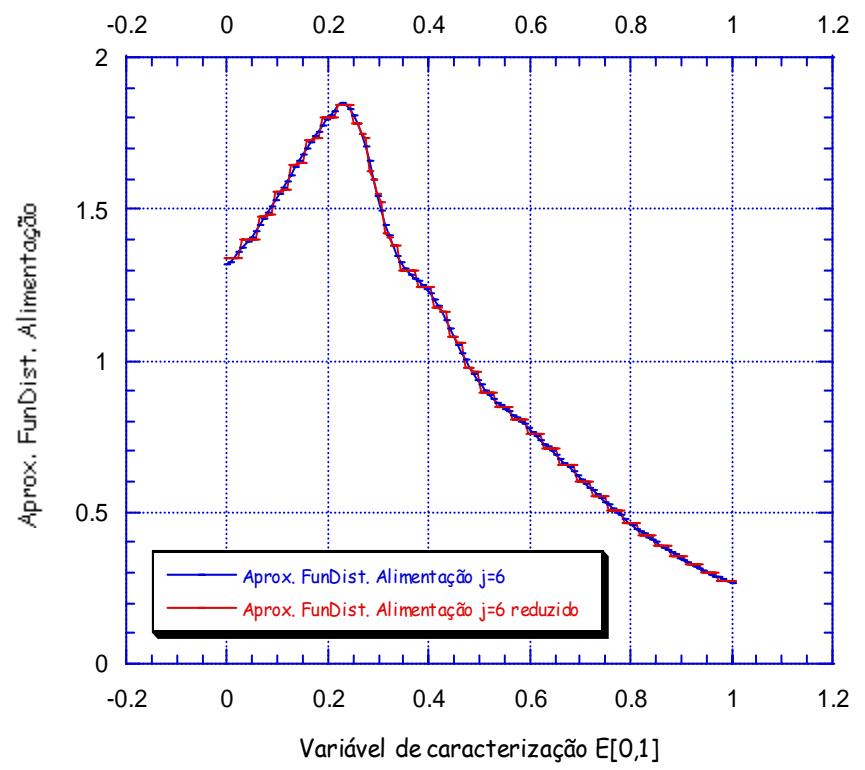

Figura 5.6: Função de distribuição da corrente de alimentação vs. variável de caracterização $\xi$. Comparação dos resultados da aproximação reduzida, a uma escala $\hat{j}_{s}=3$, com a aproximação de referência, $\hat{j}_{s}=6$.

Nos itens seguintes este conceito de aproximaçaõ reduzida forma parte das análises na programação do algoritmo proposto neste trabalho. 


\subsubsection{Formulação contínua das equações do modelo do separador flash}

A modo de ilustrar o separador flash incluindo a representação da composição com as funções de distribuição contínua apresenta-se a figura seguinte:

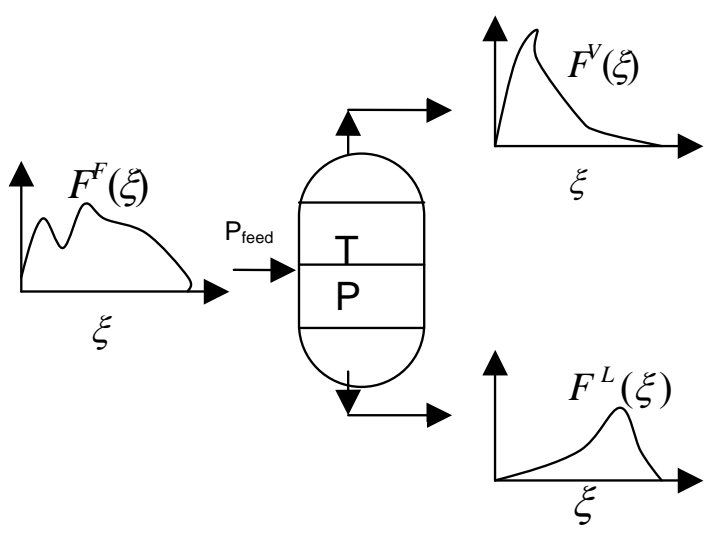

Figura 5.7. Esquema do separador flash representando as composições das correntes com funções de distribuição contínua

As equações do modelo proposto, onde as composições das correntes são descritas através das funções de distribuição, estão apresentados a seguir:

$\begin{array}{llll}\text { Balanço de material } & : & P_{\text {feed }} F_{i}{ }^{F}(\xi)-V F_{i}^{V}(\xi)-L F_{i}{ }^{L}(\xi)=0 \\ \text { Equilíbrio de fases } & : & F_{i}^{V}(\xi)-K\left[F_{i}{ }^{F}(\xi), F_{i}{ }^{L}(\xi), T, p\right] F_{i}{ }^{L}(\xi)=0 \\ \text { Fator de vaporização } & : & \alpha P_{\text {feed }}-V=0 \\ \text { Condição de fechamento } & : & \int_{0}^{1} F_{i}{ }^{V}(\xi) d \xi-1=0 \\ \text { Balanço global } & : & P_{\text {feed }}-V-L=0\end{array}$

onde:

$P_{\text {feed }}, V, L=$ correntes de a limentação e produtos vapor e líquido

$F_{i}(\xi)=$ função de distribuição do componente $i$

$\alpha=$ fator de vaporização

considerando-se as condições de operação de flash com pressão e $\alpha$ especificados, as únicas equações consideradas para a simulação são 5.8, 5.9 e 5.11 
$\mathrm{Na}$ aproximação das funções de distribuição dos produtos do separador flash é utilizada, também, a wavelet, similarmente ao procedimento descrito no item 4.2, eq. 5.5 e 5.6. Pois, como já for dito, as bases wavelet permitem tratar a informação de forma mais simples devido à compressão dos dados, além de introduzir as propriedades das técnicas multi-escala.

As metodologias mais usuais passam pela utilização da wavelet de Haar (ver item 4.2.). Assim, as equações do modelo representadas com as bases wavelets são:

Balanço de material : :

$P_{\text {feed }}\left(d_{j, k}^{\text {aproxT }} . \Psi_{j, k}\right)^{F}-V\left(d_{j, k}^{\text {aproxT }} . \Psi_{j, k}\right)^{V}-L\left(d_{j, k}^{\text {aprox } T} . \Psi_{j, k}\right)^{L}=0$

Equilíbrio de fases :

$\left(d_{j, k}^{\text {aproxT }} . \Psi_{j, k}\right)^{V}-\left(d_{j, k}^{\text {aprox } T} . \Psi_{j, k}\right)^{K} \cdot\left(d_{j, k}^{\text {aprox } T} . \Psi_{j, k}\right)^{L}=0$

Condição de fechamento :

$\int_{0}^{1}\left(d_{j, k}^{\text {aproxT }} . \Psi_{j, k}\right)^{V} d \xi-1=0$

\subsubsection{Discretização das equações do modelo flash}

Para estabelecer o esquema de discretização são definidos e construídos os espaços de aproximação (em multi-escala ou escala simples). As funções base destes espaços, são precisamente as wavelets de Haar que também são utilizadas como as funções de projeção para o esquema de discretização, por isso ela é nomeada discretização Wavelet-Galerkin. Este esquema tem a vantagem de simplificar a complexidade de um sistema de equações facilitando sua resolução. Além de permitir que seja especificado um critério de erro e com a possibilidade de introduzir técnicas adaptativas, fatos que não ocorrem no método de pseudocomponentes.

O sistema gerado após a discretização sobre as equações 5.8a, 5.9a e 5.11a, corresponde a um sistema de equações algébricas, não lineares, que podem ser resolvidas por um método tipo Newton, e são as seguintes:

A representação resumida das equações discretizadas, 5.13 até 5.15, é como segue: 
Balanço de material
$P_{\text {feed }} d_{j, k}{ }^{F}-V d_{j, k}{ }^{V}-L d_{j, k}{ }^{L}=0 \longrightarrow f\left(d_{j, k}, X, p\right)=0$

Equilíbrio de fase :

$d_{j, k}{ }^{V}-d_{j, k}{ }^{E L V}=0 \longrightarrow f\left(d_{j, k}, X, p\right)=0$

Condição de fechamento :

$d_{-1,0}^{V}-1=0 \longrightarrow g\left(O\left[d_{j, k}\right], X, p\right)=0 \quad$ ou

$\int_{0}^{1}\left(d_{j, k}^{\text {aproxT }}\right)^{V} d \xi-1=0$

onde:

$L=$ operador nãolinear

$d_{i}=$ coeficiente wavelet

$X, p=$ variáveis e parâmetros do processo

$g=$ operador que estabelece condições iniciais nos contornos

$O\left[F_{i}(\xi)\right]=$ operador que resulta emum vetor de valores escalares

A representação residual das equações discretizadas descreve-se como segue:

$\left(\begin{array}{l}\left\langle L\left(F_{Z}(\xi), X_{Z}, p\right), \Psi\right\rangle \\ g\left\{O\left[F_{Z}(\xi)\right], X_{Z}, p\right\}\end{array}\right)=\left(\begin{array}{l}\tilde{f}\left(d_{Z}, X_{Z}, p\right) \\ \tilde{g}\left(d_{Z}, X_{Z}, p\right)\end{array}\right)$

onde:

$F_{Z}(\xi)$ : aproximaçã o da função de distribuiç ão int ermediária

$X_{Z}$ : estado int ermediário das variáveis

$p$ : parâmetros

$\Psi$ : função base wavelet

$\tilde{f}, \tilde{g}$ : operadores não lineares

O coeficiente wavelet “ $d_{i}{ }^{E L V}$ ”, representa o produto das funções de distribuição da constante de equilíbrio e da distribuição da fase líquida, é tratado de maneira especial. Pois, este não é um produto vetorial simples, como pode-se observar na sua representação pela equação 5.14. No apêndice é descrito com detalhe o tratamento desta variável. 


\subsection{Desenvolvimento do Algoritmo Proposto}

O algoritmo proposto utiliza três técnicas matemáticas:

- aproximação numérica

- técnica multi-escala

- técnica de adaptação de malhas

Estas ferramentas são consideradas eficientes na determinação dos objetivos da proposta de melhor aproximação, devido à sua simplicidade e seu rigor, tanto matemática, quanto de cálculo.

O algoritmo proposto por Briesen e Marquardt (2003), abordado neste trabalho, apresenta seis etapas principais, os detalhes de cada uma delas são descritas a seguir. Algumas modificações foram introduzidas na abordagem permitindo melhor desempenho e eficiência do algoritmo. Além disto um outro objetivo destas variações foi aproveitar a flexibilidade das ferramentas matemáticas e computacionais atuais.

Antes de passar à descrição detalhada do algoritmo, este é apresentado de forma sucinta a seguir:

Etapa 1. Seleção de um valor inicial razoável para as funções e variáveis de estado $\left(F_{i}^{V / L}(\xi)\right.$ e temperatura respectivamente) em uma uma malha completa $\Lambda^{(*)}$ (para obter este valor inicial utiliza-se uma escala menor à escala de referência js, que é chamada escala reduzida ${ }^{(*)}$ ), além de se escolher uma malha de discretização em escala reduzida, que é chamada de malha reduzida $\Lambda^{r(\star \star *)}$. Aqui o valor incial foi selecionado para uma escala $j=2$ (8 funções base ou 8 intervalos para a discretização), com estes valores continua-se para as etapas seguintes.

\footnotetext{
(*) Neste trabalho, chama-se malha completa $\Lambda$, no contexto da análise wavelet, ao conjunto de pontos, espaços ou séries geradas para a discretização pela maior escala, (na análise wavelet cada escala j, gera $2^{\mathrm{j}+1}$ funções bases, assim, em particular para js $=6$ geram-se 128 pontos para a discretização).

(**) Neste trabalho, chama-se escala reduzida a qualquer valor de $\mathrm{j}<\mathrm{js}(\mathrm{j}=1,2,3,4,5)$.

${ }_{(\star \star \star)}$ Neste trabalho, chama-se malha reduzida $\Lambda^{r}$ a qualquer quantidade de pontos $<128$, e malha reduzida completa é a quantidade de pontos $\left(2^{\mathrm{j}+1}\right)$ obtidas estritamente para algum $\mathrm{j}$ fixo.
} 
Etapa 2. Sobre a malha reduzida $\Lambda^{r}$ escolhida, as equações do modelo são discretizadas com o método wavelet-Galerkin para achar uma primeira aproximação das distribuições do líquido e do vapor.

Etapa 3. As equações do modelo, não lineares, discretizadas na etapa 2 são resolvidas através do método de Newton Raphson.

Etapa 4. Desenvolve-se um processo adaptativo, no qual considera-se um critério do erro das aproximações, em cada iteração do algoritmo, e uma seleção de pontos da malha completa para criar uma malha adaptada. Se a aproximação convergir, segundo o critério de erro, segue-se à etapa 5 para representar os resultados finais. Caso contrario continua-se na etapa 6.

Etapa 5. Através do conceito de resolução multipla wavelets, os coeficientes de aproximação multi-escala, obtidos na etapa 4, são convertidos a coeficientes na escala simples para a representação das distribuições, aproximadas, do líquido e vapor em malha completa.

Etapa 6. Retorna-se ao algoritmo, a partir da etapa 2, considerando a malha adaptada, obtida na etapa 4 , como malha reduzida.

\subsubsection{Passos do algoritmo proposto para a simulação do processo}

\section{Passo 1: Inicializar}

O algoritmo começa fornecendo valores iniciais à função de estado (função de aproximação das distribuições do líquido e vapor), $F_{0}(\xi)$, em termos dos coeficientes de distribuição multi-escala, $\mathbf{d}_{0}\left(\right.$ Fdliq $\left._{0}, \mathbf{F d v a p}_{0}\right)$, e também para as variáveis de estado $\mathbf{X}_{0}$ (neste caso, temperatura $\mathbf{T}_{\mathbf{0}}$ ). Para isso, escolheu-se previamente uma malha reduzida, $\Lambda^{r}$, estabelecendo-se uma quantidade de funções base para uma aproximação inicial $\mathbf{d}_{0 Z}$. 
Na escala reduzida $j=2$ obtem-se uma malha reduzida completa $\Lambda^{r}$ com 8 funções bases, logo, esta $\Lambda^{r}$ é escolhida como a primeira malha reduzida para inicio das iterações do algoritmo. Então, consideram-se como valores iniciais de Fdliq $_{0}$ e Fdvap $_{0}$ os 8 primeros coeficientes multi-escala extraidos da aproximação da distribuição da alimentação do flash na malha completa $\Lambda$.

\section{Passo 2: Discretizar}

A discretização das equações do modelo do flash é feita sobre a malha reduzida $\Lambda^{r}$, logo, os coeficientes Fdliq e Fdvap são calculados para esta malha. Em uma primeira iteração adota-se como malha reduzida $\Lambda^{r}$ a malha completa gerada pela escala de aproximação inicial $j=2$ (com 8 funções base).

\section{Passo 3: Resolver}

O método de Newton Raphson resolve o sistema de equações não lineares geradas no passo 2 para obter os valores de Fdliq, Fdvap e $X_{Z}$ (temperatura do processo flash).

\section{Passo 4: Verificar}

Um esquema de adaptação é implementado com o objetivo de melhorar a aproximação dos resultados de Fdliq, Fdvap e $X_{Z}$. Para isso, adota-se um critério de erro para verificar a convergência dos resultados segundo o esquema de adaptação. Este esquema é aplicado sobre cada uma das equações do modelo em que se aplica a discretização (equações do balanço de material e do equilibrio L-V). Este esquema leva à seleção de novos pontos para as malhas a cada iteração do algoritmo correspondendo uma estratégia de adaptação.

A seleção da malha e o critério do erro segundo a estratégia de adaptação são descritos nos seguintes passos:

p.4.1 Primeiro, obtém-se a medida do erro das aproximações intermediárias, para isso, avaliam-se os resíduos $\delta d_{(j, k)}$, das equações do balanço de material 
e de equilibrio líquido-vapor, para cada coeficiente da malha completa (que não foram utilizados na obtenção das aproximações), e calcula-se a norma $L_{2}$ dos mesmos $\left(R R i=\sqrt{\sum_{1}^{n}\left|\delta \mathbf{d}_{i}\right|^{2}}\right)$ obtendo-se RR1 (para equação de balanço de material) e RR2 (equação de equilibrio L-V). Logo, esses erros residuais são multiplicados por um fator de peso FPi (escolhido segundo o tipo de problema; para o flash o fator de peso $F P 1=1$ é adotado para o balanço material e $F P 2=1 / P_{\text {feed }}$ para o equilibrio L-V), estes dois critérios $F P 1 x R R 1$ e FP2xRR2 são comparados com uma tolerância, Etol, que se estabelece arbitrariamente (ver tabela 5.7). Se FP1xRR1<Etol e FP2xRR2<Etol considera-se que o algoritmo convergiu, então a aproximação intermediária é a solução final, caso contrário, continua-se à etapa seguinte.

p.4.2 Adota-se uma estratégia de adaptação, de acordo com os seguintes passos:

- Chama-se $\Lambda^{r, a d}$ à malha adaptada e $m 1$ e $m 2$ ao número de novas funções base selecionadas a cada iteração do algoritmo (por cada tipo de equação, $m 1$ para as equações de balanço de material e $m 2$ para as de equilíbrio L-V). A inicialização destes parâmetros no algoritmo de adapatação de malha é dado por:

$$
\Lambda_{i}^{r, a d}=\{\quad \quad \text { e } \quad m 1=0 ; m 2=0
$$

- Selecionam-se os componentes do vetor de resíduos, $\delta d_{\left(j^{*}, k^{*}\right)}$, que contribuem de maneira mais significativa à norma do erro através de:

$$
\left(\delta d_{\left(j^{*}, k^{*}\right)}\right)^{2}=\max \left\{\operatorname{diag}\left(\delta \mathbf{d}_{i}\right) \cdot \delta \mathbf{d}_{i}\right\}^{2}
$$

onde $\left(j^{*}, k^{*}\right)$ é o índice correspondente à posição do elemento do vetor de resíduos selecionado, que é diferente de $(j, k)$ (o índice $(j, k) \in \Lambda$, malha completa, e são selecionados em cada iteração do 
algoritmo, isto significa que cada índice que forma parte dos valores iniciais (etapa 1) e daqueles que estão sendo selecionados em cada iteração, já não serão parte de estes índices $(j, k)$ na seguinte iteração.

- A função base correspondente à posição selecionada $\left(j^{*}, k^{*}\right)$ é utilizada na iteração seguinte, e o resíduo correspondente a esta mesma posição toma o valor de zero, assim, na seguinte avaliação do residual, este não terá mais efeito sobre o erro, de tal forma que se poderia continuar selecionando outras posições $\left(j^{*}, k^{*}\right)$ nas iterações seguintes até atingir a condição de $\bar{\varepsilon}_{i} \times F P i<$ Etol, no entanto, limitase o número de iterações a um valor máximo de $M_{\max }$. E as novas funções base são acrescidas à malha.

Onde:

$$
\bar{\varepsilon}_{i}=\sqrt{\left\|\delta \mathbf{d}_{i}\right\|_{L_{2}}^{2}-\left(\delta d_{i,\left(j^{*}, k^{*}\right)}\right)^{2}} \quad ; \quad R R i:=\bar{\varepsilon}_{i}
$$

e antes de continuar a seleção das posições $\left(j^{*}, k^{*}\right)$ adota-se:

$$
\left(\delta d_{i,\left(j^{*}, k^{*}\right)}\right)=0
$$

- Finalmente, os coeficientes de discretização e o número de funções base $m 1$ e $m 2$ usadas são atualizados.

$$
\Lambda_{i}^{r, a d}:=\Lambda_{i}^{r, a d} \cup\left\{\left(j^{*}, k^{*}\right)\right\} \quad \text { e } \quad m_{i}:=m_{i}+1
$$

Isto é necessário para prevenir a seleção de um grande número de funções base, o que pode originar um mal desempenho. Se o erro estimado em cada iteração $\bar{\varepsilon}_{i} \times F P i>E t o l$ e o número de funções base $m_{i}<M_{\max }$ volta-se à seleção dos componentes do vetor resíduo, (p.4.2), caso contrário segue-se para a etapa seguinte (p.4.3). 
p.4.3 A próxima etapa, após a implementação da estratégia de adaptação, consiste em fazer um pós-processamento dos índices dos coeficientes adaptados $\left(j^{*}, k^{*}\right)$ para o problema específico. No caso de estudo o método é aplicado às equações de balanço de material e de equilíbrio L-V do modelo flash. Nesta etapa combina-se os índices das funções de base, adaptadas a cada iteração e, ao mesmo tempo, atualizam-se para dar início à próxima iteração.

$$
\Psi_{Z+1, i}^{r}:=\left(\ldots . ., \psi_{j, k} \ldots . .\right) \quad(j, k) \in \Lambda_{i}^{r, a d} \quad \Lambda^{r, a d}=\Lambda^{r} \cup \Lambda_{1}^{r, a d} \cup \Lambda_{2}^{r, a d}
$$

p.4.4 Como última etapa, atualiza-se a série reduzida das funções de projeção de acordo com a $\Lambda_{Z+1}^{r}=\Lambda^{r, a d}$, que agora é a nova malha para a iteração seguinte.

\section{Passo 5: Interpolar}

A interpolação dos coeficientes de distribuição $d_{z}^{r}$ (Fdliq e Fdvap ) a partir da malha reduzida para uma malha completa (para obter $d_{Z}$ ) é feita através da reconstrução da distribuição a partir destes coeficientes $d_{Z}^{r}$ e a decomposição dos mesmos, mas em malha completa. Em termos mais claros, neste procedimento introduzem-se todos os coeficientes multi-escala da malha completa $d_{j, k}$, e consideram-se nulos aqueles que não fazem parte da malha adaptada.

\section{Passo 6: Reinicializar}

Finalmente, atualizam-se as variáveis de estado $X_{Z+1}=X^{\text {int }}$ (temperatura do processo flash) e com a nova aproximação, obtida para a malha adaptada, volta-se ao passo 2 e seguem-se as iterações até a convergência da aproximação intermediária segundo o critério de $\bar{\varepsilon}_{i} \times \mathrm{FPi}>$ Etol seja atingido, quando o algoritmo finaliza.

A figura 5.8 mostra um esquema do algoritmo. 


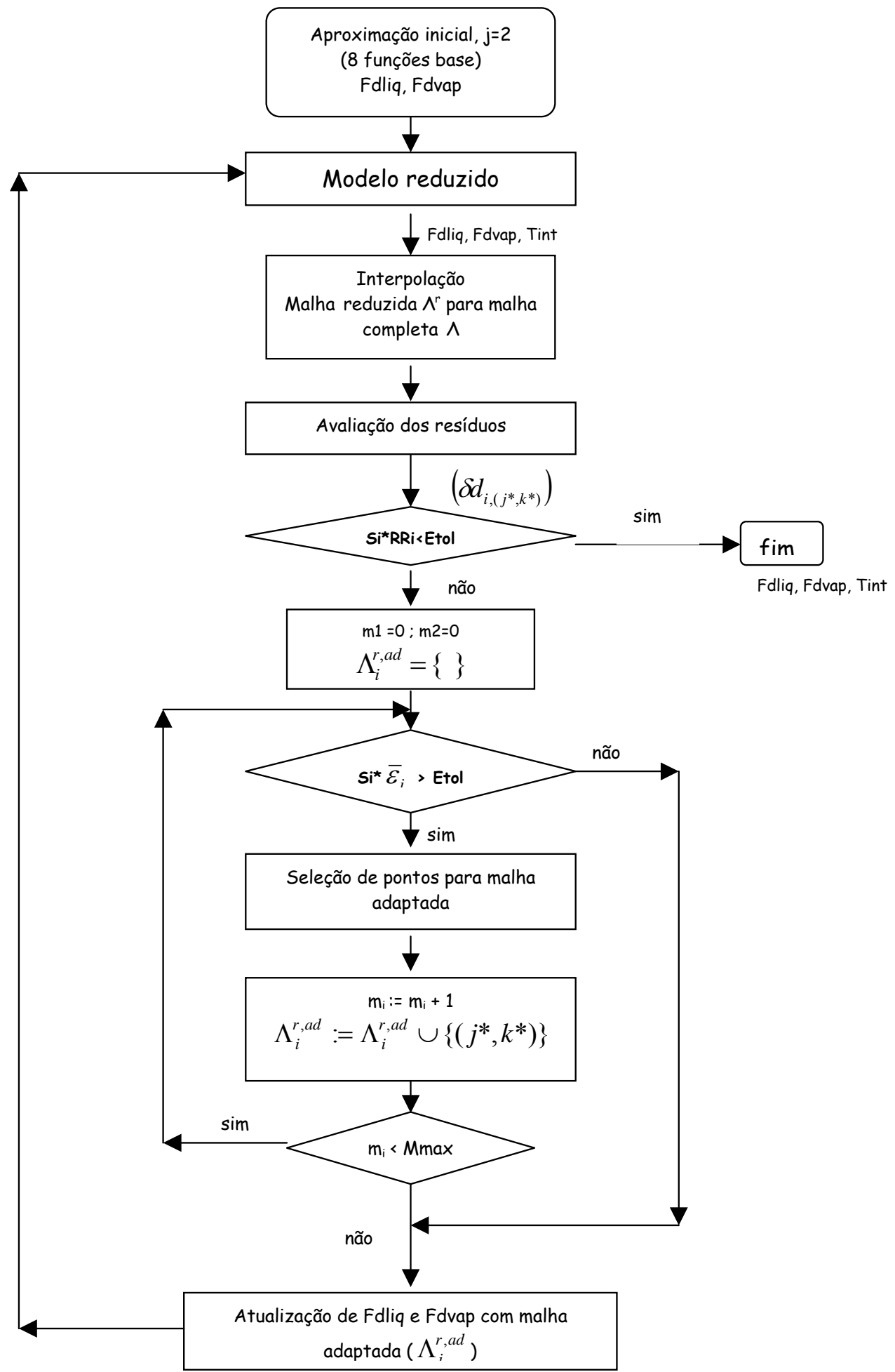

Figura 5.8. Esquema do algoritmo multi-malha adaptativo. 


\subsection{Simulação do modelo do separador Flash}

Simulações baseadas na metodologia de representação contínua das misturas e a solução do modelo baseada na discretização wavelet-Galerkin são apresentadas. $\mathrm{Na}$ primeira parte não é incluido o algoritmo de seleção adaptativa de malhas. $\mathrm{Na}$ segunda parte a seleção de malhas é considerada. Uma simulação com o simulador comercial HYSYS v. 2.1, que utiliza o método de representação por pseudocomponentes foi realizada para comparação. A princípio, a comparação entre o resultado das duas primeiras simulações tem como objetivo verificar a eficiência do algoritmo em relação ao custo computacional e à precisão. A comparação entre os resultados das duas primeiras partes com a terceira, permite verificar a eficiência de aproximação e a representação entre as duas metodologias, wavelet-Galerkin com e sem adaptação de malhas e o de pseudocomponentes.

As simulações apresentadas utilizam os parâmetros definidos na tabela 5.7.

Tabela 5.7. Parâmetros considerados nas simulações

\begin{tabular}{|c|c|}
\hline & Parâmetros \\
\hline $\begin{array}{l}\text { Dados } \\
\text { físicos } \\
\text { de } \\
\text { entrada }\end{array}$ & $\begin{array}{l}\text { T0 }=300 \text { kelvin (temperatura de alimentação) } \\
\mathbf{p}=1 \text { bar, pressão de alimentação e de processo } \\
\alpha=\operatorname{VIF}\{0.5,0.05,0.1,0.9,0.95\} \text { (fator de vaporização, relação entre fluxo de vapor e alimentação) }\end{array}$ \\
\hline $\begin{array}{l}\text { Dados } \\
\text { de } \\
\text { entrada }\end{array}$ & 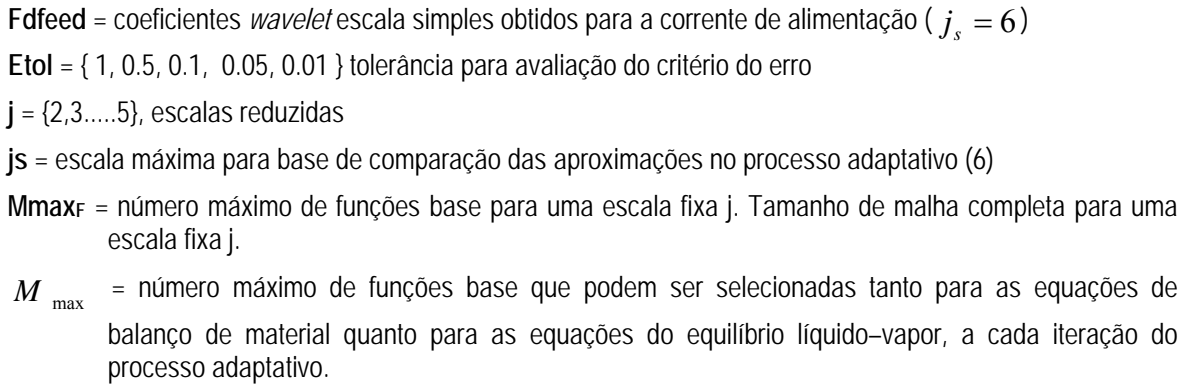 \\
\hline $\begin{array}{l}\text { Dados } \\
\text { de saída }\end{array}$ & $\begin{array}{l}\text { Iter = número de iterações do algoritmo adaptativo } \\
\text { Fdliq = Coeficientes wavelet de aproximação multi-escala da fase líquida. } \\
\text { Fdvap = Coeficientes wavelet de aproximação multi-escala da fase vapor. } \\
\text { Tint = temperatura do processo }(\mathrm{K}) \\
\text { RR1 = erro residual das equações de balanço de material } \\
\text { RR2 = erro residual das equações de equilíbrio líquido-vapor } \\
\text { Tempo = tempo de simulação do algoritmo (seg) } \\
\text { Msel = número total de funções base utilizadas para a representação do modelo adaptado. (Msel = todas as } \\
\quad \text { funções base da aproximação inicial + funções base selecionadas a cada iteração) }\end{array}$ \\
\hline
\end{tabular}




\subsubsection{Método wavelet-Galerkin com escalas fixas $j=1,2,3$ e 6}

Nesta simulação com escalas fixas cinco aspectos foram avaliados. O primeiro são as aproximações das funções de distribuição das fases líquido e vapor. Testados a várias escalas fixas $j=1,2,3 e 6$. Pode-se verificar a qualidade da aproximação da escala $\hat{j}_{s}=3$ em relação à aproximação da escala de referencia $\hat{j}_{s}=6$, através dos resultados qualitativos desta aproximação mostrados na figura 5.9. Estes resultados foram obtidos para um $\alpha=0.5$.

(a)

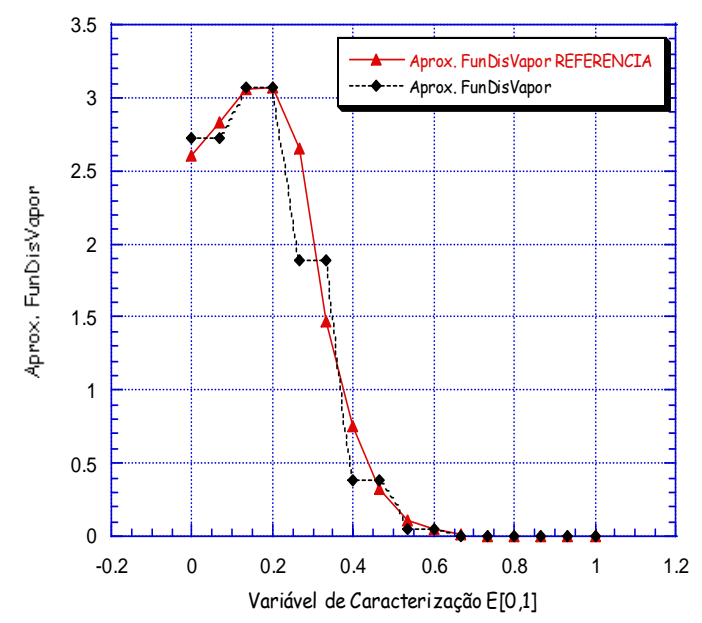

(b)

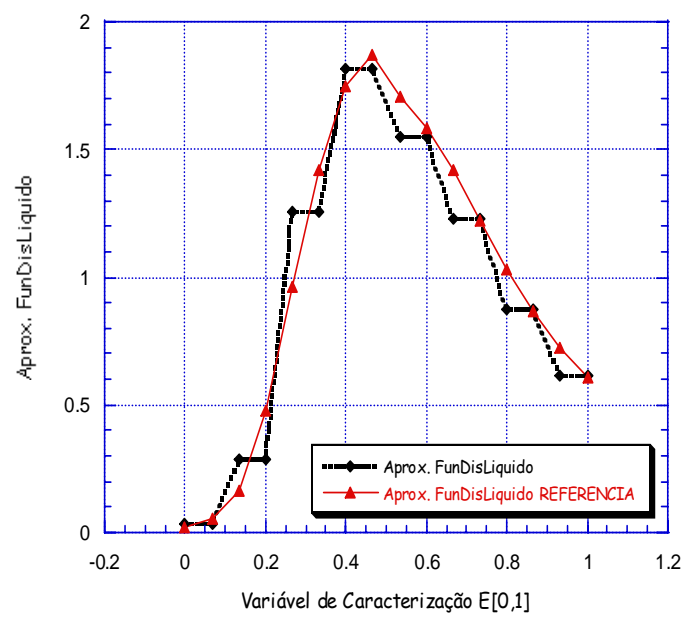

Figura 5.9. Aproximação das funções de distribuição nas escalas $\hat{j}_{s}=3 \quad e \quad 6 \cdot v s$. $\xi$ Para $\alpha=0.5$. (a) Distribuição de vapor. (b) Distribuição de líquido.

Na figura 5.9 nota-se uma aproximação grosseira das distribuições na escala $\hat{j}_{s}=3$, com 8 funções base. Embora, esta aproximação mantém uma correlação com a aproximação de referência (escala $\hat{j}_{s}=6$ ), a comparação entre a qualidade da representação das distribuições, obtidas nas duas escalas, permite deduzir uma representação com poucos detalhes nas baixas escalas.

O segundo e o terceiro aspectos avaliados foram os tempos de simulação e os erros residuais de aproximação das equações do modelo para cada escala fixa $\hat{j}_{s}=2,3,4,5$ e 6 . Para avaliar os erros considerou-se como referência de 
comparação a aproximação obtida na escala $\hat{j}_{s}=6$. Para ilustrar esta avaliação, trabalhou-se com $\alpha=0.5$. Os resultados são apresentados na tabela 5.8 e na figura 5.10 .

Tabela 5.8. Tempos da simulação e erros ponderados de aproximação das equações do modelo obtidos para cada escala fixa $\hat{j}_{s}=2,3,4$ e 5 em relação a escala de referência $\hat{j}_{s}=6$ para $\alpha=0.5$.

\begin{tabular}{|c|c|c|c|c|}
\hline Parâmetros & \multicolumn{4}{|c|}{$\alpha=0.5$} \\
\hline$\hat{j}_{s}$ & Mmax $_{F}$ & $\begin{array}{c}\text { Tempo } \\
\text { (seg) }\end{array}$ & $\begin{array}{c}\text { RR1xFP1 } \\
\text { (Balanço de material) }\end{array}$ & $\begin{array}{c}\text { RR2xFP2 } \\
\text { (Equilibrio L-V) }\end{array}$ \\
\hline 2 & 8 & 3.9531 & 1.0332 & 0.0903 \\
3 & 16 & 7.8125 & 0.4967 & 0.0454 \\
4 & 32 & 11.4375 & 0.2430 & 0.0222 \\
5 & 64 & 18.1719 & 0.1087 & 0.0100 \\
6 & 128 & 33.5313 & 0 & 0 \\
\hline
\end{tabular}

(a)

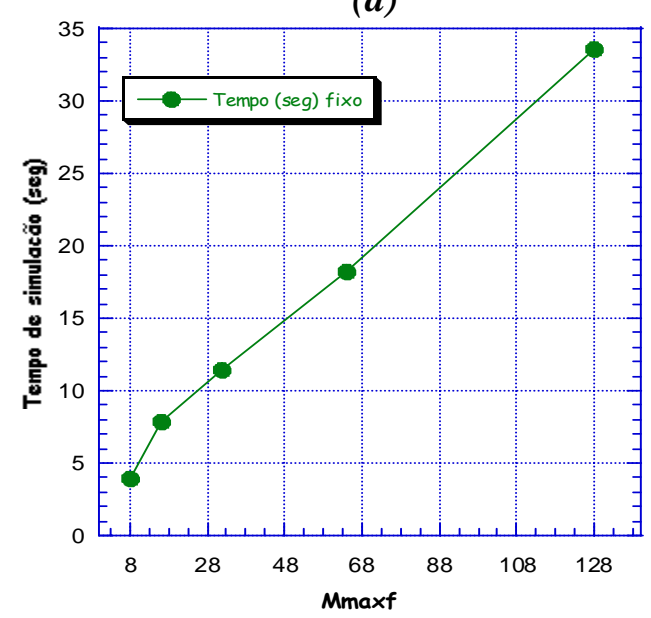

(b)

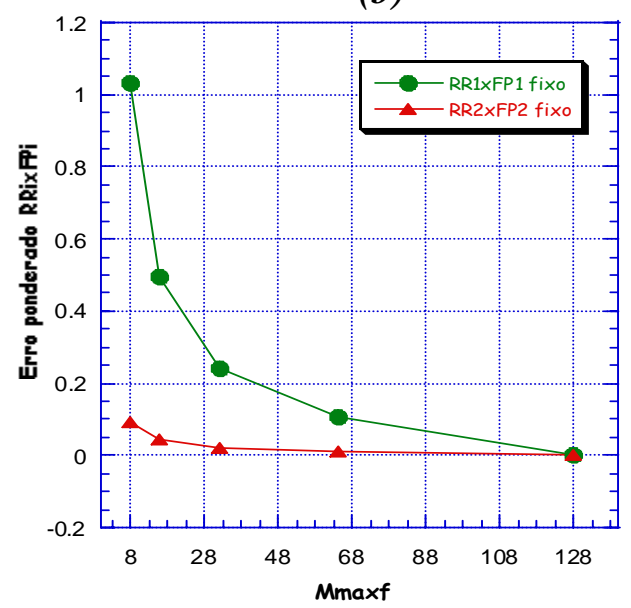

Figura 5.10. Simulação do modelo flash com escalas fixas. (a) Tempos de simulação vs. $\operatorname{Mmax}_{\mathrm{F}}$ (b) Erros ponderados de aproximação das equações do modelo vs. $\operatorname{Mmax}_{\mathrm{F}}$

A análise dos resultados dos tempos de simulação mostrou o seu aumento em relação ao incremento de cada escala fixa $\hat{j}_{s}$. Por outro lado, os resultados dos erros ponderados de aproximação, FP1xRR1 e FP2xRR2, mostraram que nas escalas maiores, a aproximação é melhor se comparada a uma escala de referência. Este fato está relacionado, diretamente, ao número de funções base geradas por cada escala, 
pois, quanto mais funções base utilizadas para a aproximação, esta é considerada com melhor detalhe, porém, o gasto computacional é maior.

O quarto e o quinto aspectos avaliados foram a temperatura do processo e os tempos de simulação para diferentes fatores de vaporização, $\alpha=\{0.05,0.1,0.9,0.95\}$ à escala de referência $\hat{j}_{s}=6$. Nesta escala os erros ponderados de aproximação são zero e a quantidade de funções base utilizadas $\operatorname{Mmax}_{\mathrm{F}}=128$ (ver tabela 5.8). Os resultados, desta avaliação são apresentados na tabela 5.9 e na figura 5.11. Mais adiante os mesmos servem como base de comparação com os resultados das simulações com os métodos wavelet-Galerkin com malhas adaptadas e de pseudocomponentes.

Tabela 5.9. Resultados da simulação do modelo flash em estado estacionario. Método wavelet-Galerkin malha fixa. Temperatura do processo, Tint, e tempo de simulação para $\alpha=\{0.05,0.1,0.9,0.95\}$ à escala $\hat{j}_{s}=6$

\begin{tabular}{|c|c|c|}
\hline Parâmetros & \multicolumn{2}{|c|}{$\hat{j}_{s}=6 ;$ Mmax $_{\mathbf{F}}=\mathbf{1 2 8}$} \\
\hline$\alpha$ & $\begin{array}{c}\text { Tint } \\
\text { (Kelvin) }\end{array}$ & $\begin{array}{c}\text { Tempo } \\
\text { (seg) }\end{array}$ \\
\hline 0.05 & 365.88 & 23.41 \\
0.1 & 377.2 & 23.45 \\
0.5 & 475.08 & 33.69 \\
0.9 & 632.34 & 51.67 \\
0.95 & 659.85 & 82.89 \\
\hline
\end{tabular}

(a)

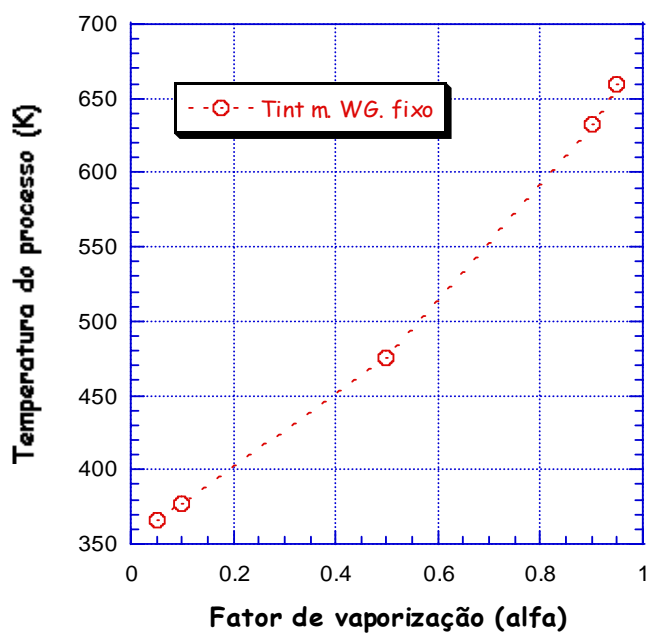

(b)

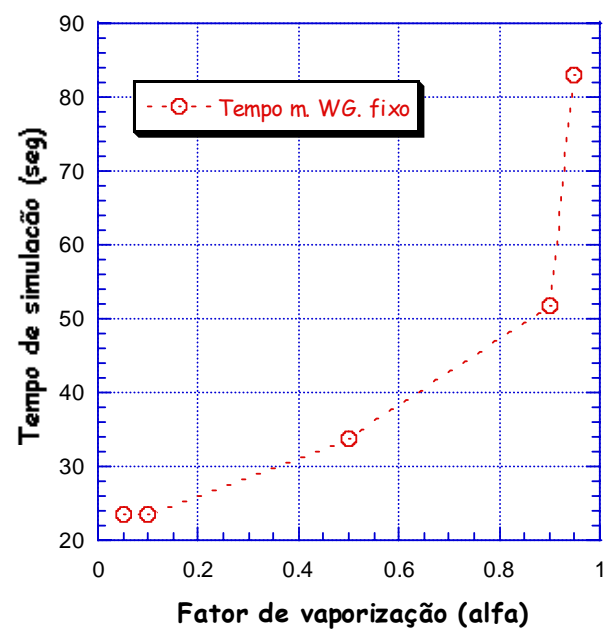

Figura 5.11. Simulação do modelo flash. Método wavelet-Galerkin malha fixa. (a) Temperatura do processo, Tint (K) vs. $\alpha$ (b) Tempos de simulação (seg) vs. $\alpha$ 
Uma análise dos resultados da figura 5.11 (b) permite discutir a importância dos valores iniciais que devem-se considerar para resolver um problema de aproximação. Neste resultado mostra-se como uma boa aproximação inicial pode resolver o problema com menos custo computacional, a explicação fisica deste fato está em que na simulação do processo flash, considerou-se, em todos as simulações para $\alpha=$ $\{0.05,0.1,0.9,0.95\}$, como aproximação inicial a composição da alimentação. Isto significa que para $\alpha$ menores, a composição da corrente de líquido não tem variação significativa, mantendo-se assim próxima à composição da alimentação. Isto não acontece no caso em que $\alpha$ aumenta. Por isso, para $\alpha$ maiores em que a composição do líquido já não está próximo à de alimentação, pode-se notar um aumento significativo no tempo para resolver as equações do modelo flash

\subsubsection{Método wavelet-Galerkin com adaptação de malhas, escalas $\hat{j}_{s}=[2-6]$}

Nestas simulações dois aspectos são analisados. No primeiro consideram-se alguns critérios para verificar a eficiência do algoritmo proposto para este método. Para isso foram construidos dois casos baseados em dois diferentes valores para o parâmetro $M_{\max }$ (8 e 16), e uma escala de inicialização fixa $j=2 \operatorname{com} 8$ funções bases. Foram definidos, também, 5 valores diferentes para o parâmetro Etol a fim de realizar cinco simulações para cada um dos casos (ver detalhes dos parâmetros na tabela 5.7).

Os critérios avaliados são o número total de funções base selecionadas pelo algoritmo Msel, o tempo de simulação, o número de iterações do algoritmo, Iter, a temperatura do processo e os erros ponderados de aproximação das equações do modelo $F P i \times R R i$. Os resultados para os dois casos com o parâmetro $\alpha=0.5$ são apresentados na tabela 5.10 e nas figuras 5.12 e 5.13 . 
Tabela 5.10. Simulação do modelo flash em estado estacionário usando malhas adaptativas. Resultados dos casos 1 e 2 com parâmetro $\alpha=0.5$.

\begin{tabular}{|c|c|c|c|c|c|c|c|}
\hline \multirow{3}{*}{ Parâmetros } & \multicolumn{7}{|c|}{$\boldsymbol{\alpha}=\mathbf{0 . 5}$} \\
\cline { 2 - 8 } & \multicolumn{7}{|c|}{ escala de inicialização $\mathbf{j}=\mathbf{2}$} \\
\cline { 2 - 8 } & Etol & Iter & Tempo & Msel & Tint & FP1*RR1 & FP2*RR2 \\
\hline & 1 & 1 & 7.0 & 9 & 471.38 & 0.810 & 0.086 \\
CASO 1 & 0.5 & 1 & 7.9 & 16 & 474.01 & 0.434 & 0.043 \\
Mmax = 8 & 0.1 & 7 & 22.8 & 64 & 475.00 & 0.087 & 0.011 \\
& 0.05 & 10 & 34.9 & 88 & 475.02 & 0.049 & 0.008 \\
& 0.01 & 13 & 54.6 & 128 & 475.08 & 0.000 & 0.000 \\
\hline & 1 & 1 & 7.1 & 9 & 471.38 & 0.810 & 0.086 \\
CASO 2 & 0.5 & 1 & 8.7 & 24 & 474.48 & 0.281 & 0.029 \\
Mmax = 16 & 0.1 & 4 & 18.1 & 72 & 475.00 & 0.073 & 0.011 \\
& 0.05 & 5 & 22.3 & 88 & 475.02 & 0.049 & 0.008 \\
& 0.01 & 7 & 34.4 & 128 & 475.08 & 0.000 & 0.000 \\
\hline
\end{tabular}

(a)

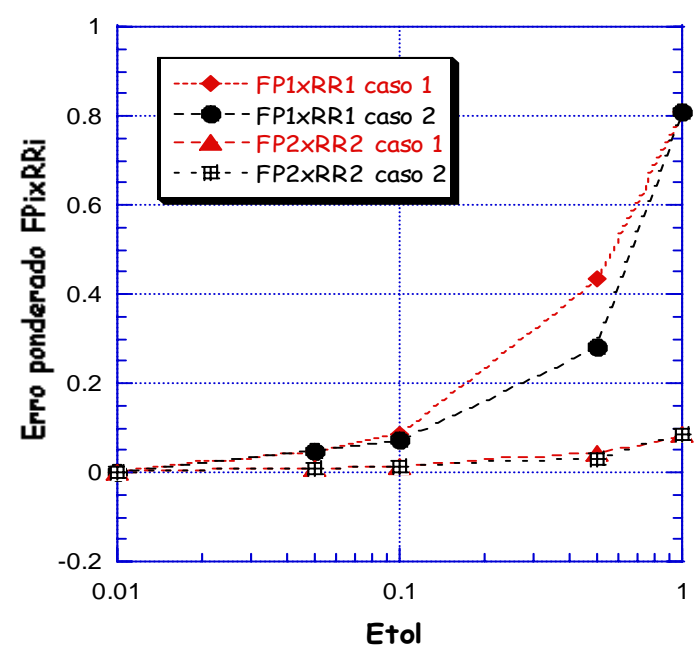

(b)

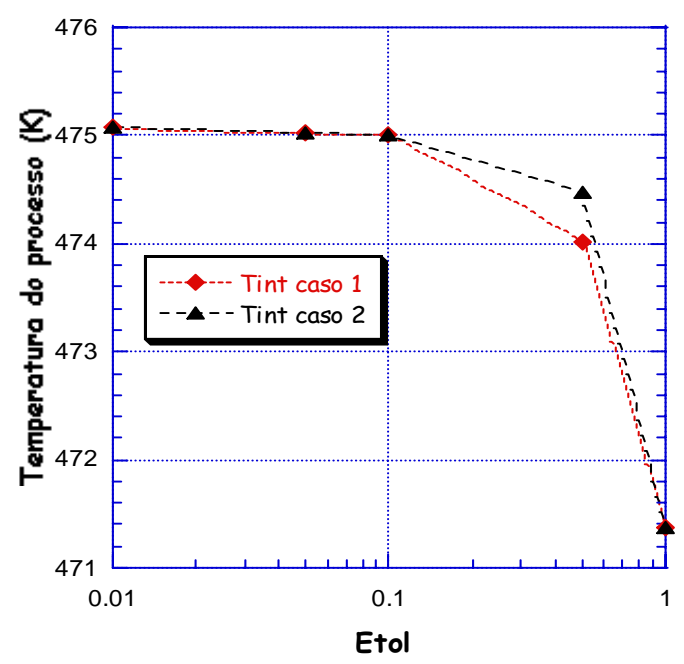

Figura 5.12. Simulação do modelo flash utilizando malhas adaptativas para $\alpha=0.5$. (a) FPi $\times$ RRi vs. Etol (b) Tint. (K) vs. Etol

Pode-se observar nos resultados da figura 5.12 (a) que os erros ponderados das equações do modelo para ambos os casos diminuem em relação direta ao parâmetro Etol, nota-se também, que estes erros ponderados não sufrem variação significativa em relação comparativa entre os casos 1 e 2, e que además, estes definem uma correlação linear com tendencia a zero para valores de Etol $<0.1$. Por outro lado, a figura 5.12 (b) mostra que a aproximação da temperatura do processo Tint, ainda seja a faixa em que é avaliada não muito distante (4 $\mathrm{K}$ aproximadamente), o 
comportamento dela é linear com tendencia a manter-se constante para valores de Etol $<0.1$.

(a)

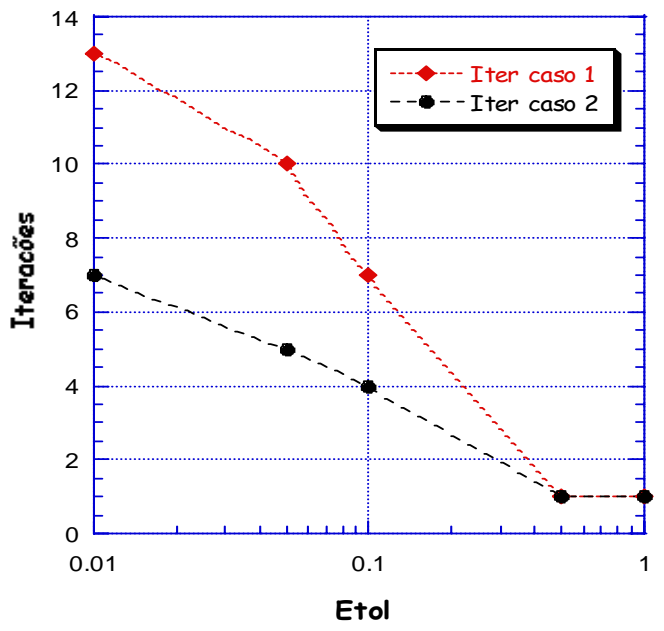

(b)

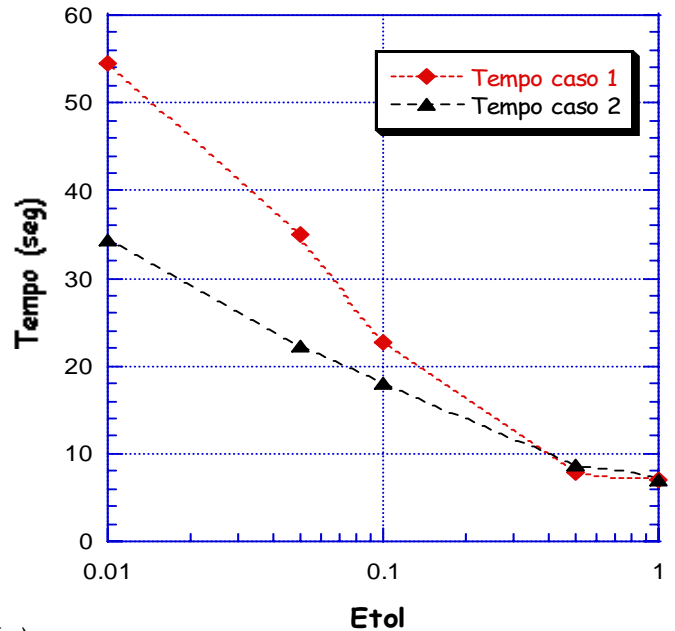

(c)

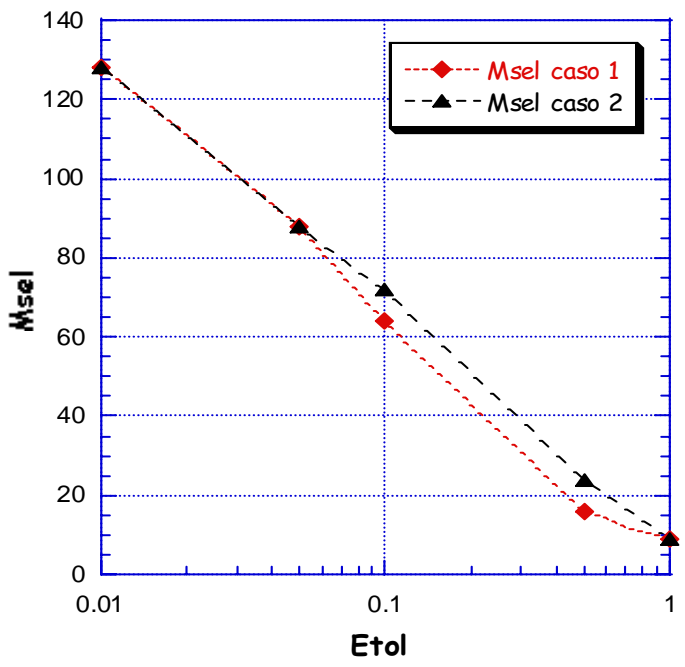

Figura 5.13. Simulação do modelo flash em estado estacionário usando malhas adaptativas. Resultado para os casos 1 e 2 para $\alpha=0.5$ (a) Iterações vs. Etol (b) Tempo vs. Etol (c) Msel vs. Etol

$\mathrm{Na}$ figura 5.13 (a e b) nota-se a relação inversa dos parâmetros Iter e tempo em relação a Etol e, se os casos 1 e 2 são comparados, um caso em relação ao outro, observa-se a diminuição dos valores destes parâmetros. Desta análise pode-se considerar o caso 2 como mais eficiente. No entanto, na figura 5.13 (c) o parâmetro Msel mantém a mesma relação inversa que os parâmetros Iter e tempo em relação a Etol, mas, a comparação dos valores de Msel para os casos 1 e 2 verificam a 
tendencia de ser iguais para ambos casos. Assim, pode-se dizer que a análise feita sobre o parâmetro Msel não permite definir qual dos casos é mais eficiente um em relação ao outro.

Os mesmos critérios que foram avaliados para verificar a eficiência do algoritmo (ver tabela 5.10 e figuras $5.12,5.13)$ também foram avaliados para diferentes valores do parâmetro $\alpha=\{0.05,0.1,0.9,0.95\}$. Os resultados das simulações para estes $\alpha$ diferentes são apresentados nas tabelas 5.11 - 5.14 e nas figuras 5.14 - 5.21.

Tabela 5.11. Simulação do modelo flash em estado estacionário usando malhas adaptativas. Resultados dos casos 1 e 2 com parâmetro $\alpha=0.05$.

\begin{tabular}{|c|c|c|c|c|c|c|c|}
\hline \multirow{3}{*}{ Parâmetros } & \multicolumn{7}{|c|}{$\mathbf{\alpha = 0 . 0 5}$} \\
\cline { 2 - 8 } & \multicolumn{7}{|c|}{ escala de inicialização j = 2 } \\
\cline { 2 - 7 } & Etol & Iter & Tempo & Msel & Tint & FP1*RR1 & FP2*RR2 \\
\hline & 1 & 1 & 5.4 & 9 & 361.14 & 0.810 & 0.178 \\
CASO 1 & 0.5 & 1 & 6.6 & 16 & 364.60 & 0.434 & 0.095 \\
Mmax = 8 & 0.1 & 7 & 22.6 & 64 & 365.82 & 0.087 & 0.021 \\
& 0.05 & 10 & 34.8 & 88 & 365.86 & 0.049 & 0.015 \\
& 0.01 & 14 & 49.5 & 127 & 365.88 & 0.004 & 0.000 \\
\hline & 1 & 1 & 5.3 & 9 & 361.14 & 0.810 & 0.178 \\
CASO 2 & 0.5 & 1 & 7.8 & 24 & 365.57 & 0.281 & 0.048 \\
Mmax = 16 & 0.1 & 4 & 17.9 & 72 & 365.83 & 0.073 & 0.021 \\
& 0.05 & 5 & 22.5 & 88 & 365.86 & 0.049 & 0.015 \\
& 0.01 & 7 & 32.1 & 125 & 365.88 & 0.007 & 0.000 \\
\hline
\end{tabular}

(a)

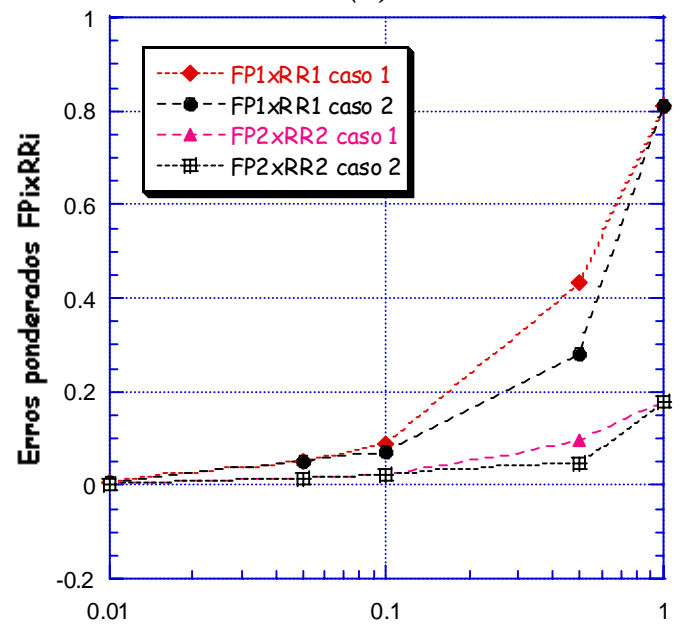

Etol (b)

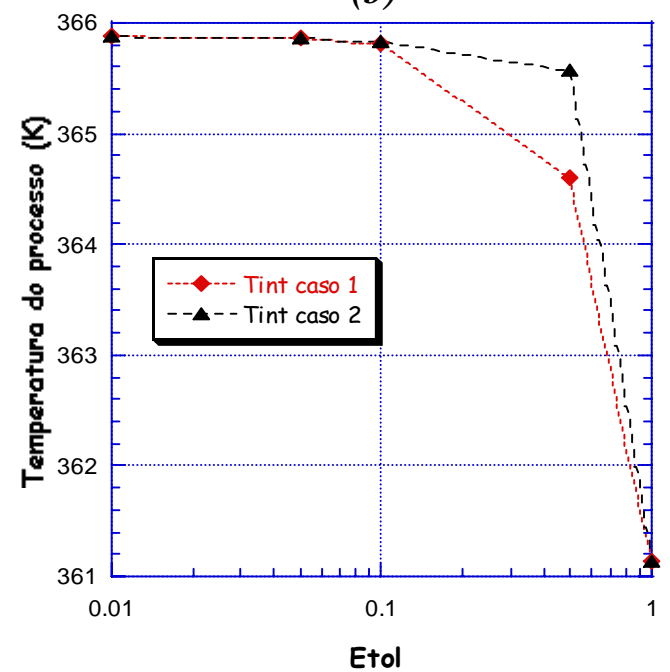

Figura 5.14. Simulação do modelo flash utilizando malhas adaptativas para $\alpha=$ 0.05.(a) FPixRRi vs. Etol (b) Tint. (K) vs. Etol 
(a)

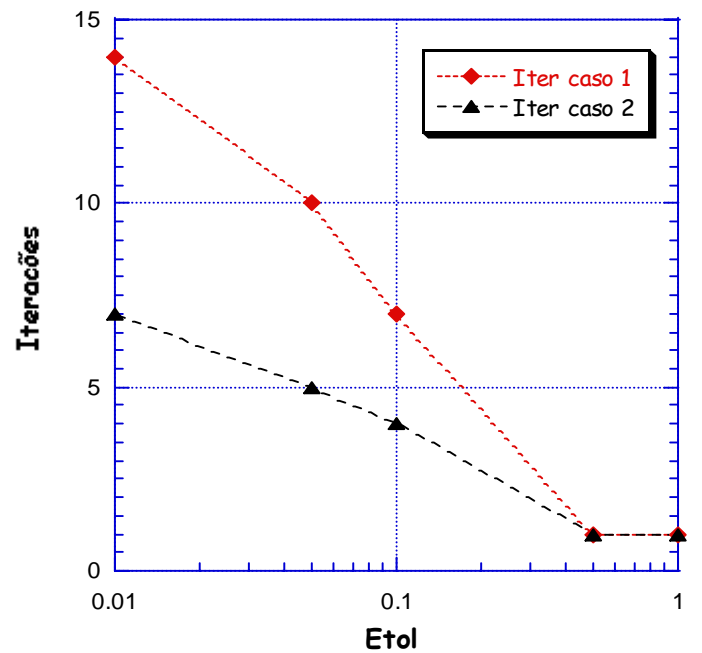

(b)

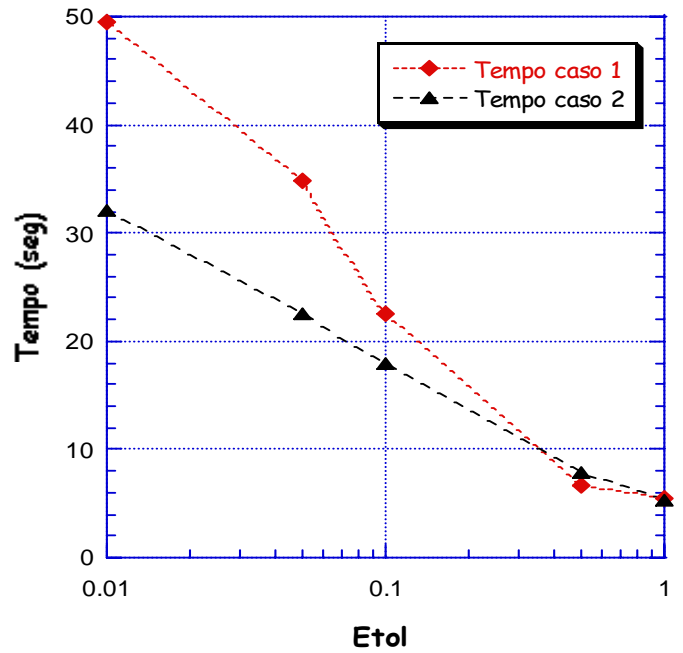

(c)

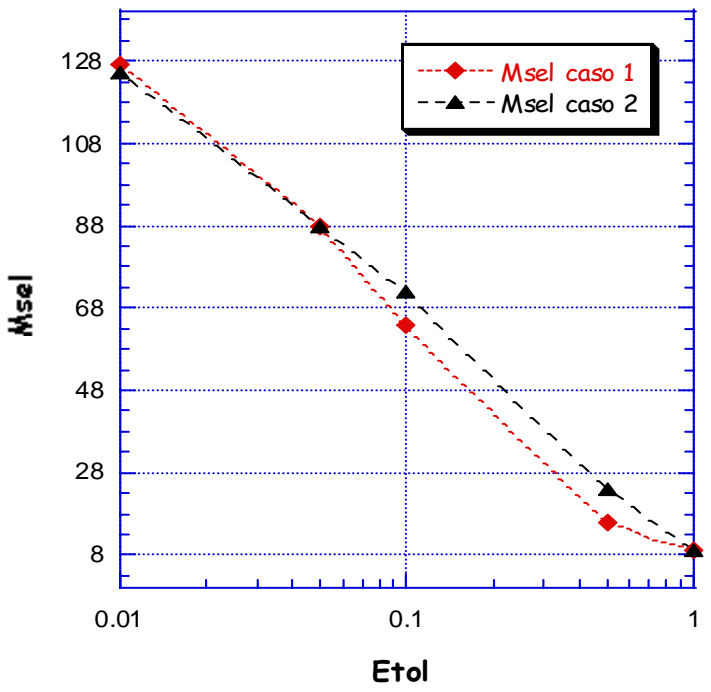

Figura 5.15. Simulação do modelo flash em estado estacionário usando malhas adaptativas. Resultado para os casos 1 e 2 para $\alpha=0.05$ (a) Iterações vs. Etol (b) Tempo vs. Etol (c) Msel vs. Etol 
Tabela 5.12. Simulação do modelo flash em estado estacionário usando malhas adaptativas. Resultados dos casos 1 e 2 com parâmetro $\alpha=0.1$.

\begin{tabular}{|c|c|c|c|c|c|c|c|}
\hline \multirow{3}{*}{ Parâmetros } & \multicolumn{7}{|c|}{$\mathbf{\alpha = \mathbf { 0 . 1 }}$} \\
\cline { 2 - 8 } & \multicolumn{7}{|c|}{ escala de inicialização j = 2 } \\
\cline { 2 - 7 } & Etol & Iter & Tempo & Msel & Tint & FP1*RR1 & FP2*RR2 \\
\hline & 1 & 1 & 5.4 & 9 & 370.43 & 0.810 & 0.166 \\
CASO 1 & 0.5 & 1 & 6.6 & 16 & 375.51 & 0.434 & 0.085 \\
Mmax = 8 & 0.1 & 7 & 21.0 & 64 & 377.11 & 0.087 & 0.019 \\
& 0.05 & 10 & 33.0 & 88 & 377.17 & 0.049 & 0.012 \\
& 0.01 & 14 & 48.8 & 128 & 377.20 & 0.000 & 0.000 \\
\hline & 1 & 1 & 5.5 & 9 & 370.43 & 0.810 & 0.166 \\
CASO 2 & 0.5 & 1 & 7.8 & 24 & 376.77 & 0.281 & 0.042 \\
Mmax = 16 & 0.1 & 4 & 17.8 & 72 & 377.12 & 0.073 & 0.018 \\
& 0.05 & 5 & 22.3 & 88 & 377.17 & 0.049 & 0.012 \\
& 0.01 & 7 & 29.7 & 128 & 377.20 & 0.000 & 0.000 \\
\hline
\end{tabular}

(a)

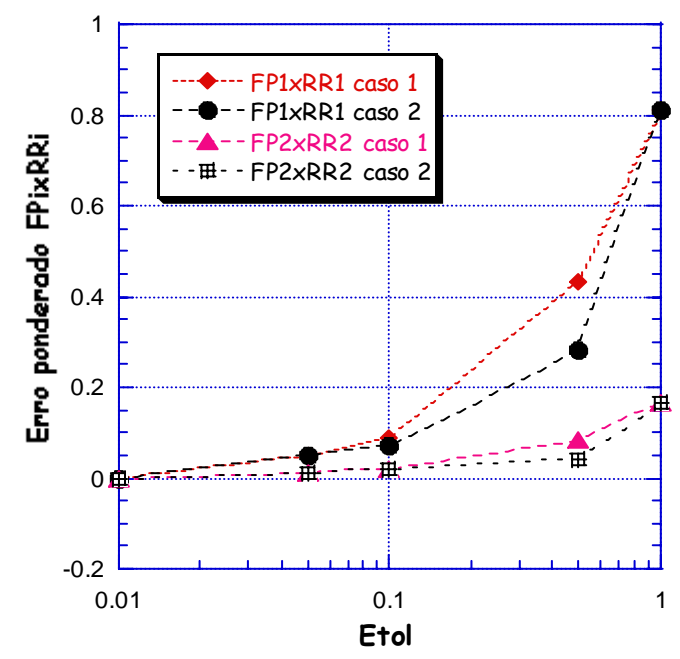

(b)

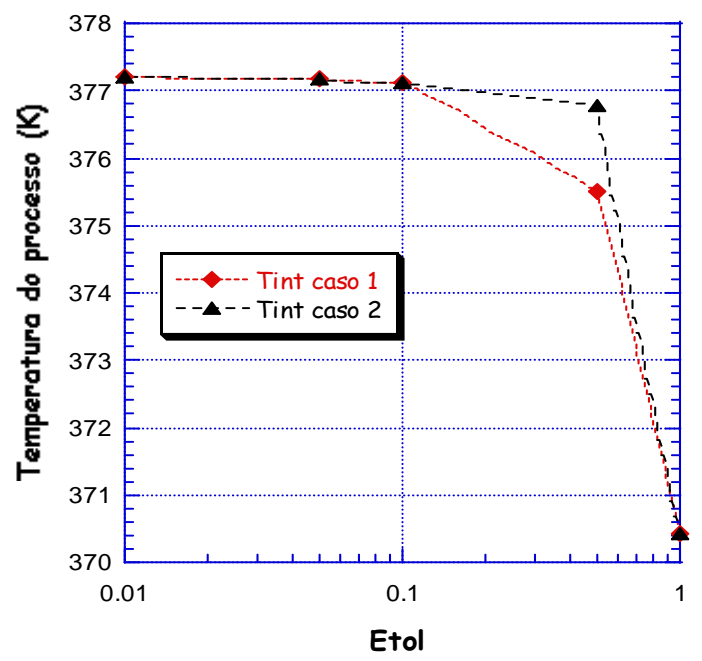

Figura 5.16. Simulação do modelo flash utilizando malhas adaptativas para $\alpha=$ 0.1.(a) FPixRRi vs. Etol (b) Tint. (K) vs. Etol 
(a)

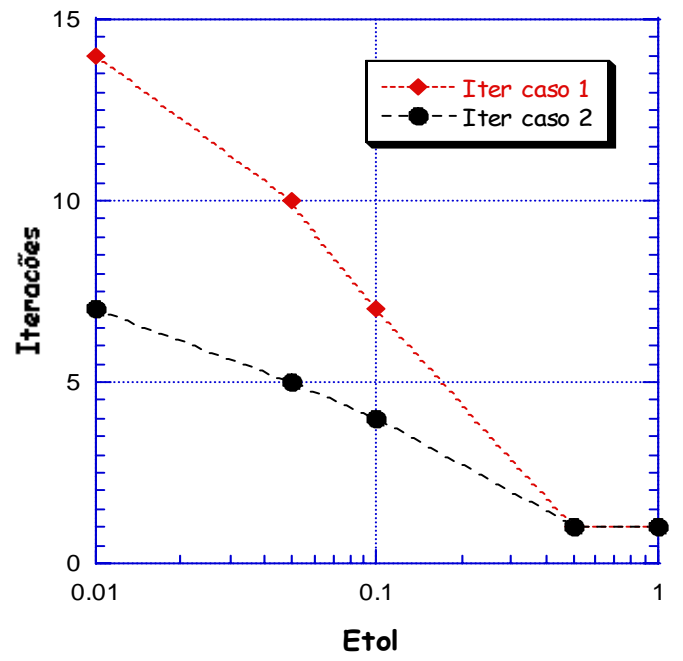

(b)

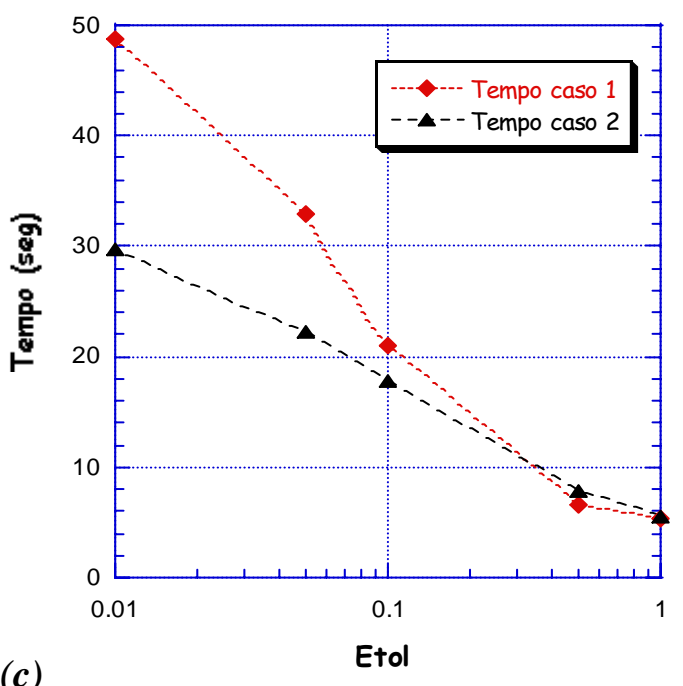

(c)

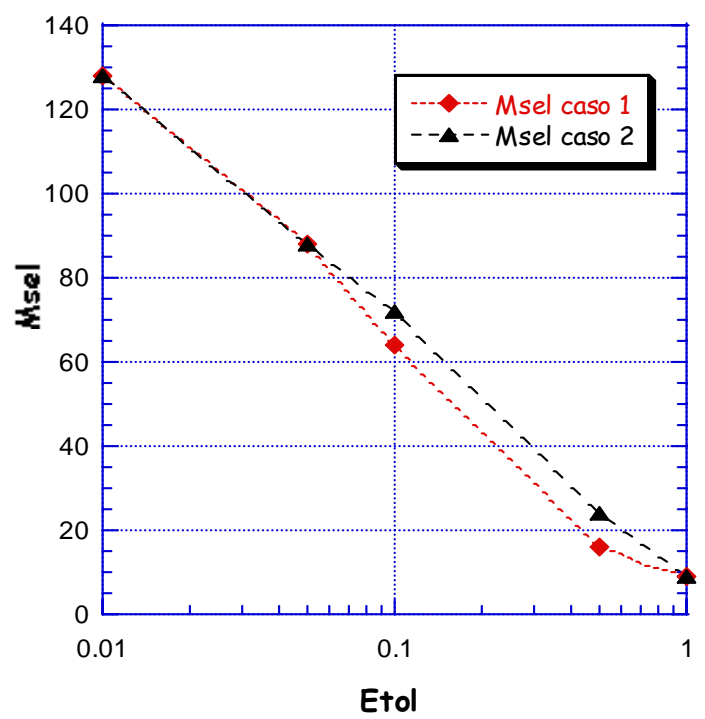

Etol

Figura 5.17. Simulação do modelo flash em estado estacionário usando malhas adaptativas. Resultado para os casos 1 e 2 para $\alpha=0.1$ (a) Iterações vs. Etol (b) Tempo vs. Etol (c) Msel vs. Etol 
Tabela 5.13. Simulação do modelo flash em estado estacionário usando malhas adaptativas. Resultados dos casos 1 e 2 com parâmetro $\alpha=0.90$.

\begin{tabular}{|c|c|c|c|c|c|c|c|}
\hline \multirow{3}{*}{ Parâmetros } & \multicolumn{7}{|c|}{$\mathbf{\alpha = 0 . 9}$} \\
\cline { 2 - 7 } & \multicolumn{7}{|c|}{ escala de inicialização j = 2 } \\
\cline { 2 - 7 } & Etol & Iter & Tempo & Msel & Tint & FP1*RR1 & FP2*RR2 \\
\hline & 1 & 1 & 8.3 & 9 & 629.35 & 0.810 & 0.047 \\
CASO 1 & 0.5 & 1 & 9.2 & 16 & 631.64 & 0.434 & 0.024 \\
Mmax = 8 & 0.1 & 7 & 23.5 & 64 & 632.30 & 0.087 & 0.006 \\
& 0.05 & 10 & 35.7 & 88 & 632.31 & 0.049 & 0.005 \\
& 0.01 & 14 & 61.5 & 127 & 632.34 & 0.004 & 0.000 \\
\hline & 1 & 1 & 8.2 & 9 & 629.35 & 0.810 & 0.047 \\
CASO 2 & 0.5 & 1 & 9.8 & 24 & 631.68 & 0.281 & 0.017 \\
& 0.1 & 4 & 19.2 & 72 & 632.30 & 0.073 & 0.006 \\
& 0.05 & 5 & 23.5 & 88 & 632.31 & 0.049 & 0.005 \\
& 0.01 & 7 & 37.0 & 127 & 632.34 & 0.004 & 0.000 \\
\hline
\end{tabular}

(a)

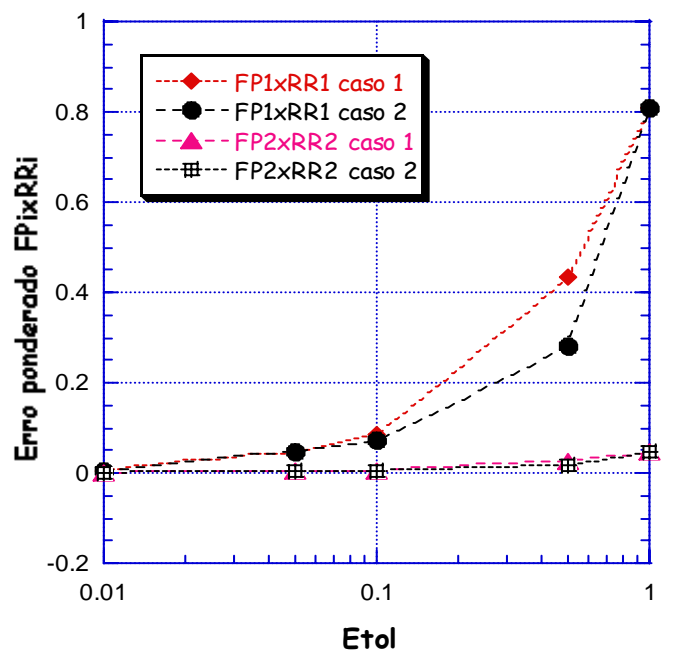

(b)

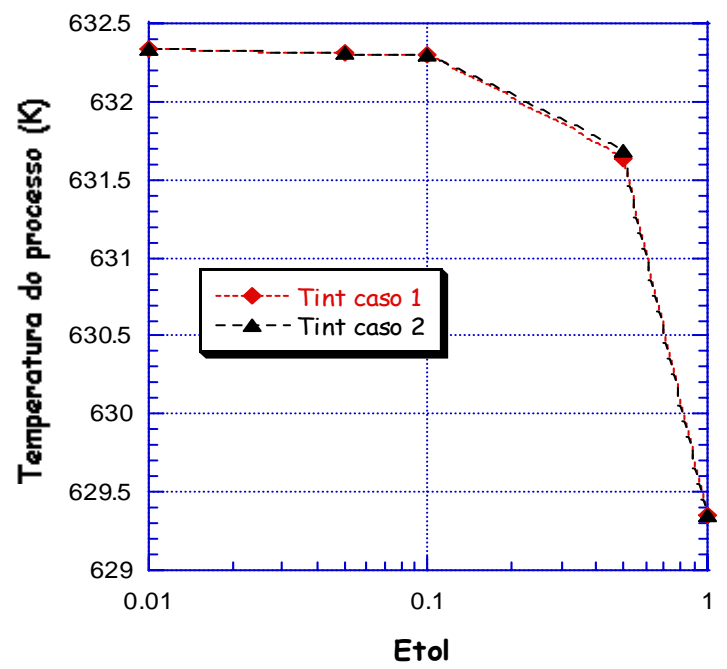

Figura 5.18. Simulação do modelo flash utilizando malhas adaptativas para $\alpha=$ 0.9.(a) FPixRRi vs. Etol (b) Tint. (K) vs. Etol 
(a)

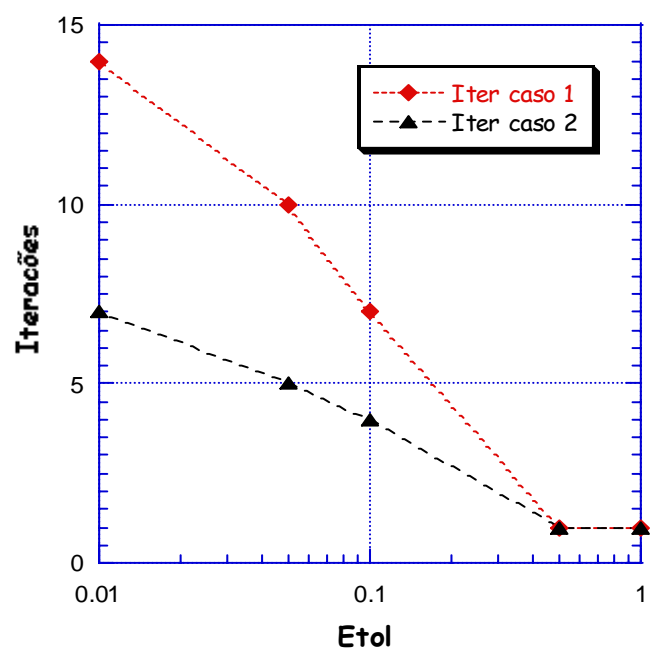

(b)

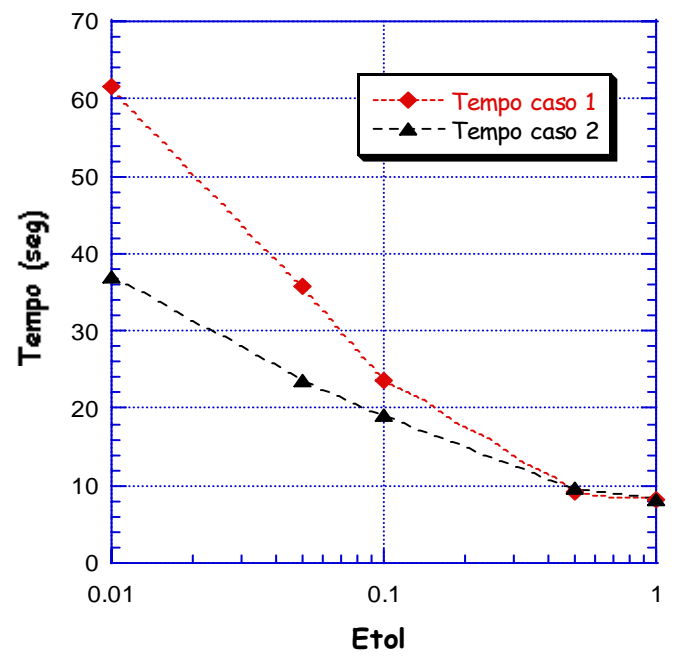

(c)

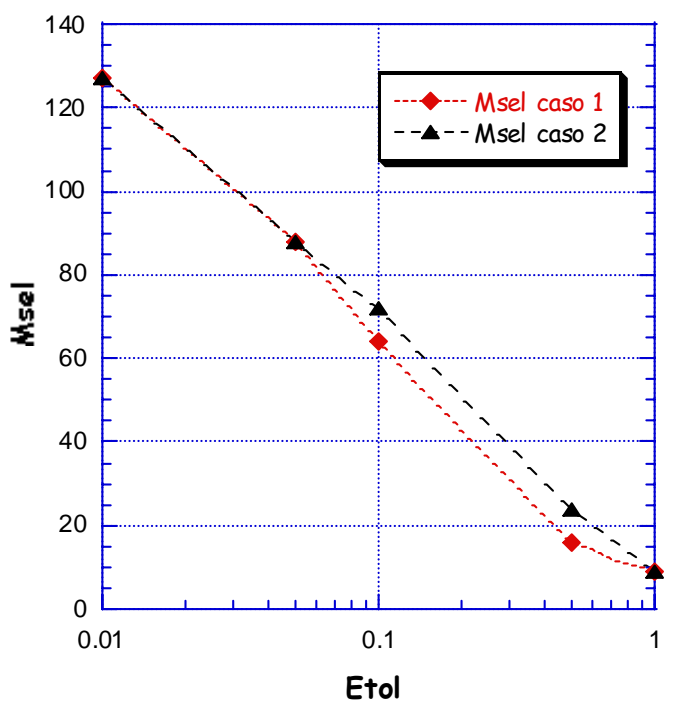

Figura 5.19. Simulação do modelo flash em estado estacionário usando malhas adaptativas. Resultado para os casos 1 e 2 para $\alpha=0.9$ (a) Iterações vs. Etol (b) Tempo vs. Etol (c) Msel vs. Etol 
Tabela 5.14. Simulação do modelo flash em estado estacionário usando malhas adaptativas. Resultados dos casos 1 e 2 com parâmetro $\alpha=0.95$.

\begin{tabular}{|c|c|c|c|c|c|c|c|}
\hline \multirow{3}{*}{ Parâmetros } & \multicolumn{7}{|c|}{$\mathbf{\alpha = 0 . 9 5}$} \\
\cline { 2 - 7 } & \multicolumn{7}{|c|}{ escala de inicialização j = 2 } \\
\cline { 2 - 7 } & Etol & Iter & Tempo & Msel & Tint & FP1*RR1 & FP2*RR2 \\
\hline & 1 & 1 & 9.3 & 9 & 656.65 & 0.810 & 0.043 \\
CASO 1 & 0.5 & 1 & 10.1 & 16 & 658.79 & 0.434 & 0.023 \\
Mmax = 8 & 0.1 & 7 & 25.0 & 64 & 659.77 & 0.087 & 0.006 \\
& 0.05 & 10 & 37.0 & 88 & 659.81 & 0.049 & 0.004 \\
& 0.01 & 14 & 62.8 & 127 & 659.85 & 0.004 & 0.000 \\
\hline & 1 & 1 & 9.2 & 9 & 656.65 & 0.810 & 0.043 \\
CASO 2 & 0.5 & 1 & 10.8 & 24 & 659.09 & 0.281 & 0.016 \\
Mmax = 16 & 0.1 & 4 & 20.2 & 72 & 659.80 & 0.073 & 0.005 \\
& 0.05 & 5 & 24.4 & 88 & 659.81 & 0.049 & 0.004 \\
& 0.01 & 7 & 37.5 & 126 & 659.85 & 0.006 & 0.000 \\
\hline
\end{tabular}

(a)

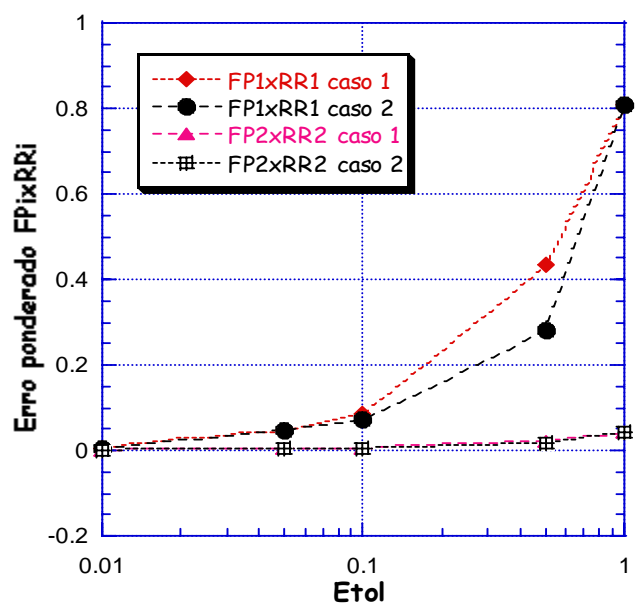

(b)

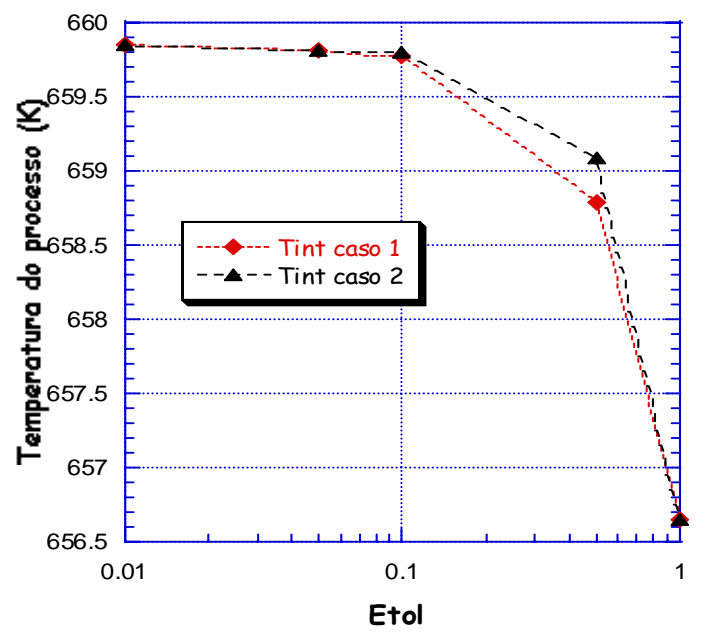

Figura 5.20. Simulação do modelo flash utilizando malhas adaptativas para $\alpha=$ 0.95.(a) FPixRRi vs. Etol (b) Tint. (K) vs. Etol 
(a)

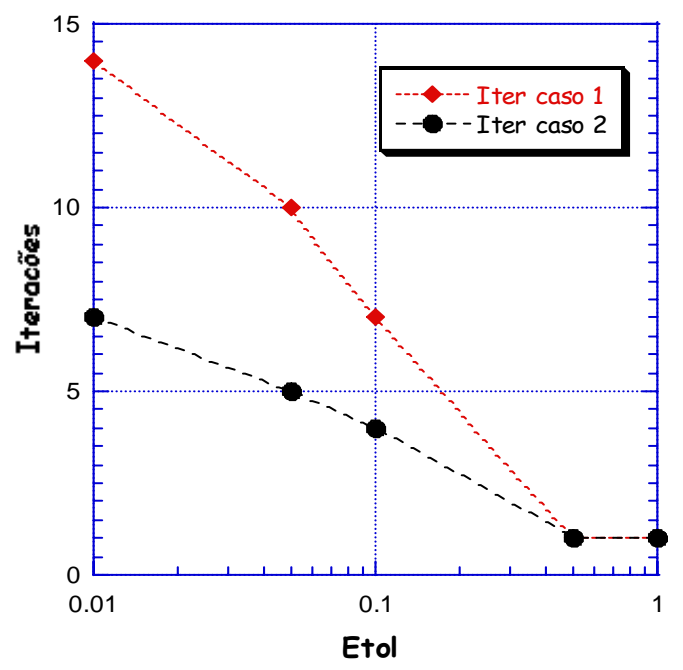

(b)

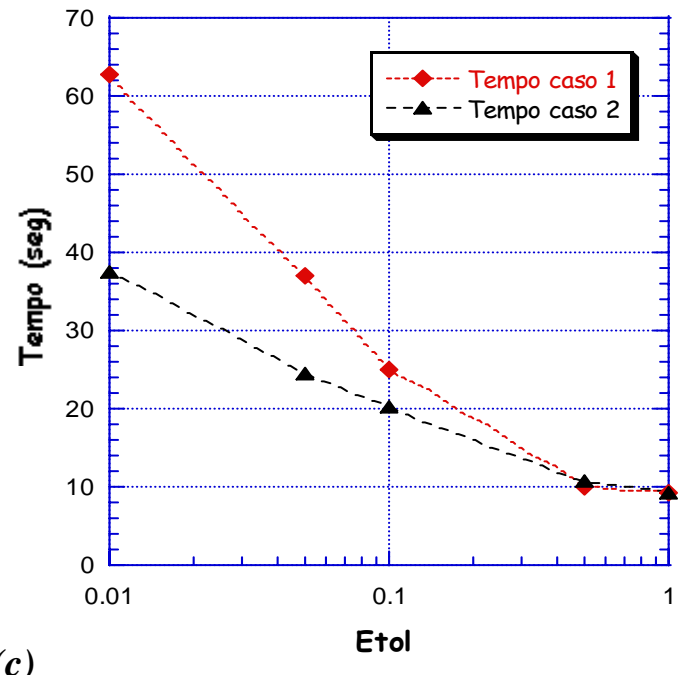

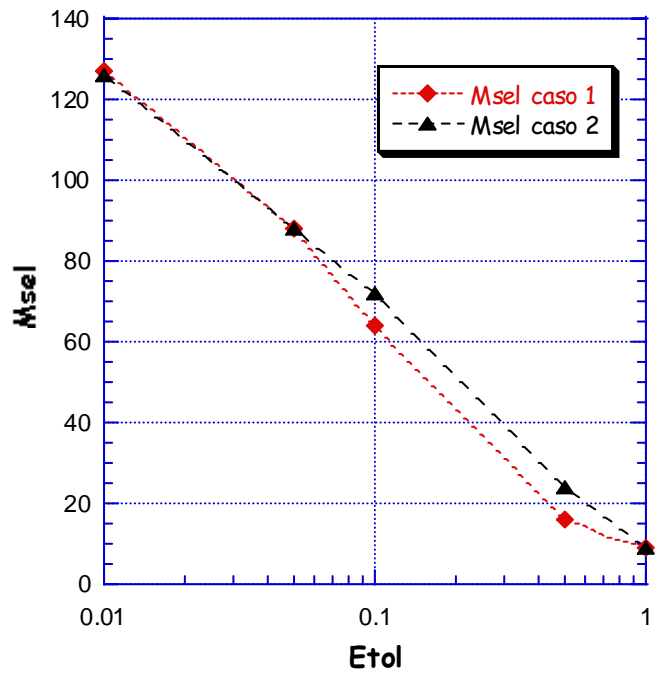

Figura 5.21. Simulação do modelo flash em estado estacionário usando malhas adaptativas. Resultado para os casos 1 e 2 para $\alpha=0.95$ (a) Iterações vs. Etol (b) Tempo vs. Etol (c) Msel vs. Etol

O segundo aspecto a ser avaliado é precisão da aproximação das distribuições de líquido e vapor. Simulan-se dois casos que diferenciam-se pelo parâmetro $M_{\max }$, com cinco possíveis representações destas aproximações, determinadas pelo parâmetro Etol, que definem um maior ou menor grau de detalhes pelo valor de Msel . A análise dos resultados apresentados na tabela 5.10 e nas figuras 5.12 e 5.13, detalhados a seguir, a mesmo análise é para os resultados das simulações para $\alpha=$ 
$\{0.05,0.1,0.9,0.95\}$, nas tabelas $5.11-5.14$ e figuras $5.14-5.21$ leva as seguintes conclusões:

- Os parâmetros $M_{\max }$ e Etol, utilizados na inicialização do algoritmo, influenciam tanto no custo computacional, medido pelo número de iterações Iter, pelo tempo de simulação, quanto pela precisão da aproximação, medido pela quantidade de funções base Msel a serem selecionadas e, pelo erro ponderado das equações do modelo $F P i \times R R i$.

- As figuras 5.12 (a e b) mostram que em qualquer dos dois casos existe uma relação inversa entre Etol com o número de iterações Iter e os tempos da simulação, isto é, quanto menor é o valor de Etol maior o número de iterações, e assim, o tempo da simulação. A diminuição do valor de Etol implica diretamente na maior precisão na resolução do modelo, mas com aumento no gasto computacional.

- Por outro lado, as figuras 5.11 (a) e 5.12 (c) mostram que nos dois casos a relação entre os erros ponderados das equações do modelo, $F P i \times R R i$, com a quantidade de funções base, Msel, também, é inversa. Mas a relação inversa destes critérios implica diretamente em uma melhor aproximação, pois utilizando mais funções base consegue-se menor erro na aproximação. Porém, $F P i \times R R i$ está em relação inversa ao tempo e ao número de iterações e Msel esta em relação direta aos mesmos. Isto implica novamente no fato da procura de maior precisão na resolução do modelo, mas com aumento no gasto computacional.

- É importante ressaltar que, não necessariamente, a maior quantidade de funções base implica em uma melhor aproximação. Como a metodologia proposta refere-se a um processo de seleção de malhas adaptativas, que abrange as mais altas escalas, então, a seleção restrita de valores significativos de coeficientes wavelet, pelo algoritmo (que significa seleção de funções base), permitiram uma melhor aproximação da função. Além 
disso, o grau de aproximação das variáveis de estado, temperatura de processo, $T$ int $(\mathrm{K})$, observado na figura 5.12 (b) mostra que o modelo resolvido a uma precisão de $E$ tol $=0.1$ representa um resultado satisfatório.

- A análise dos casos 1 ou 2 definidos pelo parâmetro $M_{\max }=8$ e $M_{\max }=16$, permiten estabelecer que quanto maior o valor para $M_{\max }$ a eficiência do algoritmo em quanto a tempo da simulação, número de iterações, seleção de funções base e erros de ponderação aumenta. Isto, pode ser observado nos cinco testes realizados para os diferentes Etol $=\{1,0.5,0.1,0.05,0.01\} \mathrm{e}$ para cada valor de $\alpha=\{0.05,0.1,0.5,0.9,0.95\}$. Apresentados nas tabelas 5.10-5.14 e nas figuras 5.12, 5.14, 5.16, 5.18, 5.20 (a) e 5.13, 5.15, 5.17, 5.19, 5.21 ( $\mathrm{a}, \mathrm{b}$ e c). Ainda que não foram incluidos resultados de outros testes realizados para diferentes valores de $M_{\max }$, eles permitiram chegar a esta conclusão.

A partir destas conclusões apresentam-se na tabela 5.15 as condições nas que são construidas as distribuições de líquido e vapor consideradas como uma solução do modelo adaptativo. Esta representação é tomada para comparação com os resultados de uma terceira simulação desenvolvida com o método de pseudocomponentes, descrito no item 5.4.3. A representação qualitativa desta comparação é apresentada nas figuras 5.22-5.26.

Tabela 5.15. Simulação do modelo flash em estado estacionário, malhas adaptativas, resultados do caso 2 com Etol $=0.1$ para $\alpha=\{0.5 ; 0.05 ; 0.1 ; 0.9 ; 0.95\}$, (o número de iterações Iter, o tempo da simulação, os erros ponderados das equações do modelo $F P i \times R R i$, e as funções base selecionadas $M s e l$ ).

\begin{tabular}{|c|c|c|c|c|c|c|}
\hline Parâmetros & \multicolumn{7}{|c|}{ Mmax $=16:$ Etol $=0.1$} \\
\hline$\alpha$ & Iter & Tempo & RR1xFP1 & RR2xFP2 & Msel & Tint (K) \\
\hline 0.05 & 4 & 17.9 & 0.073 & 0.021 & 72 & 365.83 \\
0.1 & 4 & 17.8 & 0.073 & 0.018 & 72 & 377.12 \\
0.5 & 4 & 18.1 & 0.073 & 0.011 & 72 & 475 \\
0.9 & 4 & 19.2 & 0.073 & 0.006 & 72 & 632.3 \\
0.95 & 4 & 20.2 & 0.073 & 0.005 & 72 & 659.8 \\
\hline
\end{tabular}




\subsubsection{Método Pseudocomponentes, simulador HYSYS v. 2.1}

A simulação do modelo flash com o simulador HYSYS permite obter uma aproximação das composições das misturas, nas fases líquido e vapor, através de sua representação pelo método de pseudocomponentes. A finalidade é de comparar estes resultados e aqueles obtidos com o método wavelet-Galerkin com malhas adaptativas. Um simulador comercial como o HYSYS simula um processo de forma eficiente a partir de um conjunto de dados e parâmetros (por exemplo, uma curva TBP, as condições de operação, a seleção das correlações termodinâmicas e equações de estado (para a base de comparação dos resultados deste trabalho utilizou-se a equação de estado de Peng Robinson), e equipamentos utilizados no processo, isto para obter uma representação aproximada da composição das misturas, e também considerando-se o número de pseudocomponentes a utilizar na simulação. A tolerância por default do simulador não foi modificada.

As composições das fases líquido e vapor, para $\alpha=\{0.5,0.05 ; 0.1 ; 0.9 ; 0.95\}$ obtidos por ambos os métodos, são representadas nas figuras 5.22 - 5.26 respectivamente. No caso do método wavelet-Galerkin com malhas adaptadas a representação é feita com a temperatura de ebulição normalizada $\xi[0,1]$ (chamada de variável de caracterização) em relação à fração molar acumulativo [0,1] de cada uma das fases, líquido e vapor. No caso do método de pseudocomponentes a representação e feita com as curvas TBP das fases, líquido e vapor, obtidas pelo simulador, em relação a fração molar acumulativa [0,1]. O objetivo de se fazer isto deve-se a representar melhor comparativamente os resultados obtidos em cada um dos métodos. 


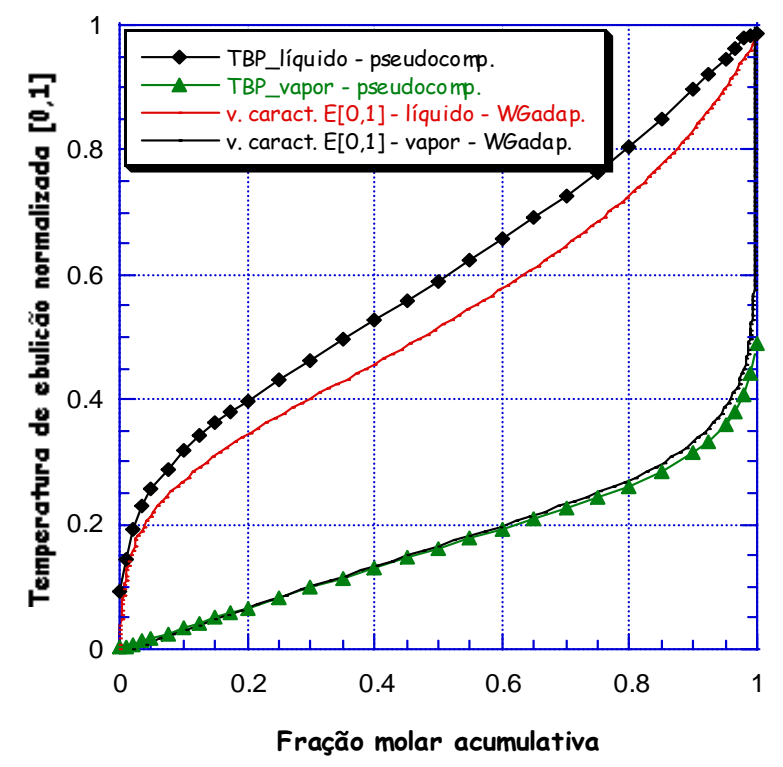

Figura 5.22. Comparação entre os resultados da simulação do processo flash pelo método de malhas adaptativas com o método de pseudocomponentes (HYSYS 2.1). Fases líquido e vapor. Representação de temperatura de ebulição normalizada $\mathrm{E}[0,1]$ vs. fração molar acumulativa $[0,1]$. Para $\alpha=0.5$.

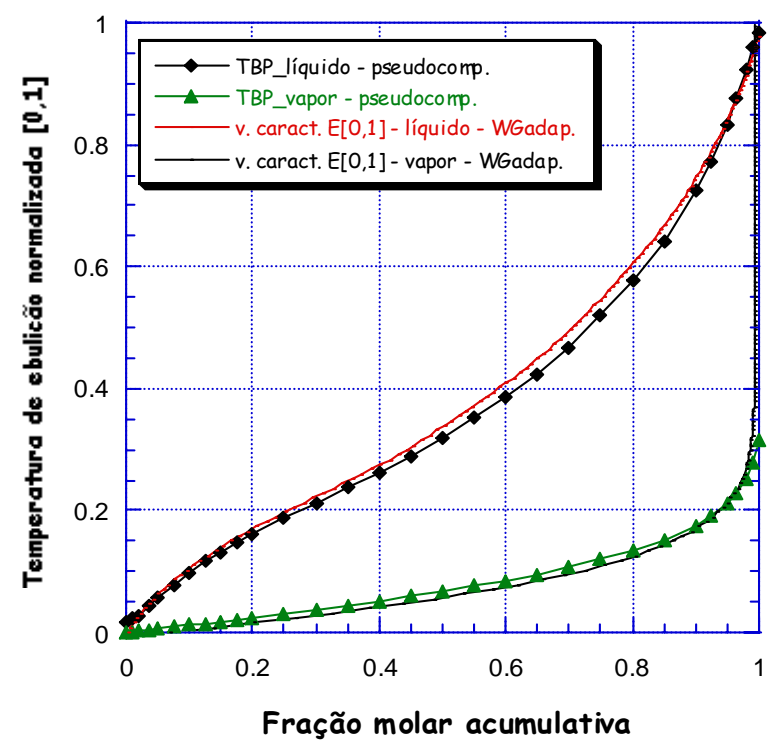

Figura 5.23. Comparação entre os resultados da simulação do processo flash pelo método de malhas adaptativas com o método de pseudocomponentes (HYSYS 2.1). Fases líquido e vapor. Representação de temperatura de ebulição normalizada $\mathrm{E}[0,1]$ vs. fração molar acumulativa $[0,1]$. Para $\alpha=0.05$. 


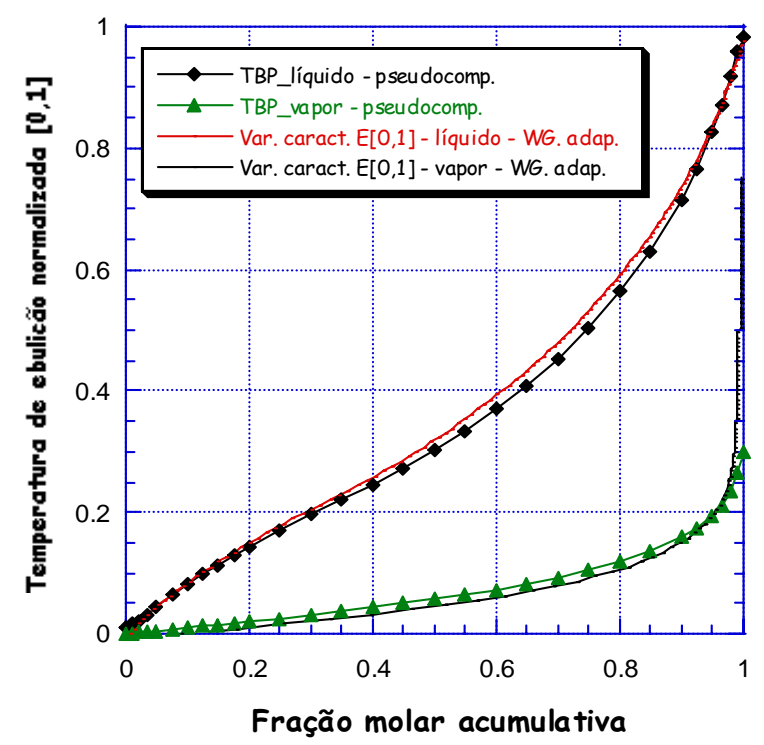

Figura 5.24. Comparação entre os resultados da simulação do processo flash pelo método de malhas adaptativas com o método de pseudocomponentes (HYSYS 2.1). Fases líquido e vapor. Representação de temperatura de ebulição normalizada $\mathrm{E}[0,1]$ vs. fração molar acumulativa $[0,1]$. Para $\alpha=0.1$.

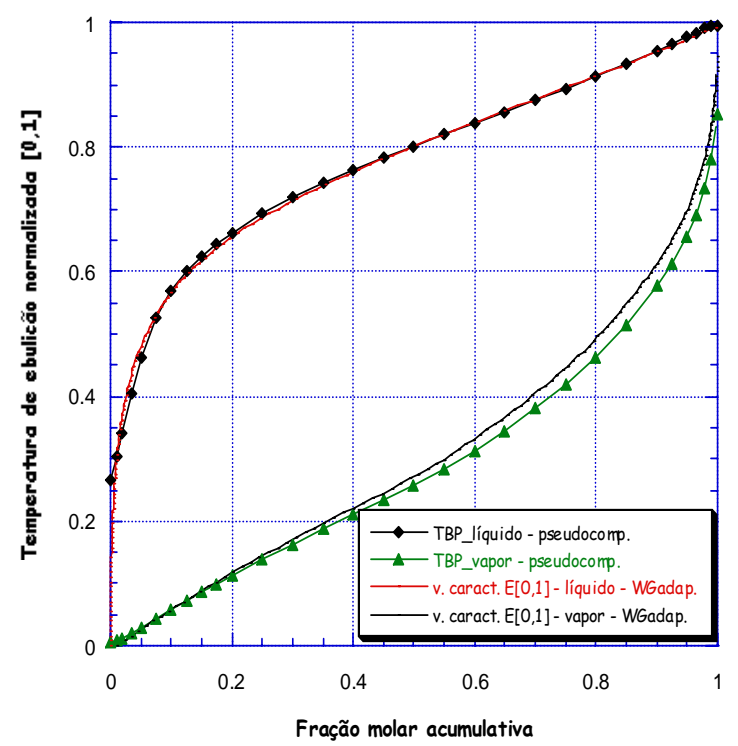

Figura 5.25. Comparação entre os resultados da simulação do processo flash pelo método de malhas adaptativas com o método de pseudocomponentes (HYSYS 2.1). Fases líquido e vapor. Representação de temperatura de ebulição normalizada $E[0,1]$ vs. fração molar acumulativa $[0,1]$. Para $\alpha=0.9$. 


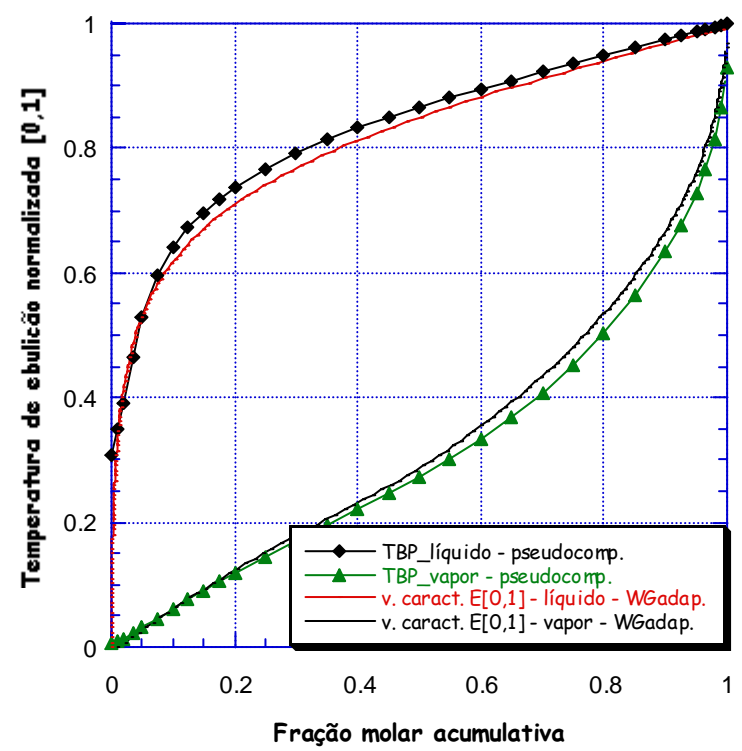

Figura 5.26. Comparação entre os resultados da simulação do processo flash pelo método de malhas adaptativas com o método de pseudocomponentes (HYSYS 2.1). Fases líquido e vapor. Representação de temperatura de ebulição normalizada $\mathrm{E}[0,1]$ vs. fração molar acumulativa $[0,1]$. Para $\alpha=0.95$.

\subsubsection{Comparação entre os resultados das simulações}

A comparação das metodologias tratadas neste trabalho, wavelet-Galerkin com malhas fixas, multi-malhas adaptativas e o tradicional método dos pseudocomponentes, não deve levar à procura de um resultado ótimo. A ideia fundamental de se fazer esta comparação é mostrar a qualidade das aproximações, em relação à sua eficiência, medida pelo esforço computacional. Isto, é mostrado comparativamente na tabela 5.16 e nas figuras 5.27 e 5.28 para valores diferentes de $\alpha=\{0.05,0.1 ; 0.5 ; 0.9 ; 0.95\}$. 
Tabela 5.16. Simulação do modelo flash em estado estacionário. Comparação de métodos wavelet-Galerkin malhas fixas (tabela 5.9), malhas adaptativas (tabela 5.15), e método pseudocomponentes. Avaliação para $\alpha=.\{0.5 ; 0.05 ; 0.1 ; 0.9 ; 0.95\}$.

\begin{tabular}{|c|c|c|c|c|c|c|}
\hline Parâmetros & alfa $(\alpha)$ & Tint & Tempo & $\operatorname{Mmax}_{F}$ & FP1xRR1 & FP2xRR2 \\
\hline \multirow{5}{*}{$\begin{array}{l}\text { Método Wavelet - } \\
\text { Galerkin malhas } \\
\text { fixas }\end{array}$} & 0.05 & 365.88 & 23.41 & 128 & 0 & 0 \\
\hline & 0.1 & 377.2 & 23.45 & 128 & 0 & 0 \\
\hline & 0.5 & 475.08 & 33.69 & 128 & 0 & 0 \\
\hline & 0.9 & 632.34 & 51.67 & 128 & 0 & 0 \\
\hline & 0.95 & 659.85 & 82.89 & 128 & 0 & 0 \\
\hline \multirow{6}{*}{$\begin{array}{l}\text { Método Wavelet - } \\
\text { Galerkin malhas } \\
\text { adaptativas }\end{array}$} & & & & Msel & & \\
\hline & 0.05 & 365.83 & 17.9 & 72 & 0.073 & 0.021 \\
\hline & 0.1 & 377.12 & 17.8 & 72 & 0.073 & 0.018 \\
\hline & 0.5 & 475 & 18.1 & 72 & 0.073 & 0.011 \\
\hline & 0.9 & 632.3 & 19.2 & 72 & 0.073 & 0.006 \\
\hline & 0.95 & 659.8 & 20.2 & 72 & 0.073 & 0.005 \\
\hline \multirow{6}{*}{$\begin{array}{c}\text { Método } \\
\text { pseudo- } \\
\text { componentes }\end{array}$} & & & & $\begin{array}{c}\text { Pseudo- } \\
\text { componentes }\end{array}$ & & \\
\hline & 0.05 & 376.67 & n.a & 128 & n.a & n.a \\
\hline & 0.1 & 385.61 & n.a & 128 & n.a & n.a \\
\hline & 0.5 & 469.83 & n.a & 128 & n.a & n.a \\
\hline & 0.9 & 632.31 & n.a & 128 & n.a & n.a \\
\hline & 0.95 & 667.1 & n.a & 128 & n.a & n.a \\
\hline
\end{tabular}

n.a: não avaliado

Uma explicação à diferença nos resultados das temperaturas entre os dois métodos, wavelet-Galerkin e pseudocomponentes, deve-se ao fato de utilizar correlações termodinâmicas diferentes para cada um deles, mantendo as condições do modelo de separador flash invariantes.

(a)

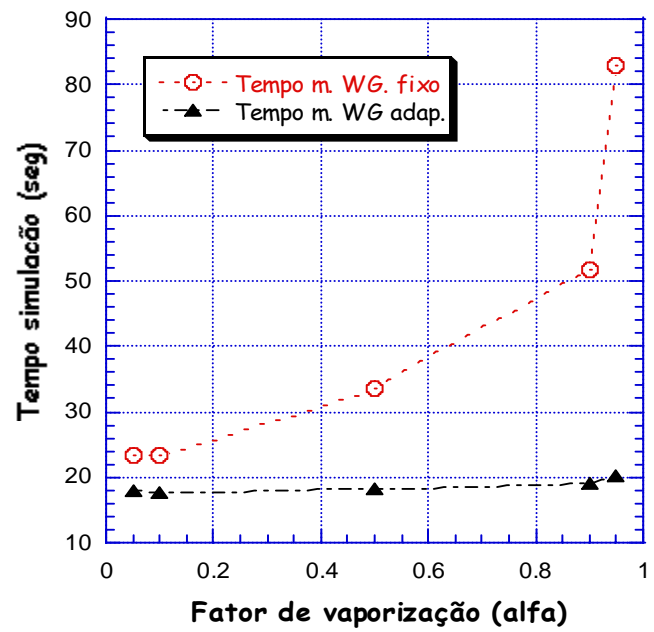

(b)

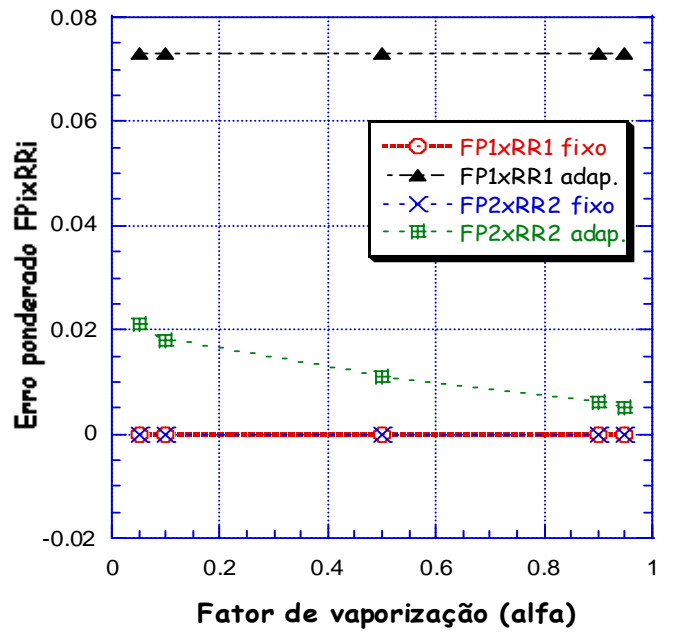


(c)

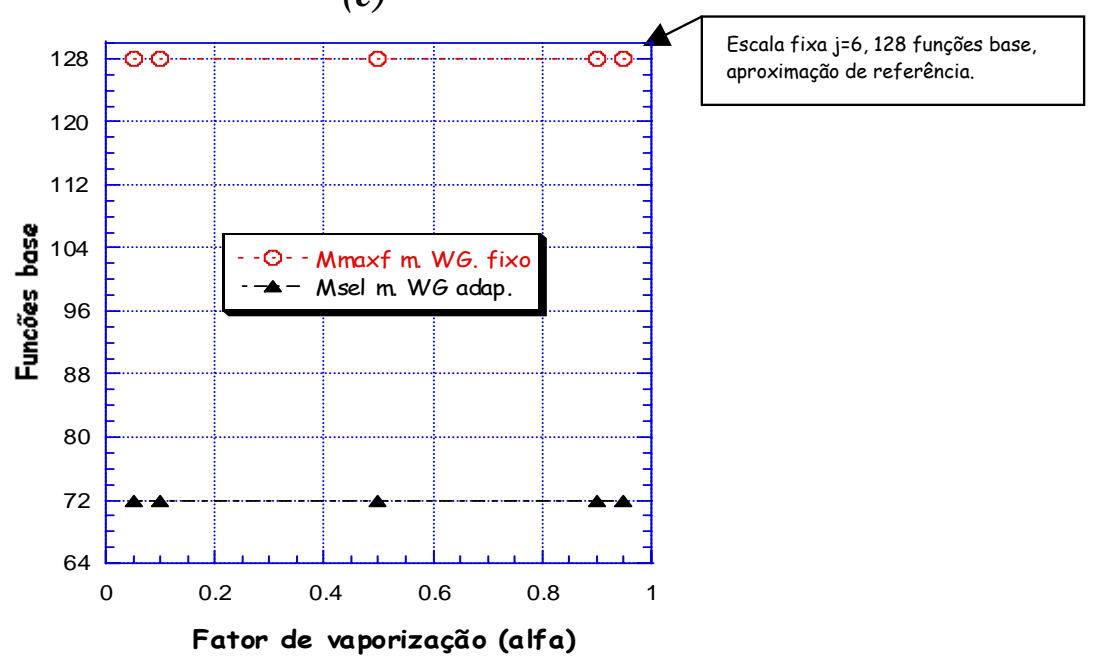

Figura 5.27. Comparação de métodos wavelet-Galerkin com malha fixa e com malha adaptada. (a) Tempo de simulação vs. $\alpha$. (b) RRixFPi vs. $\alpha$. (c). Número de funções base vs. $\alpha$

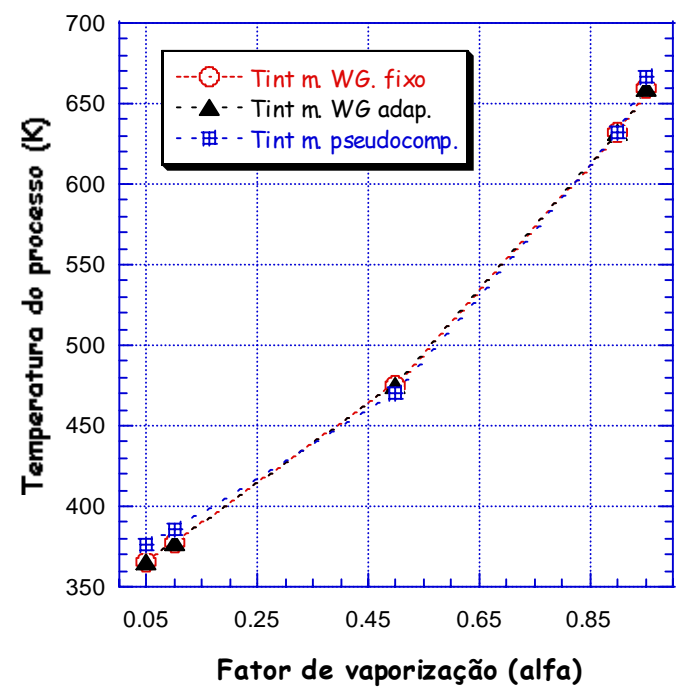

Figura 5.28. Comparação de métodos wavelet-Galerkin com malha fixa e com malha adaptada, e com o método de pseudocomponentes. Temperatura de processo, Tint (kelvin) vs. $\alpha$.

A comparação entre o método wavelet-Galerkin com malhas adaptativas, em relação ao método wavelet-Galerkin com malhas fixas, passa pela observação dos critérios avaliados nas simulações, como são os tempos de simulação, os erros ponderados das 
equações do modelo e o número de funções base utilizadas para a representação da aproximação das distribuições líquida e vapor. Assim, na figura 5.27 (a) pode-se observar que além de ter os dois métodos as mesmas condições iniciais para as simulações, os tempos para o método de malhas adaptadas é menor e permanecem quase constantes para todos os casos avaliados. Por outro lado, observando a figura 5.27 (b e c) pode-se dizer que, no método de malhas adaptadas, além de ela, utilizar quase a metade de funções base comparado com o de malhas fixas, os erros são valores pequenos. Esta análise pode definir ao método que utiliza malhas adaptadas como mais eficiente em relação ao método que usa malhas fixas.

Enquanto aos resultados na comparação do método wavelet-Galerkin com malhas adaptativas e o tradicional método de pseudocomponentes, apresentadas nas figuras 5.22-5.26, tabela 5.16 e figura 5.28, pode-se dizer que o grau de aproximação da abordagem proposto por Briesen e Marquardt (2003) atingiu os resultados esperados, além de utilizar conceitos e correlações termodinâmicas simples, como são: a representação contínua da composição das misturas, conceito da termodinâmica contínua, e regras de misturas multicomponentes complexas, equação de Clausius Clapeyron e a regra de Truton (ver apéndice A).

\subsection{Conclusões da Simulação do modelo do separador Flash}

Os resultados da primeira parte (ver figura 5.10) baseados na modelagem do processo com o esquema wavelet-Galerkin com malhas fixas, estabelecem uma relação direta entre o tempo da simulação para cada escala $\hat{j}_{s}=2,3,4,5$ e 6 . Por outro lado, a relação entre a qualidade da aproximação e o número de funções base, medida pelo erro ponderado das equações do modelo $(F P i \times R R i)$ é inversa.

Entretanto, a análise feita sobre os resultados da segunda simulação, realizada com o esquema proposto, wavelet-Galerkin, com multi-malhas adaptativas, parece apresentar uma melhor forma de tratar os problemas gerados pela modelagem complexa dos processos. 
A avaliação para valores diferentes do parâmetro fisico $\alpha$ (fator de vaporização) em relação ao número de iterações do algoritmo, Iter , tempo de simulação do processo, quantidade de funções base selecionadas para a aproximação das distribuições de líquido e vapor, erros ponderados $F P i \times R R i$ das equações do modelo, e a a aproximação da temperatura de processo apresentada nas tabelas. 5.10 até 5.14, indica que o uso de um estimador do erro e uma estratégia adequada de adaptação, detalhados na descrição do algoritmo (ver item 5.3.1) permitem a seleção de um número reduzido de bases que geran uma malha reduzida, com a qual pode-se alcançar uma aproximação razoável das distribuições das fases líquida e vapor a um custo computacional reduzido, além de se obter uma boa aproximação da variável de estado, temperatura de processo.

De acordo com estes resultados no que se refer à eficiência do algoritmo, medida no aspecto do custo computacional, pode-se concluir, que o parâmetro $M_{\max }$, pode ser ajustado o menor possível, pois quanto maior o valor de $M_{\max }$ menor tempo é empregado para a simulação. Na mesma medida, o parâmetro Etol, que permite definir o grau de precisão para a aproximação do modelo, também influi inversamente no custo computacional. Porém, este parâmetro deve ser estabelecido arbitrariamente.

Nas tabelas 5.10 até 5.14 pode-se observar que o erro ponderado para as equações de equilibrio L-V, FP2xRR2, são, aproximadamente, de 1/10 em relação a FP1xRR1. Isto é devido ao valor do peso utilizado para as primeiras equações. Se estes erros ponderados FP2xRR2 fossem multiplicados por 10 os resultados dos parâmetros avaliados nas simulações manteriam o mesmo comportamento. Dessa forma, nas figuras 5.12(a), 5.14(a), 5.16(a), 5.18(a), 5.20(a) e 5.27(b) com estes novos valores, teriam as curvas de FP2xRR2 bem próximas às curvas de FP1xRR1. Desta análise conclui-se que o peso utilizado para ponderar os erros das equações do modelo podem ser escolhidos seguindo um criterio simples de equiparar os valores dos mesmos. 
Os resultados da simulação do modelo de separador flash, baseado na representação pelo método tradicional de pseudocomponentes (realizada com o simulador HYSYS v. 2.1), são a base de referência para os resultados obtidos pela abordagen proposta (ver figs. 5.22-5.26 e 5.28). A qualidade na aproximação das funções de composição (distribuições das fases líquido e vapor, ou, frações molares dos componetes de mistura) e variáveis de estado (temperatura do processo, Tint) permitem concluir, que a abordagem proposta pode ser considerada uma alternativa ao método tradicional. Porém, esta abordagen, além de apresentar um algoritmo relativamente simples, tem que ser testada em processos mais complexos do que o separador flash para verificar sua eficiência envolvendo estes casos. 


\section{COMENTÁRIOS FINAIS PERSPECTIVAS E SUGESTÕES}

\subsection{Comentarios finais}

Um critério muito importante na simulação de processos é a precisão. Visando o aumento desta precisão têm sido desenvolvidos muitos estudos relacionados à simulação de processos de refino. O objetivo disso é desenvolver alternativas promissoras com menor custo computacional.

A resolução de problemas gerados por misturas complexas requer o uso de ferramentas eficiêntes. A matemática aplicada esta continuamente desenvolvendo muitas destas ferramentas com o proposito de implementar novas metodologias.

O método wavelet-Galerkin com multi-malhas adaptativas, tratado neste trabalho, é uma ferramenta matemática que combina vários conceitos matemáticos. A particularidade de cada uma das técnicas envolvidas no método se mostraram adaptadas para resolver problemas complexos de grande escala.

No presente trabalho mostrou-se o desempenho desta metodologia verificando a eficiência do algoritmo proposto por Briesen e Marquardt (2003), com algumas modificações introduzidas, aplicado a um flash de petróleo.

A eficiência do algoritmo proposto (ver item 5.3.1), é avaliada através de cinco critérios (ver tabelas 5.10-5.14 e figuras 5.12-5.21), é medida pela precisão na aproximação das funções de distribuição das fases líquida e vapor. Esta precisão é julgada comparativamente com o método de pseucocomponentes, isto pode-se observar nos resultados apresentadas na tabela 5.16 e nas figuras 5.22-5.26 e 5.28.

A avaliação quantitativa da aproximação é feita com uma série de diferentes especificações de precisão $(E t o l=1,0.5 ; 0.1 ; 0.05 ; 0.01), M_{\max }=8 ; 16$ que são atribuidas para cada uma das simulações do processo e testados para cinco valores de $\alpha=\{0.05,0.1,0.5,0.9,0.95\}$. Desta maneira são gerados dois casos, definidos por $M_{\text {max }}$, com cinco testes para cada um, definidos por Etol, e repetindo-se estes testes 
cinco vezes devido a cada valor de $\alpha$, foram realizados em total 25 simulações para o método wavelet-Galerkin com malhas adaptadas.

A adaptação de malha é utilizada e avaliada na resolução do modelo através do número de funções base acumuladas que permanecem ativas graças ao processo de adaptação. Neste trabalho a complexidade do modelo do processo flash passa somente por um processo de adaptação relativamente simples.

Comparado com o método de pseudocomponentes, o algoritmo provê a solução aproximada e adaptada do sistema, através do controle do erro. Porém, a adaptação necessária para garantir uma estratégia eficiente de solução é muito dependente do problema e a maneira como ela se dá não pode ser prevista a priori.

Briesen e Marquardt (2003) indicam que a precisão de um modelo, definido a várias escalas, permite simular partes específicas de um processo em maior detalhe que outras. Em um projeto de processo, esta característica pode ser interessante visando a analisar um grande número de configurações possíveis em níveis grosseiros de detalhes e, usando-se a sub-série de configurações mais promissora sem necessidade de remodelar em um alto nível de detalhes mais elevado.

\subsection{Perspectivas e Sugestões}

A wavelet de Haar utilizada nesta metodologia é de ordem zero, sugere-se utilizar outras familias de wavelet, por exemplo de ordem dois, três, etc, considerando que elas pertençam à familia de wavelet com suporte compacto como no caso das wavelet de Haar, pois destas wavelet pode-se esperar o aumento na regularidade da função de forma linear quando aumenta a amplitude do suporte. Como uma vantagem desta característica, pode-se obter, também, um melhor ajuste na correlação dos dados das funções a serem aproximadas, ainda mais, por exemplo, quando elas são altamente irregulares.

As perspectivas atuais na resolução de problemas que envolvem misturas multicomponentes complexas, como é o caso do petróleo, são relacionadas a sua 
análise e tratamento em diferentes escalas. Uma ferramenta que permite esta análise, precisamente, são as funções wavelet. Tal como foi mostrado no enfoque avaliado neste trabalho, as wavelets representam uma boa alternativa ao tratamento da aproximação da composição de misturas complexas de petróleo, porém, sua combinação com os algoritmos multi-malha adaptativo, implicam no entendimento mais profundo de conceitos matemáticos que ainda não tem muito desenvolvimento nas aplicações atuais, limitando, por este fato, as pesquisas que abordam esta metodologia.

Embora, a matemática aplicada (que utiliza conceitos multi-nivel) esteja em contínuo desenvolvimento para obter alternativas promissoras aos problemas complexos; existem atualmente outras alternativas, aparentemente, mais simples na suas aplicações sobre os problemas de caracterização de misturas complexas. Assim, além de continuar em uma revisão e avaliação mais voltada ao método wavelet-Galerkin com multi-malhas adaptativas, pode-se considerar a avaliação de novos enfoques, como por exemplo, o apresentado por Eckert e Vaneck (2006), o qual baseia-se na representação da mistura original por um sistema de componentes reais. Um outro enfoque é apresentado por Lage (2006), este método desenvolve-se no contexto dos pseudocomponentes e baseia-se na regra de quadratura gaussiana na que as funções de peso são as distribuições da fração molar da mistura complexa. 


\section{REFERÊNCIAS BIBLIOGRÁFICAS}

ABDEL-QADERA, Z.; WILLIAM, L. H. H.; The role of liquid mixing in evaporation of complex multicomponent mixtures: modelling using continuous thermodynamics. Chemical Engineering Science v. 60, p. 1629-1640, 2005.

AMERICAN PETROLEUM INSTITUTE. Petroleum fraction distillation interconversions. In: __ Petroleum refining: technical data book. $5^{\text {th.ed. }}$ Philadelphia: API, 1992. c. 3, p. 3.1-3.23.

AMERICAN PETROLEUM INSTITUTE. Characterization of hydrocarbons. In: . Petroleum refining: technical data book. $6^{\text {th }}$. ed. Philadelphia: API, 1997. c. 2 , p. $2.1-2.25$

STURN, G.P.; SHAY, J.Y. Comprehensive report of API crude oil characterization measurements. Bartlesvile: TRW Petroleum Technologies, 2000. 35p. (THW-APICOMP-RPT).

BA, A.; ECKERT, E.; VANEK T. Procedures for the selection of real components to characterize petroleum mixtures. Chemicke Zvesti, Bratislava, v. 57, n. 1, p. 53$62,2003$.

BACKX, T.; BOSGRA, O; MARQUARDT, W. Industrial challenges in modeling of process and model reduction. In: INTERNATIONAL SYMPOSIUM ON ADVANCED CONTROL OF CHEMICAL PROCESS, Gramado, 2006. ADCHEM'06: proceedings. Londres: IFAC, 2006. p. 143-151.

BEHME, S.; SADOWSKI, G.; SONG, Y.; CHEN, C-C. Multicomponent flash algorithm for mixtures containing polydisperse polymers. AIChE Journal, New York, v. 49, n. 1, p. 258-268, 2003.

BELOHLAV, Z.; ZAMOSTNY, P.; HERINK, T.; ECKERT, E., VANEK, T. A novel approach for the prediction of hydrocarbon thermal cracking products yields from the substitute feedstock composition. Chemical Engineering and Technology, Weiheim, v. 28, n. 10, p.1166-1176, 2005.

BINDER, T.; BLANK, L.; DAHMEN, W.; MAQUARDT, W. Iterative algorithms for multiscale state estimation. Part 1: Concepts. Journal of Optimization Theory and Applications, New York, v. 111, n. 3, p. 501-527, 2001.

BITTENCOURT, M. L.; DOUGLAS, C. C.; FEIJÓO, R. A. Adaptive non-nested multigrid methods. Engineering Computations, Swansea, v. 19, n. 2, p. 158-176, 2002 .

BRIESEN, H.; MARQUARDT, W. Adaptive multigrid solution strategy for the dynamic simulation of petroleum mixture processes. Computing Chemical Engineering, v. 29, n. 1, p. 139-148, $2004 a$. 
BRIESEN, H.; MARQUARDT, W. A new approach to refinery process simulation with adaptive composition representation. AIChE Journal, New York, v. 50, n. 3, p. $633-645,2004 b$.

BRIESEN, H.; MARQUARDT, W. An Adaptive multigrid method for steady-state simulation of petroleum mixture separation processes. Industrial and Engineering Chemistry Research, Washington, v. 42, n. 11, p. 2334-2348, 2003.

BRIESEN, H.; MARQUARDT, W. Adaptive model reduction and simulation of thermal cracking of multicomponent hydrocarbon mixtures. Computers and Chemical Engineering, New York, v. 24, n. 2-7, p.1287-1292, 2000.

BRIESEN, H.; MARQUARDT, W. An adaptive multiscale Galerkin method for dynamic simulation of continuous mixture separation processes. In: AIChE ANNUAL MEETING, 1999, Dallas. AICHE 1999: proceedings. Dallas: American Institute of Chemical Engineers, 1999.

BRIGGS, W. L.; HENSON, V. E. MCCORMICK, S. F. A multigrid tutorial. 2.ed. Philadelphia: SIAM, 2000. 193p.

CAI, J.; PRAUSNITZ, J. M. Thermodynamics for fluid mixtures near to and far from the vapor-liquid critical point. Fluid Phase Equilibria. v. 219, p. 205-217, 2004.

CAI, J.; QIU, D.; ZHANG, L.; HU, Y. Vapor-liquid critical properties of multicomponent fluid mixture. Fluid Phase Equilibria. v. 241, p. 229-235, 2006.

CHUI, C. K. An introduction to wavelets. Boston: Academic Press, 1992. v. 1, 266p. (Wavelet analysis and its applications series).

CHEN, C-C.; MATHIAS, P. M.. Applied thermodynamics for process modeling, AIChE Journal, New York, v. 48, n. 2, p. 194-200, 2002.

CHEN, X.; HE, Z.; XIANG, J.; LI, B. A dynamic multiscale lifting computation method using Daubechies wavelet. Journal of Computational and Applied Mathematics, Antwerp, v. 188, n. 2, p. 228-245, 2006.

COMINCIOLI, V.; SCAPOLLA, T.; NALDI. G.; VENINI, P. A wavelet-like Galerkin method for numerical solution of variational inequalities arising in elastoplasticity. Communications in Numerical Methods in Engineering, New York, v. 16, n. 2, p. 133-144, 2000.

COTTERMAN, R. L.; BENDER, R.; PRAUSNITZ, J. M. Phase equilibria for mixtures containing very many components. Development and application of continuous thermodynamics for chemical process design. Industrial Engineering and Chemical Processing Design and Development. v. 24, n. 1, p. 194-203, 1985.

COTTERMAN, R. L.; PRAUSNITZ, J. M. Flash calculations for continuous or semicontinuous mixture using and equation of state. Industrial Engineering and Chemical Processing Design and Development. v. 24, n. 2, p. 434-443, 1985. 
CRUZ, P; MENDES, A.; MAGALHÃES, F. D. Wavelet-based adaptive grid method for the resolution of nonlinear PDEs. AIChE Journal, New York, v. 48, n. 4, p. 774-785, 2002.

DAUBECHIS, I.. Ten lectures on wavelets. Philadelphia: SIAM, 1992. v. 61, 377p. (CBMS-NSF Regional conference series in applied mathematics).

DOMÍNGUEZ, M. C.; FERRAGUT, L. Adaptive multigrid method using duality in plane elasticity. International Journal for Numerical Methods in Engineering, London, v. 50, n. 1, p. 95-118, 2001.

DIPPR 801 Design Institute for Physical properties sponsored by AIChe Disponível em: http://dippr.byu.edu/product .asp. Acesso em: Jan 2006.

EDMISTER, W. C. Improved integral technique for petroleum distillation calculations. Industrial and Engineering Chemistry Research, London, v. 47, n. 9, p. 1685-1690, 1955.

ECKERT, E. Non-traditional characterization of petroleum mixtures in terms of selected components. Collection of Czechoslovak Chemical Communications, Praha, v. 64, n. 3, p. 571-584, 1999.

ECKERT, E.; VANEK, T. Simulation of separation columns using substitute mixtures. In: INTERNATIONAL CONFERENCE SLOVAK SOCIETY OF CHEMICAL ENGINEERING, 30., Tatranské Matliare, 2003. SSCHE 2003: proceedings. Tatranské Matliare: Academic Press, 2003.

ECKERT, E.; VANEK, T. Procedures for the selection of real components to characterize petroleum mixture. Chemical Papers - Slovak Academy of Science, v. 57, n. 1, p. 53-62, 2003.

ECKERT E.; VANEK T. Substitute mixtures in the simulation of petrochemical processes. In: INTERNATIONAL CONGRESS OF CHEMICAL AND PROCESS ENGINEERING, 16., Prague, 2004. CHISA 2004: proceedings. Prague: CSCHI, 2004. p. 3-8, trab. 1173-P3.

ECKERT, E.; VANEK, T. Extended utilization of the characterization of petroleum mixtures based on real components. Chemical Papers - Slovak Academy of Science, v. 59, n. 6, p. 428-433, $2005 a$.

ECKERT, E.; VANEK, T. New approach to the characterisation of petroleum mixtures used in the modelling of separation processes. Computers and Chemical Engineering, New York, v. 30, n.2, p. 343-356, 2005 b.

ENGIN, K.; MUSA, A. A new approach to fuzzy wavelet system modeling. International Journal of Approximate Reasoning, New York, v. 40, n.3, p. 302$322,2005$.

FANG, W.; LEI, Q.; Continuous thermodynamic correlation and calculation of vapor pressure and vapor-liquid equilibrium constant of hydrocarbon fuel fractions. Fluid Phase Equilibria. v. 213, p. 125-138, 2003. 
FISH, J.; BELSKY, V. Multi-grid method for periodic heterogeneous media: Part 2. Multiscale modeling and quality control in multidimensional case. Computer Methods in Applied Mechanics and Engineering, Amsterdam, v. 126, n. p. 17-38, 1995.

FORBES, J. F.; MARLIN, T. E. Design cost: A systematic approach to technology selection for model based real time optimization systems. Computers \& Chemical Engineering, New York, v. 20, n. 6-7, p. 717-734, 1996.

BEYLKIN, G. On the representation of operator in bases of compactly supported wavelets. SIAM Journal on Numerical Analysis, Philadelphia, v. 29, n.6, p. 1716$1740,1992$.

HU, S.; TOWLER, G.; ZHU, X. X. Combine molecular modeling with optimization to stretch refinery operational. Industrial Engineering and Chemistry Research, Washington, v. 41, n. 4, p. 825-841, 2002.

HU, Y.; YING, X.; WU, D. T.; PRAUSNIT, J. M. Liquid-liquid equilibria for solutions of polydisperse polymers. Continuous thermodynamics for the lattice-fluid model. . Fluid Phase Equilibria. v. 98, p. 113-128, 1994.

HU, Y.; YING, X.; WU, D. T.; PRAUSNIT, J. M. Continuous thermodynamics for polydisperse polymer solutions. Fluid Phase Equilibria. v. 104, p. 229-252, 1995.

HUANG, S. H.; RADOSZ, M. Phase Behavior of Reservoir Fluids III: Molecular Lumping and Characterization. Fluid Phase Equilibria. Amsterdam, v. 66, p. 1-21. 1991.

JANG, G. W.; KIM, J. E.; KIM, Y. Y. Multiscale Galerkin method using interpolation wavelets for two-dimensional elliptic problems in general domains. International Journal Numerical Methods in Engineering, London, v. 59, n. 2, p. 225-253, 2004.

JÁCOME, P. A. D.; PEIXOTO, F. C.; PLATT, G. M.; AHÓN, V. R. R. A new approach to distillation of continouos mixtures: modelling and simulation. Latin American Applied Research, Bahia Blanca, v. 35, n. 3, p. 233-239, 2005.

JUSTEN, L. A.; TESCHKE, G.; LEHMANN, V. Wavelet-based methods for clutter removal from radar wind profiler data. Zentrum fur Technomathematik, Bremen, Disponível em: http://www.math.unibremen.de/zetem/projekte/bildsignal/docs/mepros_spie_2003 paper.pdf. Acesso em: 12 maio 2005.

KAISER, G.; A friendly guide to wavelets. 6 ed. New York: Birkhauser, 1994. $300 \mathrm{p}$.

KATZ, D. L.; BROWN, G. G. Vapor pressure and vaporization of petroleum fractions. Industrial and Engineering Chemestry, Ann Arbor, v. 20, n. 12, p. 1373-1384, 1933. 
KO, J.; KIM, C.; KURDILA, A. J.; STRGANAC, T. W. Wavelet Galerkin methods for game theoretic control of distributed parameter systems. In: STRUCTURES, STRUCTURAL DYNAMICS AND MATERIALS CONFERENCE, 34., La Jolla, 1993. AIAA/ASME/ASCE/AHS/ASC: proceedings. La Jolla: AIAA, 1993. p. 3437-3443, paper 93-1674.

$\mathrm{KOPSCH}, \mathrm{H}$. Thermal methods in petroleum analysis. Weinheim: VCH, 1995. $515 \mathrm{p}$.

KWON, K. Multiscale multigrid adaptive method for elliptic equations. Disponível em: http://idealab.snu.ac.kr/autoset/apache/htdocs/research/Opt/multiscale_eq/multi_eq.h tm. Acesso em: 29 nov, 2005.

LAGE. P. L.C. The quadrature method of moments for continuous thermodynamics. Computers and Chemical Engineering. No prelo. Disponível em : http://www.sciencedirect.com/science? ob=ArticleListURL\&_method=list\&_Article ListID $=513312086 \&$ st $=13 \&$ sort $=\mathrm{d} \&$ sisterm $=$ The $\% 20$ quadrature $\% 20$ method $\% 20$ of $\% 20$ moments $\% 20$ for $\% 20$ continuous $\% 20$ thermodynamics \& acct $=\mathrm{C} 000049650 \&$ version $=1 \&$ urlVersion $=0 \&$ userid $=972067 \& \mathrm{md} 5=\mathrm{ab} 3 \mathrm{bbaff} 2 \mathrm{a} 679152 \mathrm{c} 0 \mathrm{~d} 2814230 \mathrm{~d}$ b7981 . Acesso em: 20 agost. 2006; oct. 2006.

LIU, J. L.; WONG, D. S. H. Rigorous implementation of continuous thermodynamics using orthonormal polynomials. Fluid Phase Equilibria. Taiwan, v. 129, p. 113-127, 1997.

LIMA, P. C. Wavelets: uma introdução. Belo Horizonte: ICEX-UFMG, 2003. Disponível em: http://www.mat.ufmg.br/\%7Elima/artigos/rmu33.pdf. Acesso em: 25 maio, 2005.

LINHARES, M. J. R.; PRADO, L. E. A. Wavelet-Galerkin method applied to a partial differential equation with variable coefficient. In: CONFERENCE ON DIFFERENTIAL EQUATIONS \& COMPUTATIONAL SIMULATIONS, 5., Starkville, 2001. Proceedings. Starkville: Mississipi State University, 2003 Disponível em: http://ejde.math.unt.edu/conf-proc/10/12/lopes.pdf. Acesso em: 30 abr. 2006.

LION, A. R.; EDMISTER, W. C. Make equilibrium calculations by computer. Hidrocarbon Processing, California, v. 54, n. 7-8, p. 119-122, 1975.

LUYBEN, W., L. Process modeling, simulation and control for chemical engineers. 2.ed. New York: McGraw-Hill, 1990. 725p.

MAHMOUDI, Y. Wavelet Galerkin method for numerical solution of nonlinear integral equation. Applied Mathematics and Computation, New York, v. 167, n. 2, p. 1119-1129, 2005.

MANAFI, H.; MANSOORI, G. A.; GHOTBI, S. Phase behavior prediction of petroleum fluids with minimum characterization data. Journal of Petroleum Science and Engineering v. 22, p. 67-93, 1999 
MEYER, Y.; Wavelets and operators. Cambridge, 1992. 223p.

MIQUEL, J.; HERNÁNDEZ, J.;CASTELL, F. A new method for petroleum fraction and crude oil characterization. SPE Reservoir Engineering, Richardson, v. 7, n. 2, p. 265-270, 1992.

MIQUEL, J.; CASTELL, F. Easy characterization of petroleum fractions (part. 1). Hidrocarbon Processing, v. 72, n. 1, p. 101-105, 1993.

MIQUEL, J.; CASTELL, F. Easy characterization of petroleum fractions (part. 2). Hidrocarbon Processing, v. 73, n; 12, p. 99-103, 1994.

MONTEL, F.; GOUEL, P. A new lumping scheme of analytical data for compositional studies. In: SPE ANNUAL TECHNICAL CONFERENCE AND EXHIBITION, 59., HOUSTON, 1984. SPE-AIME: proceedings. Houston: SPE, 1984. paper SPE13119, 59.

MORO, L. F. L. Process technology in the petroleum refining industry: current situation and future trends. Computing Chemical Engineering, New York, v. 27, n. 8-9, p. 1303-1305, 2003.

MORETIN, P. A.; Ondas e ondaletas. São Paulo: EdUSP, 1999. 272p.

NEAU, E.; JAUBERT, J.; ROGALSKI, M. Characterization of heavy oils. Industrial Engineering and Chemistry Research, Washington, v. 32, n. 6, p. 11961203, 1993.

NIELSEN, O. M. Wavelets in scientific computing. 1998. [s.p.]. Ph. D Thesis (Doutorado) - Department of Mathematical Modelling, Technical University of Denmark. Lyngby, 1998.

OLEG, V. V.; KEVLAHAN, N. K.-R. An adaptive multinivel wavelet collocation method for elliptic problems. Journal of Computational Physics, New York, v. 206, n. 2, p. 412-431, 2005.

RATHISH, K.; MANI, M. Time-accurate solutions of Korteweg-de Vries equation using wavelet Galerkin method. Applied Mathematics and Computation, New York, v. 162, p. 447-460, 2005.

RATZSCH, M. T.; KEHLEN, H. Continuous thermodynamics of complex mixtures. Fluid Phase Equilibria, Amsterdam, v. 14, p. 225-234, 1983.

RATZSCH, M. Continuous thermodynamics. Pure and Applied Chemistry, Oxford, v. 1, n. 6, p. 1105-1114, 1989.

RATZSCH, M.; KEHLEN, H.; SCHUMANN, J. Computer simulation of complex multicomponent hydrocarbon distillation by continuous thermodynamics. Fluid Phase Equilibria, Amsterdam, v. 51, p. 133-146, 1989.

RIAZI, M.R.; AL-ADWANI, H.A.; BISHARA, A. The impact of characterization methods on propierties of reservoir fluids and crude oils: options and restrictions. 
Journal Petroleum Science and Engineering, Amsterdam, v. 42, n. 2-4, p. 195207, 2004.

RIAZI, M. R.; DAUBERT, T.E. Simplify property predictions. Hidrocarbon Processing, Pennsylvania, v. 60, n. 1-3, p. 115-116, 1980.

RICE, R. G.; DO, D. D. Applied mathematics and modeling for chemical engeneers. New York: John Wiley, 1995. 706p. (Wiley series in chemical engineering).

ROQUEIRO, N.; LIMA, E. L. Wavelet Networks for modelling nonlinear process. In:__. Wavelet theory and harmonic analysis in applied sciences. Springer, 1997. cap. 2, p. 265-301.

SCHRÖDER, P.; SWELDENS, W. Building your own wavelets at home. In: . Wavelets in computer graphics. [S.1.]: ACM SIGGRAPH; 1996. cap. 1, p. 15-87. Course notes. Disponível em: http://cm.belllabs.com/who/wim/papers/athome.pdf. Acesso em: 03 mar. 2005.

SEADER, J. D.; SIIROLA, J. L.; BARICKI, S. D. Destillation. In: PERRY, R. H.; GREEN, D. W.; MALONEW, J. O (eds.). Chemical Engineers Handbook. Tokyo: McGraw-Hill, 1997. cap. 13, p. 13: 85-86.

SEQUEIRA, S. E.; GRAELLS, M.; PUIGJANER, L. Real time evolution for on-line optimization of continuous processes. Industrial Engineering and Chemical Research, Washington, v. 41, n. 7, p. 1815-1825, 2002.

SEADER, J. D.; HENLEY, E. J. Separation process principles. New York: John Wiley, 1998. 886p.

SILVA, E. R. F. Contribuição ao estudo da termodinâmica contínua na resolução de problemas na engenharia química: equilíbrio líquido-vapor de misturas complexas. 1v. 1992. Dissertação (mestrado) - Escola Politécnica, Universidade de São Paulo, São Paulo, 1992.

SILVA, E. R. F.; TERRON, L. R. Algorithm for the application of continuous thermodinamics: liquid-vapor equilibrium of complex mixtures XIII CONGRESSO BRASILEIRO DE ENGENHARIA QUIMICA. São Paulo, 2000.

SPEIGHT J. G.; The chemistry and technology of petroleum. New York: M. Dekker, 1991, 760p.

SPORTISSE, M.; BARREAU, A.; UNGERER, P. Modeling of gas condensates properties using continuous distribution functions for the characterisation of the heavy fraction. Fluid Phase Equilibria. França, v. 139, p. 255-276,1997.

STARCK, J.-L.; MURTAGH, F.; BIJAOUI, A. Image processing and data analysis. The multiscale approach. 1 ed. Cambrige, 1998. 287p.

TWU, C. H. An internally consistent correlation for predicting the critical properties and molecular weights of petroleum and coal-tar liquids. Fluid Phase Equilibria, Amsterdam, v. 16, n. 2, p. 137-150, 1984. 
TAMIM, J.; HALLET, W. L. H. A continuous thermodynamics model for multicomponent droplet vaporization. Chemical engineering science. v. 50, n. 18, p. 2933-2942, 1995.

UNGERER, P.; LACHET, V.; TAVITIAN, B. Applications of molecular simulation in oil and gas production and processing. Oil and Gas Science and Technology, Paris, v. 61, n. 3, p. 387-403, 2006.

VON WATZDORF, R.; URBAN, K.; DAHMEN, W.; MARQUARDT, W. A wavelet-Galerkin method applied to separation processes. In: F. Keil, W. Mackens, H. Vo $\beta$, J. Werther (eds.). Scientific computing in chemical engineering. Berlin: Springer, 1996. p. 246-252.

VON WATZDORF, R.; MARQUARDT, W. Fully adaptative model size reduction for multicomponent separation problems. Computers and Chemical Engineering, New York, v. 21, Suppl.1, p. S811-S816, 1997.

VASILEVA,. D.; KUUT, A.; HEMKER, P. W. An adaptive multigrid strategy for convection-diffusion problems.. In: LARGE SCALE SCIENTIFIC COMPUTING INTERNATIONAL CONFERENCE, 5., Sozopol, 2005. LSSC 2005: proceedings. Berlin: Springer, 2005. p. 138-145. (Lecture notes in computer science, n. 3743).

VAKILI-NEZHAAD， G.; H. MODARRESS; G. Mansoori. Continuous thermodynamics of petroleum fluids fractions. Chemical Engineering Processing. V. 40, p. 431, 2001

VLACHOS, D. G. Multiscale Analysis of Chemical and Biological Systems University of Delaware Newark, Disponível em: http://www.dion.che.udel.edu/research.php Acesso em: 03 mar. 2005.

VLACHOS, D. G. A Review of Multiscale Analysis: Examples from systems biology, materials engineering, and other fluid-surface interacting systems. Advances in chemical engineering - Multiscale analysis. v. 30, p.1-61, 2005. Disponível em: http://www.sciencedirect.com/science? ob=ArticleURL\& udi=B7CSC-4H57KH3$4 \&$ user $=972067 \&$ coverDate $=12 \% 2 \mathrm{~F} 31 \% 2 \mathrm{~F} 2005 \&$ alid $=512650108 \&$ rdoc $=102$ \& fmt $=$ summary\& orig $=$ search \& cdi $=18019 \&$ sort $=\mathrm{d} \&$ st $=13 \&$ docanchor $=\&$ vie $\mathrm{w}=\mathrm{c} \&$ acct $=\mathrm{C} 000049650 \&$ version $=1 \&$ urlVersion $=0 \&$ userid $=972067 \& \mathrm{md} 5=\mathrm{a} 7 \mathrm{c}$ 838f59c67eedc39cd4e7ff1a65c09 Acesso em: 03 mar. 2006.

WILLE, S. O. A non-linear adaptive tri-tree multigrid solver for finite element formulations of the navier-stokes equations. International Journal for Numerical Methods in Fluids, Chichester. v. 22, n. 11, p. 1041-1059. 1996.

XUEFENG, C.; ZHENGJIA, H.; JIAWEI, X.; BING, L. A dynamic multiscale lifting computation method using Daubechies wavelet. Journal of Computational and Applied Mathematics, North-Holland, v. 188, n. 2, p. 228-245, 2006 


\section{APÊNDICES}

\section{Apêndice A}

\section{Tratamento da representação da constante de equilibrio de fases}

No contexto do modelamento contínuo, a constante de equilibrio de fases "k", será também representada por uma função contínua $K(\xi)$ em relação à variável de caracterização. Para o cálculo das propriedades desta constante de equilibrio somente são utilizadas correlações simples. A equação de Clausius-Clapeyron, em combinação com a regra de truton, fazem ela dependente somente das temperaturas de ebulição dos componentes.

$$
\begin{aligned}
\frac{d \lg P}{d(1 / T)} & =-\frac{\Delta \bar{H}_{\text {vap }}}{R} \\
\lg \left(\frac{P}{P_{0}}\right) & =-\frac{\Delta \bar{H}_{\text {vap }}}{R}\left(\frac{1}{T}-\frac{1}{T_{0}}\right) \\
\downarrow &
\end{aligned}
$$

em que:

$P$ : pressão do processo

$P_{0}$ : pressão de vapor em equilíbrio com o líquido

$T$ : temperatur a de ebulição do componente

$T_{0}$ : temperatur a normal de ebulição

$\Delta \bar{H}_{\text {vap }}$ : calor latente de vaporizaçã o na temperatur a de ebulição

$R$ : cons tan te universal dos gases, $1.9872 \mathrm{cal} / \mathrm{mol}$

$k$ : cons tan te de equilíbrio

Regra de Truton : $\quad \Delta \bar{H}_{\text {vap }}=21 \times T_{0}$

Arrumando as equações (a1) e (a2) tem-se a constante de equilíbrio:

$$
\lg (k)=-\frac{21 \times T_{0}}{R}\left(\frac{1}{T}-\frac{1}{T_{0}}\right) \quad ; \quad k=e^{\left\{10.58 \times\left(1-\frac{1}{T}\right)\right\}}
$$


No equacionamento do equilibrio de fases do modelo, eqs. $5.9 ; 5.9 \mathrm{a}$ e 5.14 , o produto da distribuição do líquido $F^{L}(\xi)$ e a distribuição da fase de equilibrio $K(\xi)$, deve ser tratado através da discretização na representação em escala simples. Pois, o suporte disjunto das bases de escala simples permite a multiplicação direta de seus coeficientes como se mostra a seguir:

$$
\begin{aligned}
\int_{0}^{1}\left\{K(\cdot, \xi) F^{L}(\xi)\right\} \cdot \phi_{j, l} d \xi & =\int_{0}^{1}\left\{\left[\left(\mathbf{c}^{K}\right)^{T} \cdot \Phi\right] \cdot\left[\left(\mathbf{c}^{L}\right)^{T} \cdot \Phi\right]\right\} \cdot \phi_{j, l} d \xi \\
& =2^{1 / 2} \int_{0}^{1}\left\{\left(\left[\operatorname{diag} \mathbf{c}^{K}\right] \cdot \mathbf{c}^{L}\right)^{T} \cdot \Phi\right\} \cdot \phi_{j, l} d \xi \\
& =2^{1 / 2} c_{j, l}^{K} C_{j, l}^{L} \\
& =2^{1 / 2} c_{j, l}^{v l e} \quad(j, l) \in \Gamma^{r}
\end{aligned}
$$

A discretização na representação de multi-escala é mais elaborada por ser este caso um produto de duas distribuições que precisam ser projetadas. Assim, os coeficentes não podem ser diretamente multiplicados para obter os coeficientes do produto porque as funções wavelet teriam que sobrepor seus suportes. Embora, um procedimento alternativo para tratar este produto, na representação multi-escala, é descrito como segue:

$$
\begin{aligned}
\int_{0}^{1}\left\{K(\cdot, \xi) F^{L}(\xi)\right\} \cdot \psi_{j, l} d \xi & =\int_{0}^{1}\left\{\left[\left(\mathbf{c}^{K}\right)^{T} \cdot \Phi\right] \cdot\left[\left(\mathbf{d}^{L}\right)^{T} \cdot \Psi\right]\right\} \cdot \psi_{j, k} d \xi \\
& =\int_{0}^{F W T}\left\{\left[\left(\mathbf{c}^{K}\right)^{T} \cdot \Phi\right] \cdot\left[\left(\mathbf{c}^{L}\right)^{T} \cdot \Phi\right]\right\} \cdot \psi_{j, k} d \xi \\
& =2^{j / 2} \int_{0}^{1}\left\{\left(\mathbf{c}^{v l e}\right)^{T} \cdot \Phi\right\} \cdot \psi_{j, k} d \xi \\
& ={ }^{W} T^{-1} \\
& 2^{j / 2} \int_{0}^{1}\left\{\left(\mathbf{d}^{v l e}\right)^{T} \cdot \Psi\right\} \cdot \psi_{j, k} d \xi \\
& =2^{j / 2} d_{j, k}^{v l e} \quad(j, k) \in \Lambda^{r}
\end{aligned}
$$




\section{Apêndice B}

\section{Programa utilizado para a simulação do algoritmo}

\section{Programa PROG_principal}

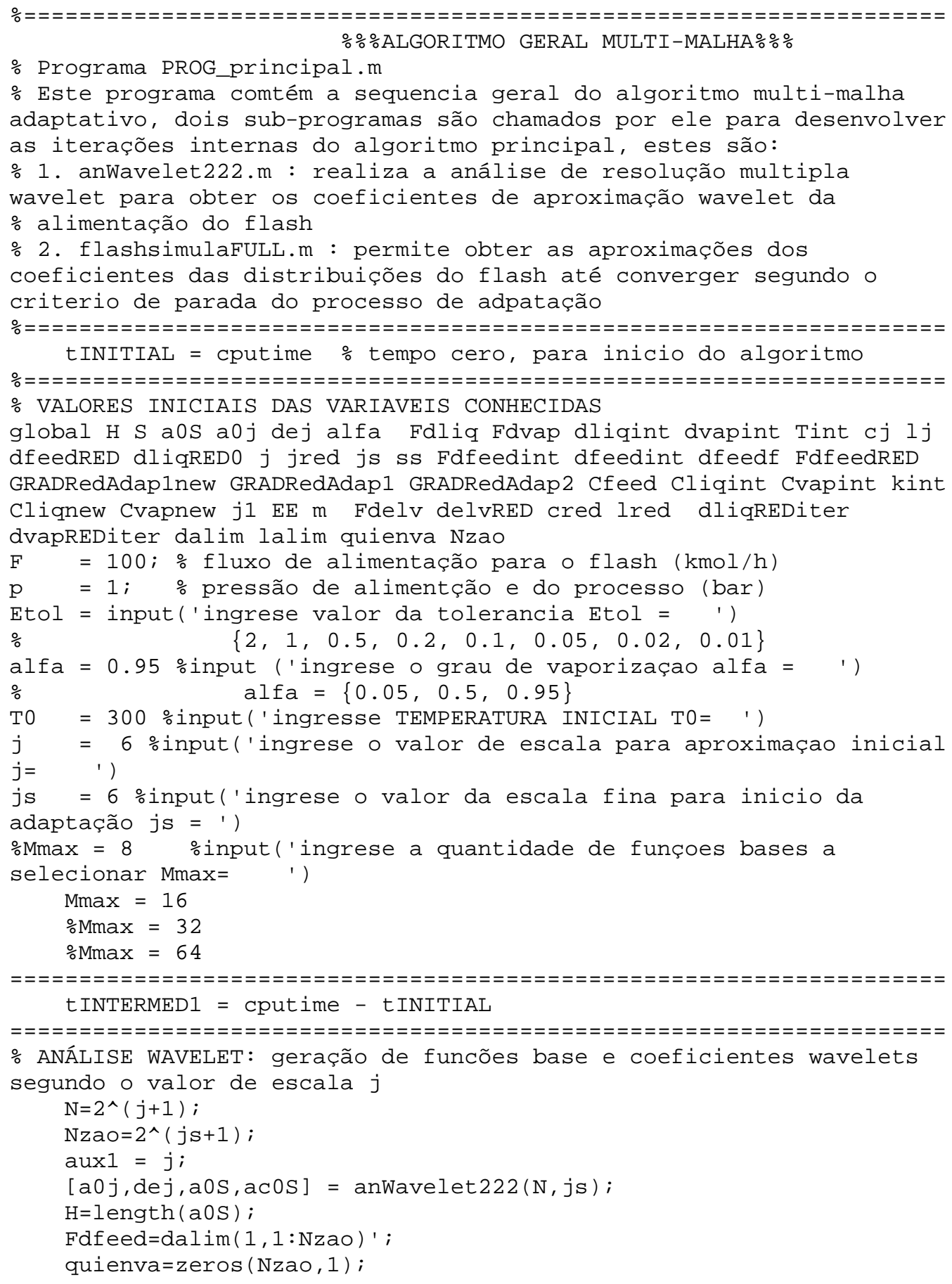


quienva $(1: \mathrm{N}, 1)=$ ones $(\mathrm{N}, 1)$;

constante_de_cosita $=$ dalim $(1,1)$;

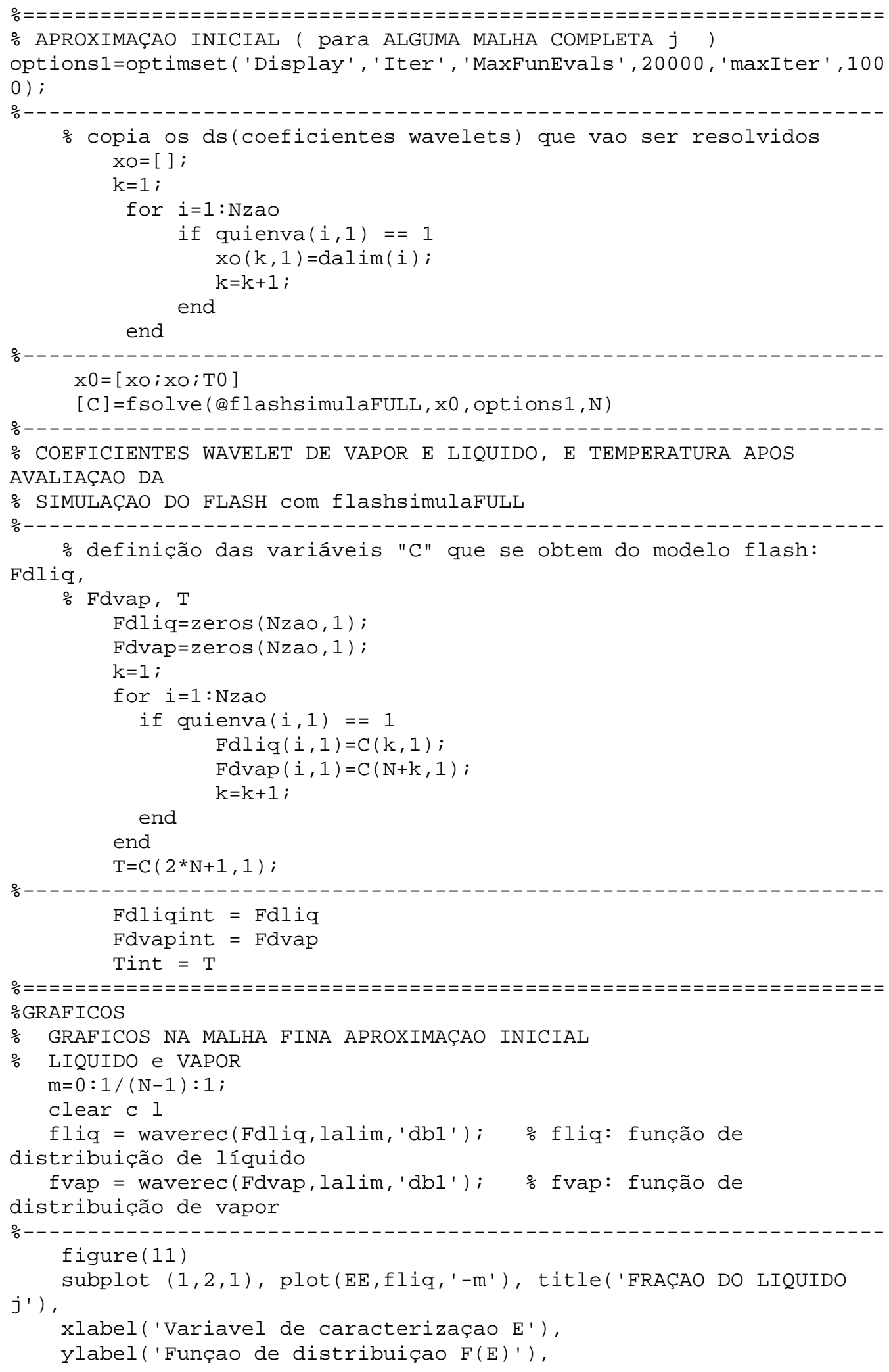


hold on

subplot $(1,2,2)$, plot (EE, fvap, '-m'), title('FRAÇAO DO VAPOR j'), xlabel('Variavel de caracterizaçao E'), ylabel('Funçao de distribuiçao $F(E)$ '),

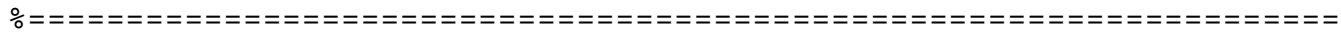

\% INICIO DA ITERAÇÃO DO ALGORITMO PRINCIPAL PARA AVALIAR A QUANTIDADE DE

\% COEFICIENTES QUE PODEM GERAR UMA BOA APROXIMAÇÃO

\%- - - - - - - - - - - - - - - - - - - count=1; \% contador da iteração

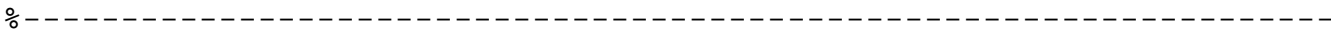

$\%$ TRATAMENTO DE REPRESENTAÇÃO CONTÍNUA DA CONSTANTE DE EQUILIBRIO

\%- - - - - - - - - - - - - - - - - - - -

\% CONSTANTE DE EQUILIBRIO EM FUNÇAO DE 'T' DO PROCESSO:

$A A=$ ones $(11,1) /$ Tint ;

\% FUNÇAO DE DISTRIBUIÇAO PARA A CONSTANTE DE EQUILIBRIO:

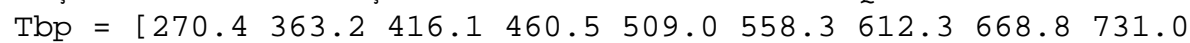

$809.5899 .9]^{\prime}$;

$E=(T b p-270.4) /(899.9-270.4)$;

$\mathrm{ki}=\exp \left(10 \cdot 58^{*}\left(1-\mathrm{Tbp} .{ }^{*} \mathrm{AA}\right)\right)$;

$\log k i=\log (k i)$;

const=spline $(E, \operatorname{logki}) ; \quad \%$ funçao continua para $k$

$\mathrm{EE}=$ linspace $(\Theta, 1, \mathrm{Nzao})$;

FUNconst=ppval (const, EE);

$\mathrm{Kk}=\exp ($ FUNconst $)$;

$\%$ EXPRESSÃO DA EQUAÇÃO DE EQUILIBRIO DE FASES NO MODELO FLASH:

\% kFL: funçao recuperada com aproximaçao wavelet

$\% \mathrm{k}(\mathrm{E})$ : constante de equilibrio

\% FL(E): fraçao de liquido destilado

tratados a $\% \mathrm{kFL}=\mathrm{kFL}(\mathrm{E})=\mathrm{k}(\mathrm{E}){ }^{*} \mathrm{FL}(\mathrm{E})$, para a discretizaçao eles sao

$\%$ escala simples:

$\% \mathrm{k}=\mathrm{k}(\mathrm{E})=\left(\mathrm{ck}^{*} \mathrm{phi}\right)$ : escala simples

$\% \mathrm{FL}=\mathrm{FL}(\mathrm{E})=\left(\mathrm{cliq}{ }^{*} \mathrm{phi}\right)$ : escala simples

$\% \mathrm{FL}(\mathrm{E})=\left(\mathrm{dliq}{ }^{*} \mathrm{psi}\right)$ : multiescala

$\%$ aplicando dwt(discret wavelet transform) para ambos:

$\%$ delv = coeficiente wavelet da constante de equilíbrio $\mathrm{x}$

fração do líquido

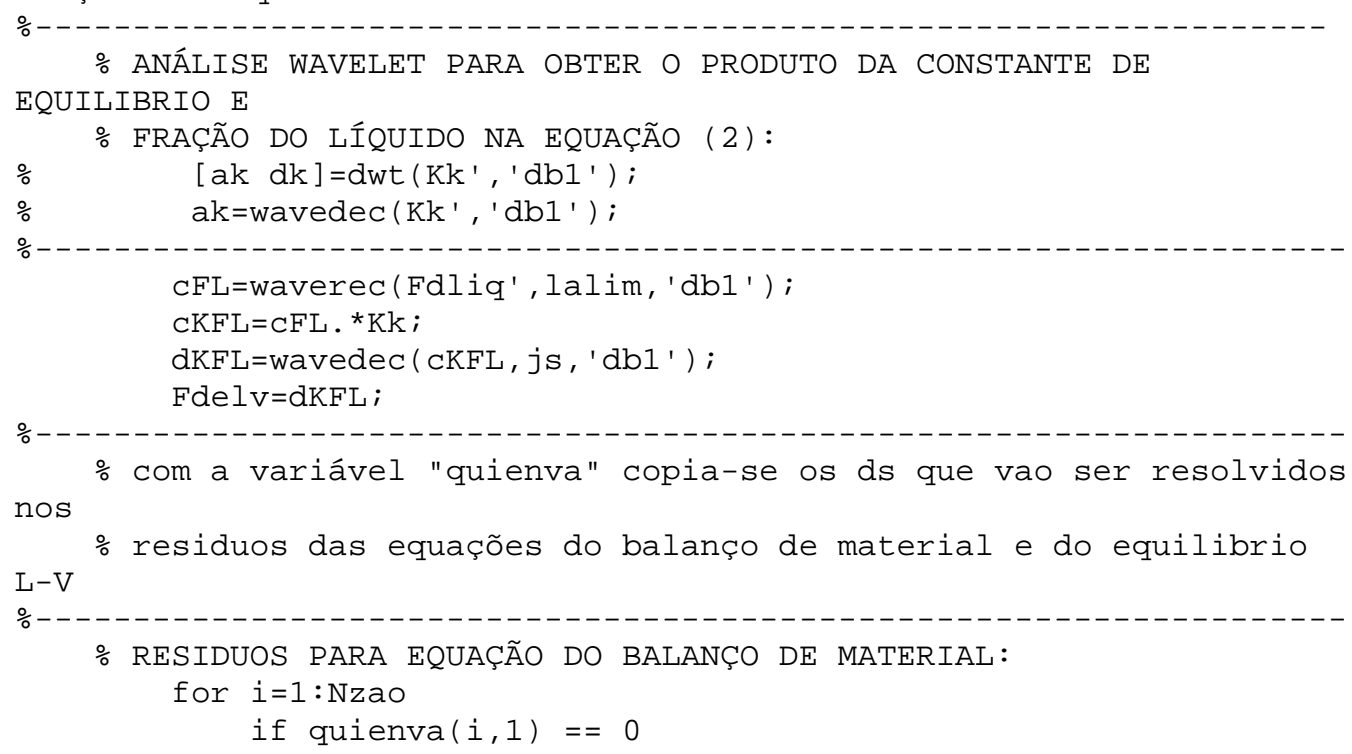




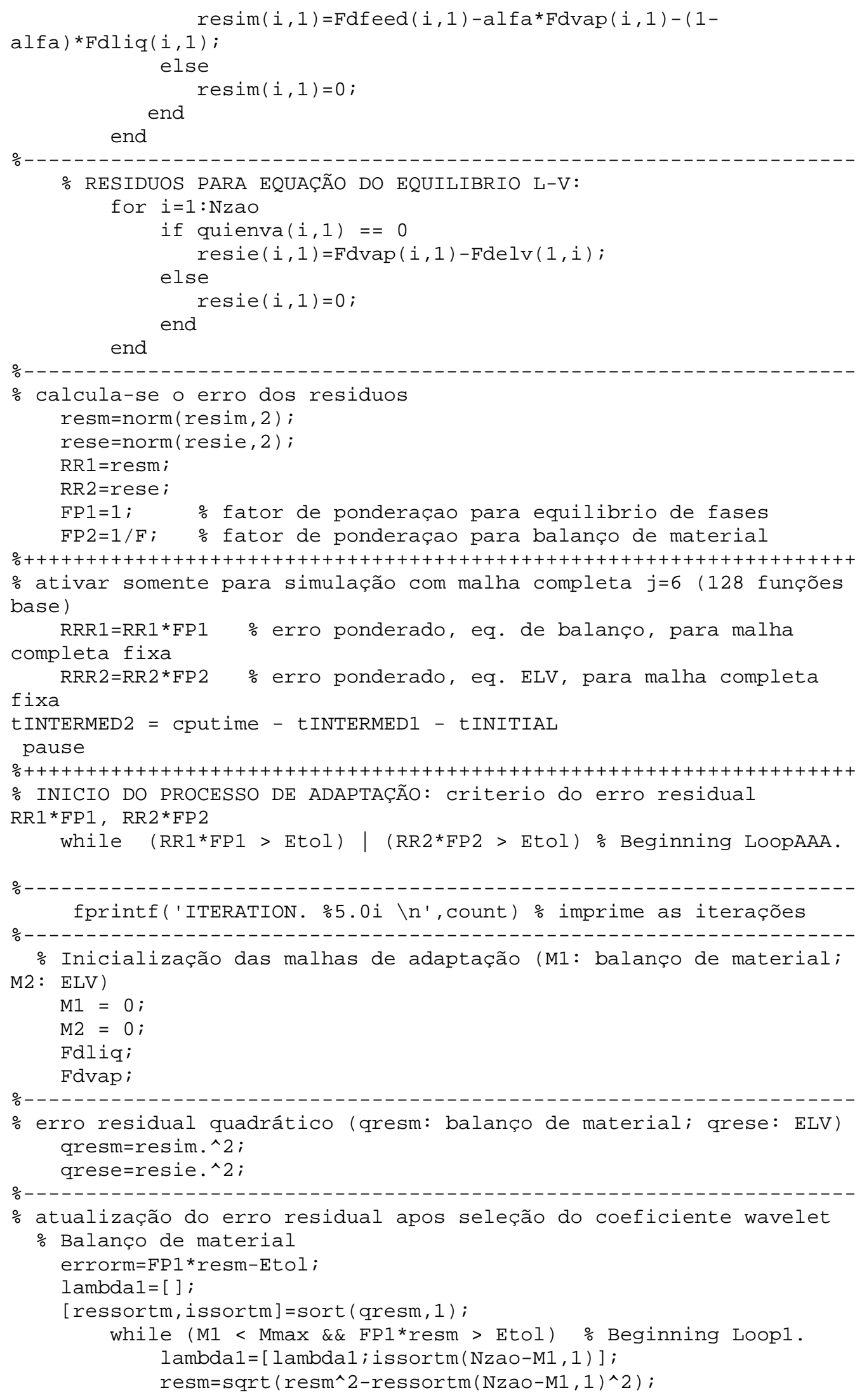




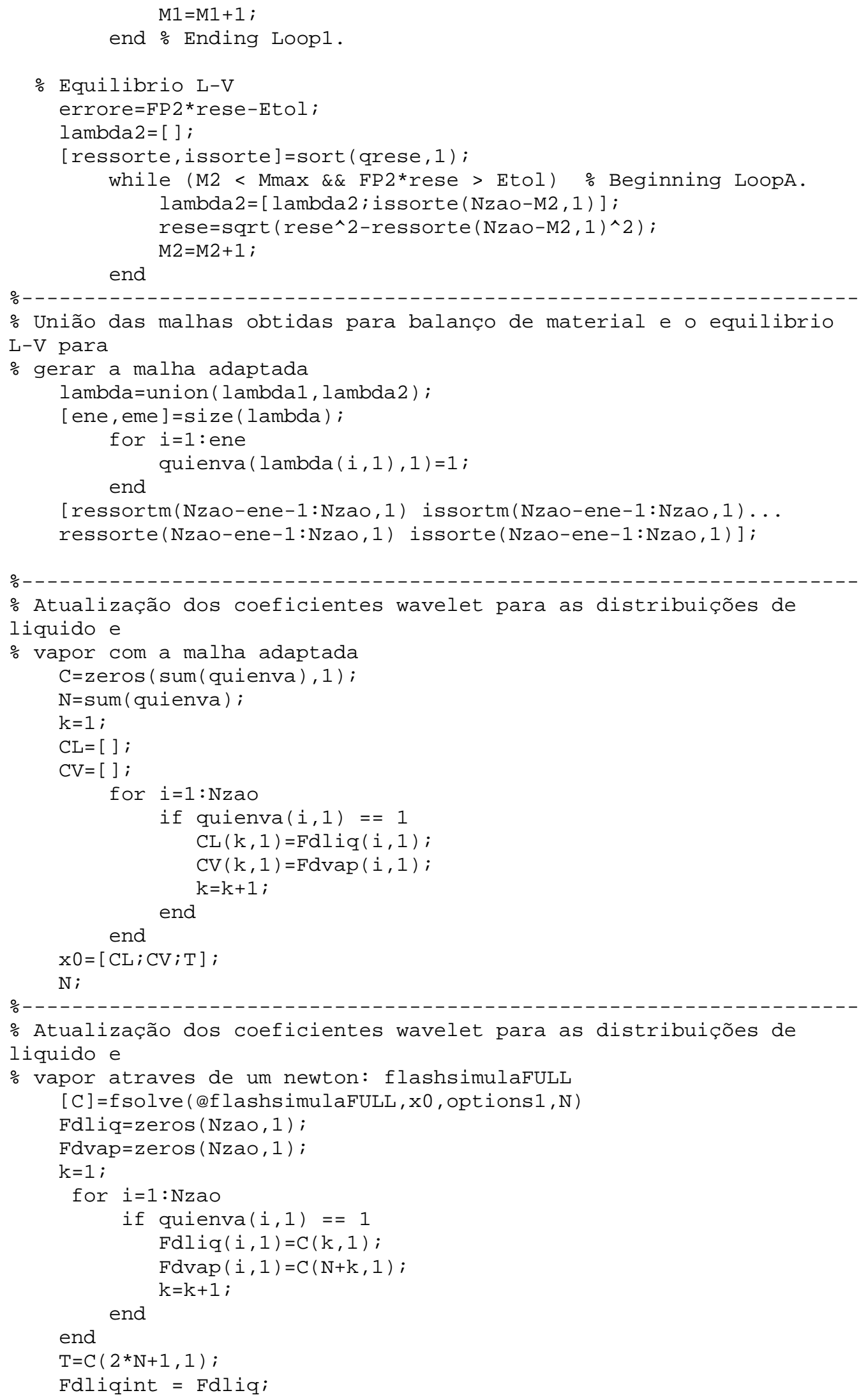




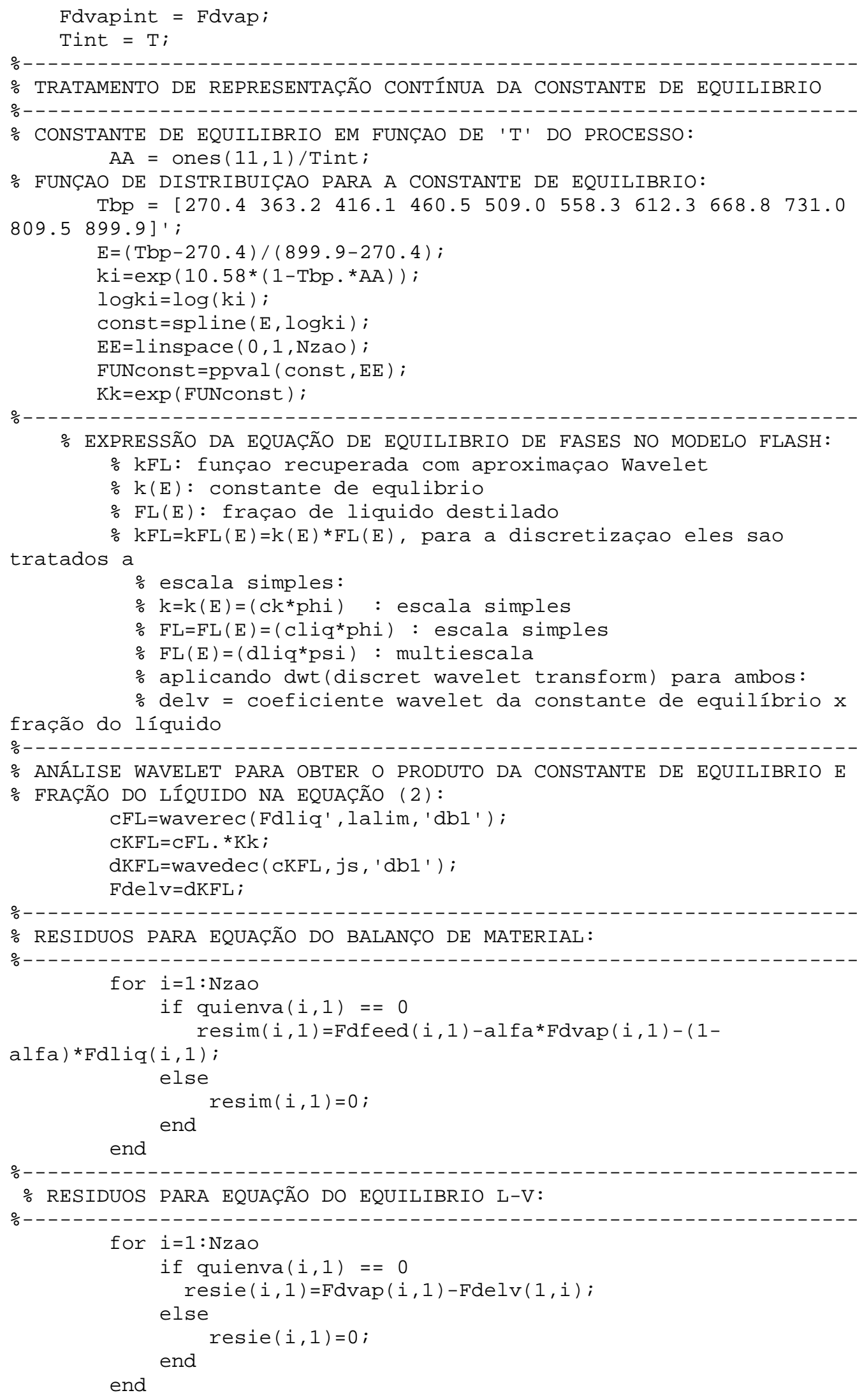




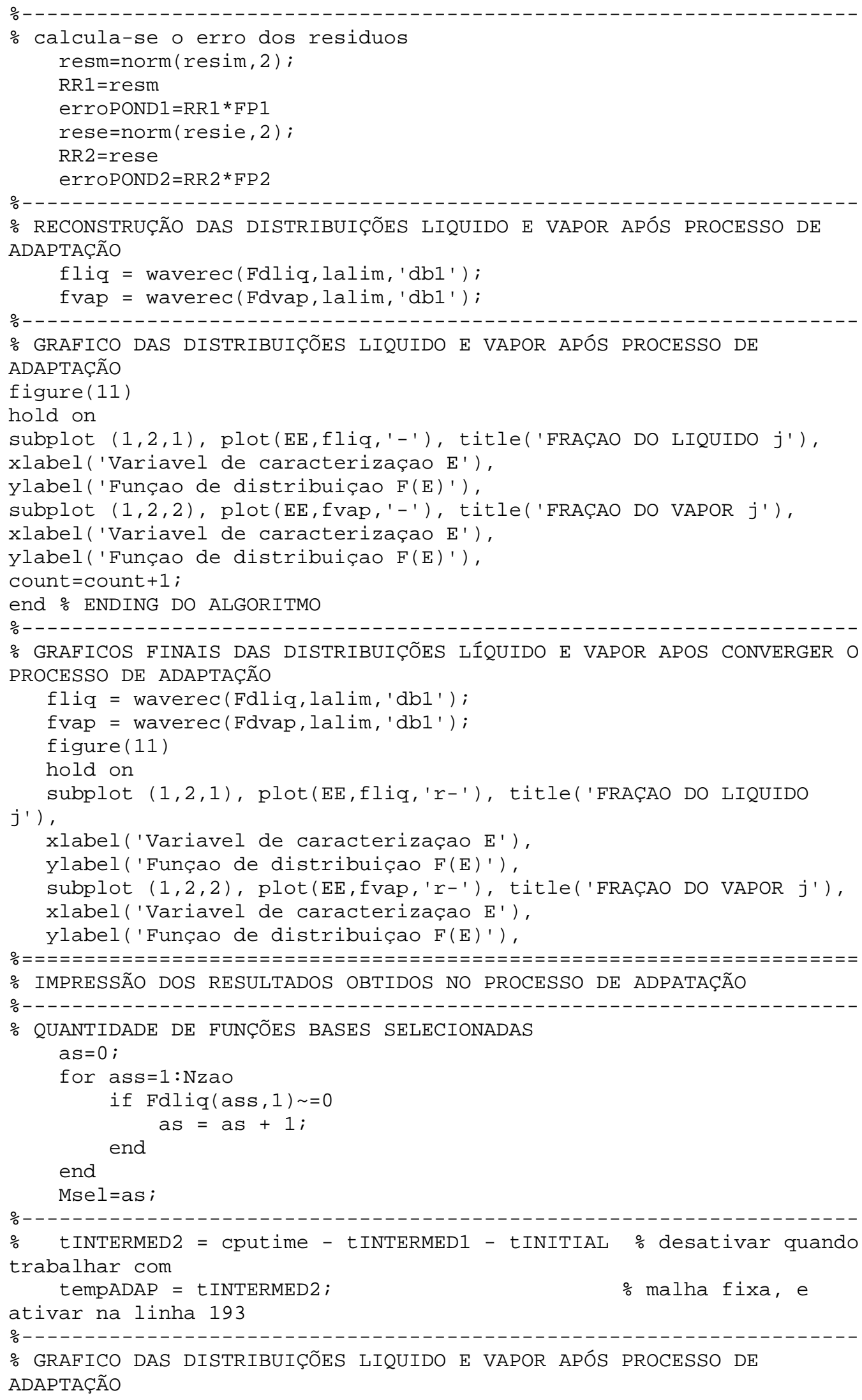


figure(12)

hold on j'),

subplot $(1,2,1)$, plot(EE,fliq,'-g'), title('FRAÇAO DO LIQUIDO

xlabel('Variavel de caracterizaçao E'),

ylabel('Funçao de distribuiçao $F(E)$ '),

subplot $(1,2,2)$, plot(EE, fvap,'-g'), title('FRAÇAO DO VAPOR j'), xlabel('Variavel de caracterizaçao E'), ylabel('Funçao de distribuiçao F(E)'),

\%- fprintf('MAXIMO DE FUNÇOES BASES Mmax \%5.0i \n', Mmax) fprintf('MAXIMO DE FUNÇOES BASES SELECIONADAS. Msel \%5.0i $\backslash n^{\prime}$, Msel)

fprintf('> Atenção! (1) o residual da distribuição é menor que a tolerância: \%5.5f \n', Etol) fprintf('> criterio de convergencia do algoritmo, balanço de material: FP1*RR1: \%5.5f \n',FP1*RR1)

fprintf('> criterio de convergencia do algoritmo, equilibrio L-

V: FP2 ${ }^{*} R R 2$ : \%5.5f $\left.\backslash n{ }^{\prime}, F P 2{ }^{*} R R 2\right)$

fprintf('TEMPO DE DESENVOLVIMENTO DO ALGORITMO (seg): \%5.4f

$\backslash n '$, tempADAP)

fprintf('ITERATION. \%5.0i \n', count)

fprintf('TEMPERATURA DO PROCESSO (K). \%5.4f $\backslash \mathrm{n}$ ', Tint)

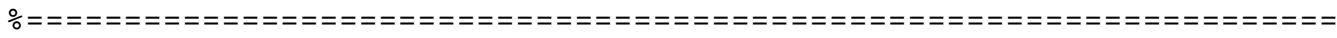

fliq

fvap 
Programa flashsimulafULL.m

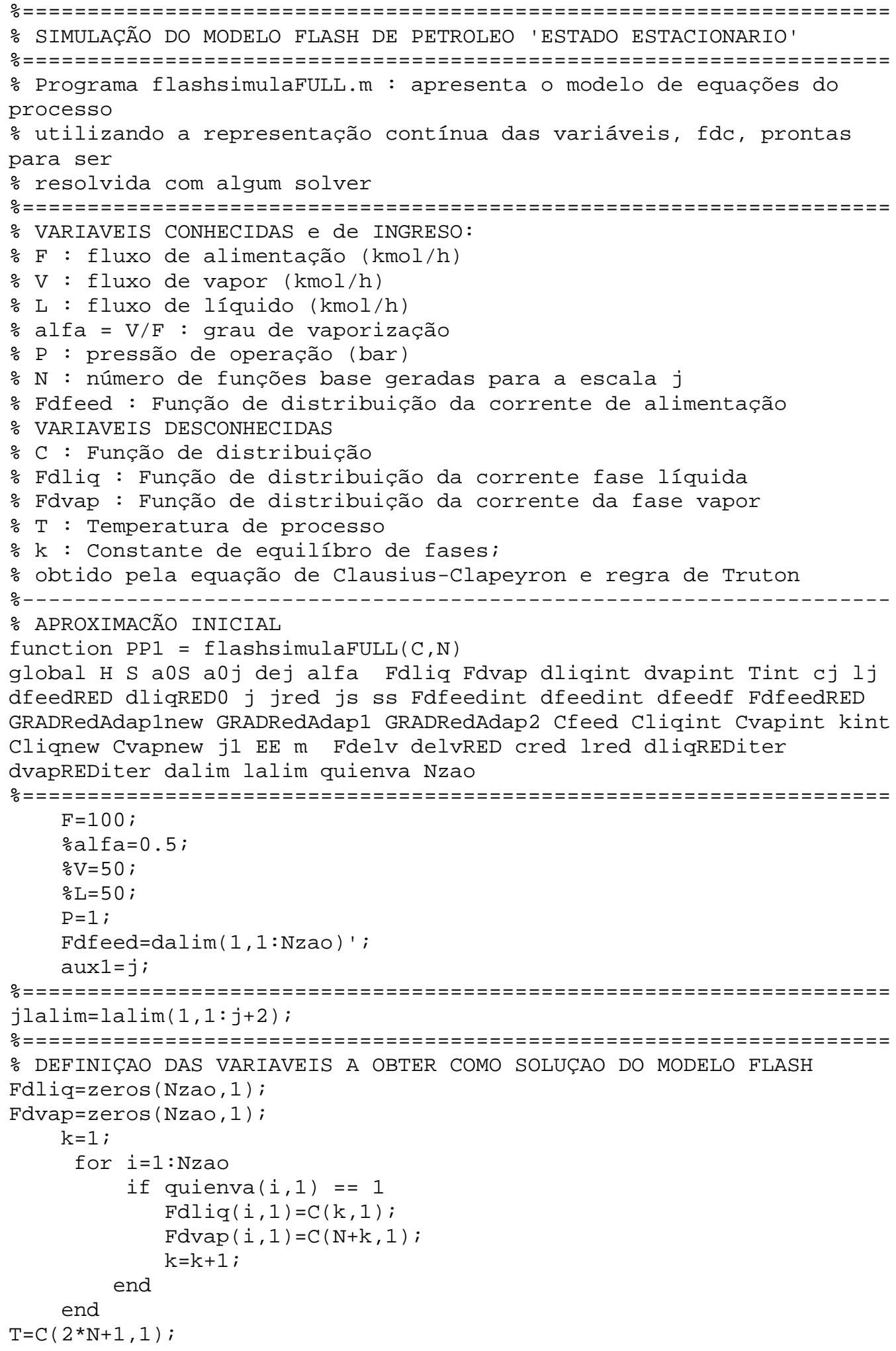




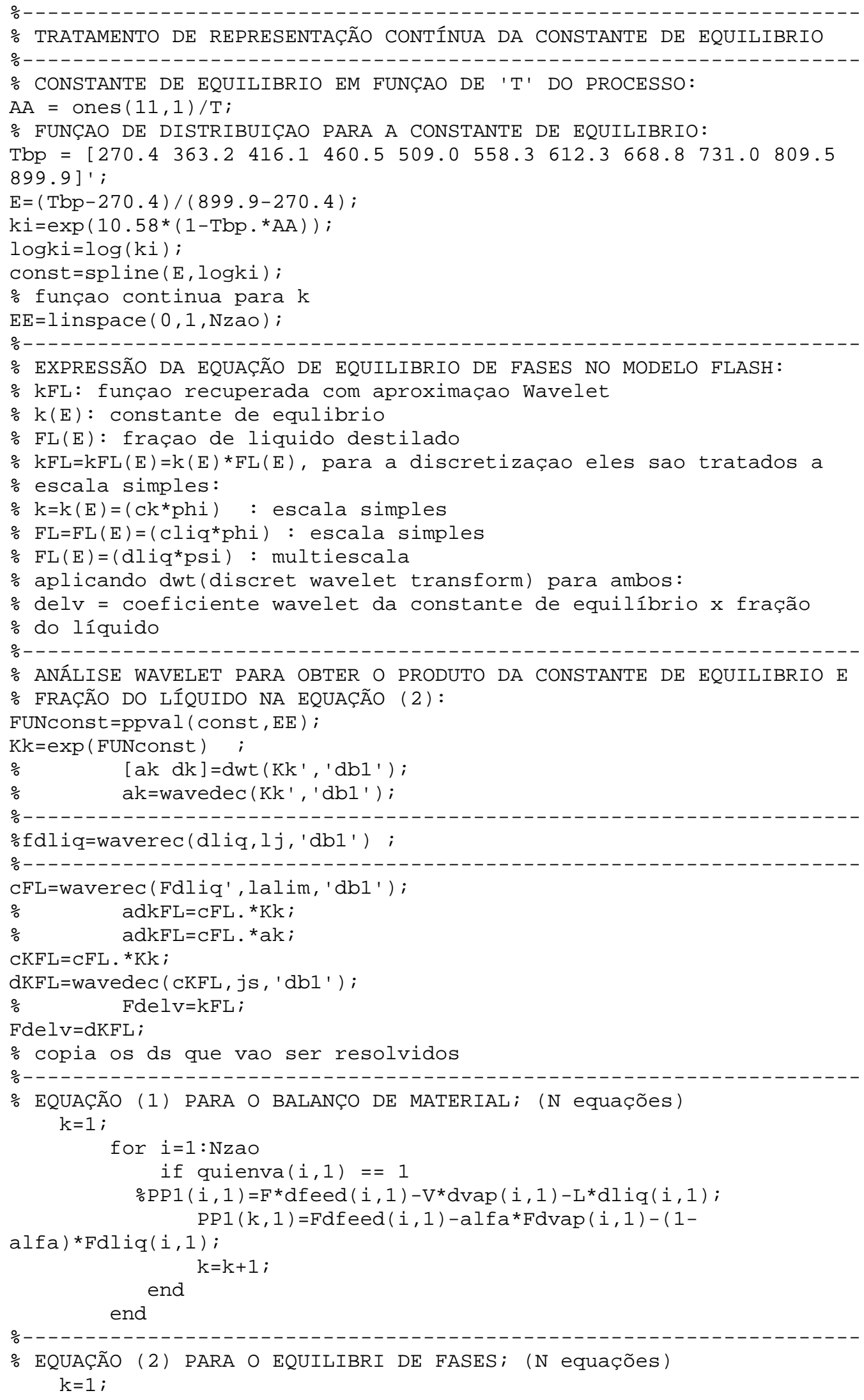




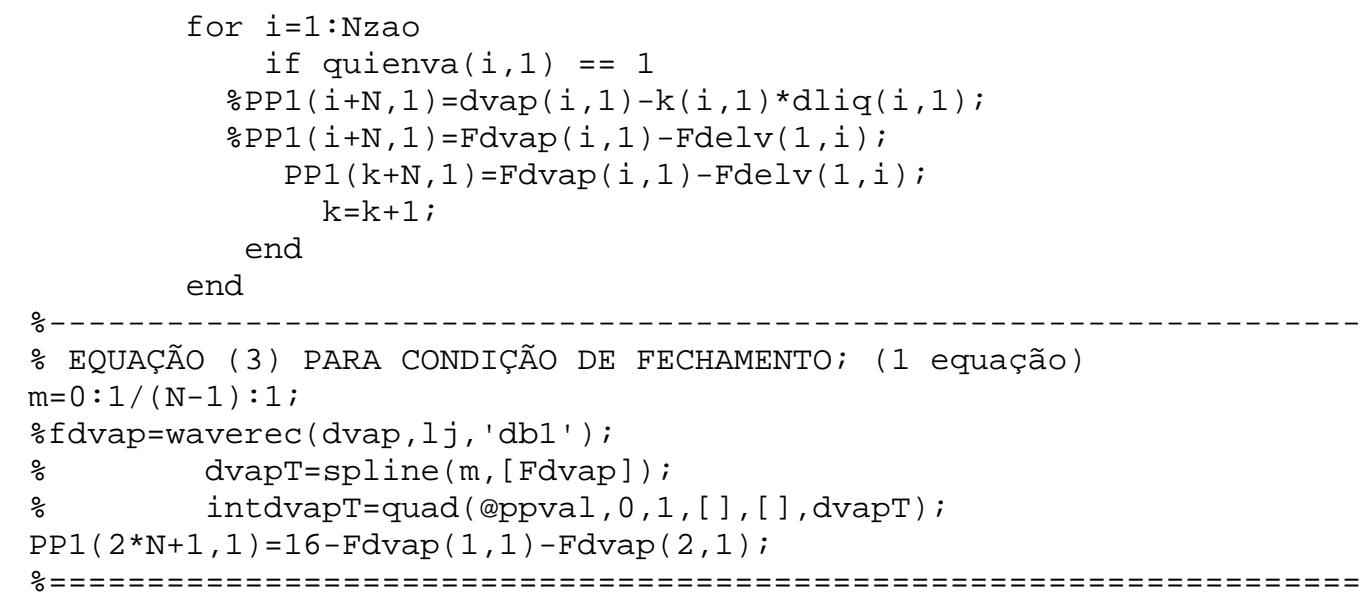




\section{Programa PRUEBA3}

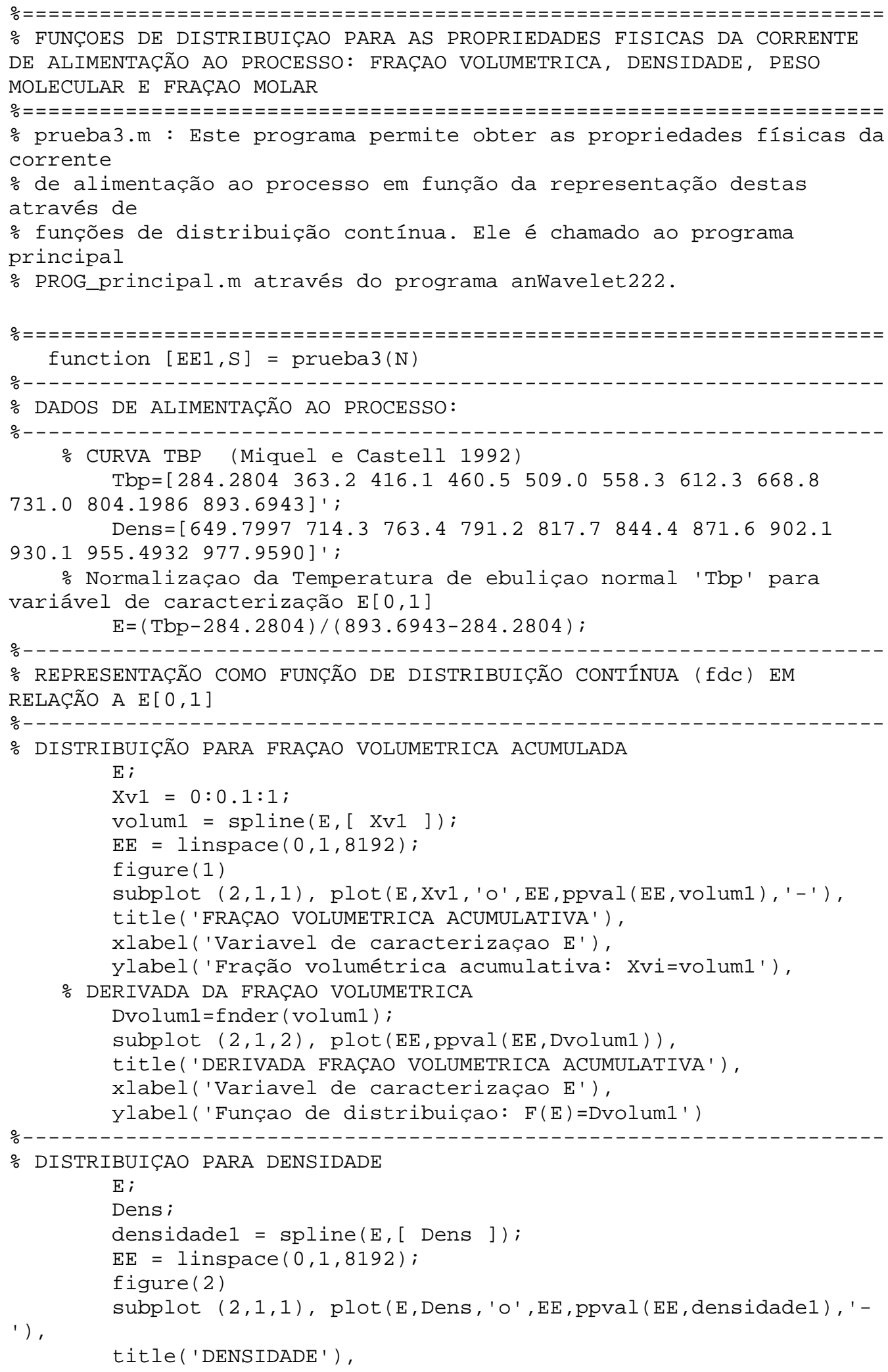




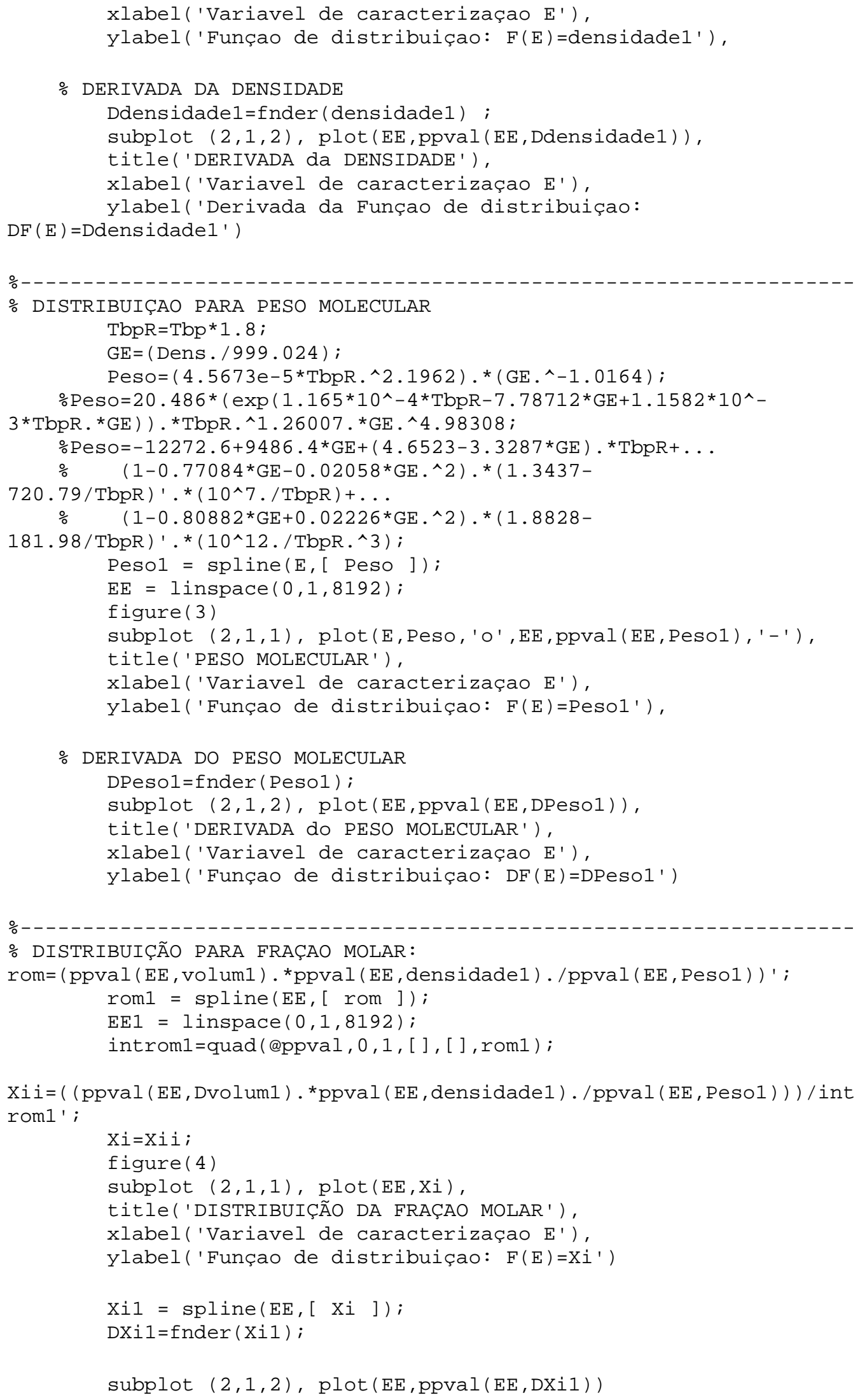


title('DERIVADA da FRAÇAO MOLAR'),

xlabel('Variavel de caracterizaçao E'),

ylabel('Funçao de distribuiçao: $D F(E)=D X i '$ )

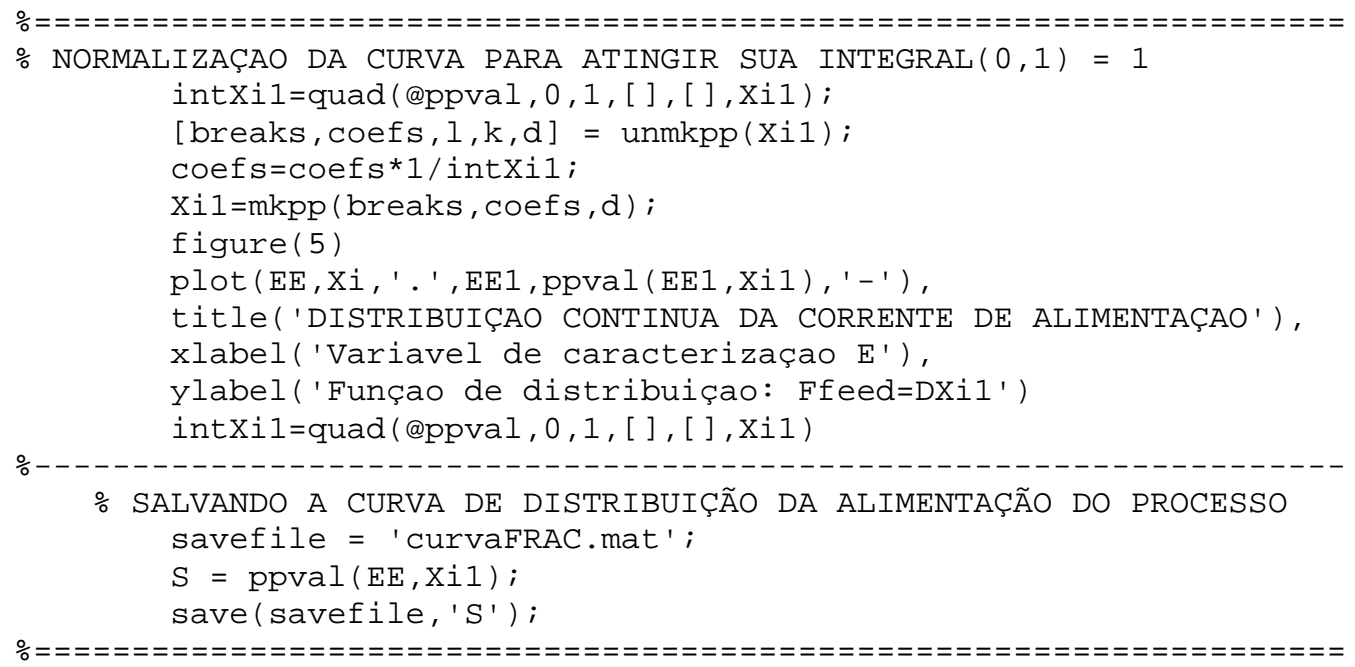


Programa ANWAVELET222

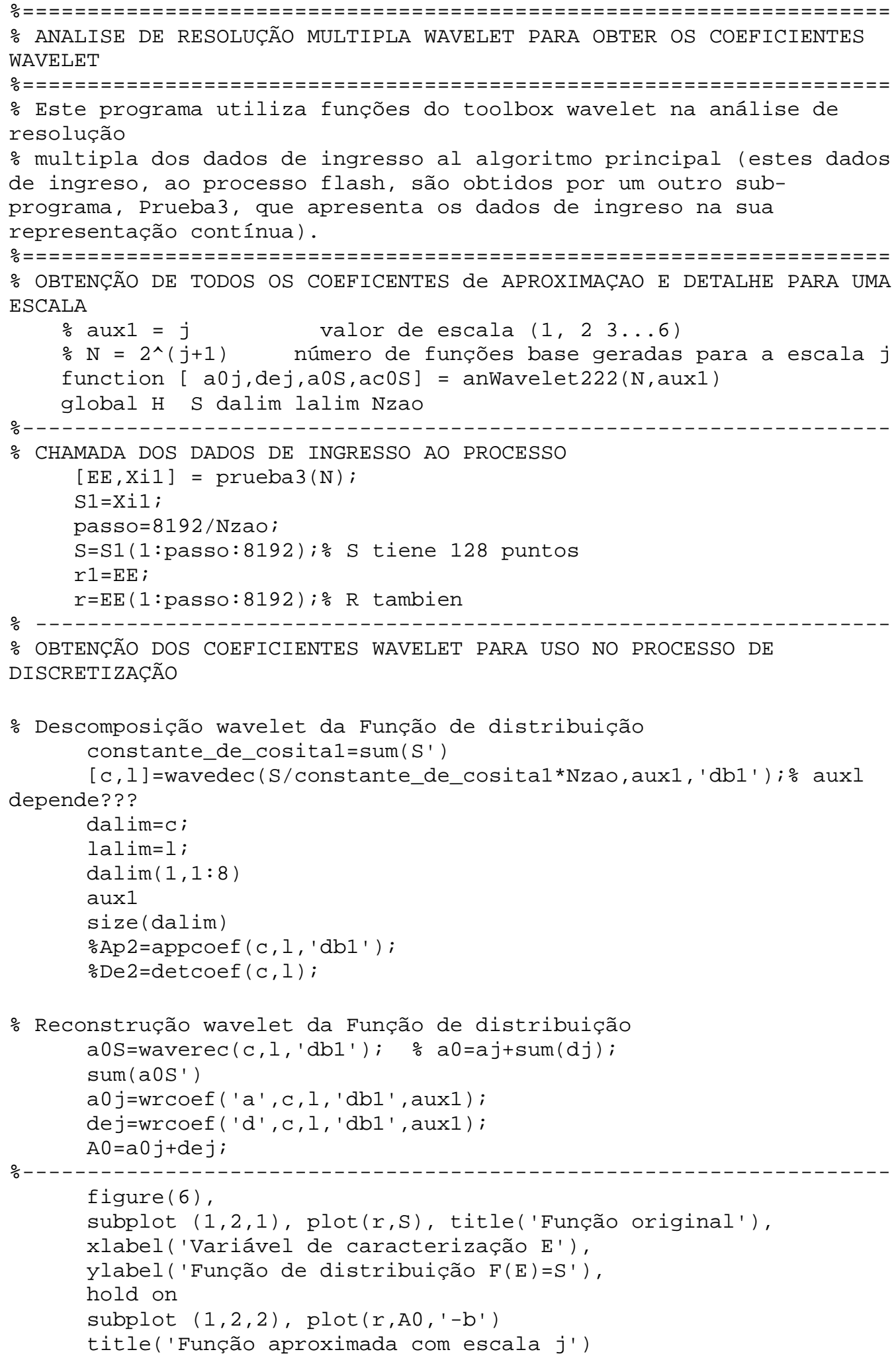


xlabel('Variável de caracterização E')

ylabel('Função de distribuição $F(E)=a \Theta S$ ')

hold on

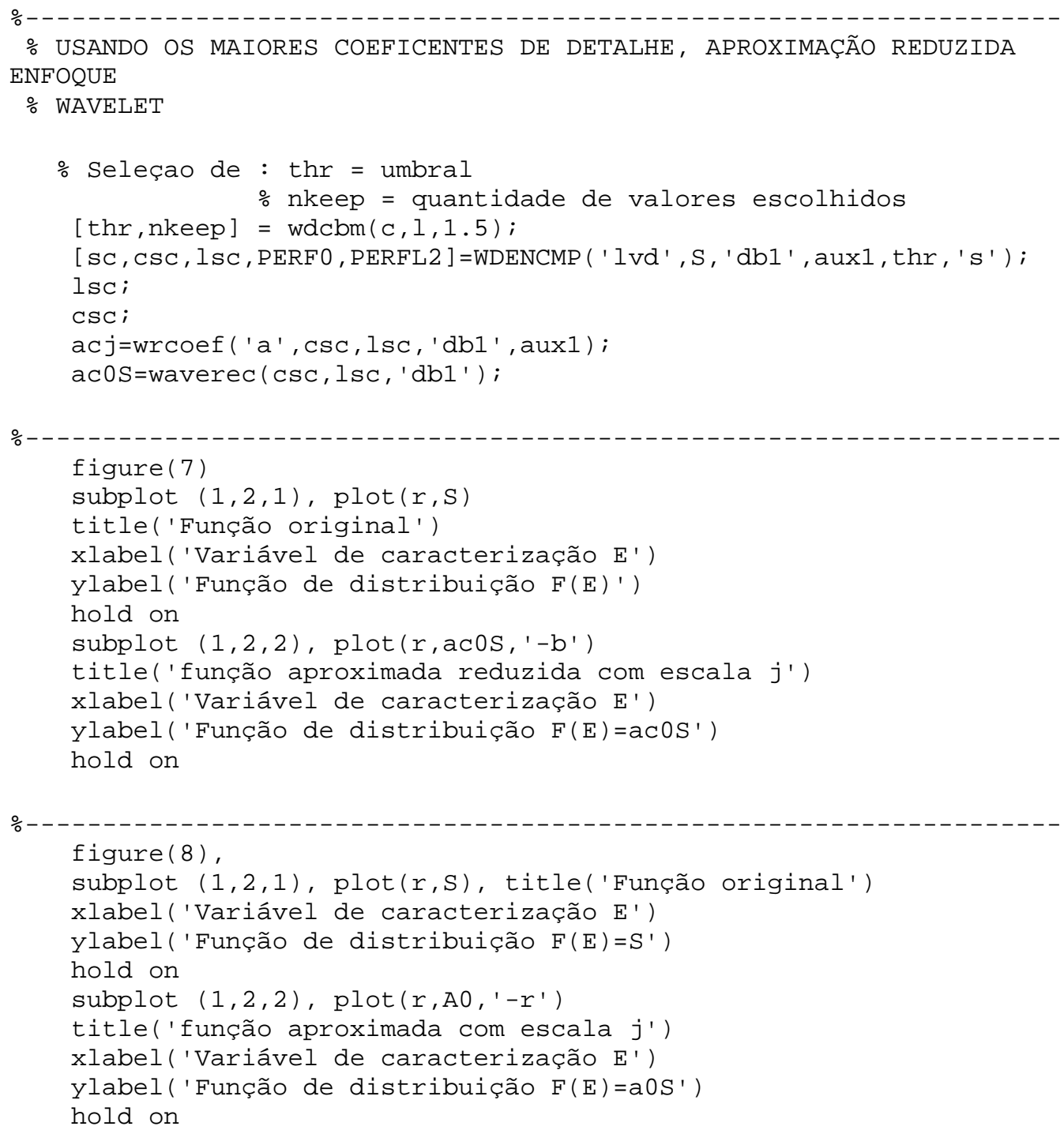

